Dissertação de Mestrado apresentada ao Instituto de Arquitetura e Urbanismo da Univ ersidade de São Paulo como parte dos requisitos para obtenção do título de Mestre em Arquitetura e Urbanismo.

Área de concentração: Teoria e História da Arquitetura e do Urbanismo
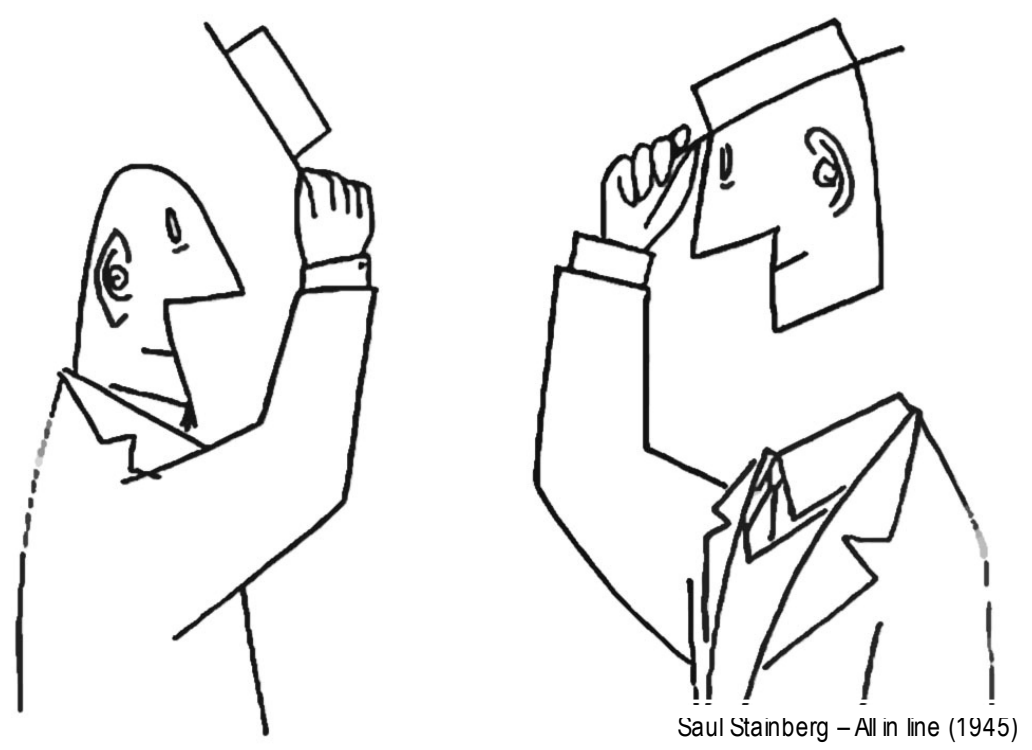

\title{
O horizonte da conversação: concepções do processo projetual arquitetônico
}

\author{
Daniel Morais Paschoalin \\ Orientadora: Profa. Dra. Anja Pratschke
}

São Carlos

2012 


\begin{abstract}
AUTORIZO A REPRODUÇÃO E DIVULGAÇÃO TOTAL OU PARCIAL DESTE TRABALHO, POR QUALQUER MEIO CONVENCIONAL OU ELETRÔNICO, PARA FINS DE ESTUDO E PESQUISA, DESDE QUE CITADA A FONTE
\end{abstract}

Ficha catalográfica preparada pela Seção de Tratamento da Inf omação do Serviço de Biblioteca - EESC/USP

o horizonte da conversação : concepções do processo projetual arquitetônico. / Daniel Morais Paschoalin ; orientador Anja Pratschke. São Carlos, 2012.

Dissertação (Mestrado - Programa de Pós-Graduação em Arquitetura e Urbanismo e Área de Concentração em Teoria e História da Arquitetura e do Urbanismo)-Instituto de Arquitetura e Urbanismo de São Carlos da Universidade de São Paulo, 2012 . 


\section{FOLHA DE JULGAMENTO}

Candidato: Arquiteto e Urbanista Daniel Morais Paschoalin

Título da dissertação: "O Horizonte da conversão: concepções do processo projetual arquitetônico"

Data da defesa: $26 / 04 / 2012$

\section{Comissão Julgadora:}

Prof ${ }^{\mathrm{a}}$. Dr ${ }^{\mathrm{a}}$. Anja Pratschke (orientadora)

(Instituto de Arquitetura e Urbanismo IAU/USP)

Prof. Dr. Manoel Antonio Lopes Rodrigues Alves

(Instituto de Arquitetura e Urbanismo IAU/USP)

Prof. Dr. Celso Carnos Scaletsky

(Universidade do Vale do Rio dos Sinos UVRS)

\section{Resultado:}
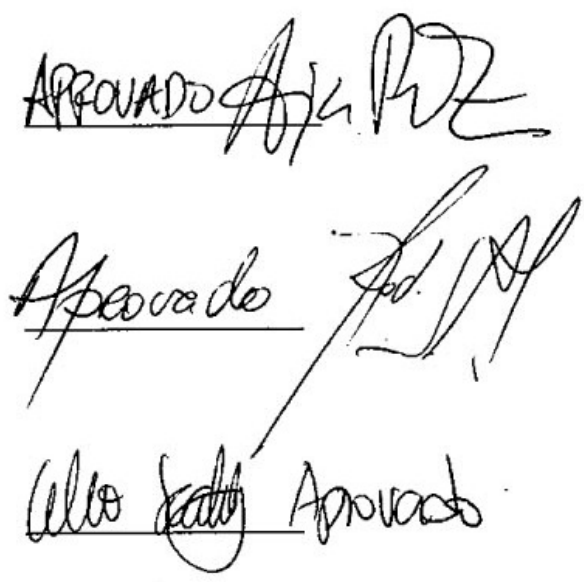

Presidente da Comissão de Pós-Graduação e Coordenador do Programa de PósGraduação em Arquitetura e Urbanismo: Prof. Titular Renato Luiz Sobral Anelli 

Aos meus pais Ney e Angela,

pela confiança, af eto e suporte 

9. The model you might use instead of the expert model of the first generation can be called a 'conspiracy model of planning'. This means that, because we cannot anticipate all the consequences of our plans, every plan, every treatment of a wicked problem is a venture, if not an aventure. Therefore, let us share the risk, let us try to find accomplices who are willing to embark on the problem with us. For one person it is too risky, but maybe if we join our forces we may take the risk and live with the uncertainty and embark upon the venture. This seems to be a somewhat tenable position to justify the courage in planning at all.

\section{AGRADECIMENTOS}

Agradeço especialmente a Profa. Dra. Anja Pratschke por ter incitado e compartilhado comigo os questionamentos que dão forma a este trabalho, por inspirar-me em todas as nossas conversações e por ter depositado em mim extrema confiança e concedido-me inestimável liberdade;

ao Nomads.USP: Prof. Dr. Marcelo Tramontano, Profa. Dra. Varlete Benevente, Dra. Denise Mônaco dos Santos, Dra. Mayara Dias de Souza, Cynthia Nojimoto, Elza Luli Miyasaka, Fábio Abreu de Queiroz, Felipe Anitelli, Gilfranco Medeiros Alves, João Paulo Marquesini Soares, Luciana Santos Roça, Maria Cecília Pereira Tavares, Priscilla Thais Marquetto, Sandra Schmitt Soster, Marta Tessarin e todos os pesquisadores graduandos, por toda a troca e amizade;

ao Prof. Dr. Manoel Rodrigues Alves e ao Prof. Dr. Celso Skaletsky pelas considerações no exame de qualificação, imprescindíveis para a conclusão desta pesquisa de mestrado; ao professor Joubert José Lancha e demais professores do IAU-USP de São Carlos pela receptividade e consideração;

a Profa. Dra. Gabriela Celani, a Profa. Dra. Regiane Pupo e a Profa. Dra. Terry Knight do MIT pela extrema cordialidade na disciplina de verão oferecida pelo curso de Arquitetura e Urbanismo da Universidade Estadual de Campinas UNICAMP aursada em janeiro de 2011;

aos funcionários do IAU-USP São Carlos Antônio João Tessarin, Sérgio Celestini, Fátima Mininel, Lucinda Brito, José Eduardo Zanardi, Evandro Cesar Bueno, Alessandro de Souza, Oswaldo de Andrade, Paulo Ceneviva, José Renato Dibo e Odinei Canevarollo, amigos de longa data, e em especial Geraldo Donizetti Pereira, Kaio Bruno Soato e Marcelo Celestini pelo zelo; 
aos amigos Elisângela Chiquito, Fábio Araujo, Eduardo Silva, Luciana Bonvino, Renato Locilento, Marcos Marchetti, Ralf Fores, Amanda Ruggiero, Itamiro Nogueira, Roberto Barbato, Leandro Schenk, Rafael Esposel, José Fabrício Ferreira, Magaly Pulhez, Sandro Canavezzi, Rodrigo Lapa e especialmente Caius Franco, com quem compartilhei docência e lições para toda a vida, e aos alunos das turmas de 2008, 2009 e 2010 do curso de Arquitetura da UNICEP São Carlos; agradeço também ao Bisnaga, Victor, Lucas e Bel, PC, Bani, Rosin, Matheus e Marisa, Renata, Kid e a Aletéia, o Minêro, Mailton, Zé Fernando, Alfa, o Cabelo, o Vinil e todos os demais presentes na amizade perpétua;

Agradeço em especial à CAPES pelo apoio financeiro a esta pesquisa através de concessão de bolsa de estudos por pouco mais de um ano e meio. Seu apoio foi imprescindível para o desenvolvimento deste trabalho.

A querida Daniela Zavisas Hladkyi, pelo companheirismo, carinho, generosidade e apoio incondicional, com todo o meu reconhecimento.

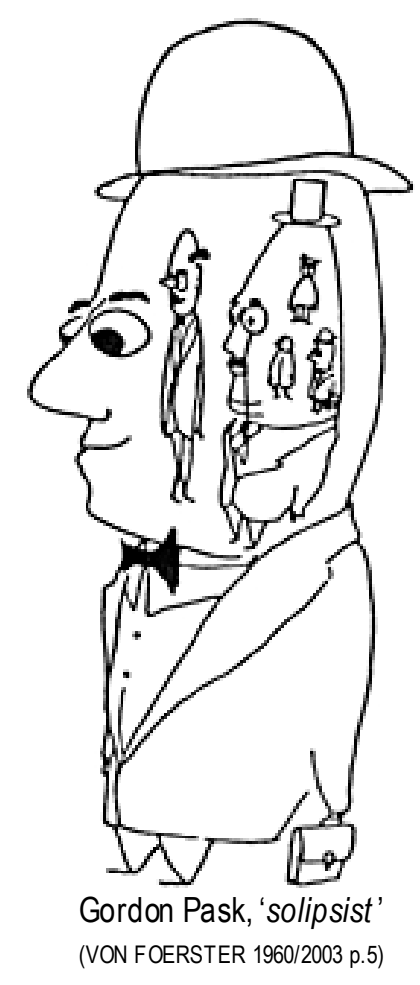


You probably imagine that philosophy is complicated enough, but let me tell you, this is nothing compared to the hardship of being a good architect. Back when I was building the house for my sister in Vienna I was so exhausted at the end of the day that the only thing I was still able to do was to go every evening to the cinema.

Ludwig Wittgenstein conversation with Maurice O'Connor Drury, 1920s

The performing of a very complicated act of faith

John Christopher Jones (1966) 

PASCHOALIN, D. M. O horizonte da conversação: concepções do processo projetual arquitetônico. Dissertação (Mestrado em Arquitetura e Urbanismo) Instituto de Arquitetura e Urbanismo, Universidade de São Paulo,São Carlos, 2012.

\title{
RESUMO
}

A pesquisa trata da compreensão da atividade de projetar através de abordagens que propõem a concepção de conversação ou diálogo na caracterização do proœsso projetual emarquitetura. Investigamos o surgimento destas abordagens na segunda metade do século XX e começo do século XXI, cuidando em apresentar uma leitura das transformações nos modos de se ver tanto o design quanto o designer arquitetônico, dentro do recorte temático a que nos referimos como 'horizonte da conversação'. Realizamos uma revisão sobre aspectos conceituais centrais às visões de teóricos do design que, além da arquitetura, transitam por outros domínios do saber como filosofia e cibemética, e que reconheœm o design como uma troca dialógica envolvendo tanto a transformação da situação projetual quanto a transformação do próprio designer pela percepção de consequências não intencionais de suas ações projetuais. A partir desta revisão, elaboramos uma reflexão sobre uma ordem de preocupạ̄oes compartilhadas entre as abordagens de nosso horizonte temático, pela qual buscamos o desenvolvimento de umentendimento mais abrangente e enriquecido sobre 0 processo projetual arquitetônio.

Palavras-chave: 1. Teoria do projeto arquitetônico; 2. Conœpções do processo projetual; 3.Conversação; 4. Troca dialógica; 5. Hermenêutica; 6 . Cibernética.

\begin{abstract}
ABST RACT
The research deals with the understanding of the design activity by approaches which proposes the concept of conversation or dialogue in the characterization of the design process in architecture. We investigate the emergence of these approaches in the second half of the twentieth century and early twenty-first century, taking care to present a reading of underlying changes in the ways of seeing of both design and the architectural designer in he thematic focus we refer as 'horizon of conversation'. We accomplished a review of œntral conceptual issues to views of design theorists that in addition to architecture, transiting through other domains of knowledge as philosophy and cybemetics, and recognize design as a dialogic exchange involving both the transformation of the design situation and the designer himself by the perception of unintended consequenœs of their design actions. From this review, we present a reflection about an order of shared concems between the approaches of our thematic horizon, which we seek the development of a broader and enriched understanding of the architectural design process.
\end{abstract}

Keywords: 1.Architectural design theory; 2. Conceptions of the design process; 3. Conversation; 4.Dialogical exchange; 5. Hermeneutics; 6.Cybernetics. 



\section{SUMÁRIO}

INTRODUÇÃO 17

PREFÁCIO 17

OBJETIVOS 23

ESTRUTURA DA DISSERTAÇÃO 25

1. EMERGÊNCIA DO HORIZONTE DA CONVERSAÇÃO 31

1.1 O projetar como resolução racional de problemas 31

1.1.1 Introdução ao contexto dos métodos em design nos anos 1960 e 197032

1.1.2 O método como exteriorização sistemática do processo projetual 38

1.1.3 Métodos e modelos do processo projetual 42

1.1.4 Ciência do design como resolução racional de problemas 50

1.1.5 Crise dos métodos em design 57

1.2 O projetar como um processo argumentativo 62

1.2.1 A v isão de Horst Rittelf rente à crise dos métodos em design 63

$\begin{array}{lll}1.2 .2 & \text { Problemas capciosos } & 68\end{array}$

1.2.3 Por uma segunda geração de métodos em design 72

1.2.4 Argumentação e sistemas de planejamento 78

1.2.5 A liberdade epistêmica do projetar 82

2. O PROJETAR COMO CONVERSAÇÃO 91

2.1 O projetar como conversação reflexiva 91

2.1.1 Donald Schön e a busca por uma epistemologia da prática 92

2.1.2 Reflexão-em-ação e arquitetura 97

2.1.3 O projetar como conversação com a situação do design 103

2.1.4 A experimentação da prática reflexiva 108

2.1.5 A transf omação da compreensão pelo projetar 115

2.2 projetar como conversação hermenêutica $\quad 120$

2.2.1 Filos of ia hermenêutica e metáforas do processo projetual 121

2.2.2 O círculo hemenêutico e a onipresença do projetar 126

2.2.3 A natureza conv ersativa do ev ento hemenêutico 132

2.2.4 O projetar arquitetônico como conversação hemenêutica 137

2.2.5 Jogos, linguagem e dois entendimentos dissonantes 144 
$\begin{array}{lll}3.1 & 0 \text { projetar como conversação cibernética } & 153\end{array}$

$\begin{array}{lll}\text { 3.1.1 Introdução à Cibernética } & 154\end{array}$

$\begin{array}{ll}\text { 3.1.2 Cibernética de Segunda Ordem } & 160\end{array}$

$\begin{array}{lll}\text { 3.1.3 Teoria Cibernética da Conv ersação } & 165\end{array}$

$\begin{array}{lll}\text { 3.1.4 Arquitetura da teoria da conv ersação } & 170\end{array}$

$\begin{array}{lll}3.1 .5 & \text { O projetar como conversação cibernética } & 177\end{array}$

$\begin{array}{lll}3.2 & O \text { projetar como conversação em expansão } & 184\end{array}$

3.2.1 Ontologia e epistemologia em transformação 185

3.2.2 Interdependência e coev olução de instâncias projetuais 193

3.2.3 Concernimentos de segunda ordem sobre o processo projetual 199

3.2.4 O Projetar como construção de sentidos e acordos sociais 207

$\begin{array}{lll}3.2 .5 & \text { O Projetar como liv revaguear } & 213\end{array}$

CONSIDERAÇÕES FINAIS $\quad 221$

Conversação sobre o processo projetual arquitetônico $\quad 221$

$\begin{array}{ll}\text { REFERÊNCIAS BIBLIOGRÁFICAS } & 231\end{array}$

$\begin{array}{lr}\text { ANEXOS } & 239\end{array}$

LISTA DE SIGLAS $\quad 239$

LISTAS DE TABELAS $\quad 239$

LISTA DE FIGURAS $\quad 240$

$\begin{array}{ll}\text { BIOGRAFIAS } & 241\end{array}$ 
Introdução 



\section{Prefácio}

Este trabalho de pesquisa parte de uma incomensurável inquietação que acredito compartilhar com grande parte dos que por alguma causa ou efeito do destino se veem envolvidos com a prática arquitetônica. No contexto da educação formal em arquitetura, compreendida como a profissão dos arquitetos, imagino que a gestação desta inquietação inicia-se logo junto à primeira sessão de estúdio de projeto, senão antes. O que é de fato projetar? Como descrever o que fazemos quando nos empenhamos na atividade projetual? Como podemos projetar melhor, para sermos melhores arquitetos? Obviamente chegar a respostas definitivas para estas perguntas está longe de ser objetivo desta investigação, de modo que meramente o esboço de uma pretensão parece quase tão incômodo quanto a formulação destas questões em público. Contudo, o fato é que estuda-se por anos em curso universitário, trabalha-se por outros anos em escritórios, eventualmente também leciona-se o assunto e, uma vez de volta à academia como pesquisador, ainda conservam-se tais indagações. A título de sobreviver e seguir o caminho do aprendizado, nos vemos inclinados a direcionar esforços de pesquisa transformando a inquietação em motivação. E aqui estamos.

Uma das lembranças mais antigas de que me recordo com relação à concepções do projetar vem de uma conversa com professores de projeto sobre bibliografias, em que foi indicada a obra 'Das Coisas Nascem Coisas' do designer italiano Bruno Munari (1907-1998) como uma referência recorrente sobre o tema. ${ }^{1}$ Nesta obra, Munari (1981) apresenta uma série de recomendações sobre a prática projetual. Logo ao início da obra, o autor cita as

\footnotetext{
1 Afirmação a qual não temos como confirmar a ver acidade, o que de antemão não representa implicação alguma, de fato, para esta arguição.
} 
quatro regras do método cartesiano e então expõe ao leitor tratar-se de um livro de metodologia projetual, ou seja, sobre procedimentos (o que se deve fazer) para alcançar a solução de problemas de projeto (MUNARI, 1981, p.11-12). Para Munari (1981, p.39-66) o processo projetual compreende uma sequência de atividades ${ }^{2}$ a serem contempladas pelo designer partindo do problema à solução do projeto, similar ao processo de preparo de um prato culinário, no caso, arroz verde (Figura 1).

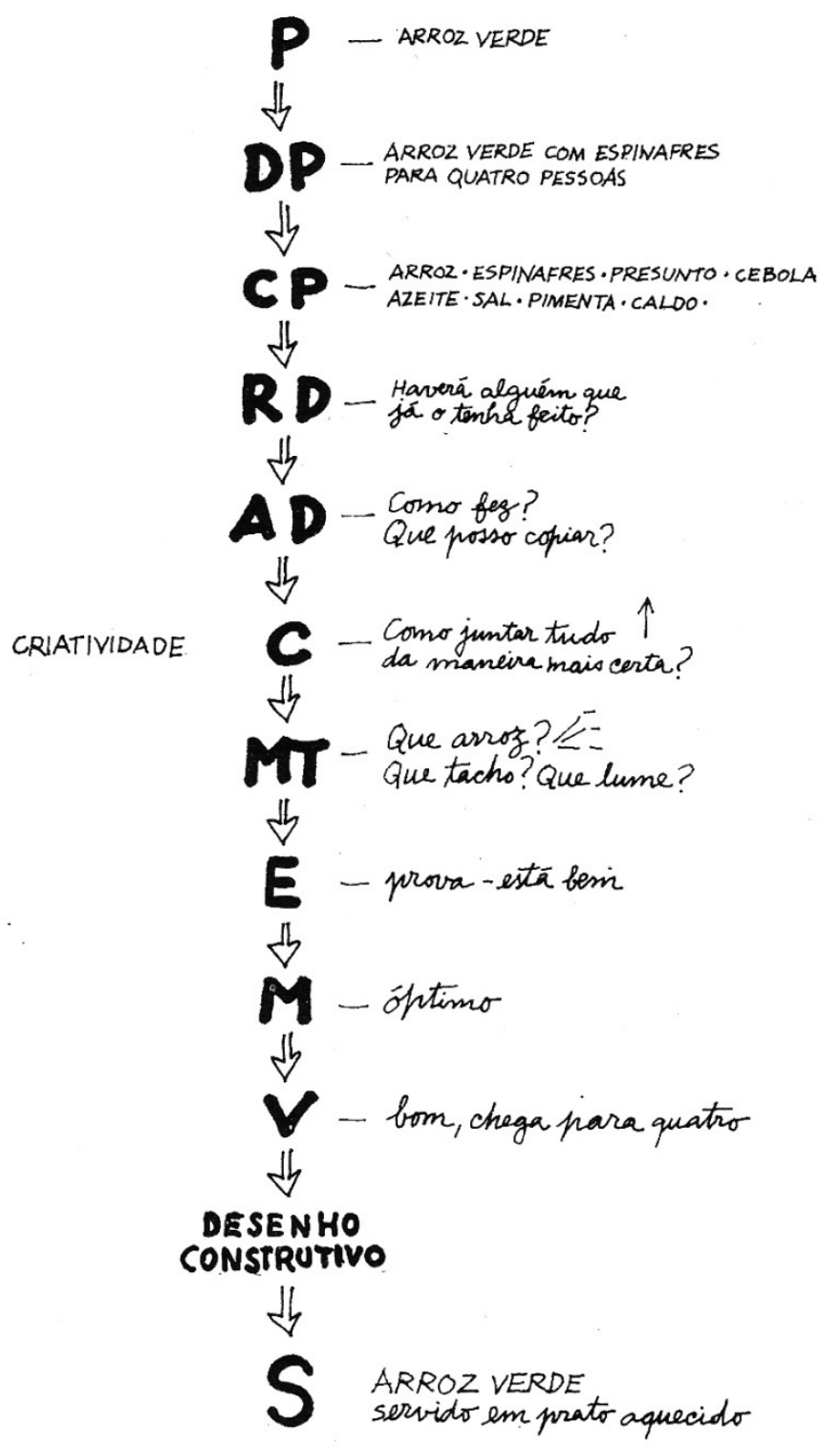

Figur a 1 - 0 projetar como receita de arroz verde. Fonte: (MUNARI, 1981, p.66)

\footnotetext{
${ }^{2}$ Neste exemplo, a saber: P. Problema; DP. Definição do problema; CP. Componentes do problema; RD. Recolha de dados; AD. Análise dos dados; C. Criatividade; MT. Materiais e tecnologias; E. Experimentação; M. Modelo; V. Verificação; Desenho Construtivo; S. Sol ução.
} 
À parte de qualquer juízo de apreciação gastronômica, percebemos que esta visão de Munari (1981) sobre a atividade projetual não é exclusiva ao autor, mas representa uma abordagem emergente no bojo do desenvolvimento tecnológico e científico dos anos 1950, que formalizou-se no chamado 'movimento de métodos em design' (CROSS, 2001; BAYAZIT, 2004), uma organização de esforços de pesquisa acadêmica emergente nos anos 1960 e 1970, que exerceu considerável influência especialmente na arquitetura (BROADBENT, 1973/1988; ROWE, 1987). Este movimento procurou entender o projetar, a partir de seu reconhecimento como um processo 'lógico', 'sistemático' e 'racional'; e contribuir para seu incremento pelo emprego de métodos, técnicas e conhecimentos científicos obtidos em diversas áreas do saber no contexto do pós Segunda Guerra Mundial (BROADBENT, 1973/1988). Como sugerido pela leitura de Munari (1981), parte-se do reconhecimento de que o cerne da atividade projetual consiste na tomada de decisões e ações para a resolução de problemas, que podem ser entendidos como discrepâncias ou desajustes entre as condições de uma situação atual com relação às condições da situação desejada ${ }^{3}$. Nesta perspectiva, pensar no projetar como resolução de problemas significa essencialmente o desenvolvimento de ações transformadoras a fim de tornar uma dada situação em outra preferida, de modo que ênfase é conferida sobre a investigação de meios otimizados de obtenção de objetivos, em outras palavras, o processo de busca pelas melhores soluções dos problemas encontrados este processo. (SIMON, 1969).

Ao começo dos anos 1970, o movimento de métodos em design enfrentou um cenário de crise, deflagrada pelas manifestações de descontento de alguns de seus principais expoentes, e pela percebida ausência de resultados concretos que comprovassem a eficácia dos métodos e modelos sistemáticos em cumprir sua proposta. Diversos problemas sociais pareceram inclusive agravar-se pela aplicação de resoluções de projeto, denunciando a necessidade de uma revisão desta abordagem do projetar. Um dos pontos centrais desta revisão partiu da compreensão de que metas e objetivos não são dados, mas negociados e acordados socialmente a partir de entendimentos, pontos de vista e interesses distintos, mesmo antagônicos, ambíguos ou contraditórios (RITTEL; WEBBER, 1973) (Figura 2).

\footnotetext{
3 Diversos teóricos do design que apresentaremos ao longo deste trabal ho têm suas conc epções do projetar atreladas a esta premissa elementar, como ver emos a seguir.
} 


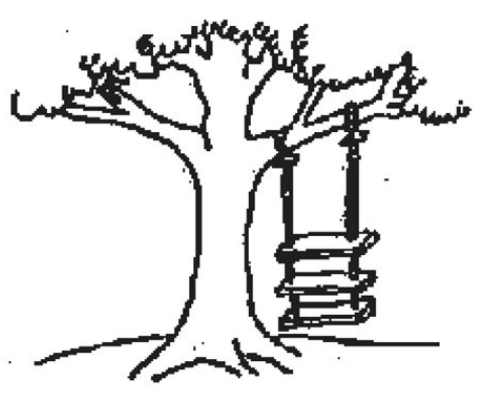

como proposto pelo usuário

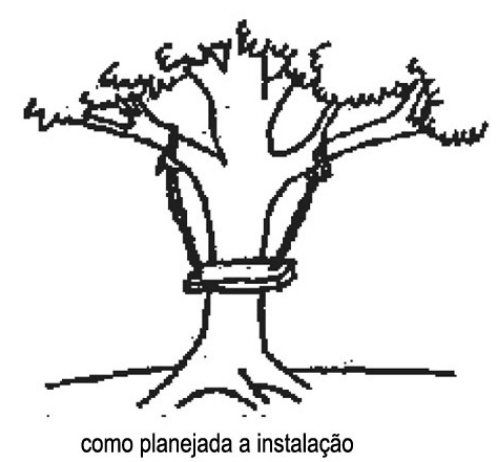

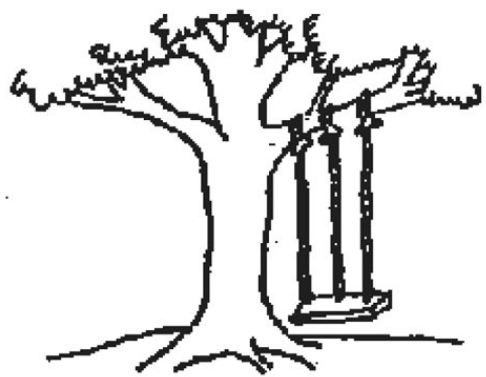

como entendido pela equipe de projeto

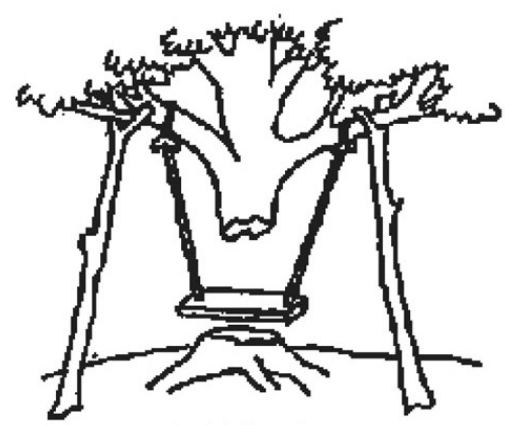

como instalado no terreno
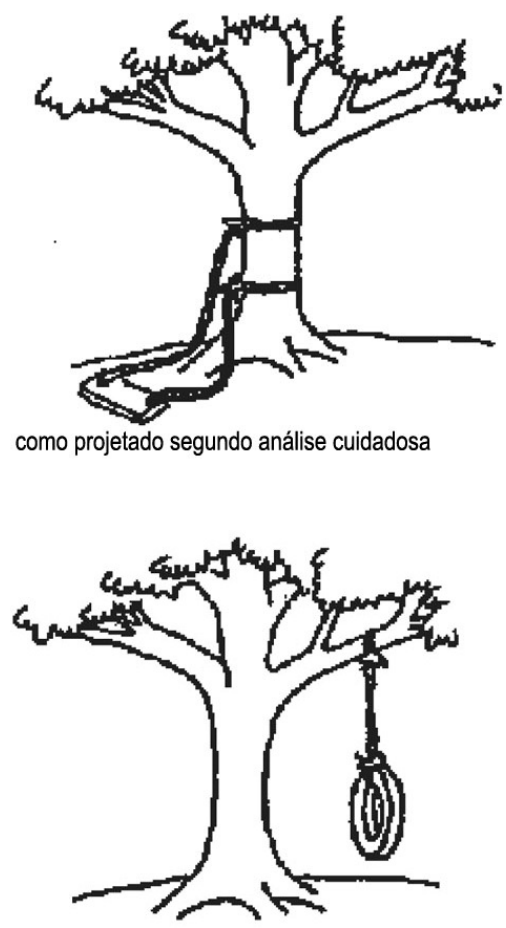

o que o usuário queria

Figura 2 - Dificuldade em fixar-se objetivos e soluções no processo projetual. Adapłado de (DUBBERLY, 2005 p.66)

Reconhecemos neste contexto um rearranjo de enfoques sobre a prática projetual, em que foi assumida uma ênfase dos processos de configuração de problemas e na busca por situar as decisões de projeto como um processo mais político do que científico (PROTZEN e HARRIS, 2010). Neste sentido destaca-se a obra de dois teóricos do design: o matemático-físico alemão Horst Rittel (1930-1990) e o filósofo norte-americano Donald Schön (1930-1997). Ambos reconheceram as limitações no emprego do instrumental técnico e dos modelos e métodos científicos ao tratar-se dos problemas de design (PROTZEN; HARRIS; CAVALLIN, 2000, p.48), e diante esta premissa, desenvolveram abordagens distintas sobre a atividade projetual, respaldados em suas experiências de docência e pesquisa em arquitetura e urbanismo. Rittel vê o projetar como um processo de argumentação em torno da definição de acordos e comprometimentos de seus agentes sobre a elaboração de planos a serem implementados, uma atividade essencialmente comunicativa de ponderações e deliberações a fim de se evitar consequências imprevistas e/ou indesejáveis pelas transformações do design (RITTEL 1987/2006, p.187-188) Schön (1983, p.79) acredita que é justamente ao deparar-se com estas consequências não intencionais que os designers refletem sobre seus pontos de vista ou 
'modos de ver' as coisas, e sobre suas ações frente às situações de projeto, levando-os a elaborar novas apreciações e repensar novas ações. Para o autor, esta dinâmica configurase metaforicamente como uma 'conversação': uma reacomodação dinâmica de intenções, ações e resultados, em que o designer transforma a situação de projeto e esta 'responde de volta' transformando o designer (SCHÖN, 1983, p.150-151). As abordagens de Rittel e Schön, guardadas suas particularidades, contemplam o projetar como uma atividade essencialmente 'dialógica', ou seja, baseada em trocas, convencimentos e acordos e assim um processo não linear e sequenciado, mas cambiante ${ }^{4}$. Estas são as qualidades a que pretendemos investigar em nosso trabalho de pesquisa sobre concepções do processo projetual arquitetônico.

Um passeio pela etimologia ${ }^{5}$ do termo conversação nos concede a compreensão seus sentidos como 'viver juntos, ter relações ou comportamentos com outros' e também 'maneira de conduzir-se no mundo', do latim 'conversationem', 'ato de viver com', de 'conversari': cum ('com') + versare (literalmente 'dar voltas, girar'). Comumente associada ao termo 'conversação' temos a palavra 'diálogo', do grego antigo 'dialogos': diá ('através de, de um lado através do outro') + logos ('palavra escrita ou fala, verbo, razão'), podendo ser utilizada no sentido de 'troca de ideias'. Conversação relaciona-se também com o termo grego 'dialegomai': diá + légō ('falar através, discutir'), que refere-se à comparação de ideias, opiniões ou possibilidades na tentativa de se atingir uma conclusão sobre algo, conduzida internamente como processo mental ou externamente como diálogo. Acreditamos que esta paisagem etimológica representa diversos aspectos relevantes ao processo projetual arquitetônico, condizentes com as caracterizações de Horst Rittel, Donald Schön e outros autores sobre o tema. Em nossos esforços preliminares de pesquisa, observamos a existência de outras duas concepções do projetar no contexto dos anos 1990 e 2000 que se propõem a tratar da dimensão conversativa na prática do design em arquitetura e que remetem-se explicitamente à visão de Schön, partindo no entanto de referenciais teóricos distintos para sua compreensão: a primeira constitui-se pelo trabalho dos pesquisadores Adrian Snodgrass e Richard Coyne (1992; 1995; 1997/2006; 2006) em sua observação da natureza

\footnotetext{
${ }^{4}$ No sentido de que não é fixo, que varia, troca, altera ou transforma.

5 De acordo com o dicionário online de etimologia pelo historiador Douglas Harper (2001/2011). Disponível em: http://www. etymonline.com/i ndex.php?search=conversation Acess o em 12/08/2011.
} 
do projetar como um processo interpretativo, segundo os preceitos da filosofia her menêutica de Hans-Georg Gadamer (1900-2002):

[...] mesmo um exame superficial dos estudos de protocolo de Donald Schön indica que 0 processo de design que ele descreve funciona de acordo com a dinâmica do círculo hermenêutico, procedendo por meio de uma troca dialógica com a situação do design ${ }^{6}$ (SNODGRASS; COYNE, 1997/2006, p.45 tradução nossa)

A segunda perspectiva corresponde às colocações de pesquisadores como o arquiteto e ciberneticista Ranulph Glanville (2007a; 2007b; 2009), que entre outros autores indicados no corpo deste trabalho, transita entre os domínios do design e da cibernética, e aponta para a obra do ciberneticista inglês Gordon Pask $(1975 ; 1976 ; 1980 ; 1987)$ e sua 'teoria cibernética da conversação"7 ao afirmar a existência de uma correlação entre estes domínios:

[...] uma série de estudiosos comenvolvimentos significativos emambos cibemética e design têm mantido, pelo último meio século, que há uma ligação significativa entre os dois. Afirmações feitas em público e privado, por vezes, tem originado publicações argumentadas incluindo as de Pask, embora mais frequentemente tenhamemergido emoutras publicaọões como comentários quase que atirados ao vento. Outros trabalhos, como o de Schön podem ser vistos, hoje, envolvendo argumentos essencialmente cibeméticos. ${ }^{8}$ (GLANVILLE, 2007a, p.1153, tradução nossa.)

Com base neste núcleo de referências nos lançamos então ao estudo da dimensão da conversação no projetar, atendo-nos a investigação de abordagens emergentes na segunda metade do século XX, de acordo com nossa orientação própria no plano da arquitetura. Esperamos contribuir assim para o desenvolvimento de uma compreensão mais abrangente e enriquecida sobre o processo projetual arquitetônico a partir deste recorte temático.

\footnotetext{
${ }^{6}$ Do original em inglês: "[...] even a cursory examination of the protocol studies of Donald Schön indicates that the design process he describes works according to the dynamics of the her meneutical circle, proceeding by way of a dialogic exchange with the design situation."

${ }^{7}$ Confor me publicada originalmente em Pask (1975a, 1976).

8 Do original em inglês: "[...] a number of scholars with meaningful involvements in both cybernetics and design have maintained, for the last half century, that is a significant connection between the two. Ass ertions made in public and private have sometimes lead to argued publications including Pask's (1969, 1979), though more often they have surfaced in other publications as comments al most tossed aside in the flow. Other works, such as Schon's (1983) can be seen, today, to involve essentially cyber netic arguments."
} 


\section{Objetivos}

Nosso trabalho objetiva a compreensão da atividade de projetar através de abordagens que propõem a concepção de conversação ou diálogo na caracterização do processo projetual arquitetônico. Para tanto, investigamos a emergência destas abordagens na segunda metade do século $X X$ e começo do século $X X I$, cuidando em apresentar uma leitura subjacente das transformações nos modos de se conceber ambos design e o designer arquitetônico neste recorte contextual.

Como objetivos específicos pretendemos investigar as implicações em se conceber o processo projetual como configuração e resolução de problemas, e a possibilidade do estabelecimento de outros sentidos para além deste entendimento, como uma atividade explorativa e de aprendizagem. Prevemos também a elaboração de um comparativo entre abordagens, procurando reconhecer ordens de concernimentos em comum e possíveis correspondências conceituais entre as visões dos autores tratados, delimitando tópicos preliminares de uma possível 'agenda da conversação' para a pesquisa, prática e ensino de projeto em arquitetura e urbanis mo.

Mas como investigar o projeto arquitetônico à luz de um processo tão abrangente como a conversação, em vista de seu reconhecimento como forma essencial à condução das ações e apreciações por parte dos diferentes agentes e em diversas instâncias do projetar? Esta pergunta configura nossa 'situação projetual' da pesquisa, ou seja, como nos posicionamos em relação a nossa intenção de estabelecer um estudo acadêmico rigoroso frente às propriedades elusivas deste tema. Como ação preliminar de projeto, procedemos então uma revisão bibliográfica delimitando o recorte de investigação sobre o tema proposto, a qual nos referimos como nosso 'horizonte da conversação'. Segundo o filósofo Gadamer (1975/1997): 
Nós determinamos o conceito da situação justamente pelo fato de que representa uma posição que limita as possibilidades de ver. Ao conceitb da situação pertence essencialmente, então, o conceito do horizonte. Horizonte é o âmbito de visão que abarca e encerra tudo o que é visível a partir de um determinado ponto. (GADAMER, 1975/1997, p.452)

Efetivamente este horizonte da conversação representa, portanto, os limites de nossa capacidade de visão a partir do ponto perspéctico conformado pela nossa situação de pesquisa. Através da análise por co-citação entre os autores chegamos a um mapeamento bibliográfico que nos permitiu distinguir cinco abordagens bem definidas sobre as concepções do projetar no recorte cronológico dos anos 1960 aos anos 2000 (Tabela 01):

\begin{tabular}{|c|c|c|c|c|}
\hline Concepções & $\begin{array}{l}\text { Principais autores } \\
\text { referenciados }\end{array}$ & $\begin{array}{c}\text { Principais } \\
\text { Referências } \\
\text { bibliográficas }\end{array}$ & Outras referências & $\begin{array}{l}\text { Contexto } \\
\text { cronológico } \\
\text { da concepçãc }\end{array}$ \\
\hline $\begin{array}{l}\text { Processo racional } \\
\text { de busca por } \\
\text { soluções }\end{array}$ & $\begin{array}{l}\text { ALEXANDER, C. } \\
\text { JONES, C. } \\
\text { SIMON, } \mathrm{H} \text {. }\end{array}$ & $\begin{array}{l}\text { JONES, J. Design methods: } \\
\text { seeds of human futures. London, } \\
\text { New York: John Wiley \& Sons, } \\
\text { 1970/1992. }\end{array}$ & $\begin{array}{r}\text { ARCHER, B.; ASIMOW M.; BAYAZIT, N.; } \\
\text { BAZANAC., V.; BROADBENT, G.; } \\
\text { CROSS, N.; DORST, K.; DOWNTON, P.; } \\
\text { EAST MAN, C.; ROWE,P.; LAWSON, B. }\end{array}$ & $1960 \mathrm{~s}$ \\
\hline $\begin{array}{c}\text { Processo } \\
\text { Argumentativo }\end{array}$ & RITTEL, H. & $\begin{array}{l}\text { PROTZEN, J.; HARRIS, D. J. (ed.), } \\
\text { The universe of design - Horst } \\
\text { Rittel's theories of design and } \\
\text { planning. London, New York: Ed. } \\
\text { Routledge, 2010. }\end{array}$ & PROTZEN,J.; HARRIS, D.; WEBBER, M.; & $1970 s$ \\
\hline $\begin{array}{c}\text { Conversação } \\
\text { reflexiva }\end{array}$ & SCHÖN, D. & $\begin{array}{l}\text { SCHÖN, D. A. The reflective } \\
\text { practitioner: how professionals } \\
\text { think in action. New York: Basic } \\
\text { Books, } 1983\end{array}$ & DEWEY, J.; WAKS, L.; WIGGINS, G.; & $1980 \mathrm{~s}$ \\
\hline $\begin{array}{l}\text { Conversação } \\
\text { hermenêutica }\end{array}$ & $\begin{array}{c}\text { COYNE, } \mathrm{R} . \\
\text { GADAMER, } \mathrm{H} \text {. } \\
\text { SNODGRASS, } \mathrm{A} \text {. }\end{array}$ & $\begin{array}{l}\text { SNODGRASS, A.; COYNE, R. } \\
\text { Interpretation in architecture. } \\
\text { Design as a way of thinking. } \\
\text { London: Routledge, } 2006\end{array}$ & HEIDEGGER,M.; WITTGENSTEIN, L.; & $1990 s$ \\
\hline $\begin{array}{l}\text { Conversação } \\
\text { Cibemética }\end{array}$ & $\begin{array}{l}\text { GLANVILLE, } \mathrm{R} ., \\
\text { PASK, G. } \\
\text { PANGARO, P. }\end{array}$ & $\begin{array}{l}\text { fI ANVIII I F R A (C.vhernetic. } \\
\text { Musina) desirn and c.vhemetics } \\
\text { In The Bhck Bonx Wien: } \\
\text { Echoraum, 2009, p. } 423-435 \text {. }\end{array}$ & $\begin{array}{r}\text { ASHBY, R.; BOYD, G.; DUBBERLY, H.; } \\
\text { HEYLIGHTEN, F;; JOSLYN, C;; } \\
\text { MATURANA,H.; SCOTT, B.; } \\
\text { VON FOERSTER, H.; }\end{array}$ & $2000 s$ \\
\hline
\end{tabular}

Tabela 01 - Definição do 'horizonte da conversação' para o desenvolvimento da pesquisa. 
O desenvolvimento do trabalho é baseado, portanto, em levantamento bibliográfico, coleta e análise de dados e informações a partir de fontes secundárias e primárias. Posterior à coleta de fontes, realizamos nova revisão bibliográfica acerca do tema proposto, estabelecendo um referencial teórico básico apropriado para a compreensão das abordagens e colocações dos principais autores aos quais nos referenciamos em nosso 'horizonte da conversação'. Em um terceiro momento, realizamos outra revisão bibliográfica, expandindo a compreensão inicial e redirecionando alguns enfoques, de acordo com o amadurecimento de alguns de nossos questionamentos preliminares sobre o tema da pesquisa.

\section{Estrutura da Dissertação}

$\mathrm{Na}$ leitura de nossas referências bibliográficas principais, percebemos a construção de verdadeiras 'narrativas' pelas abordagens dos autores sobre a forma dialógica do projetar, através de problematizações e da proposição dos conceitos que caracterizam seus respectivos pontos de vista. Procuramos evidenciar esta percepção em nosso trabalho pela distinção entre as abordagens na composição dos capítulos, dividindo cada capítulo em duas partes equivalentes, sendo que cada uma destas partes corresponde à orientação de uma concepção do projetar, excetuando-se a segunda parte do capítulo 2, em que realizamos a leitura conjunta das abordagens tratadas. A adoção desta configuração procura evidenciar contrastes, por exemplo, como a visão de cada autor e suas respectivas 'versões' do processo projetual diferem à luz de questões comuns sobre a atividade projetual. A título de exemplificar nossa intenção, nos remetemos ao filme 'Rashomon' (1950) do cineasta Akira Kurosawa (1910-1998), em que seus personagens (Figura 03) reconstroem um trágico acontecimento através de seus relatos: apesar de se tratar do mesmo evento, cada versão apresentada destoa consideravelmente uma das outras, sugerindo a impossibilidade de obtenção de uma 'verdade fatual' diante das disparidades dos pontos de vista. 


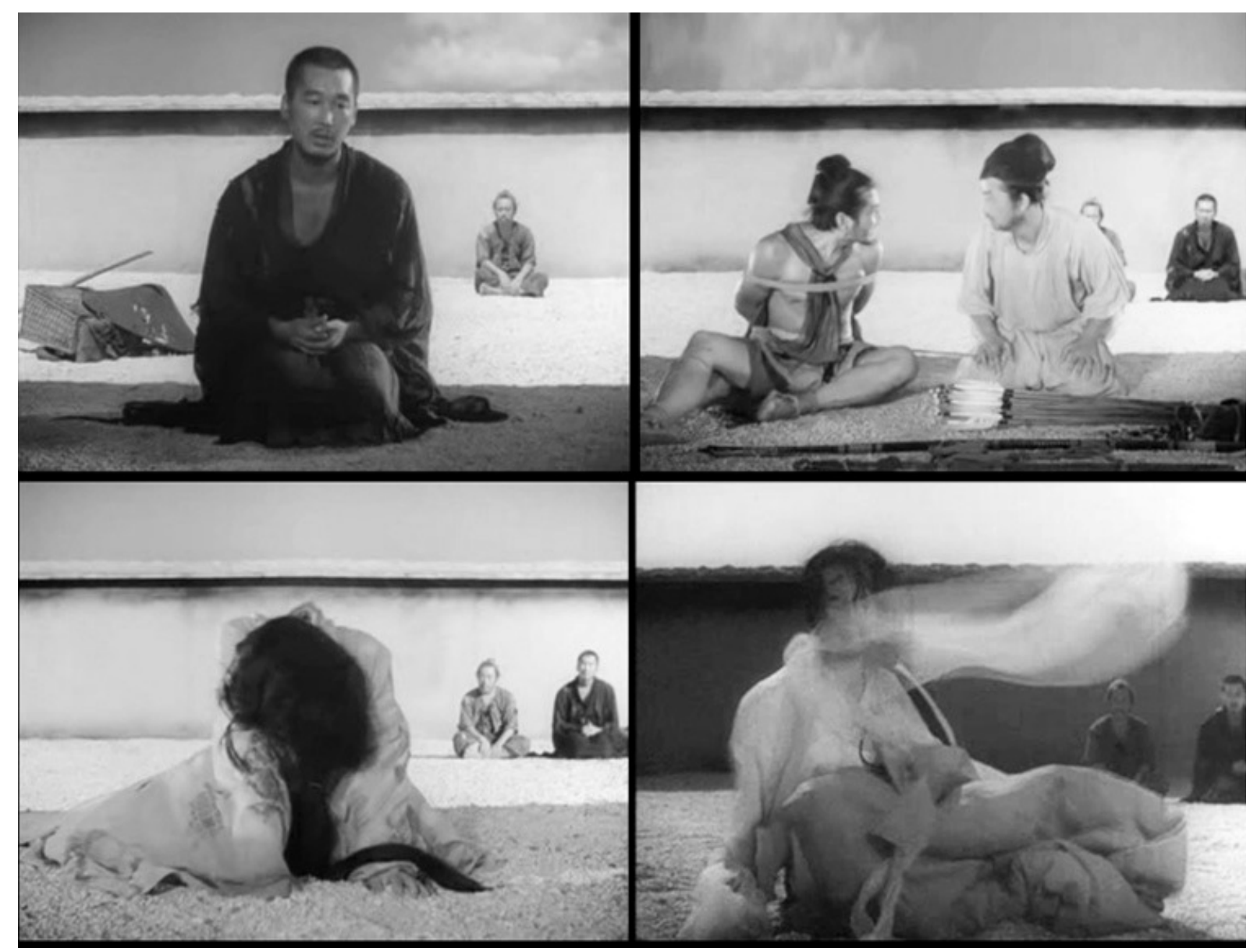

Figura 3 - Diferentes personagens, diferentes visões sobre o mesmo acontecimento. Rashomon, filme de Akira Kurosawa, 1950. Imagens coletadas do próprio filme. Daei motion picture company. Todos os direitos reservados.

Procuramos evidenciar esta compreensão, assim como Kurosaw a, utilizando-se do recurso de 'refazer' várias vezes o percurso traçado pela narrativa dos personagens, estabelecendo um movimento recursivo de referenciações, em que novos sentidos são agregados progressivamente na construção do todo. Ressaltamos que nosso trabalho não busca uma comprovação ou conclusão sobre a veracidade fatual da natureza do projetar, mas sim a apuração de suas concepções dentro do horizonte estipulado, frente a premissa de que um novo conhecimento pode ser obtido tomando nosso próprio posicionamento como intérpretes. Do mesmo modo esperamos que este estudo sirva para incitar questionamentos, inspirar outras interpretações e assim fomentar novas conversações sobre o tema. Nossa intenção de incorporar 'versões' sobre conversação e design na estrutura formal da dissertação, tal a revisão das narrativas dos personagens em 'Rashomon', visa portanto proporcionar uma maior abertura interpretativa segundo estes propósitos. 
O capítulo 1, 'Emergência do horizonte da conversação', situa o contexto preliminar de nossa investigação no bojo do movimento de métodos em design dos anos 1960 e 1970, momento de significativo valor para a pesquisa em design de um modo geral e em particular a nosso horizonte temático, por representar a gênese de concepções do processo projetual arquitetônico que permeiam o ideário da arquitetura ainda na contemporaneidade. $\mathrm{Na}$ primeira parte do capítulo, cuidamos por evidenciar uma intenção vinculada ao desenvolvimento de métodos e modelos do processo projetual a fim de proporcionar a comunicação e investigação crítica do design entre seus agentes e como este objetivo compromete-se à medida que as proposições adotadas sobre o que o projetar deveria ser convergem no sentido de uma 'ciência do design'. Na segunda parte apresentamos o alvorecer de nosso horizonte da conversação através da concepção do projetar de Horst Rittel como um processo argumentativo, vinculada à abordagem própria da chamada 'segunda geração de métodos em design' no início dos anos 1970. Observamos como Rittel reafirma os propósitos da primeira geração de métodos, distanciando-se, no entanto, dos valores e juízos característicos desta geração, em prol do reconhecimento da dimensão sociopolítica na atividade projetual.

O capítulo 2, 'O Projetar como conversação', estabelece aproximações teórico-filosóficas em relação à atividade projetual e a concepção de conversação ou diálogo, a partir das teorias pragmáticas de Donald Schön sobre o processo de reflexão na prática do projetar, e da correlação entre princípios da hermenêutica de Hans-Georg Gadamer e Martin Heidegger pela visão dos pesquisadores Adrian Snodgrass e Richard Coyne. Na primeira parte do capítulo apresentamos a abordagem de Schön, que em sua busca por uma epistemologia da prática reflexiva, trata da 'artisticidade' pela qual praticantes algumas vezes conseguem lidar satisfatoriamente com situações únicas, incertas e complexas através da investigação projetual. Schön baseia seus estudos na contemplação do design arquitetônico, descrevendo-o como uma conversação reflexiva entre o designer e a situação do design, através de uma alternância entre 'modos de ver' e ações transformadoras. Na segunda parte do capítulo apresentamos a correspondência entre a concepção do projetar de Snodgrass e Coyne sobre a abordagem de Schön como um evento hermenêutico, essencialmente interpretativo, baseado na reacomodação de compreensões, sentidos e 
juízos através de uma estrutura dialógica de questionamento. Estas abordagens apontam, por sua vez, para uma relação dinâmica entre a compreensão de uma situação projetual, sua transformação pelas ações do designer e a apreciação de consequências não intencionais que reorientam novas compreensões e ações, indicando o sentido de aprendizagem pelo projetar.

No capítulo 3, 'Horizonte em expansão', buscamos ampliar o horizonte da conversação representado pelas abordagens referenciadas anteriormente. Na primeira parte do capítulo uma excursão sobre o campo de estudos da cibernética, orientados pelo trabalho de ciberneticistas que afirmam a correspondência entre a concepção de conversação como uma interação comunicativa e o projetar arquitetônico. Na segunda parte do capítulo realizamos uma leitura de aspectos centrais às concepções que compõe o recorte temático proposto, evidenciando a configuração de uma ordem de assuntos e concernimentos comuns a estas concepções. Neste contexto, incorporamos referências de outros autores a título de complementar nossa leitura, reafirmando o sentido de expansão sugerido. Buscamos a construção de uma compreensão geral das implicações derivadas das abordagens sobre o projetar, a fim de estabelecer desdobramentos como possíveis orientações sobre o projeto arquitetônico. Realizamos finalmente uma breve reflexão sobre nosso próprio processo de investigação no projeto deste trabalho.

As Considerações Finais deste trabalho, por sua vez, correspondem a uma breve conversação reflexiva sobre o processo projetual arquitetônico de acordo com o horizonte temático abordado, em que expressamos nosso entendimento geral dos resultados de nossa investigação e sugerimos tópicos para a elaboração de uma possível agenda da conversação para a pesquisa em processos de design em arquitetura e urbanismo. 
Capítulo 1

Emergência do Horizonte da Conversação 



\section{EMERGÊNCIA DO HORIZONTE DA CONVERSAÇÃO}

\subsection{O projetar como resolução racional de problemas}

Nesta primeira parte do capítulo, apresentamos uma revisão sobre o contexto do movimento de métodos em design nos anos 1960 e 1970, em que procuramos elucidar algumas das premissas ideológicas e conceituais subjacentes à conformação dos primeiros modelos do processo projetual arquitetônico. Neste sentido, observamos uma significativa influência dos preceitos da racionalidade cartesiana sobre a pesquisa em design, bem como o interesse por teorias e técnicas provenientes da pesquisa científica sobre processos de otimização, tomada de decisões e resolução de problemas, com ênfase no desenvolvimento computacional emergente ao final da Segunda Guerra Mundial. Apresentamos a argumentação de teóricos do design como o arquiteto austríaco Christopher Alexander e o designer inglês John Christopher Jones sobre a necessidade do estabelecimento de uma base crítica do projetar que permitisse o seu esclarecimento, em detrimento dos valores 'subjetivos' ou 'intuitivos' comumente associados à atividade. O processo projetual passou então a ser modelado como um processo linear, ordenado e sequenciado de atividades bem definidas. Entretanto estes modelos assumiram uma progressiva abstração e generalização à medida que se preconizou o estabelecimento de uma 'ciência do design', concomitante com a deflagração de uma dura crítica e rejeição por parte de alguns de seus principais expoentes como os próprios Jones e Alexander, descontentes com os rumos to mados pelas pesquisas em design e sua aparente ausência de resultados efetivos, ao início dos anos 1970. 


\subsubsection{Introdução ao contexto dos métodos em designnos anos 1960 e 1970}

[...] Nossa época é hostil a cada especulação subjetiva em arte, ciência, tecnologia, etc. 0 novo espirito, que já governa quase toda a vida moderna, se opõe à espontaneidade animal, à dominação pela natureza, à parvice artística. A fim de construir um novo objeto nós precisamos de um método, que quer dizer, um sistema objetivo.9 (VAN D OESBURG, 1924 apud. CROSS, 2001, p.49, tradução nossa)

Esta passagem de Theo Van Doesburg ${ }^{10}$ presente no quinto manifesto do De Stijl, de 1924, expressa o sentido de transformação assumido pelo movimento moderno ${ }^{11}$ no Período entre Guerras, vinculado ao reconhecimento de valores da ciência como racionalidade e objetividade, como bases para a produção da arte e do design (CROSS, 2001, p.49). A eclosão das duas Guerras Mundiais contribuiu amplamente para o avanço científico com a organização dos estados em prol do suprimento de complexas demandas militares, acarretando grandes investimentos governamentais e uma significativa proliferação de centros e institutos de pesquisa em diversos países da Europa e também nos Estados Unidos (SCHÖN, 1983, p.37-39). De acordo com Donald Schön, após a Segunda Grande Guerra houve um vasto redirecionamento de desenvolvimento científico militar para fins civis nacionais $^{12}$ no contexto norte-americano, pautado na assertiva de que "[...] se um grande objetivo social pode ser claramente definido, se um compromisso nacional puder ser atrelado a ele, se recursos ilimitados podem ser empregados na pesquisa necessária e desenvolvimento, então tal objetivo qualquer que seja pode ser alcançado."13 (SCHÖN, 1983, p.37-38, tradução nossa). A Segunda Guerra Mundial foi responsável ainda por acelerar o desenvolvimento de um dos fatores tecnológicos mais importantes do século XX, a

\footnotetext{
9 Do original em inglês: "[...] Our epoch is hostile to every subjective speculation in art, science, technol ogy, etc. The new spirit, which already governs almost all modern life, is opposed to animal spontaneity, to nature's domination, to artistic flummery. In order to cons truct a new object we need a method, that is to say, a objective system."

${ }^{10}$ Theo Van Does burg (1883-1931), artista e arquiteto holandês, um dos fundadores e líderes do movi mento artístico europeu De Stijl no início do século XX.

${ }^{11}$ Para uma apreens ão aprofundada das transformações supracitadas no contexto do entre-guerras europeu e o movimento moderno, ver: ARGAN, G. C. W alter Gropius e a Bauhaus. Tradução Emilio C ampos Lima. Lisboa: Editorial Presença, 1951.

12 Donald Schön (1983, p.37) aponta que, no contexto norte-americano, seguramente o exemplo mais notável seja o "Projeto Manhattan", como um grande símbolo de us o bem suc edi do de tec nologia bas eada em ciência objeti vando-se fi ns nacionais. $O$ "Projeto Manhattan" ou "Distrito de Engenharia de Manhattan" foi um esforço norte-americano para o desenvol vimento de armas nucleares no contexto da Segunda Guerra Mundial, com o apoio do Reino Unido, Canadá, sendo responsável pela concepção e produção das bombas atômic as que devastaram Hiroshi ma e Nagas akj em 1945. Com o tér mino da guerra, a tecnologia nuclear obti da para fins militares seria então voltada ao us o ci vil sob a for ma de produção energética.

${ }^{13}$ Do original em inglês: "[...] if a great social objective could be clearly defined, if a national commitment to it could be mustered, if unli mited resources could be poured into the necessary research and development, then any such objective could be achieved."
} 
computação, uma vez que os esforços e investimentos norte-americanos e ingleses em máquinas para cálculos avançados de balística originaram os primeiros computadores eletrônicos ao final da década de $1940^{14}$. O avanço da Guerra Fria na década de 1950 com a acirrada disputa por êxitos tecnológicos e científicos impulsionou ainda mais o desenvolvimento tecnológico mundial:o lançamento do satélite Sputnik em 1957 pelos soviéticos levaria o mundo ocidental e principalmente os Estados Unidos novamente a um considerável investimento em pesquisa científica, inovação e criatividade (SCHÖN, 1983, p.39; BAYAZIT, 2004, p.18). Sob estas premissas inicia-se na década de 1960 um significativo capítulo para o pensamento em design, como observa Cross (2001):

[...] Os anos 1960 foram proclamados como 'a década da ciência do de sign' pelo tecnologista radical Buckminster Fuller, que clamava por uma 'revolução da ciência do design' baseada em ciência, tecnologia, e racionalismo a fim de superar os problemas humanos e ambientais que ele acreditava que não seriam resolvidos pela política e economia. A partir desta perspectiva, a década culminou como que Herbert Simon delineou 'As Ciências do Artificial', e seu apelo específico em favor do desenvolvimento de 'uma ciência do design' nas universidades: um corpo sólido de pensamento intelectual, analítico, parcialmente formalizável, parcialmente uma doutrina empírica e ensinável, sobre o processo de design.$^{15}$ (CROSS, 2001, p.51, tradução nossa).

Segundo Cross (2001, p.49), a 'Conferência sobre Métodos Sistemáticos e Intuitivos em Engenharia, Design Industrial, Arquitetura e Comunicação', realizada no Departamento de Aeronáutica do Colégio Imperial de Ciência e Tecnologia de Londres em setembro de $1962^{16}$, é considerada como o evento que marcou o lançamento da metodologia em design como tópico ou campo de pesquisa ${ }^{17}$. O evento foi uma primeira aproximação sobre métodos em design na Inglaterra, que consistiu em um debate baseado na sistematização das abordagens pessoais de seus participantes com relação ao processo de design, e sua externalização como métodos (BAYAZIT, 2004, p.18). Esta conferência, que reuniu pesquisadores

\footnotetext{
14 Para uma leitura apr ofundada sobre o des envol vimento da computação no final dos anos 1940 e começo dos anos 1950 , ver FONSECA FILHO, C. História da computação. O caminho do pensamento e da tec nologia. EDIPUCRS, 2007. Disponível em: <http://www. pucrs. br/edi pucrs/online/historiadac omputacao.pdf>. Acesso em 29/05/2011.

${ }^{15}$ Do original em inglês: "[...] The 1960s was her alded as the "design science decade" by the radical tec hnologist Buck mins ter Fuller, who called for a "design science revolution" bas ed on science, technology, and rationalis m to overcome the human and environmental problems that he believed could not be solved by politics and economics. From this perspective, the decade cul minated with Herbert Si mon's outline of "the sciences of the artificial," and his specific plea for the development of "a science of design" in the universities: "a body of intellectually though, analytic, partly for malizable, partly empirical, teachable doctrine about the design process."

${ }^{16}$ Do original em inglês: "Conference on Systematic and Intuitive Methods in Engineering, Industrial Design, Architecture and Communic ations", Department of Aeronautics, Imperial College of Science and Technology, London, 1962.

17 Ver também: JONES, J.C.; THORNLEY, D. G. Conference on Design Methods. Oxf ord Uni versity Press, 1963.
} 
de diversas áreas ${ }^{18}$ envolvidos com o pensamento em design no contexto de análise e proposição de processos sistemáticos, proporcionou aos métodos em design reconhecimento acadêmico substancial (CROSS, 1992, p.15). Bayazit (2004, p.18-21) observa que a partir da realização da conferência de 1962, houve uma expressiva propagação, difusão e aplicação de pesquisa sobre o tema, pela criação e desenvolvimento de novos grupos, laboratórios, centros de pesquisa, a divulgação de trabalhos através de periódicos, jornais e boletins $^{19}$, além de novas conferências na Europa assim como Estados Unidos, como também descreve Murray Milne (1975, p.35, tradução nossa):

[...] Na Inglaterra, a primeira conferência intemacional sobre metodologia em design aconteœu em 1962, e a Sociedade de Pesquisa em Design - DRS formou-se logo após. Neste país foi em 1966, após uma conferência em Waterloo, Ontário, que o Grupo de Métodos em Design - DMG foi formado. O jornal do DMG apareceu quase que imediatamente, editado por Gary Moore, que era entao um estudante de arquitetura da Berkeley. Gary merece grande créditb em manter o jornal vivo naqueles anos críticos. Ele preparou a primeira conferência do DMG no Instituto de Tecnologia de Massachusetts - MIT, em 1967 e terminou editando os procedimentos (que foram publicados pelo MIT como 'Métodos Emergentes em Design e Planejamento Ambiental'. Esta conferência de fato gerou ainda outro grupo de pesquisa, a Associação de Pesquisa em Design Ambiental - EDRA, que tem patrocinado conferências anuais desde então, e aplicações œmputacionais é um de seus vários temas. 0 elemento mais positivo do começo dos anos setenta é que o DMG e 0 DRS se uniram para realizar conferências em conjunto exclusivamente voltadas à metodologia em design? ${ }^{20}$

Geoffrey Broadbent (1973/1988, p.260-261) observa ainda a realização de uma conferência/curso na Escola da Forma - Hochsüle für Gestalung de Ulm, na Alemanha em 1966, intitulada ‘O

\footnotetext{
18 Dentre os quais podemos citar, rel acionados ao escopo deste trabalho: o engenheiro e designer galês J. Christopher Jones (1927-), o engenheiro mecânico inglês L. Bruce Archer (1922-2005), o arquiteto e pesquisador norte-americano Christopher Alexander (1936-), o arquiteto e profess or inglês Dennis Thornley e o ciberneticista inglês Gordon Pask (1928-1996).

${ }^{19}$ Conforme a descrição de Cross, "[...] um des envolvi mento particular mente significante foi o surgimento de novos periódicos de pesquisa, teoria e metodologia em design. Para nos referirmos, novamente, a publicações na língua inglesa, temos Design Studies, desde 1979, Design Issues desde 1984, Res earch in Engineering Design des de 1989, o Journal of Engineering Design desde 1990 e o Journal of Design Management desde 1990." (CROSS, 1992, p.18, tradução nossa).

${ }^{20}$ Do original em inglês: "[...] In England, the first international conference on design methodology was held in 1962, and the Design Research Society (DRS) was for med shortly thereafter. In this country, it was not until 1966, after a conference at the University of Waterloo in Ontario, that the Design Methods Group (DMG) was for med. The DMG Newsletter appear ed al most immediately, edited by Gary Moore, who was then a architecture student at Berkeley. Gary deserves a great deal of credit for keeping DMG alive during those early critical years. He set up DMG's first conference at MIT in 1967, and even ended up editing the proceedings (which were published by MIT as 'Emerging Methods in Environmental Design and Planning'). This conference in fact spawned still another research-oriented group, the Environmental Design Research Association (EDRA), which has spons ored annual confer ences since then even thoug h computer applications are only one of its many concerns. The most positive element of the early seventies is that the DMG and the DRS have come together to hold joint conferences devoted exclusively to design methodology."
} 
ensino de design - Métodos de design em Arquitetura', seguida de outra grande conferência de mes mo nome em 1967 na Escola de Arquitetura da Politécnica de Ports mouth, Reino Unido. Em 1966, os pesquisadores britânicos também fundaram a Sociedade de Pesquisa em Design em Londres, mes mo ano em que o Grupo de Métodos em Design foi formado no contexto norte-americano. Toda esta movimentação esteve concernida com o desenvolvimento e aplicação de 'métodos', procedimentos sistemáticos em auxílio ao process $0^{21}$ projetual conduzido por arquitetos, engenheiros, artistas, entre outros praticantes do projetar, com o intuito essencial, como propôs o engenheiro galês Christopher Jones (1962), de permitir uma distinção ef etiva entre o raciocínio lógico da imaginação criativa, a fim de que ambos pudessem ser explorados em sua plenitude:

O método é essencialmente um meio de resolver um conflito que existe entre a análise lógica e pensamento criativo. [...] Métodos existentes dependem em grande parte em manter a lógica e a imaginação, problema e a solução, separados apenas por força de vontade, e seus fracassos podem ser largamente atribuídos à dificuldade de manter ambos os processos em curso, separadamente, na mente de uma pessoa. Então design sistemático é principalmente um meio de manter a lógica e a imaginação separadas por meios extemos emvez de meios internos.22 (JONES, 1962 apud. BROADBENT, 1973/1988, p.257, tradução nossa).

O método apresenta assim um recurso para a devida separação entre ideias imag inativas (e portanto, subjetivas) de declarações dedutivas provenientes de dados e informações, permitindo aferições e a condução do raciocínio lógico, elementos extremamente valorizados no contexto dos anos 1960 com a ascensão da computação eletrônica e de diversos outros êxitos científicos, como observamos anteriormente. Guarda-se, portanto, uma significante aproximação do racionalis mo do método cartesiano²3: "É salutar a nós notar

\footnotetext{
21 Jones sublinha a importância da mudança no pensamento do século XX a partir da ideia de 'produto' par a a ideia de 'processo', que segundo o autor, ocorreu em todos os campos do empr eendimento humano: "o movimento de métodos em design pode ser visto co mo nossa modesta versão desta mudança histórica." (JONES, 1970, p.XXXIV, tradução nossa).

22 Do original em inglês: "The method is primarly a means of resolving a conflict that exists between logical analysis and creative thought. [...] Existing methods depend largely on keeping logic and imagination, problem and solution, apart only by an effort of will, and their failures can largely be ascribed to the difficulty of keeping both these processes going separately in the mind of one person. So systematic design is primarly a means of keeping logic and imagination separate by ex ternal rather than internal means."

23 De acordo com a obra 'Discurso sobre o método' de 1637 do filósofo franc ês René Descartes (1596-1650), em que o mesmo descreve as regras em que seus próprios pensamentos são disciplinados: "1. A primeira consistia em nunca ac eitar algo como ver dadeiro sem conhec ê-lo evidentemente como tal: isto é, evitar cuidadosamente a precipitação e a prevenção; não incluir nos meus juízos nada que não se apresentasse tão clara e distintamente à minha inteligência a ponto de excluir qualquer possibilidade de dúvida. 2. A s egunda era di vidir o problema em tantas partes quantas foss em necessárias para melhor poder resolvê-lo. 3. A terceira, conduzir por ordem os meus pensamentos, começando pelos objetos mais simples e mais fáceis de conhecer, para subir pouco a pouco, gradualmente, até o conheci mento dos mais compostos; e admitindo uma or dem mes mo
} 
que já em 1637, a base estava disponível para todos os racionalizados e sistematizados métodos de design já então construídos." ${ }^{24}$ (BROADBENT, 1973/1988, p.60, tradução nossa). Segundo Broadbent, atitudes racionalistas foram sido trazidas à arquitetura ainda no século XVIII por teóricos como Marc-Antonie Laugier (1973-1769) ${ }^{25}$, conformando uma tradição que se estendeu ao longo dos séculos através de arquitetos como o neoclássico Karl Friedrich Schinkel (17811841) ao moderno Mies Van Der Rohe (1886-1969). Por todo contexto dos métodos de design, os princípios da racionalidade encontram-se subjacentes, influenciando de modo significativo a maneira de ver e conceber o processo projetual, permeando os mais variados apontamentos teóricos de seus expoentes: neste sentido, reconhecemos o mérito da racionalidade em promover uma coesão entre a diversidade do conjunto de assertivas sobre 'o que o design deveria ser' conforme coloca Peter Downton (2003, p.39). Na sequência, faremos uma leitura de diversos aspectos sobre este 'o que deveria ser' o projetar no contexto dos métodos em design dos anos 1960 e 1970, a fim de estabelecer uma compreensão inicial acerca das implicações para o projeto arquitetônico vinculadas à adoção de tais concepções.

\subsubsection{O método como exteriorização sis tem ática do processo projetual}

Ambas as obras de Alexander (1964) e Jones (1970), consideradas seminais no contexto da movimentação sobre os métodos e teorias do processo de design nas décadas de 1960 e 1970 (BAYAZIT, 2004, p.18; DOWNTON, 2003, p.36) remetem-se ao modo como o fazer entendido como 'design' ${ }^{26}$ na cultura ocidental transformou-se ao longo dos séculos, provocando a necessidade da revisão do projetar em adequação às condições particulares de seu contexto atual. Em seu 'Notes on the Synthesis of Form', Alexander observa o caráter determinante das mudanças na organização da atividade do design ocorridas no bojo do

\footnotetext{
entre aqueles que não apres entam nenhuma ligação natur al entre si. 4. Por último, sempre fazer enumerações tão compl etas, e revis ões tão gerais, que tivesse certeza de nada ter omitido." DESCARTES, R. Discur so do Método. Tradução Guins burg, J.; Prado Júnior, B. São Paulo: Nova Cultural, 1637/1987.

24 Do original em inglês: "It is salutary for us to note that already, in 1637, the basis was available on which all rationalized and systematized design methods have since been built". O autor referencia-se à obra de René Descartes, conforme citado.

25 Ver: LAUG IER, M.A. An Essay on Architecture. Hennessey \& Ingalls, 1735/1977.

${ }^{26}$ É pertinente observar que Alexander (1964, p.1) compreende o processo do designcomo o processo de invenção de coisas físicas (que apres entam novas configurações de or dem, organização ou forma) em res pos ta à função; Jones (1970, p.4), por sua vez, baseia suas coloc ações na definição elementar de design como o processo de "iniciar transformações em coisas feitas pelo homem" (do original em inglês: "to initiate change in man- made things").
} 
desenvolvimento da arquitetura quanto disciplina, enfatizando a ascensão do fazer arquitetônico como uma atribuição individualizada:

O desenvolvimento do individualismo da arquitetura é a mais clara manifestação do momento em que a arquitetura pela primeira vez se transforma em uma disciplina autoconsciente. E o autoconsciente individualismo do arquiteto não é inteiramente voluntário também. É uma consequência natural da decisão de um homem a dedicar sua vida exclusivamente a uma atividade chamada 'arquitetura'. Claramente, é nesta fase também que a atividade amadureœ quanto ao pensamento e teoria. Então, com uma arquitetura uma vez estabeledida como uma disciplina, e 0 indivíduo arquiteto estabelecido também, instituições inteiras são logo dedicadas exdusivamente ao estudo e desenvolvimento de design. As academias são formadas. À medida que as academias desenvolvem-se, os preceitos da tradição não formulados dão lugar a conœitos formulados claramente cuja própria formulação convida à crítica e debate. Perguntas levam agitação, à liberdade arquitetônica para mais autoconsciência, até que se desœobre que (para o momento, de qualquer maneira) a liberdade do fazedor de formas tem sido comprada a um preço caro. A descoberta da arquitetura como uma disciplina independente custa ao proœsso de fazer formas muitas mudanças fundamentais. De fato, no sentido que deve agora tentarei descrever, a arquitetura realmente falha desde o momento da sua criação. Com a invenção de uma disciplina ensinável chamada 'arquiteura', o velho processo de fazer formas foi adulterado e suas chances de sucesso destruídas. ${ }^{27}$ (ALEXANDER, 1964, p.57-58, tradução nossa)

Para Alexander (1964, p.55-56), em culturas inconscientes de seus processos de design (como em culturas primitivas), a transformação das formas realizada pelos artistas, artesãos ou construtores é incorporada naturalmente na manufatura e evolui ${ }^{28}$ sob a forma de incrementos feitos ao longo de décadas e séculos, em resposta, por exemplo, às próprias mudanças no contexto ambiental a que respondem estas formas. Em contrapartida,

\footnotetext{
27 Do original em inglês: "The development of architectural individualism is the clearest manifestation of the moment when architecture first turns into a selfconscious discipline. And the selfconscious architect's individualis mis not entirely willful either. It is a natural consequence of a man's decision to devote his life exclusively to the one activity called 'architecture.' Clearly, it is at this stage too that the activity first becomes ripe of serious thought and theory. Then, with architecture once established as a discipline, and the individual architect established, entire institutions are soon devoted excl usively to the study and development of design. The academies are formed. As the academies develop, the unformulated precepts of tradition give way to clearly formulated concepts whose very formulation invites criticism and debate. Questions leads to unrest, architectural freedom to further selfconsciousness, until it turns out that (for the moment anyway) the form maker's freedom has been dearly bought. For the discovery of architecture as an independent discipline costs the for m making process many fundamental changes. Indeed, in the sense I shall now try to describe, architecture did actually fail from the very moment of its inception. With the invention of a teachable discipline call ed 'architecture', the old process of making for m was adulterated and its chances of success destroyed." 28 Este termo aqui empregado remete-se à biologia 'dar winiana' no sentido da existência de uma 'seleção natur al' de formas, de ac ordo com o comentário de que, para o indivíduo agente, no sistema inconsciente de seus processos de design, "tudo o que é necessário é que ele deve reconhecer desajustes e responder a eles, fazendo pequenas alter ações. Não é mes mo necessário que essas mudanças sejam para melhor. [...] o sistema, sendo autoajus tável, encontra o seu próprio equilíbrio promovido até que o des ajuste incite alguma reação no artesão." (ALEXANDER, 1964, p.57-58, traduçãonossa).
} 
Alexander observa (1964, p.57-58) que em civilizações como a nossa, as transformações de design são conduzidas profissionalmente por indivíduos que, autoconscientes de si como fazedores de formas, propõem-se (às vezes, compelidos) a resolver desajustes de forma/contexto, respondendo de modo subjacente a uma série de valores agregados ao próprio fazer, como promover-se por sua inventividade obtendo assim clientes e uma boa reputação, o que confere uma série de implicações ao projetar:

[...] O reconhecimento de sua individualidade pelo artista aubconsciente tem um efeito profundo sobre o processo do fazer da forma. Cada forma é agora vista como o trabalho de um único homem, e seu sucesso é o seu êxito pessoal. Autoconsciência traz consigo o desejo de libertar-se, o gosto pela expressão individual, a fuga da tradição e do tabu, a vontade de autodeterminação. Mas a selvagenia do desejo é temperada pela invenção limitada do homem. Para alcançar em poucas horas na prancheta de desenho o que antes levava séculos de adaptção e desenvolvimento, inventar uma forma de repente, que claramente se encaixe a seu contexb, a extensão da invenção neœssária está além do designer mediano.29 (ALEXANDER, 1964, p.59, tradução nossa)

O autor afirma assim que "[...] o que antes levou muitas gerações de desenvolvimento gradual agora é tentado por um simples indivíduo" 30 (ALEXANDER, 1964, p.5, tradução nossa) e que no contexto da modernidade, a complexidade ${ }^{31}$ do projetar tende a subjugar os esforços do designer: "[...] suas chances de sucesso são reduzidas porque o número de fatores que devem ser considerados simultaneamente é muito grande" ${ }^{32}$ (ALEXANDER, 1964, p.59, tradução nossa). Encontrar a solução para problemas de design, portanto, apresenta-se como uma tarefa cada vez mais além da capacidade de racioc ínio 'intuitivo' do designer:

\footnotetext{
${ }^{29}$ Do original em inglês: "[...] The artist's self-conscious recognition of his individuality has deep effect on the process of form making. Each form is now seen as the work of a single man, and its success is his achi evement only. Selfconscious ness brings with it the desire to break loose, the taste for individual expression, the escape from tradition and taboo, the will to selfdetermination. But the wildness of the desire is tempered by man's limited invention. To achieve in a few hours at the drawing board what once took centuries of adaptation and development, to invent a form suddenly which clearly fits its context - the extent of the invention nec essary is bey ond the average designer."

30 Do original em inglês: "[...] what once took many generations of gradual development is now attempted by a single individual."

31 Aqui o termo complexidade em Alexander (1964) e Jones (1970), que faz parte do "vocabul ário" do campo da emergente 'teoria de sistemas' conforme o trabalho do biólogo Ludwig Von Bertalanffy (1901-1972), é utilizado de maneira genérica par a denomi nar algo intrincado, de difícil compreensão, que está ess encial mente além da capacidade cogniti va do designer.

32 Do original em inglês: "[...] his chances of success are small because the number of factors which must fall si multaneously into place is so enormous."
} 
Hoje mais e mais problemas de design estão chegando a níveis insolúveis de complexidade. Isto é verdade não só sobre bases lunares, fábricas e receptores de rádio, cuja complexidade é intema, mas mesmo vilarejos e chaleiras. Apesar de sua simplicidade superficial, mesmo estes problemas têm um fundo de necessidades e atividades que está se tornando muito complexo de entender intuitivamente.33 (ALEXANDER, 1964, p.3, trad.nossa)

Christopher Jones (1970, p.31-42) corrobora com o argumento de Alexander, distinguindo ainda dois tipos de complexidade ${ }^{34}$ decorrentes das condições socioculturais, tecnológicas e de produção de bens pelos designers e do sistema de organização das atividades de produção nas quais os designers estão incorporados (JONES, 1970/1992, p.34-35). Devemos observar que Jones compreende o produto do design como um sistema, composto por diversos componentes que são outros produtos de design (pode-se projetar uma casa, suas portas, as maçanetas, seus encaixes, etc., ou todo um sistema de moradia de baixo custo, por exemplo). A realização de modificações nestes produtos implica, segundo o autor (JONES, 1970/1992, p.32), em lidar com uma série de variáveis problemáticas que se articulam estruturalmente em diversas combinações hierárquicas e níveis de interdependências, demandando um outro proceder diferente dos vinculados aos meios tradicionais ${ }^{35}$ de projeto, justificando assim a busca por novos métodos de design:

[...] esta visão das razões pelas quais os problemas modemos de design são tão dificeis de resolver pode ser resumida na afirmação de que o espaço de busca œm o que temos de olhar para possiveis novos sistemas, compostos de radicalmente novos produbs e componentes, é demasiado grande para a busca racional e pouø familiar para ser penetrado e simplificado pelos julgamentos das pessoas cuja formação e experiência tem sido limitada às profissões de design e planejamento projeto existentes. [...] precisamos de novos métodos que ofereçam espaço perceptual suficiente em cada um desses níveis. ${ }^{36}$

\footnotetext{
33 Do original em inglês: "Today more and more design problems are reaching insoluble levels of complexity. This is true not only on moon bases, factories, and radio receivers, whose complexity is internal, but even of villages and teak ettles. In spite of their superficial simplicity, even these problems have a background of needs and activities which is becoming too complex to grasp intuitively."

34 Jones refere-se às complexidades externas aos produtos de design, que envolvem questões como transferências de tecnologia, a previsão de efeitos colaterais de decisões de design, a elaboração de padronagens para assegurar a compatibilidade entre componentes de um design, sensibilidade às interações humanas com os produtos do design, e problemas entre compatibilizações entre produtos diferentes com relação ao sistema total de produtos; e complexidades internas, que constituiriam, por sua vez, em outras ques tões como custo das decisões que impedem a prática de "tentativa e erro" no processo de design, a compatibilização das informações das diferentes partes envolvidas no design, al ém da constante necessidade de antecipação de novas necessidades, materiais e tecnologias ao proj etar (JONES, 1970, p.34-35)

35 Jones (1970, p.28-29) cita o desenho em escala como o instrumento principal do designer tradicional, e que soluções de problemas costumam ser encontr adas subitamente por uma ideia ou volta criativa - 'creative leap' - que corresponde a uma mudança no modo pel o qual o problema é percebido, em um process o pouco compreendido, mas essencial ao design.

${ }^{36}$ Do origin al em inglês: "[...] this view of the reas ons why modern design problems are so difficult to solve can be summed up in the statement that the search space with we have to look for feasible new systems, composed of radically new products
} 
(JONES, 1970/1992, p.42, tradução nossa)

Segundo observam Richard Coyne e Adrian Snodgrass (1995, p.34), a necessidade de sistematização foi considerada como um dos problemas centrais para os metodologistas de design e, portanto, uma ordem significativa deveria ser extraída da complexidade: "Ordem precisa ser explicitada para que ela possa ser examinada e o design controlado. O meio é a sistematização através da lógica." ${ }^{37}$ (COYNE; SNODGRASS, 1995, p.34, tradução nossa). Alexander (1964, p.62) ressalta a pertinência do uso da lógica aplicada à construção de modelos de estudo das situações complexas, neste sentido, o autor argumenta (ALEXANDER, 1964, p.63) em favor da elaboração e adoção de princípios gerais organizadores pelas estruturas abstratas lógicas que, como uma teoria do projeto arquitetônico, fossem capazes de proporcionar aos designers a fundamentação de suas decisões de projeto com clareza, promovendo assim, em correspondência, uma base comum para a crítica e discussão do design ${ }^{38}$. Jones (1970) observa a relevância deste papel que o estabelecimento de metodologias se propôs a cumprir, expondo sua compreensão da coerência dos métodos de design em função de sua dimensão comunicativa:

'O que os novos métodos êm em comum?' A resposta mais óbvia é que todos os métodos de design são tentativas de tornar público o pensament até então privado de designers, para exteriorizar o processo de design. Emalguns casos isso é feito em palavras, às vezes, com símbolos matemáticos, e quase sempre œm um diagrama representando partes do problema de projeto e as relações entre as partes. Claramente, o objetivo subjacente é uma abertura do projetar para que outras pessoas possam ver o que está acontecendo e contribuir com suas informações e conhecimentos que estão fora do conheciment e experiência individual do designer.39 (JONES, 1970/1992, p.3, tradução nossa)

and components, is too big for rational search and too unfamiliar to be penetrated and simplified by the judgments of those whose education and experience has been limited to the existing design and planning professions. [...] we need new methods that provide sufficient perceptual span at each of these levels."

38 De acordo as colocações de Al exander: "Para ajudar a si mes mo a superar as dificuldades de complexidade, o designer tenta organizar o seu problema. Ele classifica s eus vários aspectos e dando-lhe assim for ma, e torna-o mais fácil de manus ear. [...] O peso cons tante da decisão que ele atravessa, uma vez libertado da tr adição, é cans ati vo. Assim, ele o evita onde pode, por meio de regras (ou princípios gerais) que ele formul a em termos de seus conceitos inventados. Estes princípios estão na raiz de todas as chamadas 'teorias' do projeto arquitetônico. Eles são prescrições que aliviam o fardo da autoconsciência e de respons abilidade demais. É precipitado, talvez, chamar a invenção destes conc eitos ou prescrições uma tentativa consciente de simplificar problemas. Na prática, eles se desdobram como o resultado natural da discussão crítica sobre o design" (ALEXANDER, 1964, p.6263, tradução nossa).

39 Do original em inglês: "What do the new methods have in common?' The most obvious answer is that all design methods are attempts to make public the hitherto private thinking of designers, to externalize the design process. In some cas es this is done in words, sometimes in mathematical symbols, and nearly always with a diagram representing parts of the design problem and relationships between the parts. Clearly, the underlying aim is to bring designing into the open so that other people can see 
Neste sentido, Alexander (1964, p.62) compreende a adoção de estruturas formais objetivas e bem definidas no amparo ao raciocínio de projeto como uma maneira de promover a emancipação dos valores e arbítrios, o 'fardo da tradição' carregado pelos designers em suas formações, esclarecendo os pressupostos agregados no processo projetual pela autoconsciência do fazer, pelo uso da lógica como língua franca. Este desvelar contraria a ideia de um 'processo intuitivo', no sentido em que seus procedimentos 'misteriosos' (JONES, 1970/1992, p.28) não possam ser definidos:

\begin{abstract}
O uso de estruturas lógicas para representar problemas de design tem uma consequência importante. Ela traz consigo a perda da inocência. Uma imagem lógica é mais fácil de criticar do que uma imagem vaga, pois os pressupostos em que ela é baseada são trazidos à tona. Sua maior precisão nos dá a chance para aguçar nossa concepção do que o processo de design envolve. Mas, uma vez que o que fazemos intuitivamente pode ser descrito e comparado com as formas não-intuitivas de fazer as mesmas coisas, não podemos seguir aceitando o método intuitivo inocentemente. [...] Gostaria de expor claramente minha crença nesta perda da inocência, porque há muitos designers que não estão aparentemente dispostos a aceitar a perda. Eles insistem que o projeto deve ser um processo puramente intuitivo: que é inútil tentar compreendê-lo de forma sensata, porque seus problemas são muito profundos. ${ }^{40}$ (ALEXANDER, 1964, p.8-9, tradução nossa)
\end{abstract}

Alexander enfatiza a resistência à ideia de processos sistemáticos de design da parte de designers "[...] que reconhecem corretamente a importância da intuição, mas em seguida, fazem dela um fetiche, o que exclui a possibilidade de fazer perguntas razoáveis. ${ }^{, 41}$ (ALEXANDER, 1964, p.9, tradução nossa) Podemos afirmar que este juízo foi recorrente no ambiente acadêmico da época, como na afir mação de Eastman (1975): "Se uma metodologia de projeto pode ser definida como um procedimento formal e explícito ensinada a um designer, o design intuitivo pode ser considerado a antítese de uma metodologia de design." ${ }^{2}$ (EASTMAN, 1970, p.21, tradução nossa). Dow nton (2003) observa o apoio estudantil aos princípios sistemáticos,

what is going on and contribute to it information and insights that are outside the individual designer's knowledge and experience."

40 Do original em inglês: "The use of logical structures to repr esent design problems has an important consequence. It brings with it the loss of innocence. A logical picture is easier to criticize than a vague picture since the assumptions it is bas ed on are brought out into the open. It increased precision gives us the chance to sharpen our conception of what the design process involves. But once what we do intuitively can be described and compared with nonintuitive ways of doing the same things, we cannot go on accepting the intuitive method innocently. [...] I wish to state my belief in this loss of innocence very clearly, because there are many designers who are apparently not willing to accept the loss. They insist that design must be a pure intuitive process : that it is hopel ess to try and understand it sensibly because its problems are too deep."

${ }^{41}$ Do original em inglês: "[...] who recognize correctly the importance of intuition, but then make a fetis $h$ of it which excludes the possibility of asking reas onable questions".

42 Do original em inglês: "If a design methodology can be defined as a formal and explicit procedure taught to a designer, intuitive design can be considered the antithesis of a design methodology." 
ao citar a manif estação da "Associação de Estudantes de Arquitetura da Grã-Bretanha"43 em 1964: "O processo é considerado como obscuro e místico e, consequentemente, pouco conhecimento tem sido construído. Esta atitude é promovida por escolas que se interessam em resultados mais do que nos métodos para atingi-los." 44 (MANIFESTO DA ASSOCIAÇÃO DE ESTUDANTES DE ARQUITETURA DA GRÃ-BRETANHA, 1964, apud. DONWTON, 2003, p.37, tradução nossa). Este é um esboço do ideário que fundamenta a demanda por métodos e modelos sistemáticos do processo de design nos anos 1960 e1970, que por sua vez, fomentou o desenvolvimento de diversas teorias e concepções formais do projetar particularmente relevantes ao contexto da arquitetura, como veremos a seguir.

\subsubsection{Métodos e modelos do processo projetual}

A proposta de adoção de estruturas formais como métodos e modelos em detrimento do proceder intuitivo tradicional do design, como observamos anteriormente, esteve atrelada ao desejo de exposição dos critérios, propósitos e valores de julgamento individuais dos designers, bem como do estabelecimento de princ ípios gerais, no caso da arquitetura, para teorias projetuais (ALEXANDER, 1964, p.62). De acordo com Bazjanac (1974, p.3) uma colocação recorrente neste contexto era a de que a falta de uma teoria do projeto arquitetônico era responsável por uma carência de sistematização e de uma ordem geral com respeito à prática profissional, que implicava por sua vez na falta de qualidade do espaço construído e de controle dos profissionais sobre seus projetos e atividades projetuais. Segundo o autor, a preocupação com relação ao processo de projeto em arquitetura e também sobre teorias gerais do design foi influenciada pelos desenvolvimentos em matemática aplicada ${ }^{45}$ e

\footnotetext{
43 Do original em inglês: "British Architecture Students Association". Ver: British Architecture Students A ssociation Architect's Journal, 14 de outubro, 1964, p.846.

44 Do original em inglês: "The process is regarded as obscure and mystical and cons equently little knowledge has been build up. This attitude is foster ed by schools who interest thems elves in results rather than the methods of achieving them."

45 A 'nova matemática' compreendeu uma abordagem especial da disciplina no contexto da primeira metade do século XX que ocasionou uma transformação drástica no ensino dos anos 1960, principalmente nos Estados Unidos. Esta abordagem promoveu uma ênfas e em estrutura matemática, através de conceitos abs tratos da teoria dos conjuntos, funções e desenhos de diagramas, além de tópicos como lógica simbólica, matrizes e álgebra abstrata e booleana. Para uma compreensão aprof undada ver: AD LER, I. The New Mathematics. New York. John Day \& Co, 1972. Broadbent (1973/1988, p. 272) comenta que a nova matemática e uma certa parcela de estatística é quase tão influente para os métodos de design dos anos 1960 quanto a soma de todas as outras fontes das disciplinas em conjunto. Convém observar também a influência de Alexander (1964), que além de arquiteto é matemático por for mação, dedica parte considerável de sua obra "Notes on the Synthesis of For m" à formalização matemática dos princípios aplicados em seu método projetual.
} 
ciências de sistemas ocorridos na primeira metade do século XX (BAZJANAC, 1974, p.5). Broadbent corrobora com esta afirmação, apontando uma 'fascinação' dos teóricos inclinados à racionalidade matemática pela elevação do design ao nível mais alto possível de abstração (BROADBENT, 1973/1988, p.272). Ao longo da década de 1960 e 1970, diversos métodos baseados nestas premissas foram desenvolvidos e aplicados junto ao contexto do design, alguns deles incorporados efetivamente à prática projetual arquitetônica da época (BROADBENT, 1973/1988, p.260-262), como técnicas gráficas de análise por tabelas de interação (Figura 4). A obra de Jones (1970) 'Design methods: seeds of human futures' apresenta um compêndio de métodos disponíveis ao final dos anos 1960, contendo desde técnicas voltadas a atividades específicas do projetar até abordagens gerais bastante elaboradas, como por exemplo, o método de 'busca sistemática' (Figura 5) (JONES, 1970/1992, p.94).

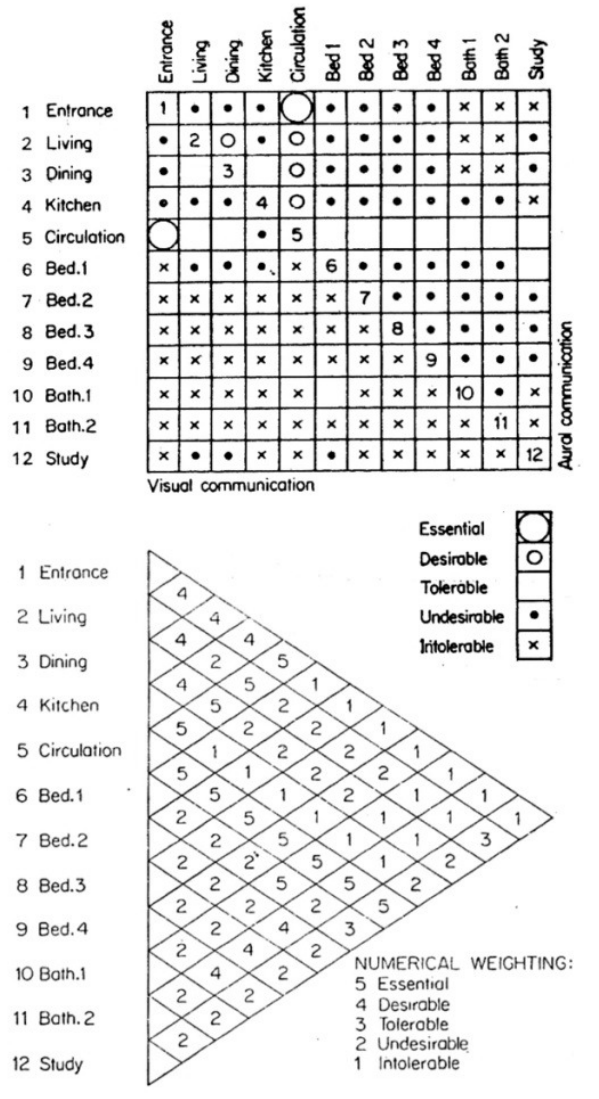

Figura 4 - Acima: Tabela para análise de œmpatibilidade ambiental entre diversos elementos de uma moradia. Abaixo: Tabela simples de interaçãc mostrando conexões entre ambientes, referindo-se à necessidade $d \epsilon$ circulação entre os mesmos. Fonte: (BROADBENT, 1973/1988, p 260-262).
DECISION TREE FOR A PASSENGER VEHICLE

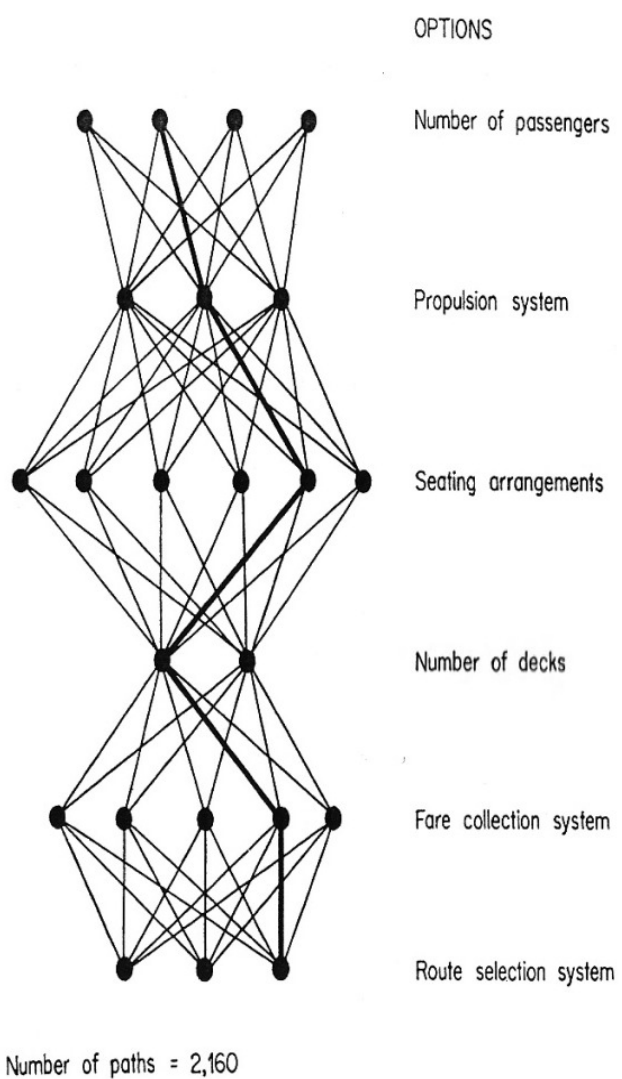

Figura 5 - Diagrama de escolhas variáveis para tomada de decisão dc método de Busca Sistemática. A linha espessa indica uma das $216 \mathrm{C}$ possibilidades de design a escolher. Fonte: (JONES, 1970, p.97). 
Neste contexto, teóricos do design procuraram descrever seus processos por meio de modelos sistemáticos, invariavelmente como uma sequência de atividades bem definidas (BAZJANAC, 1974, p.5) e essencialmente, a partir da compreensão de design como u ma atividade de resolução de problemas ${ }^{46}$. De acordo com Bazjanac (1974, p.6), um dos mais conhecidos modelos do processo de design é o de Alexander (1964) que, segundo o autor, "[...] alegou haver uma importante correspondência estrutural subjacente entre o padrão de um problema e o processo de projetar uma forma física que responde a esse problema." ${ }^{47}$ (BAZJANAC, 1974, p.6, tradução nossa). Na exposição dos fundamentos de projeto de seu método, Alexander observa que "[...] a característica estrutural mais importante e mais evidente de uma entidade complexa é sua articulação, a densidade relativa ou os agrupamentos e acoplamentos de seus elementos componentes" ${ }^{48}$ (ALEXANDER, 1964, p.81, tradução nossa). O autor afirma (ALEXANDER, 1964, p.82) que basicamente é possível distingu ir subsistemas e articulações hierárquicas destes componentes através de métodos matemáticos de decomposição e visualização por meio de representações diagramáticas, conforme a Figura 6.
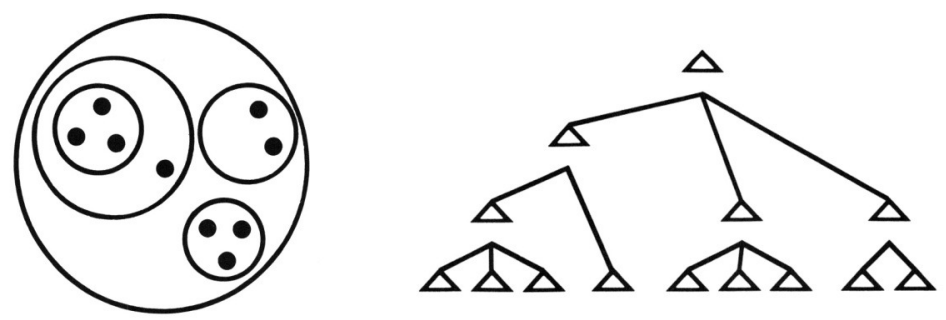

Figura 6 - Representação diagramática de estruturas de elementos em subgrupos (à esquerda) e decomposição representada em diagra ma de Venn (à direita). Fonte: (ALEXANDER, 1964, p.82-83)

Um problema é entendido como um 'desajuste' entre uma forma e seu contexto (ALEXANDER, 1964, p.15). Em uma situação complexa de design, propõe-se a utilização dos métodos de decomposição para reconhecer e separar subproblemas e inter-relações entre desajustes que assim podem ser assim resolvidos mais facilmente (ALEXANDER, 1964, p.83). Alexander afirma a existência de um tipo especial de estrutura de decomposição apropriada para cada problema, que denomina 'programa', usualmente distinta da pré-concepção do designer:

\footnotetext{
46 A leitura de diversos teóricos do contexto dos métodos em design nos anos 1960 corrobora com esta afirmação, desde Alexander (1964), Jones (1970), Archer (1963), Rittel (1967) culminando em Simon (1969), entre outros. Pela leitura de Broadbent (1973/1988, p255-257) observamos que es ta compreens ão é subjac ente às exposições coloc adas na C onf erênci a de Métodos em Design de 1962, e à explanação de diversos modelos do proc esso de design des de os anos 1960 .

47 Do original em inglês "[...] he claimed that there was a very important underlying structur al correspondence between the pattern of a problem and the processes of designing a physical for $m$ which answers that problem." 
"Nós chamamos isto de programa porque ele provê direções ou instruções ao designer [...] Este programa é uma reorganização do modo como o designer pensa sobre o problema." ${ }^{49}$ (ALEXANDER, 1964, p. 83, tradução nossa) Nestes termos, encontrar o programa 'correto' a um determinado problema de design corresponde à fase 'analítica' do processo de design, enquanto a derivação de uma solução formal deste programa constitui-se da fase complementar, denominada de 'síntese' (ALEXANDER, 1964, p.84). Em outras palavras:

De acordo com Alexander, 'todos os problemas de design começam com um esforço para obter um bom ajuste entre duas entidades: a forma e o contex to em questão'. Um desajuste constitui um problema. Cada instância de um desajuse entre a forma e o contexto pode ser indicado com uma variável. Durante o projeto, enquanto um desajuste é erradicado, outro ocorre. O sistema de variáveis muda de um estado para outro. A complexidade das interações faz necessário considerar o sistema de variáveis como formando subsistemas. Nos processos tradicionais, onde o design emerge e muda ao longo de várias gerações de atividade artesanal, em resposta às lentas mudanças no contexto, a forma é alterada de acordo com os ditames de subsistemas relativamente independentes das variáveis desajustadas. Sem tais proœssos, precisamos de métodos para decompor o sistema de variáveis - decompor problemas em subproblemas como uma árvore invertida de problemas relacionados e subproblemas. Este proœsso é a análise. Em algum momento, chegamos a um conjunto de subproblemas que levam a conhecer soluções. A tarefa é montar essas subsoluções em u ma solução total. Este é o processo de síntese.$^{50}$ (COYNE; SN ODGRASS 1995, p.38, tradução nossa)

Apesar da semelhança com o cânone cartesiano de decompor os problemas em subproblemas e resolver cada variável independentemente, para então sintetizá-las em uma solução integrada, devemos observar que a descrição do processo de Alexander (1964) prevê necessariamente a reorganização das variáveis elencadas na fase de análise pelo crivo do designer, para que então a partir desta nova organização ocorra a síntese, que corresponde à solução integrada do problema (BROADBENT, 1973/1988, p.276). Se considerarmos esta

\footnotetext{
49 Do original em inglês: "We call it a program becaus e it provides directions or instructions to the designer. [...] This program is a reorganization of the way the designer thinks about the problem."

50 Do original em inglês: "Accor ding to Alex ander, 'every design problem begins with an effort to achieve fitness between two entities: the form in question and context.' A misfit constitutes a problem. Each instance of a misfit between form and context can be indicated with a variable. During design, as one misfit is eradicated, another occurs. The system of variables changes from one state from another. The complexity of interactions makes it necessary to consider the system of variables as for ming subsystems. In traditional processes where design emerge and change over sever al generations of cr aft activity in response to slow changes in context; the form is changed according to the dictates of relatively independent subsystems of misfit variables. Without such processes, we need methods for decomposing the systems of variables -decomposing problems into subproblems like an inverted tr ee of rel ated problems and subproblems. This process is analysis. At some stage, we reach a set of subproblems that lead to know solutions. The task is to assemble these subsolutions into the total solution. This is the process of synthesis."
} 
reorganização como uma atividade em si, esta sequência de procedimentos correspondente à descrição de Jones (1970) do projetar como um processo essencialmente composto pelos estágios de 'divergência', 'transformação' e 'convergência': 51

Uma das observações mais simples e comum sobre o projetar, e uma sobre a qual muitos autores concordam, é que ele inclui os três estágios essenciais de análise, síntese e avaliação. Estes podem ser descritos em termos simples como 'quebrar os problemas em pedaços', 'juntar as peças de um modo novo' e 'testar para descobrir as consequências de colocar o novo arranjo em prática.' [...] Os três estágios aqui são referidos como divergência, transformação e convergência. ${ }^{52}$ (JONES, 1970/1992, p.63, tradução nossa)

Observamos que ao longo dos anos 1960 e 1970, diversos modelos do processo projetual foram concebidos em torno desta concepção. Broadbent (1973/1988, p.254) e Row e (1987, p.47) apontam o designer industrial Morris Asimow (1962) como um dos pioneiros na formulação da atividade de projeto como um processo sequenciado, constituído de duas escalas operacionais, uma composta de diversas fases projetuais ${ }^{53}$, denominada 'morfologia do projeto' (ASIMOW, 1962, p.23), e outra, uma estrutura de resolução de problemas composta pelos estágios de análise, síntese e avaliação (decisão) ${ }^{54}$ (BROADBENT, 1973/1988, p.255), sendo que cada fase da morfologia contem esta sequência de eventos denominada de 'processo de projeto' (ASIMOW, 1962, p.62). Broadbent discorda desta denominação de Asimow, ressaltando que a estrutura análise-síntese-avaliação deve ser entendida como uma 'sequência de decisão,55 e não como o processo projetual em si, que para o autor, consiste de "um modo

\footnotetext{
51 Jones (1970) descr eve o escopo de cada estágio do seguinte modo: "divergên cia é de-estr uturar, ou destruir, a descrição original, enquanto identific a as características da situação de proj eto que vão per mitir um grau valioso e vável de mudança. [...] transformação é a fase em que juízos de valores, bem como as pectos técnicos, são combinados nas decisões que devem refletir as realidades políticas, econômicas e operacionais de uma situação de design. A partir de tudo isso vem o caráter geral, ou padrão, do que está sendo designado [...] Convergência é reduzir uma gama de opções em único projeto escolhido da forma mais rápida e barata que pode ser gerida e sem a necessidade de retratações impr evistas. Este é o único as pecto do design que parece prestar-se a uma explicação inteiramente racional e que pode, em alguns casos, pelo menos, ser feito inteiramente por um computador." (JONES, 1970, p.64-69, tradução nossa)

52 Do original em inglês: "One of the simplest and most common observations about designing, and one upon which many writers agree, is that it includes the three essential stages of analysis, synthesis and eval uation. These can be described in simple words as 'breaking the problems into pieces', 'putting the pieces together in a new way' and 'testing to discover the consequences of putting the new arrangement into practice.' [...] The three stages are here named divergence, transformation and convergence."

53 Fases da morfologia de um projeto completo, segundo Asimow (1962, p.23): Fases primárias do projeto: I. Estudo de exequibilidade. II. Projeto prelimi nar. III. Projeto Detalhado. Fases relacionadas com o ciclo de produção e consumo: IV. Planejamento para produção. V. Planejamento para distribuição. VI. Planejamento para consumo. VII. Planejamento para retirada.

54 Que se estende nos es tágios de otimização, revisão e i mpl ementação (BRO ADBENT, 1973/1988, p.255).

${ }^{55} \mathrm{O}$ autor afirma que a estrutura análise-síntes e-avaliação poss ui uma correspondência ao modo como o filós ofo pr ag matista norte-americano John Dewey (1859-1952) descreve em sua obra "How we think" de 1909 um ato completo de pensamento,
} 
de estruturar a ordem em que várias decisões envolvidas do projetar podem ser realizadas" 56 (BROADBENT, 1973/1988, p.256, tradução nossa). Similar à proposta de Asimow, o modelo de design arquitetônico de Maver (1970) apresenta a repetição c íclica da estrutura análisesíntese-avaliação ${ }^{57}$ à medida que o projeto avança em uma progressão linear de sua concepção ao detalhamento, de acordo com a Figura 7 Figura (MAVER, 1970, p.195-196). A partir da análise crítica deste modelo, Law son (2004, p.38) observa a necessidade de 'retornos' entre as fases da sequência de decisão conforme novas percepções do problema são desenvolvidas ao longo do processo, requisitando a revisão das fases anteriores, e propõe uma alternativa para o esquema contemplando esta questão (Figura 8). Por sua vez, Row e (1987, p.48) cita o 'modelo icônico' de Mesarovic (1964) como coerente com a estruturação da atividade do design por Asimow (1962) e Maver (1970) (Figura 9)

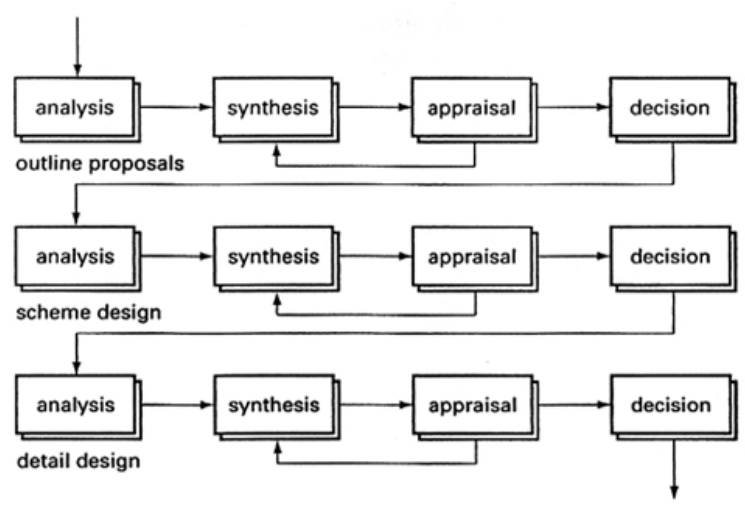

Figura 7 - modelo do processo de design por Tom Maver. Fonte: (MAVER, 1970, p.196).

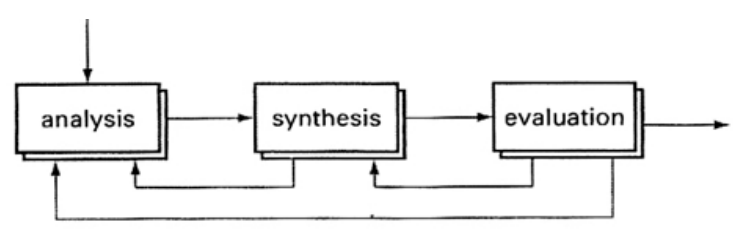

Figura 8 - Processo de design por Bryan Lawson. Fonte: (LAWSON, 2004, p.38).

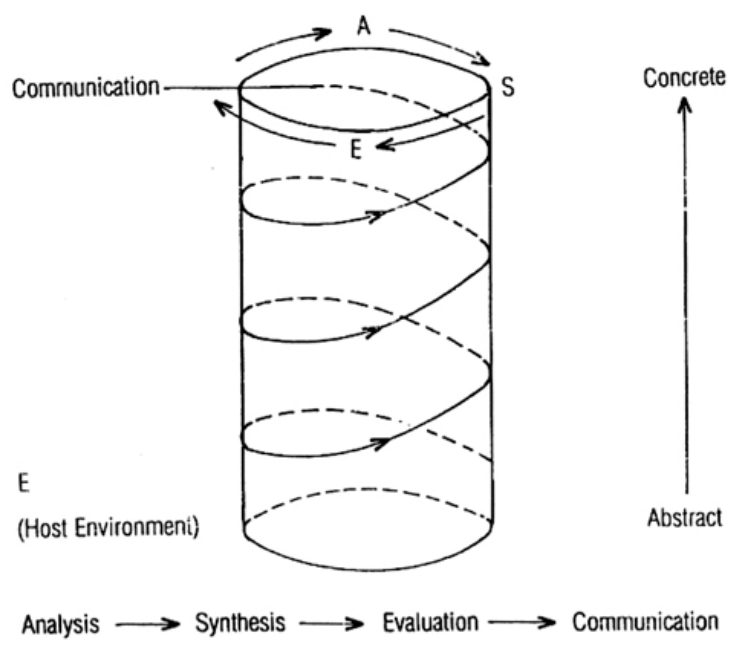

Figura 9 - "modelo icônico" apresentado por Mesarovic similar ao modelo de Asimow. Fonte: (ROWE, 1987, p.48).

dividi do em cinco passos: 1. A ocorrência de uma dificuldade. 2. A definição da dificuldade. 3. A ocorrência de uma explicação sugerida ou de uma possível sol ução. 4. A el abor ação racional de uma ideia. 5. A corroboração da ideia e a formul ação de uma crença conclusi va (BROADBENT, 1973/1988, p.179-180). Broadbent cita também o pens ador inglês Graham Wallas (1858-1932) que em sua obra "A Arte do Pensamento" descreve quatro estágios de controle em um ato completo de pensamento: 1. Preparação. 2. Inc ubação. 3. Il uminação. 4. Verificação. (BROADBENT, 1973/1988, p. 181). Para o autor, o que Dewey (1909) e Wallas (1926) descrevem compreende uma sequência de decisão: "uma pessoa sente uma dificuldade, a define, incuba possíveis explicações, tem idei as criati vas, as elabora e então às põe em prática.” (BRO ADBENT, 1973/1988, p. 181, tradução nossa)

56 Do original em inglês: "[...] a way of structuring the order in which a vast number of decisions may be made." Des de modo podemos afirmar que para o autor o proc esso de design corresponde ao que Asimow (1992) denomina ' morfol ogia do projeto'.

57 Aqui o termo 'avaliação' refere-se à tradução do termo em inglês 'appraisal', a análise avaliati va de uma decisão. 
Neste contexto do desenvolvimento de teorias do processo de design podemos citar ainda 0 arquiteto inglês Denis Thornley ${ }^{58}$ como um dos primeiros pesquisadores a desenvolver um método voltado ao ensino de arquitetura ainda ao final dos anos 1950, como docente da Universidade de Manchester, no Reino Unido (BROADBENT, 1973/1988, p.265). Nos anos 1960, o método desenvolvido por Thornley foi incorporado ao Manual de Práticas Profissionais em Arquitetura do Instituto Real de Arquitetos Britânicos (RIBA) ${ }^{59}$ formando a base para a descrição do processo de design na publicação (BROADBENT, 1973/1988, p.266). Bryan Lawson (2004, p.34) apresenta uma leitura desse modelo proposto no manual, em uma versão 'simplificada', composta por quatro fases, conforme a Figura 10, na qual aponta 0 agrupamento dos estágios de processo, já que a descrição mais detalhada deste processo corresponde ao chamado Plano de Trabalho - 'Plan of Work' - e descreve doze estágios em um curso lógico de ações, a saber: A.Início, B.Viabilidade, C.Delimitação da proposta, D. Projeto esquemático, E.Projeto detalhado, F.Informação de produção, G.Planilhas de quantidades H.Curso de ação J.Planejamento do projeto, K.Operações no lugar, L.Realização, M.Retorno ${ }^{60}$ (BROADBENT, 1973/1988, p.167; LAWSON, 2004, p.35-36).
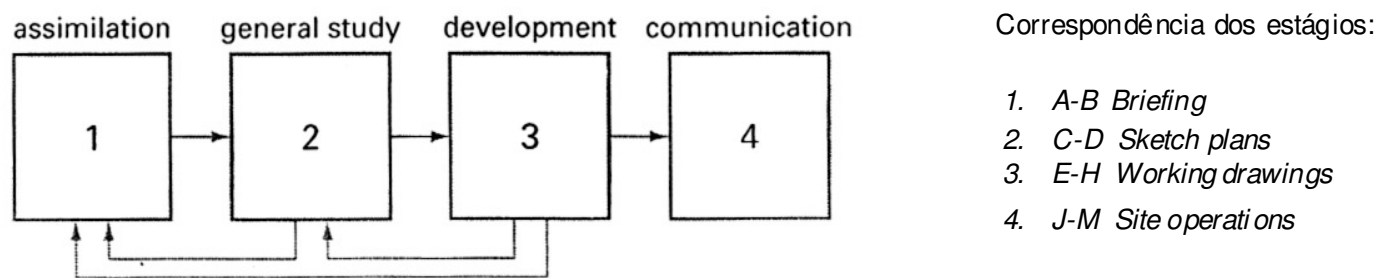

1. Assimilação - acumulação e ordenação de informações.

2. Estudo geral - investigação da natureza do problema e de possíveis soluções e meios

3. Desenvolvimento - refinamento de uma ou mais possíveis soluções isdadas na fase anterior.

4. Comunicação - divulgação da solução adiante.

(LAWSON 2004, p.34)

Figura 10 - Processo de design descrito no manual do RIBA. Fonte: (LAWSON, 2004, p.35)

\footnotetext{
58 Segundo Broadbent (1973/1988, p.264)arquiteto inglês Denis Thornl ey foi um dos participantes da conferência de métodos em design de 1962, onde apresentou seu trabalho "The Design Method in Architectural Education", desenvol vido na Uni versidade de Manchester, Reino Uni do, no final dos anos 1950.

59 RIBA. Architectural Practice and Man agement Handbook, RIBA publications, London, 1965.

60 Do original em inglês: A. Inception, B.Feasibility, C.Outline proposals, D. Scheme design, E.Detail design, F. Production information, G.Bills of quantities, H.Tender action, J.Project planning, K.Operations on site, L.Completion, M.Feed-back (LAWSON, 2004, p.35)
} 
Broadbent (1973/1988, p.167) observa que o Plano de Trabalho do RIBA foi especificamente concernido com o trabalho em equipe, ou seja, não é uma mera sequência de eventos mas indica detalhadamente as contribuições que seus membros podem fazer, inclusive do is tipos de funções são previstas para arquitetos: de gestão e de projeto. Law son (2004) em sua análise do Plano de Trabalho percebeu que uma série de descrições remetem diretamente ao contexto organizacional do próprio RIBA da época, sendo que algumas prescrições são atreladas à visões específicas do fazer arquitetônico cujo sentido é enfraquecido à luz da 'realidade' hodierna. Lawson conclui que:

\begin{abstract}
Nada disso deve ser tomado como uma crítica do Plano de Trabalho do RIBA, que provavelmente desempenha suas funções adequadamente mas, no final, nós provavelmente aprendemos mais sobre a história do papel do RIBA do que sobre a natureza dos proœssos do design arquitetônico. ${ }^{61}$ (LAWSON, 2004, p.36, tradução nossa)
\end{abstract}

Observamos assim que, se por um lado, os modelos iniciais do processo de design baseiam-se em uma estrutura seme lhante a partir da visão em comum do processo projetual como uma sequência bem definida de atividades, concernida essencialmente com a resolução de situações problemáticas pela sequência análise-síntese-avaliação (decisão), por outro lado, eles tendem a apresentar também a descrição de uma 'morfologia'62 do projetar, variável de acordo com o contexto particular ao qual o modelo remete-se (como no caso de Asimow (1962) cujo modelo é voltado às engenharias e design industrial, ou o Plano de Trabalho do RIBA (1965), voltado à organização das diversas atividades relacionadas à concepção arquitetônica segundo os padrões da época. Porém, à medida que a pesquisa em design nos anos 1960 configura-se como uma disciplina própria, centrada na incorporação de técnicas e de conhecimento científico ${ }^{63}$ sob o pretexto de proporcionar critérios racionais para a tomada de decisões e a otimização das atividades do design (BAYAZIT, 2004, p.19), notamos o surgimento de modelos gerais do processo de design ainda mais abstratos, desvinculados das particularidades 'morfológicas' das áreas tradicionais em

\footnotetext{
61 Do original em inglês: "None of this should be taken as criticism of the RIBA plan of work, which probably perfor ms its functions quite adequately, but in the end we probably learn from it more about the history of the rol e of the RIBA than about the nature of architectur al design process es."

62 Emprestando aqui o sentido para o ter mo empregado por Asimow (1962) em sua obra.

63 Broadbent (1973/1988, p.254) cita Engenharia de Sistemas, Ergonomia, Pesquisas Operacionais, Cibernética, a teoria da informação al ém da "nova" matemática dos anos 1960 e da computação como campos disciplinares os quais buscou-se a incorporação de conheci mento científico s ob a forma de técnicas e metodologias para o design.
} 
si, de acordo com os pressupostos do ideário de uma 'ciência do design' ${ }^{64}$ que configura-se ao final da década de 1960, como veremos adiante.

\title{
1.1.4 Por uma Ciência do Design como resolução de problemas
}

De acordo com a compreensão de que o processo projetual pode ser descrito como uma sequência sistemática de atividades bem definidas, relacionadas à superação de dificuldades / resolução de problemas, que ascendeu de forma hegemônica no contexto dos métodos de design nos anos 1960 e 1970, corresponde à concepção do próprio designer (o agente deste processo) como um sistema 'decisório' que 'opera' através de procedimentos sequenciados e bem-definidos, que podem ser devidamente observados e explicados, e cujo desempenho é passível de avaliação e otimização com relação às mes mas premissas da racionalidade que embasam os métodos e técnicas de tomada de decisão ${ }^{65}$ desenvolvidos em virtude das demandas logísticas da Segunda Guerra Mundial (CROSS, 2001, p.49-50). Esta idealização (Figura 11) pode ser percebida na descrição de Jones:

\begin{abstract}
A imagem do designer racional ou sistemático é muito daquela de um computador humano, uma pessoa que opera apenas pela informação que é alimentada a ele e que segue através de uma sequência planejada das etapas de análise, síntese e avaliação, em ciclos, até ele reconheœr a melhor de todas as soluções possiveis. Esta assunção de racionalidade, é claro, válida no caso de otimização œmputacional das variáveis dentro de uma situação de projeto familiar, mas também é subjacente à métodos de projeb como morfologia, engenharia de sistemas, e a abordagem da teoria da decisão, todas as quais destinam-se à solução de problemas de design muito menos familiares, pelos seus inventores ou pela sua utilização pelo 'computador' humano.6 (JONES, 1970/1992, p.50, tradução nossa)
\end{abstract}

\footnotetext{
${ }^{64}$ Nigel Cross é um exempl o de pesquisador de design que dedicou parte extensi va de sua obra, com relação a esta questão; podemos afirmar que 'Designerly Ways of Knowing' ao final dos anos 1970, consiste na síntese da argumentação de Cross em favor de uma disciplina para o design em detrimento da concepção de uma ciência do/para o design. Para uma melhor compreensão ver: CROSS, N. Designerly Ways of Knowing, Springer, London, 2006.

65 Broadbent (1973/1988, p.182-203) descreve uma série de técnicas e métodos desenvolvidos neste contexto voltadas à resolução de problemas e tomada de decisões, como os utilizados no campo das pesquisas operacionais. Do original em inglês: Linear Programming, Transportation Method, Network Analysis, Monte Carlo Method, Queuing Theory, Value Analysis, Decision Theory, entre outros.

${ }^{66}$ Do original em inglês: "The picture of the rational, or systematic, designer is much that of a human computer, a person who operates only on the information that is fed to him and who follows through a planned sequence of analytical, synthetic, and evaluative steps and cycles until he recognizes the best of all possible solutions. This assumption of rationality is, of course, valid in the case of computer optimization of the variables within a familiar design situation, but it also underlies such design methods as morphology, system engineering, and the decision theory approach, all of which are intended by their inventors or
} 


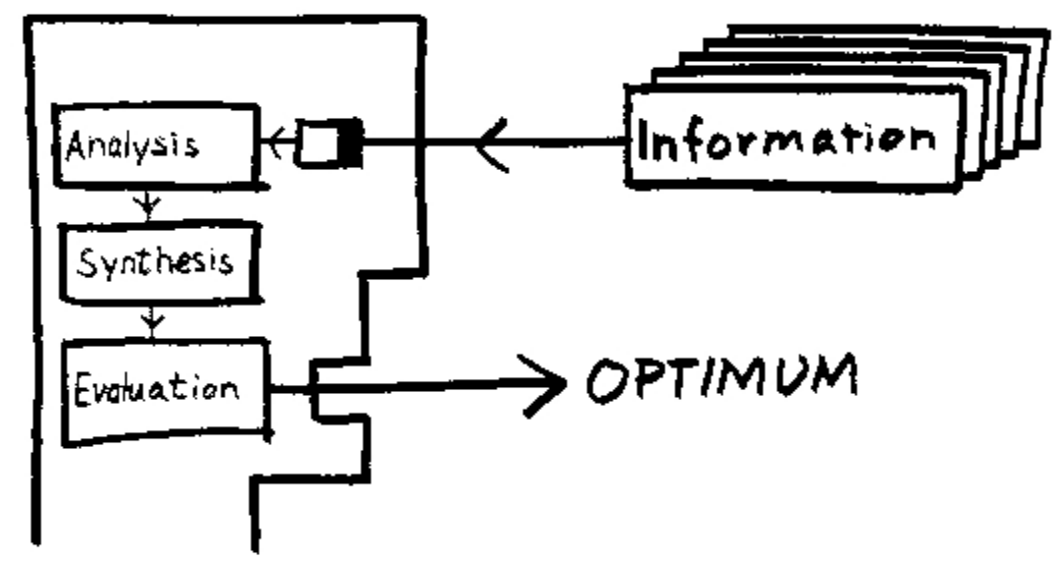

Figura 11 - Designer como um computado r humano. Fonte: (JONES, 1970/1992, p.50)

Nestas colocações de Jones percebemos especialmente a influência computacional sobre o pensamento e ideário dos métodos em design que ascendeu ao final da década de 1950, impulsionada por pesquisas como a dos cientistas norte-americanos Allen New ell (1927-1992), John Clifford Shaw (1922-1991) e Herbert Simon (1916-2001), que em 1957 publicaram o trabalho intitulado 'Elements of a Theory of Problem Solving' no qual descrevem os princípios da 'Teoria de Processamento de Informação' na resolução de problemas (ROWE, 1987, p.51), um conjunto de assertivas teórico-experimentais que utilizava conceitos de processamento de informação no estudo da formulação conceitual e resolução de problemas (EASTMAN, 1970, p.23). Esta linha de pesquisa (fecundada no bojo da computação e dos primórdios da Inteligência Artificial nos anos 1960, e posterior Ciência da Cognição, a partir dos anos $1970^{67}$ ) baseou-se na concepção de que o pensamento é processamento de informação: "Cognição, ou o pensar, é uma resultante da informação proveniente do ambiente e da memória trazidos em conjunto em uma única sequência” ${ }^{68}$ (EASTMAN, 1970, p.23, tradução nossa), ou seja, "Em vez de considerar que o domínio cognitivo ilude a análise e portanto é irrelevante, os defensores da nova perspectiva teórica procuraram explicar o comportamento

use by the human 'computer' in solving much less familiar design problems."

67 Para uma melhor compreens ão ver: DREYFUS, H. L. What computers still can't do. C ambridge, MA: MIT Press, 1992.

68 Do original em inglês: "Cognition, or thinking, is a resultant of infor mation from the environment and from memory being brought together in unique sequence." 
de resolução de problemas por meio de processos básicos de informação"69 (ROWE, 1987, p.51, tradução nossa). A proposta teórica consiste na elucidação de um número pequeno e finito de mecanis mos básicos de processamento de informações, que podem ser agrupados ou organizados em estratégias ou programas computacionais, per mitindo assim a resolução de problemas complexos (NEWELL; SHAW; SIMON, 1957, p.151-152). A pretensão de elucidar os processos cognitivos humanos envolvidos na resolução de problemas e de reproduzir seu comportamento em sistemas computacionais é evidente na descrição dos propósitos de tal teoria:

1. Ela mostra especificamente e em detalhes como os processos que ocorrem na resolução de problemas humana pode ser compostos por processos de informação elementares, e portanto, como eles podem realizados por mecanismos. 2. Mostra que um programa que incorpora tais proœssos, com a organização adequada, pode de fato, resolver problemas. Este aspecto da resolução de problemas tem sido pensado ser 'misterioso' e inexplicável porque não era entendido como sequêndias de proœssos simples poderiam prestar-se para a resolução bem sucedida de problemas complexos. A teoria dissolve o mistério, mostrando que nada mais precisa ser adicionado à constituição de um solucionador de problemas bem sucedido.70 (NEWELL; SHAW; SIMON, 1957, p.152, tradução nossa)

Segundo Peter Rowe, esta abordagem possuiu influência no pensamento sobre processos de design a partir da década de 1960, especialmente, no campo da arquitetura, com relação à pesquisa de sistemas computacionais em auxilio ao design ${ }^{71}$ :

Um número de pesquisadores emarquitetura preocupados como proœsso de design têm se envolvido comeste tipo de atividade, ou pelo menos nessa linha de especulação. A teoria de processamento de informação também forneœu uma base para o trabalho contemporâneo em projeto arquitetônico auxiliado por computador, particularmente em tentativas de desenvolver 'ambientes de design completos e hospitaleiros'. Aqui o trabalho de Negroponte, Mitchell e Eastman fornecemexemplos claros. ${ }^{72}$ (ROWE, 1987, p.55, tradução nossa).

\footnotetext{
69 Do original em inglês: "Instead of regarding the cognitive real mas el uding analysis and therefore irrelevant, proponents of the new theoretical perspective sought to explain problem-solving behavior by way of basic infor mation processes."

70

original em inglês: "1. It shows specifically and in detail how the process es that occur in human problem solving can be compound out of elementary information processes, and hence how they can be carried out by mechanis ms. 2. It shows that a program incorporating such processes, with appropriate organization, can in fact solve problems. This as pect of problem solving has been thought to be 'mysterious' and unexplained because it was not understood how sequences of simple processes could account for the successful solution of complex problems. The theory dissolves the mystery by showing that nothing more need be added to the constitution of a successful problem solver."

71 Do original em inglês: "computer aided design, $C A D$ "

72 Do original em inglês: "A number of architectural researchers concerned with the design process have become involved with this kind of activity, or at least in this line of specul ation. The infor mation processing theory has also provided a basis for contemporary work in computer-aided architectural design, particularly for attempts to develop 'compl ete and hospitable design
} 
Podemos afirmar que esta abordagem sobre o pensamento em design da época contribuiu amplamente para a pesquisa acerca do desenvolvimento de ferramentas computacionais objetivando a auto mação e otimização de atividades espec íficas do projetar (JONES, 1970/1992, p.69), bem como para alimentar a crença ${ }^{73}$ de que isto significava, no limite, a eliminação completa do designer do processo projetual:

0 raciocínio envolvido nas primeiras tentativas nos métodos de design era relativamente claro e direto: se as etapas dos processos de um designer pudessem ser identificadas, examinadas e compreendidas, elas poderiam ser melhoradas ou corrigidas e na melhor das circunstâncias, o designer poderia ser substituído por um proœsso mecânico ou uma máquina - o então emergente computador. Saltos criativos feitos misteriosamente por pessoas com talento para tanto poderiam ser substituídos por proœssos controlados e ordenados para produzir certos resultados previsíveis. ${ }^{74}$ (DOWNTON,2003,p.41, trad.nossa).

Uma perspectiva menos radical, mas igualmente complexa, foi a que contemplou a elevação do projetar ao status de ciência, pelo desenvolvimento de teorias gerais do design, embasadas em modelos formais e conhecimento científico (CROSS, 2001, p.53). Em alguns centros acadêmicos, o crescente desejo pela sistematização da prática do design por modelos e métodos respaldados por premissas científicas pode ser percebido com bastante clareza, como o caso da Escola da Forma - Hochsüle für Gestalung de Ulm, em que diversos modelos sistemáticos do processo projetual foram propostos e empregados na educação e também para o desenvolvimento de produtos famosos da época ${ }^{75}$ (ROWE, 1987, p.48). Segundo Broadbent (1973/1988, p.253), Tomás Maldonado, ${ }^{76}$ um dos principais líderes da Hochsüle für Gestalung nos anos 1960, manteve um sério interesse em uma 'ciência do design'. Row e sublinhou como esteve incorporada na visão dos processos de projeto da

environments'. Here the work of Negroponte, Mitchell and Eastman provides clear examples."

73 Uma ideia recorrente (obviamente infundada) des de meados da década de 1950, associada ao imaginário acerca das 'possibilidades ilimitadas' do advento do computador el etrônico, segundo vários relatos em: NEGROPONTE, N. (ed.) Reflections on Computer Aids to Design and Architecture. New York: Petrocelli Charter, 1975.

74 Do original em inglês: "The reasoning involved in the first attempts at design methods was relatively clear and straightfoward: if the steps in a designer's process es could be identified, examined, and understood, they could be improved, or corrected and in the best circumstances, the designer could be replaced by a mechanical process or a machine - the then emerging computer. Creative leaps made mysteriously by people with a talent for leaping could be replaced by orderly, controlled processes certain to produce predictable outcomes."

75 Rowe cita o desenvol vimento de produtos para empresas alemãs famosas Braun e Lufthansa.

76 Broadbent observa que após a sucessão da direção da escola ao final dos anos 1950, que era dirigida pelo arquiteto Max Bill (e tinha carregado consigo o legado educacional da Bauhaus de Dessau), e com a ascensão Maldonado (que perseguia uma linha mais fortemente orientada à ciência), instaurou-se uma abordagem distinta na ins tituição: "dur ante a segunda fase do 'design científico' da Ulm a 'arte' e intuição que Bill tinha sublinhado estavam para ser substituídas por metodologia analítica." (BRO ADBENT, 1973/1988, p.252, tradução nossa). 
escola uma ideologia correspondente a este sentido:

Além disso, aqui tal especulação foi além da descrição e explicação do comportamento do design para o reino da idealização. Não só foi a possibilidade de uma abordagem 'científica' e totalmente objetiva para o design seriamente cogitada, isto tornou-se um objetivo em si. Um senso confiante do determinismo racional prevaleceu; todo o processo de design, acreditava-se, poderia ser estabelecido de forma clara e explícita, os dados relevantes coletados, parâmetros estabelecidos, e um artefato ideal produzido.77 (ROWE, 1987, p.49, tradução nossa)

Esta concepção também foi almejada pelo engenheiro inglês Bruce Archer (1922-2005), outro relevante teórico do design na Hochsüle für Gestalung, que em $1963^{78}$ apresentou a proposta de um modelo geral do processo de design $^{79}$ (Figura 12) aplicável a diversos domínios como arquitetura, engenharia ou desenho industrial:

Bruce Archer, em seu artigo para o Simpósio de Portsmouth [...] tenta estabeleœr as bases para uma ciência do design, distinta do proœsso de design vigente. [...] Archer conscientemente busca fomeœr uma estrutura geral œntra a qual os problemas de design em qualquer área (arquitetura, engenharia e desenho industrial) podem ser percebidos, e ele é ansioso para provar que a 'lógica' de projetar é amplamente independente da coisa a ser concebida. Tendo configurado o seu modelo lógico, sua terminologia e notação, Archer espera que designers em vários campos irão usá-la como base para seu trabalho, assim facilitando a comparação entre eles, e a derivação de leis gerais mais precisas para 0 projeto. ${ }^{80}$ (BROADBENT, 1973/1988, p.289, tradução nossa)

\footnotetext{
77 Do original em inglês: "Further more here such speculation moved beyond description and explanation of design behavior into the realm of idealization. Not only was the possibility of a 'scientific' and totally objective approach toward design seriously entertained, it became a goal in itself. A confident sense of rational deter minis m prevailed; the whole process of design, it was believed, could be clearly and explicity stated, relevant data gathered, parameters established, and an ideal artifact produced."

78 Ver: ARCHER, B. Systematic Method for Designers. Design Journal, n. 172-188, 1963.

79 Novamente aqui o design é visto como uma sequência linear de estágios onde atividades são definidas por suas orientações e pel o tipo geral de tar efa envol vida (ROWE, 1987, p.49). Segundo Bazjanac (1974, p.7), a car acterística mais essencial do model o é a notação de retorno contínuo (feedback) entre as fas es. Na fas e analítica, Archer prevê a definição de objeti vos, fatores influentes no design e suas rel ações, bem como a for mulação de probl emas e subproblemas. Bazj anac observa que 0 resultado desta fase, denomi nado de "definição do problema" é similar ao resultado da fase analítica do proc esso de Alexander (1964) denominado programa. De fato, a distinção entre os modelos de Archer e Alexander começa a tornar-se evidente na fase de síntese, em que Archer, de modo diferente de Alexander, afirma Bazjanac, aceita que a forma dependa dos valor es indivi duais do designer e da incidência de ideias originais durante o processo de design, e portanto, estes tipos de raci ocíni os deveriam ser descritos na fase de síntese no processo de procura por sol uções do problema (BAZJANAC, 1974, p.7). Aqui jaz, sugere Broadbent, um ponto crítico da proposta de Archer, que propõe em contrapartida proc edi mentos de parametrização e quantificação destes fatores de 'não-confiabilidade' agregados à experiência e aos julgamentos avaliati vos do raciocínio dos designers (BRO ADBENT, 1973/1988, p.292-293).

${ }^{80}$ Do original em inglês: "Bruce Archer, in his paper to the Ports mouth Symposium [...] tries to lay down the foundations for a science of design, as distinct from an actual design process. [...] Archer's conscious aim is to provide a common framework against which design problems in any field (architecture, engineering and industrial design) may be perceived, and he is anxious to establish that the 'logic' of designing is largely independent of the thing being designed. Having set up his logical model, terminology and notation, Archer hopes that designers in various fields will use it as a basis for their work thus facilitating comparison between them, and the derivation of more precise general laws for design."
} 


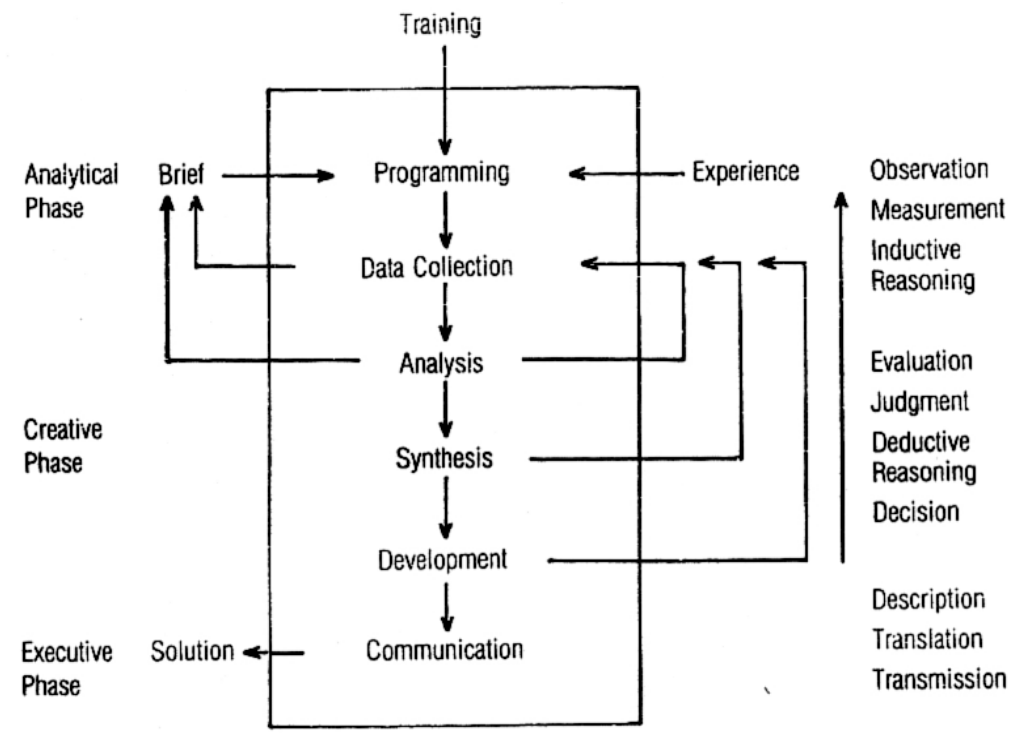

Figura 12 - Modelo simplificado dos estágios do processo de design por Archer. Fonte: (ROWE, 1987, p.14)

A proposta de Archer no sentido de desenvolvimento de uma estrutura geral capaz de enquadrar e descrever o processo de design independente de suas especificidades quanto à ordem de seus produtos, ilustra uma pretensão teórica que provavelmente encontra-se ao final dos anos 1960 no ápice de sua expressão: em 1969, o cientista político e econômico Herbert A. Simon (1916-2001) publicou a obra 'The Sciences of the Artificial', onde propôs a criação de uma nova ciência sobre a produção humana, uma ciência do design, aplicável de maneira generalizada como disciplina aos diferentes campos de atuação e esferas sociais, à medida que "[...] o estudo próprio da humanidade é a ciência do design, não somente como o componente profissional de uma educação técnica, mas como uma disciplina central para qualquer pessoa educada de forma liberal." ${ }^{81}$ (SIMON, 1969/1996, p.138, tradução nossa). Nesta obra, Simon (1969) abordou o design com relação à produção geral de artefatos, sistemas artificiais construídos pelo homem para a obtenção de seus objetivos, segundo a concepção geral de que design constitui-se da elaboração de cursos de ação que "[...] visa a transformar situações existentes em preferidas. ${ }^{182}$ (SIMON, 1969/1996, p.111, tradução nossa). Obtém-se assim uma base universal para o desenvolvimento de uma epistemologia própria a esta ciência do design sobre os campos profissionais:

${ }^{81}$ Do original em inglês: "[...] the proper study of mankind is the science of design, not only as the professional component of a technical education but as a core discipline for every liberally educated person."

82 Do original em inglês: "[...] aimed at changing existing situations into preferred ones." 
[...] Design, assim construído, é o œntro de todo treinamento profissional, é o principal aspecto que distingue as profissões das ciências. Escolas de engenharia, assim como escolas de arquitetura, administração, educação, direito, e medicina, são todas centralmente preocupados como processo de design.$^{83}$ (SIMON, 1969/1996, p.111, tradução nossa)

No entanto, os pesquisadores Dorst e Dijkhuis (1996), evidenciaram que a proposta de Simon $(1969,1996)$ fundamentava-se na abordagem do processo design como a resolução de problemas $^{84}$ pela aplicação dos métodos, técnicas e modelos emergentes das disciplinas científicas e das diversas teorias sobre o processo de tomada de decisões que emergiram de seu bojo, e portanto, permanecia com "[...] a estrutura lógico-positivista da ciência, utilizando as ciências clássicas como a física como o modelo para uma ciência do design" 85 (DORST; DIJKHUIS, 1996, p.254, tradução nossa). Desta forma, a produção de conhecimento sobre design mantém-se atrelada aos princípios da metodologia científica tradicional, de modo que "análises lógicas e contemplação do design são os principais modos de produção de conhecimento sobre o processo de design"86 (DORST; DIJKHUIS, 1996, p.254, tradução nossa). Neste sentido, a concepção de design como resolução racional de problemas pela aplicação do conhecimento científico, conforme a formalização de Simon, configurou-se na colocação dos autores como um paradigma ${ }^{87}$ da pesquisa de design, cuja influência se estendeu para muito além de sua gênese ao final dos anos 1960:

[...] Teorias de resolução de problemas introduzidas por Simon proporcionavam uma estrutura para esta extensão do escopo dos estudos de design ao permitir o estudo de designers e problemas de design através do paradigma da racionalidade écnica. Simon também promoveu uma base sonora, rigorosa para muito do conhecimento existente em metodologia de design. Este paradigma, em que o design é visto como um processo racional

\footnotetext{
83 Do original em inglês: "[...] Design, so construed, is the core of all professional training; it is the principal mark that distinguishes the professions from the sciences. Schools of engineering, as well as schools of architecture, business, education, law, and medicine, ar e all centrally concer ned with the process of design."

84 Segundo a caracterização de Dorst e Dijkhuis: "A abordagem de res olução de problemas significa olhar para o designcomo um processo de busca, em que o escopo dos passos tomados no sentido de uma solução é limitado pela capacidade de processamento de i nfor mação do sujeito agente. A definição do problema é s uposta ser estável, e defi ne o 'es paço de soluç ão' a ser pesquisado." (DORST; DIJKHUIS, 1996, p.254, tradução nossa)

85 Do original em inglês: "[...] the logic-positivistic framework of science, taking 'classical sciences' like physics as the model for a science of design."

${ }^{86}$ Do original em inglês: "[...] Logical analysis and contemplation of design are the main ways of producing knowledge about the design process."

87 Dorst e Dijkhuis ( 1996) referem-se com 'paradigma da racionalidade técnica', à denominação de Schön (1983) em sua compreensão da abordagem cientificista de inclinação positi vista do final do século XIX / início do sécul o XX, como veremos mais adiante no corpo do trabal ho.
} 
de resolução de problemas tem sido a visão dominante e influente que conforma uma metodologia de design prescritiva e descritiva desde ent̃o. Muito do trabalho realizado em metodologia de design hoje em dia ainda segue as assunções, visão de ciência e objetivos desta escola de pensamento.88 (DORST; DIJKHUIS, 1996, p.253-254, tradução nossa)

Este delineamento da pesquisa em design assumido ao final dos anos 1960 implicou assim, em um progressivo afastamento das especificidades da prática dos campos tradicionalmente envolvidos com o design, e parte da rejeição de seus expoentes iniciais no início dos anos 1970, como Alexander e Jones, diz respeito ao modo com que a pesquisa em métodos de design tornou-se de certo modo um fim em si mes ma, em detrimento do objetivo de melhorar a qualidade dos espaços construídos, por exemplo, no caso da arquitetura. A aparente ausência de resultados com relação a este último objetivo contribuiu igualmente para que o movimento de métodos em design sofresse uma severa crítica, configurando-se um cenário de crise na década de 1970 que levou à revisão de alguns de seus valores e princípios subjacentes neste contexto. (CROSS, 2001; BAYAZIT, 2004, p.20).

\subsubsection{Crise dos métodos em design}

Ao passo de quase uma década das primeiras conferências sobre os métodos em design, no começo dos anos 1970, o movimento havia se consolidado como um campo de pesquisa e seus preceitos difundidos o suficiente para possibilitar uma revisão de seu estado da arte (DOWNTON, 2003, p.45). Em 1971, o 'Grupo de Métodos em Design’ da Universidade da Califórnia em Berkeley perguntou a alguns teóricos do design a questão "O que você vê que a metodologia em design está tentando fazer?" ${ }^{89}$. As respostas variam bastante, refletindo aspectos do caráter ideológico vinculado à adoção dos métodos em design pelo ponto de vista particular de cada entrevistado. Contudo, pode ser percebido um tom de crítica variado entre as opiniões:

\footnotetext{
88 Do original em inglês: "[...] Problem solving theories introduced by Simon provided a framew ork for this extension in the scope of design studies by allowing the study of designers and design problems within the paradigm of technical rationality. Simon also provided a sound, rigorous basis for much of the existing knowledge in design methodology. This paradigm, in which design is seen as a rational problem solving process, has been the dominant influence shaping prescriptive and descriptive design methodology ever since. Most of the work done in design methodology today still follows the assumptions, view of science and goals of this school of thought."

89 Do original em inglês: "What do you see design methodology as trying to do?" D MG Newsletter, n.5, 1971.
} 
Horst Rittel: A ocorrência de interesse na metodologia em um determinado campo é geralmente um sinal de aise dentro do campo... 0 principal objetivo da metodologia de projeto parece ser o de esclarecer a natureza da atividade de design e a estrutura dos seus problemas. Este papel de metodologia de design me parece ser muito mais importante do que a sua utilização prática em lidar com problemas concretos. ${ }^{90}$ (RITTEL, 1971 apud. DOWNTON, 2003, p.46, tradução nossa)

Christopher Jones: Eu vejo a metodologia de design como uma resposta à neœssidade de técnicas generalistas aplicáveisaos problemas de larga escala que surgem hoje em dia. Isso significa que eles não são neœssariamente de qualquer uso para as tradicionais profissões de projeto de arquitetura, engenharia, e assim por diante.91 (JONES, 1971 apud. DOWNTON, 2003, p.45, tradução nossa)

Geoffrey Broadbent: As técnicas em geral têm sido úteis - elas poderiam ser aplicadas ao design em vários níveis por designers reais enfrentando problemas reais. Mas as estratégias, em geral, têm sido muito menos úteis. 0 erro, eu acho, tem permanecido em tentar usar modelos dessas novas disciplinas... (teoria da informação, cibemética, etc.)... para descrever processos de design generalizados, que se esperava utilizar em todos os campos do projetar. ${ }^{92}$ (BROAD BENT, 1971 apud. DOWNTON, 2003, p.45, tradução nossa)

Christopher Alexander: Obviamente, a intenção é tentar criar procedimentos bem definidos que irão permitir que as pessoas projetem edificios melhor. 0 curioso é que na imensa maioria da literatura as pessoas perderam de vista completamente deste objetivo. No momento, as pessoas que estão se divertindo com computadores têm, obviamente, tornadose interessado em algum tipo de brinquedo. Eles tem definitivamente perdido a motivação para fazer melhores construçoes.93 (ALEXANDER, 1971 apud. DOWNTON, 2003, p.46 tradução nossa)

Apesar do Movimento Métodos de Design ter alcançado grande repercussão e êxito no

90 Do original em inglês: "The occurrence of inter est in methodology in a certain field is usually a sign of crisis within that field... The main purpose of design methodology seems to be to clarify the nature of design activity and the structure of it problems. This role of design methodology seems to me to be much more important than its practical use in dealing with concrete problems." Ver: RITTEL, H. Son of Rittelthink. DMG 5th Anniver sary Report, DMG Occasional Paper, n. 1 janeiro de 1972, p.5.

91 Do original em inglês: "I see design methodology as a response to the need for generalist techniques applicable to the larger scale problems that arise today. This means that they are not necessarily of any use at all within the traditional design professions of architecture, engineering, and so fourth." Ver: JONES, J.C. The state of the art in design methodology. DMG Newsletter, n.5 (10), 1971, p.2.

92 Do original em inglês: "The techniques on the whole have been useful -they could be applied to design at many levels by real designers faced with real problems. But the strategies, on the whole, have been much less useful. The mistake, I think, has lain in trying to use models from these new disciplines... (infor mation theory and cybernetics, etc...) ... to describe generalised design processes, which - it was hoped - could be us ed in all fields of designing." Ver: BROADBENT, G. The state of the art in design methodology. D MG Newsletter, n. 5 (8-9), 1971, p. 2-3.

93 Do original em inglês: "Obviously the intent is to try and create well-defined procedures which will enable people to design better buildings. The odd thing is that in the vast proportion of the literature people have lost sight completely of this objective. For instance, the people who are messing around with computers have obviously became interested in some kind of toy. They have very definitely lost the motivation for making better buildings." Ver: ALEXANDER, C. The state of the art in design methodology. DMG Newsletter, n.5 (3), 1971, p.3-7. 
desenvolvimento da pesquisa em design dos anos 1960, na década de 1970 instaurou-se uma dura crítica ao movimento marcada pela a manifestação pública de descontento de alguns de seus pioneiros, como o próprio Christopher Alexander e John Christopher Jones (CROSS, 1992, p.16). Alexander expôs sua insatisfação a respeito do mau entendimento acerca de sua obra através de uma passagem incorporada no prefácio da reedição de 'Notes on the Synthesis of Form' em 1971:

De fato, desde que o livro foi publicado, toda uma área acadêmica tem crescido em torno da ideia de 'métodos de design' - e eu tenho sido saudado como um dos expoentes líderes destes assim chamados métodos de design. Eu estou chateado que isso tenha acontecido, $\mathrm{e}$ quero dedarar, publicamente, que eu rejeito toda a ideia de métodos de design como um assunto de estudo, porque considero um absurdo separar o estudo de design da prática do design.94 (ALEXANDER, 1964/1971, prefácio, tradução nossa)

Anos depois, em artigo para o periódico 'Design Methods and Theories' 95 de 1977 Christopher Jones comentou: "[...] Nos anos 1970 eu reagi contra os métodos de design. Eu não concordo com a linguagem da máquina, o behaviorismo, a tentativa contínua de enquadrar a vida toda em um quadro lógico." ${ }^{96}$ (JONES, 1977 apud. CROSS, 2001, p.50 tradução nossa). Nigel Cross considera que as rupturas de Alexander e Jones não devem ser entendidas como incidentes isolados, chamando atenção para o clima de desconforto que marca o in ício dos anos 1970, principalmente no cenário norte-americano, e o aparente insucesso do movimento dos métodos de design na resolução dos chamados 'problemas reais' da prática do design:

[...] para colocar as citações de Alexander e Jones em contexb, pode ser neœssário recordar o clima social / cultural do final dos anos 1960 - as revoluções nos campi e os movimentos políticos radicais, o novo humanismo liberal, e a rejeição de valores conservadores. Mas também deve ser reconhecido que existiu uma falta de suœsso na aplicação de métodos científicos à prática cotidiana do design.97 (CROSS, 2001, p.50

\footnotetext{
94 Do original em inglês: "Indeed, since the book was published, a whole academic field has grown up around the idea of "design methods" - and I have been hailed as one of the leading exponents of thes e so-called design methods. I am very sorry that this has happened, and want to state, publicly, that I reject the whole idea of design methods as a subject of study, since I think it's absurd to separate the study of designing from the practic e of design."

95 Ver: JONES, J. C. How my thoughts about design methods have changed during the years. Design Methods and Theories, v.11, n. 1, 1977, p.45-62.

96 Do original em inglês: "[...] In the 1970s, I reacted against design methods. I dislike the machine language, the behavioris $m$ the continual attempt to fix the whole of life into a logical framework."

97 Do original em inglês: "[...] to put the quotations of Alexander and Jones into context, it may be necess ary to recall the social / cultural climate of the late 1960s - the campus revol utions and radical political movements, the new liberal humanis m, and the rejection of conservative values. But also it had to be acknowledged that there had been a lack of success in the application of scientific methods to everyday design practice." Milne (1975) comenta sobre um episódio em especial que
} 
tradução nossa)

Peter Dow nton (2003) comentou que a despeito da tentativa de aprimorar o processo de projeto através do desenvolvimento de metodologias racionais, que "foram acompanhadas de garantias virtuais de que seu uso iria banir a concepção irracional e anunciar a aurora da era da racionalidade", pode-se afirmar que "é difícil, talvez impossível, citar um único exemplo de um edifício ou desenho urbano produzido através da utilização rigorosa e imaculada de um dos métodos." 98 (DOWNTON, 2003, p.39, tradução nossa). O autor apontou outro fator problemático relacionado à proposta dos métodos em design, acerca da falta de correspondência entre as descrições sistemáticas do processo de design defendidas pelos metodologistas e a condução prática habitual do projetar:

Em uma palestra que eu dei no RMIT por volta de 1977, com Greg Missingham, pedimos cerca de cinquenta alunos de arquitetura que estavam todos empenhados na prática diária para descrever como eles faziam para projetar. Respostas foram escritas e cletadas. Uma examinação rápida nos mostrou que quase bdos afirmaram realizar alguma variação do modelo coletar dados-analisar-sintetizar. Pedimos para que quem já eve alguma ideia esboçada antes da própria coleta de dados, talvez com um cliente emuma reunião inicial, ou que primeiro tenham posto o problema de design, para levantar suas mãos. Todos levantaram as mãos. Nós perguntamos por que havia a falta de honestidade, uma vez que perguntamos como eles projetavam, não como eles deveriam projetar de acordo comalguma visão prescrita. A confusão deles, mesmo culpa, era típica dos designers na época e originou-se no conflito entre o que eles liame o que eles naturalmente faziam para alcançar um resultado de projeto. ${ }^{99}$ (DOWNTON, 2003, p.44, tradução nossa)

exemplifica a questão da instabilidade no mei o uni versitário norte-americano com relação à participação do país na guerra do Vietnã: "Para mi m, a gota d'água foi o horror das mortes em Ken State; aquele evento es magou o oti mismo do começo dos anos sessenta e a ideia de que se seus objetivos forem justos, com coragem e determi nação você poderia mudar o sistema. Olhando para trás agora, este foi o fundo do poço." (MILNE, 1975, p.36, tradução nossa). O professor Milne refere-se ao confronto entre policiais e manifestantes no campus da universidade do Estado de Kent, Ohio. Durante a manifestação em protesto ao governo Nixon que manteve a posição de expansão da participação americana na guerra do Vietnã em 1970, quatro estudantes foram mortos. O confronto teve grande impacto sobre a mídia provocando grande comoção social e agravou a reprovação da opini ão pública sobre a participação americana na guerra, que se estenderia até 1975.

98 Do original em inglês: "[...] were accompanied by virtual guarantees that their use would banish irrational design and herald the dawn of the era of rationality. [...] It is hard, perhaps impossible, to cite a single example of a building or urban design produced through the rigorous and unsullied us e of one of the methods."

99 Do original em inglês: "In an early lecture I gave at RMIT in about 1977, with Greg Missingham, we asked some fifty partytime architecture students who were all engaged in daily practice to describe how they went about designing. Answers were written and collected. Quick scrutiny showed us that nearly everyone claimed to perform some variation on the collect dataanalyse-synthesise model. We asked for any one who had ever sketched some idea prior to proper data collection, perhaps with a client at an initial meeting or on first having the design problem put to them, to raise their hands. Every hand went up. We asked why there was such a lack of honesty given that we had asked them how they designed, not how they were supposed to design according to some prescribed view. Their confusion, even guilt, was typical of designers at the time and originated in the conflict between what they read and what they naturally did to achi eve a design outcome." 
Nesta passagem coloca-se a questão de que o desenvolvimento de métodos formais e da modelagem do processo projetual encarados como instrumental valorosos para a investigação projetual, uma vez assumindo a configuração de estruturas rígidas e formalis mos dos mais variados, acaba por evidenciar as próprias limitações dos mes mos, restritos às premissas de seus criadores e, uma vez postos em prática, denunciam o caráter 'descritivo' e 'prescritivo' destas estruturas, gerando uma dificuldade em sua efetiva aplicação ou adaptação com relação às condições da prática projetual. Broadbent (1966) compartilhou desta crítica observando o modo como a formalização dos processos de design através da modelagem rígida e sistemática comprometeu a adoção efetiva dos mes mos no contexto da prática projetual:

\begin{abstract}
Tem havido uma tendência de fazer do método de design uma forma demasiado rígida, e construir modelos bonibs e elegantes dos proœssos de design não têm qualquer aplicação prática. E qualquer um que enha realmente projetado alguma coisa sabe que tais sistemas 'ideais' não podem funcionar. Em qualquer situação real de projeto, o designer se vê quase que literalmente andando em círculos. Por razões de conveniência, é usual apresentar o processo de design como uma sequência linear, e tem havido tentativas de construir nele voltas, espirais, ações de transferência e outras distbrções para indicar que, na prática, ele será complexo. [...] Qualquer método de design que force um padrão não natural de comportamento sobre o designer está fadado ao fracasso, especialmente se ele ignora as características da ferramenta mais barata e mais comum disponivel para o designer - 0 cérebro humano. ${ }^{100}$ (BROAD BENT, 1966 apud. DOWNTON, p.43, tradução nossa)
\end{abstract}

Concluímos que o processo de contínua abstração assumido pelos métodos e modelos de design propostos nos anos 1960, inicialmente justificados pela crença no estabelecimento de uma linguagem comum para a comunicação entre designers e assim uma abertura do projetar para a investigação crítica, acaba por sabotar seu êxito com relação a esta intenção pela rigidez e hermetis mo que as estruturas assumem, denunciando os limites das visões pessoais e escopos de seus criadores, mesmo nas propostas mais abrangentes como as

\footnotetext{
100 Do original em inglês: "There has been a tendency to make design method over-rigid in this way, and to construct beautiful and elegant models of design processes which have no application whatsoever in practice. Yet anyone who has actually designed any thing at all knows that such 'ideal' systems cannot work. In any real design situation, the designer finds himself, al most literally going round in circles. For reasons of convenience, it is usual to present the design process as a linear sequence, and there have been attempts to build into it loops, spirals, shuttle actions and other distortions to indicate that, in practice, it will be complex. [...] Any design method which forces an unnatural pattern of behavior on the designer is bound to fail, especially if it ignores the characteristics of the cheapest and most common tool available to the designer - the human brain." Ver: BROADBENT, G. D esign M ethods in Architecture. Architect s Journal, n.14, 1966.
} 
que contemplaram a instituição de uma ciência do design. A partir do juízo comum do processo projetual como a organização de tomadas de decisões visando à resolução de problemas, configuram-se abordagens bastante prescritivas do que o 'design deveria ser', principalmente com relação ao emprego das técnicas e modelos derivados dos avanços científicos da época e subjacente aplicação dos princ ípios racionais e do método cartesiano no lidar com os problemas de design. Entretanto, ao final dos anos 1960, podemos observar a emergência de abordagens distintas, vinculadas a outras propostas e compreensões do processo projetual.

\subsection{O projetar como processo argumentativo}

Na sequência do capítulo apresentamos a concepção do alemão Horst Rittel ${ }^{101}$ (1930-1990), então professor de design arquitetônico e de planejamento urbano da Universidade da Califórnia em Berkeley. A visão de Rittel constitui-se da primeira das quatro visões envolvidas com a metáfora da conversação ${ }^{102}$ de que nos debruçamos em nossos esforços de pesquisa e que compõem nosso horizonte temático. A contribuição de Rittel apresenta-se como um desdobramento direto do movimento dos métodos em design, nosso (contra) ponto de partida, representando uma transição de 'gerações' como o mes mo propôs, ${ }^{103}$ baseada na adoção de princípios, conceitos e ações que remetem-se essencialmente ao modo distinto colocado pelo autor de se conceber os problemas de design e suas implicações para o processo projetual.

\footnotetext{
101 Horst Willhelm Jakob Rittel (1930-1990), de naci onalidade alemã, for mou-se físico e matemático pela Uni versidade de Göttingen. Sua rel ação com o design iniciou-se logo em sua carreira profissional, ao aplicar seus conhecimentos nes tas áreas para desenvol ver sistemas de auxílio ao projeto para engenheiros mecânicos da Maschinenfabrik Deutschl and em Dortmund. Em 1958, Rittel filiou-se à Sozialforschungsstelle da Universidade de Münster, estudando soci ologia e lógica matemática. No mes mo ano que se juntou a Hochschule für Gestaltung ( $\mathrm{HfG}$ em Ulm, onde ministrou aulas de metodologia de design, período em que fez parte também do Sudiengruppe für Systemforschung (Grupo de Estudos para Pesquisa em Sistemas) de Heidelberg. Em 1963, foi convidado a lecionar na Uni versidade da Califórnia, Berkeley pelo Departamento de Arquitetura e Departamento de Planejamento Regional e Urbano da instituição. Em 1973, Rittel torna-se professor de planejamento da Faculdade de Arquitetura e Planej amento Urbano da Uni versidade de Stuttgart, onde fundou e dirigiu o Institut für Grundlagen der Planung. Desenvol veu pesquisa na Uni versidade de Ber keley e em Stuttgart em teoria do design e sistemas informacionais em auxílio ao processo de tomada de decisões e de planejamento até o final de sua vida.

102 Embora Rittel não utilize o termo conversação em sua obra e pensamento, assumimos pelo estudo do mesmo a proximidade de suas colocações ao escopo teórico e conc eitual dos outr os autores abordados, bemcomo da orientação geral sobre os pressupostos e implicações de se conc eber o processo projetual arquitetônico através desta compr eens ão.

103 Confor me apres entaremos na sequência.
} 


\subsubsection{A visão de Horst Rittel frente à crise dos métodos em design}

De acordo com uma concepção de cooperação interdisciplinar e interdependência entre campos profissionais relacionados ao projeto e planejamento do ambiente construído que se instaurou no ambiente acadêmico da Universidade da Califórnia em Berkeley ${ }^{104}$ nos anos 1960 e ao crescente interesse pela pesquisa em processos de design, ocasionado pela repercussão do movimento de métodos da época, somaram-se aos docentes da instituição Christopher Alexander, recém-doutorado na Universidade de Harvard e Horst Rittel, que então lecionava na Escola Superior da Forma - Hochschule für Gestaltung de Ulm, na Alemanha. Foi no contexto efervescente da Berkeley em que Rittel, matemático-físico por formação, desenvolveu docência em arquitetura e planejamento urbano: "Rittel ensinou design e arquitetura por mais de 30 anos, ainda que nunca tenha projetado um edifício ou atuado como um arquiteto." ${ }^{105}$ (RITH; DUBBERLY, 2006, p.1, tradução nossa). Na introdução de um artigo publicado em 1967 (RITTEL, 1967/1971), em que expõe princípios para um sistema de ensino em design referindo-se especificamente à arquitetura, Rittel comenta brevemente sua relação com a referida área, enunciando o escopo da contribuição de sua pesquisa:

Vou discutir as ferramentas intelectuais que imagino que um arquiteto deva ter e sugenir maneiras de proporcionar-Ihes as mesmas. Vou tentar lidar comeste assunto, apesar do fato de eu mesmo não ser um arquiteto, pois tenho vivido entre os arquitetos e outros tipos de designers por vários anos, tentando entender o que são os seus problemas e como eles lidam com eles, observando seu trabalho, tentando teorizar sobre sua atividade, e ocasionalmente, até mesmo propondo um truque para superar algumas dificuldades em seu trabalho. ${ }^{106}$ (RITTEL, 1967/1971, p.16, tradução nossa)

Rittel compreende a arquitetura como uma das práticas profissionais que fundamentam-se

\footnotetext{
104 Segundo os pesquisadores Jean-Pierre Protzen e David J. Harris (2010, p.8-9), um dos principais núcleos de pesquisa em teoria e métodos em design que originaram o chamado Movi mento de Métodos em Design no contexto da década de 1960, a Universidade da Califórnia em Berkeley, havia passado em 1959 por uma significante reconfiguração organizacional, em que as uni dades educacionais do Colégio de Arquitetura - Architectural College, o Departamento de Paisagismo - Department of Landscape Architecture e o Departamento de Planejamento Regional e da Cidade - Department of City and Regional Planning da instituição foram integradas em uma única unidade originando o Colégio de Design Ambiental - College of Environmental Design.

105 Do original em inglês: "Horst Willhel m Jakob Rittel taught design and architecture for over 30 years, yet he never designed a building or otherwise pr acticed as an architect."

106 Do original em inglês: "I shall discuss the intellectual tools I think an architect should have and suggest ways of providing them. I shall try to deal with this subject, in spite of the fact that I am not an architect mys elf, because I have been living among architects and other kinds of designers for several years -trying to understand what their problems are and how they deal with them, observing their work, attempting to theorize about their activity, and occasionally even proposing a trick for overcoming some particular difficulty in their work."
} 
na atividade de projetar, entendido como uma atividade humana ubíqua: para o autor, o homem projeta sempre que tem um propósito em mente e desenvolve um plano para realizar tal propósito, desta forma, design e planejamento compartilham um sentido de equivalência ${ }^{107}$ (RITTEL, 1967/1971, p.19). Diante do vasto escopo de entidades projetadas e de conhecimentos empregados em seus projetos, Horst Rittel afirmou que é possível referir-se a design através de pontos em comum envolvidos nos diversos processos de projetar:

Quais são esses pontos em comum? Todos os designers pretendem intervir no curso esperado de eventos por ação premeditada. Todos eles querem evitar erros por ignorância e espontaneidade. Eles querem pensar antes de agir. Em vez de manipular diretamente e imediatamente os seus arredores por tentativa e erro até que estes assumam a forma desejada, designers querem pensar detalhadamente emum curso de ação antes que eles se comprometam a sua exeaução. Design é elaborar planos. Planejadores, engenheiros, arquitetos, gestores de empresas, legisladores, educadores são (às vezes) designers. Eles são guiados pela ambição de imaginar umestado desejável de mundo, jogando comformas alternativas em que isto pode ser éito, cuidadosamente traçando as consequências das ações œntempladas. Design toma seu lugar no mundo da imaginação, onde se investem e manipulamideias e conceibs em vez da coisa real, a fim de preparar a intervenção real. Eles trabalham com modelos como meios de percepção vicária e manipulação. Esboços, modelos de papel, diagramas e modelos matemáticos, e o mais flexível de todos eles, o discurso, servem como meios no suporte à imaginação. 0 design termina como co mpromisso de u m plano que se destina a ser realizado.108 (RITTEL, 1987/2010, p.187, tradução nossa)

Nesta concepção, o que distingue o fazer do design de outras atividades intelectuais é justamente o comportamento humano ao elaborar esquemas, planos ou projetos, ou seja, a aplicação de um raciocínio de antecipação das consequências de ações visando um

\footnotetext{
107 De acordo com Protzen e Harris: "Algumas pessoas sustentam que design e planejamento são duas ati vidades distintas: um arquiteto pr ojeta, um engenheiro de tráfego planeja. Rittel não fez tal disti nção, na verdade, el e consider ou os termos como sendo sinônimos, o que é consistente com o uso comum, tanto atual como histórico. $O$ uso dos termos por Rittel como sinôni mos é consistente com a sua definição geral de design, e revela seu foco: ele estava olhando para a natureza do problema e as questões de como resol ver mel hor os problemas." (PROTZEN; HARRIS, 2010, p.2, traduçãonossa)

108 Do original em inglês: "What are these commonalities? All designers intend to intervene into the expected course of events by premeditated action. All of them want to avoid mistakes through ignorance and spontaneity. They want to think before act. Instead of immediately and directly manipulating their surroundings by trial and error until these ass ume the desired shape, designers want to think up a course of action thoroughly before they commit themselves to its execution. Designing is planmaking. Planners, engineers, architects, corporate managers, legislators, educators are (sometimes) designers. They are guided by the ambition to imagine a desirable state of world, playing through alternative ways in which it might be accomplished, carefully tracing the consequences of contemplated actions. Design takes the place in the world of imagination, where one invests and manipulates ideas and concepts instead of the real thing -in order to prepare the real intervention. They work with models as means of vicarious perception and manipulation. Sketches, cardboard models, diagrams, and mathematical models, and the most flexible of them all, speech, serve as media to support the imagination. Design ter minates with a commitment to a plan that is meant to be carried out."
} 
determinado propósito comum (PROTZEN; HARRIS, 2010, p.118). Esta é a premissa fundamental da pesquisa de Rittel ao propor o desenvolvimento de teorias, ferramentas e procedimentos metodológicos em auxílio do projetar: "Horst Rittel era um pragmático no sentido de que ele estava preocupado com implicações práticas..."109 (PROTZEN; HARRIS, 2010, p.233, tradução nossa) A tônica do trabalho de Rittel é a de um teórico de sistemas e seu direcionamento o de um metodologista, "alguém preocupado com os aspectos processuais de uma atividade, em abordagens a problemas e sua lógica"110 (RITTEL, 1967/1971, p.16, tradução nossa). Como os outros pesquisadores envolvidos com o movimento de métodos de design dos anos 1960, Rittel considerou com otimismo ${ }^{111}$ o emprego de metodologia e do racionalis mo característicos do pensamento científico moderno (PROTZEN; HARRIS, 2010, p.235). Ao contrário de muitos dos membros do movimento filiados a um ideário positivista, convém ressaltar que Rittel compartilhou da visão de ciência do filósofo britânico Karl Popper (1902-1994) ${ }^{112}$, refutando a existência de verdades absolutas ou de outras formas totalitárias ou definitivas respaldadas no conhecimento científico e assim, "de um modo equivalente, na vida comum, e em muitas das profissões, não há garantia para verdades estabelecidas, constantemente desafiadas. Portanto há, em áreas como arquitetura, apenas algumas teorias gerais e pouco conhecimento testável"113 (RITTEL, 1967/1971, p.18, tradução nossa). Como na concepção científica de Popper, para Rittel o design envolve um processo de investigação no qual o "design deveria ser um processo aberto e transparente, onde as diferentes questões, posições e argumentos estariam disponíveis para todos aqueles crucialmente envolvidos, e as decisões que foram tomadas sendo as que resistiram aos testes mais rigorosos."114 (PROTZEN; HARRIS, 2010, p.235, tradução nossa). Consciente das implicações sociais dos problemas de design no

\footnotetext{
109 Do original em inglês: "Horst Rittel was a pragmatist in the sense that he was concerned with practical implications ..."

110 Do origin al em inglês: "someone who is concerned with the procedural aspects of an activity, in approaches to problems and their logic."

111 Protzen e Harris comentam a este respeito, que "Quando Rittel começou sua carreira, o otimismo no uso de métodos científicos e sistemáticos domi nava a cultura. A Racionalidade era soberana. Era muito do espírito dominante do dia, tendo crescido no poder e força ao longo do século anterior à medida que as maravilhas tecnológicas da Revolução Industrial mudavam o mundo. E aquelas maravilhas tec nológicas eram vistas em grande parte como produto do pensamento racional e do modelo científico. Tal otimismo científico entrou na sociedade em geral, per meando campos como a arquitetura e a arte." (PROTZEN; HARRIS, 2010, p.235, tradução nossa)

112 Ver: POPPER, K. R. A lógica da pesquisa científica. São Paul o: Cultrix, 1959/1972.

113 Do original em inglês: "In ordinary life, and in many of the professions, there is no equival ent guarantee for per manently challenging established truths. Ther efore, there are, in fields like architecture, few general theories and little testable knowledge." 114 Do original em inglês: "Design was supposed to be an open, transparent process where the differ ent issues, positions and arguments would be available to all those crucially involved, and the decisions that were made were those that withstood the most rigorous tes ting."
} 
contexto do planejamento, de acordo com a perspectiva emergente no ambiente acadêmico integrado da Universidade da Califórnia em Berkeley, ao final dos anos 1960, Rittel engendrou uma série de reflexões críticas, questionando a postura positivista vinculada à abordagem de sistemas e sua proposta de resolver os problemas de design, entendidos como os problemas de planejamento:

Em geral, pode-se dizer que a era de esperança e expectativa configurada nesta abordagem de sistemas tem se seguido de uma era de desapontamento. [...] Pode-se dizer semexagero que a abordagem clássica de sistemas não atingiu o esperado e em vários grandes projetos só pode ser considerada como uma falha. [...]A abordagem de sistemas é baseada emuma ideia científica ingênua que o cientista tem, um outro papel emadição ao papel tradicional de coletar ou produzir conheciment e oferecê-lo ao mundo, de atacar problemas práticos de modo que os ideais e princípios do fazer científico são transportados para o contex to de planejamento. Por que não é possivel fazer isso com sucesso no contexto dos problemas práticos de planejamento, corporativos ou outros? ${ }^{115}$ (RITTEL, 1972a/2010, p.152-153, tradução nossa)

Como resposta a este questionamento, Rittel (1972a/2010, p.153-158) of ereceu duas hipóteses, sendo que a primeira remete à crítica da própria concepção de racionalidade incorporada ao cerne da abordagem sistêmica, à medida que certas contradições lógicas, que o autor chama de "Paradoxos da racionalidade", ${ }^{116}$ representam a impossibilidade efetiva da

\footnotetext{
115 Do original em inglês: "In general it can be said that the era of hope and expectation set into this systems approach has been followed by an era of disappointment. [...] It can be said without exaggeration that the classical systems approach has not yielded what was expected of it and in a number of large projects can only be considered as a failure. [...] The systems approach is based on a certain naive scientific idea that the scientist has, in addition to the traditional role of gathering or producing knowledge and offering this to the world, a further role of attacking practical problems and that the ideals and principles of scientific work are carried over into the context of planning. Why is it not possible to do this successfully in the context of the practical planning problems, corporate or other?"

116 De acordo com Horst Rittel, podemos tomar como quatro paradoxos da racionalidade: 1. Não existe um modo de começar a ser racional: deve-se sempre começar em um passo anterior: "[...] antes que eu possa começar a traçar as consequências de minhas ações, eu deveria traçar as consequências de traçar as cons equências de minhas ações. Isto é com certeza, por sua vez, consequencial, porque eu investi tempo e dinheiro em traçar as consequências de traçar consequências, portanto, antes de traçar as consequências de traçar consequências, eu deveria traçar as consequências de traçar consequências de traçar consequências. E cada próximo passo não é necessariamente mais fácil ou mais simples que o anterior, porque as questões a responder tornam-se cada vez mais fundamentais." 2. Uma vez iniciado o processo traçar consequên cias, ele não pode mais ser parado: "Vamos supor que alguém consiga de alguma for ma ser racional. Ele está então traçando consequências, o que significa que ele tem a percepção de que todas as cons equências têm consequências, que por sua vez significa que não há razão para ele parar em qualquer ponto do tempo de traçar consequências, porque a cada cons equências es pera-se ter ainda mais outras. Portanto, uma vez que ele conseguiu começar a ser racional, ele não pode parar mais, ele só para por razões extralógicas ou extrarracionais, por exemplo se ele ficou sem tempo, dinheiro ou paciência." 3.Quanto mais alguém obtém sucesso em ser racional, mas isso o in capacita: "Isto é assim porque quanto mais des envol vem-se cadeias casuais de consequências para o futuro, mais os ef eitos da incerteza entr arão em vigor e quanto mais no futuro uma cadei a de efeitos causal é desenvol vida menos pode-se dizer qual des tes termi nais acabará por se tornar 0 caso c omo uma consequência de um curs o particular de ação. Isto significa que o melhor que se consegue ser racional, menos pode-se derivar do que deveria se fazer agora." 4. Paradoxo do autoconfinamento do modelo: "A fim de estudar as
} 
aplicação da racionalidade no processo de design / planejamento:

As razões mais importantes são paradoxos conectados ao conceito de racionalidade. A racionalidade tem muitas definições e eu vou escolher um particularmente simples: comportamento racional significa tentar antecipar as consequências das ações contempladas. Em outras palavas, pense antes de agir. A abordagem de sistemas de primeira geração implica esta obrigação de ser racional, o que significa que você tenta entender o problema como um todo, e olhar para as consequências [...] Va mos supor que alguém tente realmente ser racional neste sentido. Ele enão tentaria antedpar as consequências de cursos de ações altemativas: 'Eu posso fazer isso, ou aquilo, ou aquilo, mas antes de eu fazer a minha escolha eu devo descobrir quais consequências elas terão'. Ao fazer isso, ele descobre que antecipar as œnsequências é uma consequência por si só, porque leva tempo, esforço e dinheiro traçar consequências, porque é trabalho. [...] Portanto não há œmo começar a ser racional: deveria-se sempre œmeçar um passo atrás. ${ }^{117}$ (RITTEL, 1972a/2010, p.153-154, tradução nossa)

A outra hipótese proposta por Rittel (1972a, p.155) diz respeito à natureza dos problemas de design em si; neste sentido, Rittel atestou a ineficácia dos métodos racionais e científicos da abordagem sistêmica, usualmente aplicados na resolução dos problemas tradicionais do bojo da ciência, frente à natureza "capciosa"118 dos problemas enfrentados nas situações práticas de planejamento e processos de design, elencando uma série de conjunturas especiais destes problemas, como apresentaremos a seguir.

consequências das ações contempladas, um modelo (uma descrição casual dos fenômenos que são afetados pelas ações contempladas ou que afetam as ações) é necessário. Agora, este modelo deve, porque preocupa-se com todas as consequências, conter e descrever todos estes fatores ou fenômenos que são importantes. Mas o que é mais importante do que o modelo causal em si, que determina o que pode ser traçado como uma consequência? Portanto, o model o deve ser parte do modelo, porque influencia o que pode ser descoberto como consequência. Em outras palavras, um modelo deve conter em si, e isso é impossível." (RITTEL, 1972a:2010, p.153-154, tradução nossa)

117 Do original em inglês: "The most important reasons are deep-lying paradoxes connected with the concept of rationality. Rationality has many definitions and I shall choose a particularly simple one: rational behavior means trying to anticipate the consequences of contemplated actions. In other words, think before you act. The systems approach of the first generation entails this obligation to be rational, which means that you try to understand the problem as a whole, and to look at the consequences [..] Let us assume somebody seriously attempts to be rational in this sense. He would then try to anticipate the consequences of the alternative courses of actions: 'I can do this, or that, or that, but before I make my choice I must figure out what the consequences will be'. In doing this, he finds out that anticipating the consequences is consequential by its elf because it takes time, labor, and money to trace cons equences because it is work.[...] Therefore there is no way to start to be rational: one should always start a step earlier."

118 Aqui optamos pela utilização do termo "capcio so" em tr adução ao termo original em língua inglesa "wicked", segundo o dicionário Houaiss da Língua Brasileira, no senti do de: "que proc ura confundir", "que induz ao erro", "ar diloso". 


\subsubsection{Problemas Capciosos}

Protzen e Harris (2010, p.148) observam que a concepção de que os problemas do design e de planejamento têm características que os colocam à parte dos outros tipos de problemas foi apresentada inicialmente $^{119}$ por Horst Rittel e o urbanista Melvin Webber (1920-2006) em ocasião do Painel em Ciências Políticas da Associação Americana para o Avanço da Ciência ${ }^{120}$ em 1969, sob o título 'Dilemmas in a General Theory of Planning', publicada como artigo apenas quatro anos depois, em 1973, no jornal Policy Sciences (RITTEL; WEBBER, 1973). Neste trabalho, questionou-se a viabilidade real de uma teoria geral sistêmica contextualizando a compreensão moderna do planejamento como um processo de resolução de problemas, com base na perspectiva racional cientificista dominante no final do século XIX e primeira metade do século XX (RITTEL; WEBBER, 1973, p.158-160). Na investigação dos propósitos implícitos nesta visão (como o paradigma de 'eficiência' e a busca por valores 'ótimos' ou 'ideais' para situações problemáticas), os autores procuraram delimitar um dilema no âmago do planejamento contemporâneo:

[...] Estamos todos começando a perceber que um dos mais intratáveis problemas é o da definição de problemas (de saber o que distingue uma condição observada de uma condição desejada) e de localizar problemas (enœntrar onde nas complexas redes casuais 0 problema realmente está). ${ }^{121}$ (RITTEL; WEBBER, 1973, p.160, tradução nossa)

Frente este dilema, exprime-se a dificuldade em lidar com os problemas sociopolíticos, que os autores qualificam como 'capciosos'122, apontando a ineficiência da abordagem de resolução de problemas em voga, baseada nos procedimentos tradicionais aplicados pelas ciências e algumas engenharias ${ }^{123}$, distinguindo os problemas típicos destas áreas como

\footnotetext{
119 O filósofo e cientista de sistemas norte-americano Charles W. Churchman (1913-2004), amigo e colega de Rittel na Berkeley, também é refer enciado por ter introduzido o conceito de problemas capciosos de Rittel em artigo publicado no editorial da revista Management Science, da qual era membro da comissão editorial, em dezembro de 1967. Ver: CHURCHMAN, C. W. Wicked Problems. Man agement Science, v.4, n. 14.

120 Do original em inglês: "Panel on Policy Sciences of the American Association for the Advancement of Science"

121 Do original em inglês: "[...] we are all beginning to realize that one of the most intractable problems is that of defining problems (of knowing what distinguishes an observed condition from a desired condition) and of locating problems (finding where in the compl ex casual netw orks the trouble really lies)."

122 Sobre a escolha do termo em inglês 'wicked', Rittel e Webber afirmam que "Nós utilizamos o termo 'wicked' em um sentido semelhante ao de 'maligno' (em contraste com 'benigno') ou 'vicioso' (como um círculo) ou 'astucioso' (como um 'leprechaun') ou "agressi vo" (como um leão, em contraste com a docilidade de um cordeiro). (RITTEL; WEBBER, 1973, p.160 tradução nossa)

123 Cross, (1992, p.17) comenta como, a princípio, a conc epção de problemas capciosos confor me proposta por Rittel e Webber (1973) parece ter uma relevância relativizada com relação a campos do design de predominância tecnológica como as engenharias em geral, que continuam a desenvolver suas metodologias e procedimentos em design pautados no modelo racional científico da primeira metade do século XX. Este raciocínio nos parece valioso no sentido de contribuir para a
} 
'benignos' ou 'domesticáveis', por exemplo, problemas de matemática (a resolução de uma função, ou equação), a tarefa de um químico em descobrir a estrutura de algum composto desconhecido ou o problema de um jogador de xadrez tentando efetuar um xeque-mate em poucos movimentos (RITTEL; WEBBER, 1973, p.160). Segundo os autores, estes são problemas definíveis e separáveis (em um sentido propriamente cartesiano), enquanto os problemas capciosos são mal definidos e baseiam-se em julgamentos elusivos para a sua resolução ${ }^{124}$, ou seja, essencialmente a dificuldade em tratar os problemas capciosos está relacionada com suas formulações indefinidas, que respondem a interesses sociopolíticos instáveis e conflitantes, pelos quais os gestores carecem de meios de aferição, mensura ou mesmo critérios confiáveis para basear suas decisões ${ }^{125}$ (RITTEL; WEBBER, p.168-169). Deste modo:

\begin{abstract}
A busca por bases cientíicas para enfrentar problemas de política social está fadada ao fracasso, por causa da natureza destes problemas. Eles são problemas capciosos, ao passo que a ciência se desenvolveu para lidar com problemas domesticados. Problemas políticos não podem ser definitivamente descritos. Além disso, em uma sociedade pluralística não há nada como um interesse público indiscutível; não existe definição objetiva de equidade; políticas que respondem à problemas sociais não podem ser significativamente corretas ou falsas; e não faz sentido falar sobre "soluções ótimas" a respeib de problemas sociais a menos que qualificaọões severas forem impostas de antemão. Ainda pior, não existem soluções no sentido de respostas objetivas e definitivas. ${ }^{126}$ (RITTEL; WEBBER, 1973, p.155 tradução nossa)
\end{abstract}

Rittel e Webber apontaram uma série de atributos em definição dos 'problemas capciosos', que apresentamos na Tabela 02 em contraposição às características dos chamados 'problemas domesticados' de acordo com as formulações posteriores de Horst Rittel (1972aR2010, p.155-158):

compreensão das distinções entr e pensamento e pers pectivas de design com relação a campos como os da arquitetura e eng enharia ci vil, por exemplo.

124 De acordo com os autores, apropriadamente 're-solução', portanto 'não 'solução'. Os problemas sociais nunca são solucionados. Na mel hor das hipóteses eles são apenas ressolucionados outra vez e outra vez. (RITTEL; WEBBER, 1973, p.160, tradução nossa).

125 Esta questão é ilustrada pel a s eguinte colocação dos autores: "Nosso ponto, por outrolado, é que diferentes valores são mantidos por diferentes grupos de indivíduos, que o que satisfaz um pode aborrecer para o outro, que o que compreende a solução do problema para um é a geração do problema par a o outro. Sob tais circunstâncias, e na ausência de uma teoria social primor dial ou uma preponderante ética social, não há como distinguir qual grupo está certo e qual deveria ter os seus fins ser vidos." (RITTEL; WEBBER, 1973, p.169, tradução nossa)

${ }^{126}$ Do original em inglês: "The search for scientific bases for confronting problems of social policy is bound to fail, because of the nature of these problems. They are "wicked" problems, whereas science has developed to deal with "tame" problems. Policy problems cannot de definitively described. Moreover, in a pluralistic society there is nothing like the undisputable public good; there is no objective definition of equity; policies that respond to social problems cannot be meaningfully correct or false; and it makes no sense to talk about "opti mal solutions" to social problems unless severe qualifications are impos ed first. Even worse, there are no "sol utions" in the sense of definitive and objective answers". 


\begin{tabular}{|c|c|c|}
\hline $\begin{array}{l}\text { Problemas Domesticados } \\
\text { Tame Problems }\end{array}$ & $\begin{array}{l}\text { Problemas Capciosos } \\
\text { Wicked Problems }\end{array}$ & $\begin{array}{l}\text { Comentários de Rittel } \\
\text { Rittel's commentaries }\end{array}$ \\
\hline $\begin{array}{l}\text { 1.Podem ser formulados } \\
\text { exaustivamente } \\
\text { 1.Can be ex haustively } \\
\text { formulated }\end{array}$ & 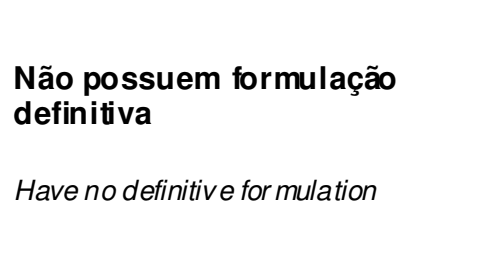 & $\begin{array}{r}\text { "Você não pode compreender o } \\
\text { problema sem resolvê-lo, e resolver o } \\
\text { problema é o mes mo que } \\
\text { compreendê-lo" }\end{array}$ \\
\hline $\begin{array}{l}\text { 2.Uma coisa é o problema } \\
\text { e outra a solução } \\
\text { 2. One thing is the problem and } \\
\text { another the solution }\end{array}$ & $\begin{array}{l}\text { Cada formulação corresponde } \\
\text { a uma afirmação da solução e } \\
\text { vice-versa } \\
\text { Every for mulation corresponds to a } \\
\text { statement of the solution and vice- } \\
\text { versa }\end{array}$ & $\begin{array}{l}\text { "Qualquer que s eja a afir mação é feita } \\
\text { sobre o problema é uma declaração de } \\
\text { solução. Isto é muito difer ente da noção } \\
\text { de um proble ema como a pri meira } \\
\text { geração ti nha em mente" } \\
\text { "Whichever statement is made about the } \\
\text { problem is a statement of sol ution. That } \\
\text { is very differ ent from the notion of a } \\
\text { problem as first-generation approach had } \\
\text { in mind" }\end{array}$ \\
\hline $\begin{array}{l}\text { 3.Existe uma solução } \\
\text { reconhecida e 'fixa' } \\
\text { 3.Ther e is a recognized and } \\
\text { 'fixed' solution }\end{array}$ & $\begin{array}{l}\text { Não há regra de parada para } \\
\text { os problemas capciosos } \\
\text { There is no stopping rule for wicked } \\
\text { problems }\end{array}$ & $\begin{array}{l}\text { "Você pode sempr e tentar melhorar e } \\
\text { não há nada na natur eza do problema } \\
\text { que poderia pará-lo" } \\
\text { "You can always try to do better and } \\
\text { there is nothing in the nature of the } \\
\text { problem that could stop you." }\end{array}$ \\
\hline $\begin{array}{l}\text { 4. Uma solução pode ser } \\
\text { testada e categorizada por } \\
\text { correto ou falso } \\
\text { 4.A solution can be tested and } \\
\text { categorized by 'correct or false' }\end{array}$ & $\begin{array}{l}\text { Não há sistema de critério ou } \\
\text { regra para validação de uma } \\
\text { solução, 'correto ou falso' não } \\
\text { é aplicável } \\
\text { There is no criterion system nor rule } \\
\text { for validating a solution i.e., 'correct } \\
\text { or false' is not applicable }\end{array}$ & $\begin{array}{l}\text { "Nós só podemos diz er que é bom ou } \\
\text { rui me isso em vários graus e talvez de } \\
\text { for mas diferentes para pessoas } \\
\text { diferentes, pois normal mente, o que é } \\
\text { bompara A não é bom para B" } \\
\text { "We can only say that is good or bad and } \\
\text { this to varying degrees and may be in } \\
\text { different ways for different people; for } \\
\text { nor mally, what is good for A is not good } \\
\text { to B" }\end{array}$ \\
\hline $\begin{array}{l}\text { 5. Existe uma lista } \\
\text { exaustível de operações } \\
\text { para chegar a soluções } \\
\text { 5.There is a exhaustible list of } \\
\text { operations to achi eve solutions. }\end{array}$ & $\begin{array}{l}\text { Não existe uma listagem } \\
\text { exaustível e enumerável de } \\
\text { operações para chegar a } \\
\text { soluções } \\
\text { There is no exhaustive, enumer able } \\
\text { list of permissible operations to } \\
\text { achieve solutions }\end{array}$ & $\begin{array}{r}\text { "Tudo ocorre como uma ques tão de } \\
\text { princípio e fantasia" }\end{array}$ \\
\hline $\begin{array}{l}\text { 6. Pode ser declarado como } \\
\text { uma discrep ância, algo } \\
\text { comparado com como algo } \\
\text { deveria ser. Há uma } \\
\text { explicação para a } \\
\text { discrepância, cau sa, t estável } \\
\text { e explicação } \\
\text { 6.Can be stated as a } \\
\text { discrepancy, something } \\
\text { compared with something as it } \\
\text { ought to be. There are a } \\
\text { explanation for the discrepancy, } \\
\text { testable cause and expl anation }\end{array}$ & $\begin{array}{l}\text { Pode ser declarado como uma } \\
\text { discr epância, algo comp arado } \\
\text { com como algo deveria ser. } \\
\text { Exist em várias explicações par a a } \\
\text { mesma discrep ância e nenhum } \\
\text { teste par a discernir a melhor } \\
\text { Can be stated as a discrepancy, } \\
\text { something compared with something } \\
\text { as it ought to be. There are many } \\
\text { explanations for the same } \\
\text { discrepancy and no test for the best } \\
\text { one. }\end{array}$ & $\begin{array}{r}\text { "Dependendo de qual explicação você } \\
\text { escolher para a discrepância, a solução } \\
\text { será levada em direções diferentes. A } \\
\text { direção em que a sol ução aponta } \\
\text { depende do passo inicial de investigação } \\
\text { (por que há um probl ema?)" } \\
\text { "Depending on which explanation you } \\
\text { choose for the discrepancy, the solution } \\
\text { will be led into different directions. The } \\
\text { direction in which the sol ution goes } \\
\text { depend on the very first step of } \\
\text { examination (why is there a problem?)" }\end{array}$ \\
\hline
\end{tabular}




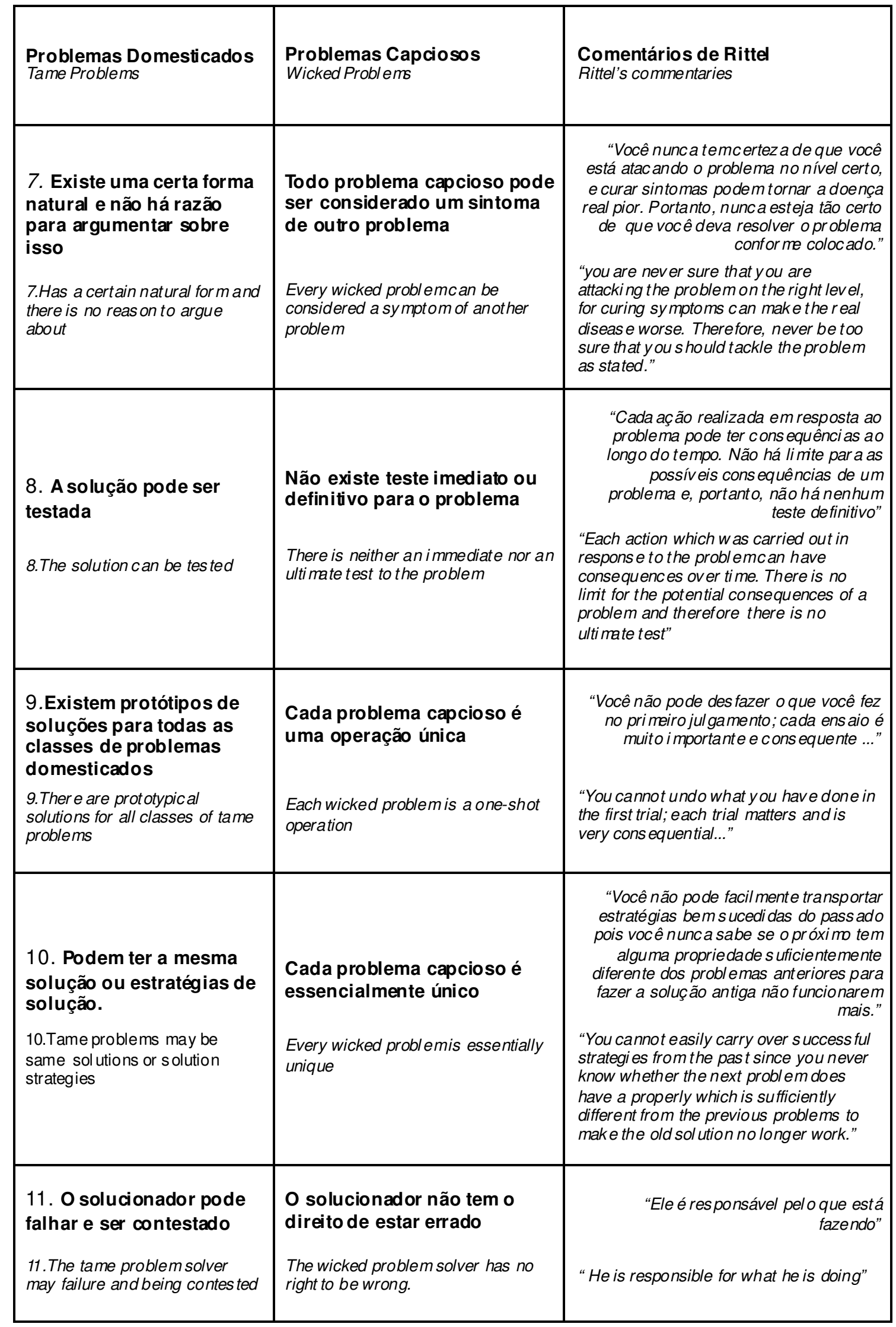


Sobre esta caracterização, Bazjanac fez a seguinte observação em respeito ao contexto particular da arquitetura:

Considerando as propriedades dos problemas capciosos é claro que praticamente todos os problemas de projeto arquitetônico são capciosos. Virtualmente todas as propriedades de problemas capciosos podem ser detectadas em qualquer problema de projeto arquitetônico: novas questões são continuamente levantadas na definição de uma solução de design, pode-se sempre adicionar à solução de projeto já formulada, nenhuma solução de design arquitetônico pode ser denominada 'correta' ou 'falsa', etc. Paralelos similares podem ser estabelecidos para cada propriedade dos problemas capciosos.27 (BAZJANAC, 1974, p.10 tradução nossa)

A abordagem dos problemas capciosos é bastante referenciada na pesquisa em design, desdobrando-se em discussões e investigações sobre a natureza do projetar conduzidas por teóricos e pesquisadores ao longo dos anos. ${ }^{128}$ É com base nesta abordagem que Rittel efetivou sua crítica reflexiva às ações dos métodos em design dos anos 1960, desenvolvendo o conjunto de assertivas que fundamentam sua proposta para uma 'nova geração' de métodos em design.

\subsubsection{Por uma segunda geração de métodos em design}

Horst Rittel promoveu uma série de ponderações teóricas sobre design e planejamento (conforme podemos observar em seu artigo 'Some principles for the Design of an Educational System for Design' (1971, p.16-27) de 1967, direcionado especificamente ao ensino de arquitetura), contemplando a crítica à postura tradicional dos métodos de design no seminal artigo 'On the Planning Crisis: Systems Analysis of the First and Second Generations' ${ }^{129}$. Neste trabalho, Rittel expôs a inadequação da abordagem dos métodos

\footnotetext{
127 Do original em inglês: "Considering the properties of wicked problems it is clear that virtually all architectural design problems are wicked. Virtually all properties of wicked problems can be detected in any problem of architectural design: new questions are continuously raised in the definition of a design solution; one can always add to an already for mulated design solution; no architectural design solution can be termed 'correct' or 'false', etc. Similar parallels can be established for every property of wicked problems."

${ }^{128}$ Neste sentido, podemos citar trabalhos como: BAZJANAC, V. Design Theory: models of the design process. In: SPILLERS, W. R. (ed.) Basic questions of Design Theory. New York: North Holland, 1974, p. 8-16; BUCHANAN, R. Wicked Problems in Design Thinking. Design Issues, MIT Press, v8, n.2, 1992, p. 5-21; COYNE, R. Wicked problems revisited. Design Studies, v.26, n.1, Janeiro, 2005, p.5-17, entre outros .

129 Publicado originalmente no periódico norueguês Bedrifts Økonomen. 8 (1972): 390-396. Nas indicações das citações no
} 
sistemáticos em design diante da natureza dos problemas capciosos e referindo-se a esta abordagem como uma 'primeira geração', apresentou uma série de apontamentos conceituais conformando a gênese do que acredita ser uma nova abordagem, uma 'segunda geração' do movimento (RITTEL, 1972aR2010, p.158-159, PROTZEN; HARRIS, 2010, p.148-149). Inaugura-se assim uma segunda fase para o movimento de métodos em design, uma resposta efetiva à 'situação de crise' que se anunciara alguns anos antes, como observou Cross (1992, p.16, tradução nossa):

\begin{abstract}
A Metodologia de Design estava emporariamente salva, entretanto, pela brilhante proposta de Rittel de 'gerações' de métodos. Ele sugeriu que os desenvolvimentos dos anos 1960 tinham sido apenas métodos de 'primeira geração' (o que naturalmente, em reconhecimento à realidade pode parecer pouco simplista, mas de qualquer forma era um começo necessário) e que uma nova segunda geração estava começando a emergir. Esta sugestão foi brilhante porque permitiu aos novos metodologistas escapar de seu compromisso comos métodos inadequados da 'primeira geração', e abriu uma perspectiva de umfuturo infindável para gerações sobre gerações de novos métodos. ${ }^{130}$
\end{abstract}

As colocações de Rittel (1972a, p.158) basearam-se na afirmação da existência de incompatibilidades entre os procedimentos sequenciais e operacionais de resolução de problemas usualmente adotados pela primeira geração de métodos em design (representados, por exemplo, pelo modelo de design como um processo linear de 'análise, síntese e avaliação') frente às propriedades dos problemas capciosos. O autor observou que, essencialmente, a compreensão de um problema implica na adoção inevitável de uma perspectiva de solução, de modo que "você não pode obter informação sem ter uma ideia da solução, porque a questão que você pergunta depende da natureza da solução que você tem na mente." ${ }^{131}$ (RITTEL, 1972a, p.158, tradução nossa). Deste modo, a geração de soluções não pode ser considerada um 'passo' sequenciado do processo do design, pois "com o primeiro passo de explicar o problema você já determina a natureza da solução. A primeira

corpo de nosso texto remetemo-nos à versão publicada em PROTZEN, J.; HARRIS, D. J., (ed), The universe of Design Horst Rittel's Theories of Design and Planning. Ed. Routledge, 2010.

130 Do original em inglês: "Design methodology was temporarily saved, however, by Rittel's (1973) brilliant proposal of "gener ations" of methods. He suggested that the developments of the 1960s had been only "first generation" methods (with naturally, with hindsight, seemed a bit simplistic, but nonetheless had been a necessary beginning) and that a new second generation was beginning to emerge. This suggestion was brilliant because it let the new methodologists escape from their commitment to inadequate "first gener ation" methods, and it opened a vista of an endless future of generation upon generation of new methods."

131 Do original em inglês: "So you cannot get infor mation without having an idea of the solution, bec ause the question you ask depends on the nature of sol ution you have in mind." 
declaração de problema já é uma declaração de solução. Você não pode separar a geração de soluções da compreensão do problema, etc." ${ }^{132}$ (RITTEL, 1972a, p.158, tradução nossa). Ao explicitar esta relação entre a compreensão de um problema e a determinação de sua solução, Rittel procura situar a efetividade dos métodos de resolução de problemas baseados na lógica racionalista, como os empregados na área de pesquisas operacionais $^{133}$, ressaltando o modo como o estabelecimento prévio de decisões e as escolhas determinantes envolvidas nos processos de design, mesmo as considerações sobre parâmetros restritivos e premissas, são comumente desconsideradas nestes procedimentos de resolução de problemas:

[...] PO começa quando o capcioso está fora do problema, uma vez que voœ̂ tenha dib o que uma solução boa, admissivel, viável é. Você pode dizer: 'As restrições são naturalmente dadas'. Mas isso não é assim. Cada restrição representa uma decisão, essencialmente uma decisão de resignação. [...] é só que você resigna-se à existência irremovivel de uma circunstância crítica. A restrição não é absolutamente uma entidade lógica e técnica objetivamente dada; cada restrição ou limitação que œloœ no meu espaço de ação é uma decisão, ou pelo menos uma indicação implícita de resignação. ${ }^{134}$ (RITTEL, 1972a/2010, p.159, tradução nossa).

A 'segunda geração de métodos em design' como defendida por Rittel apresenta-se como uma revisão da abordagem sistêmica que, consciente da dimensão sociopolítica das decisões que conformam os processos de resolução de problemas, orienta seu foco sobre o modo como seus agentes estabelecem julgamentos e decisões acerca dos problemas capciosos (PROTZEN; HARRIS, 2010, p.235). Rittel (1972a) propôs alguns princípios conceituais para esta abordagem, dentre os quais destacamos 'simetria de ignorância', 'transparência' e

\footnotetext{
132 Do original em inglês: "With the first step of explaining the problem you already deter mine the nature of the solution. The first statement of problem is already a statement of solution. You cannot separate the generation of solutions from understanding the problem etc."

133 A 'Pesquisa Operacional - PO - Operational Research - OR' também conhecida como 'Investigação Operacional Operational Investigation - 10', é um ramo interdisciplinar da matemática aplicada que faz uso de modelos matemáticos, estatísticos e de algoritmos na aj uda à tomada de decisões. É us ada sobr etudo para analisar sistemas complexos através de modelagem com o objeti vo de melhorar ou oti mizar a performance de uma ação neste sistema. O físico norte-americano Philip McCord Morse (1903-1985) pioneiro da pesquisa operaci onal na Segunda Guerra M undial é considerado uma das referênci as do campo nos Estados U nidos. Para uma compreens ão expandida do tema ver: MORSE, P.M.; KIMBALL, G. E. Methods of Operational Research, OEG Report (Classified), 1942-45.

134 Do original em inglês: "[...] OR starts once the wickedness is out of the problem, once you have said what a good admissible, feasible sol ution is. You can say: 'Constraints are naturally given'. But that is not so. Every constraint repres ents a decision, mainly a decision of resignation. [...] it is only that you resign yourself to the irremovable existence of a critical circumstance. The cons traint is not at all a technical and objectively given logical entity; every cons traint or limitation I pose on my action space is a decision, or at least an implicit indic ation of resignation."
} 
'objetificação', que culminam na concepção de 'design como argumentação' que segundo Protzen e Harris $(2010, p .168)$ tornou-se o referencial para todo o desenvolvimento posterior do trabalho de Rittel ao longo de sua carreira.

Horst Rittel (1972a/2010, p.159-160) argumentava em favor da atividade do planejamento/design como um processo essencialmente participativo, de modo que as pessoas afetadas pelas ações de planejamento fossem envolvidas ativamente no processo de planejamento. $O$ autor evidenciou a necessidade de uma revisão sobre as atribuições profissionais tradicionalmente conferidas aos então 'especialistas e peritos' do planejamento ${ }^{135}$, a partir da proposição de que, frente à natureza inconstante dos problemas capciosos, tanto as habilidades necessárias para seu trato, quanto a ignorância sobre os mesmos estão igualmente distribuídas entre os diversos atores envolvidos na situação: "A perícia e a ignorância é distribuída sobre todos os participantes em um problema capcioso. Há uma simetria de ignorância entre aqueles que participam, porque ninguém sabe melhor em virtude de seu grau ou seu status."136 (RITTEL, 1972a/2010, p.159, tradução nossa). Portanto, podemse considerar os agentes do planejamento como especialistas em conduzir o processo projetual, mas não sobre o assunto do problema em si. O autor ressalta do mesmo modo a compreensão da necessidade de exposição dos propósitos, assunções, valores e direcionamentos individuais e coletivos incorporados no julgamento destes agentes ${ }^{137}$, o conjunto de elementos denominado 'premissas deônticas'138, que Rittel considera determinante no processo de tomada de decisões, sublinhando que o processo projetual

\footnotetext{
135 Rittel vê o planejador um agente que de forma cuidadosa e respeitosa faça da dúvida sobre algo uma virtude, mas de modo moderadamente 'otimista'; sua situação é delicada, pois planejar com responsabilidade envolve ser racional, uma condição impossível de ser alcançada objetivamente. Sobre esta reflexão, Rittel propõe que: "O modelo que você pode usar em vez do modelo especialista da primeira geração pode ser chamado de um modelo de conspiração de planejamento. Isso significa que, porque não podemos antecipar todas as consequências dos nossos planos, cada plano, cada tratamento de um problema capcioso é uma ventura, se não uma aventura. Portanto, vamos compartilhar o risco, vamos tentar encontrar cúmplices que estão dispostos a embarcar no problema com a gente. Para uma pessoa é muito arriscado, mas talvez se juntar mos nossas forças, podemos assumir o risco e viver com a incerteza e embarcar na aventura. Esta parece ser uma posição um tanto s ustentável para jus tificar a corag em em pl anejar de qualquer modo." (RITTEL, 1972a/2010, p.162, tradução nossa)

136 Do original em inglês: "The expertise and ignorance is distributed over all participants in a wicked problem There is a symmetry of ignorance among those who participate because nobody knows better by virtue of his degrees or his status."

137 De modo similar à proposta de Alexander (1964), observando a incorporação destes na configuração de um processo argumentati vo explícito. Aqui a intenção subjacente de promover uma comunic ação efeti va no proc esso projetual é reafirmada. ${ }^{138} \mathrm{O}$ adjetivo 'deôntico' expresso no pensamento de Rittel, diz respeito à resignações de desejo, da vontade, propósito ou idealização de algo com bas e na experiência do indi víduo que o expr essa - é utilizada para definir uma modalidade linguística e um ti po de lógica - lógica deôntica, que trata do mundo do "deveria" como uma possi bilidade lógica. Para maior compreensão ver: HILPINEN, R. (ed.) New Studies in Deontic Logic: norms, actions, and the foundations of ethics. Dordrecht Holland: D. Reidel Publishing Company, 1981.
} 
fundamenta-se no domínio político em detrimento do científico: "Não há planejamento científico. O Lidar com problemas capciosos é sempre político. Não há aquela atitude objetiva, científica, imparcial no planejamento; ele é sempre político devido a estas premissas deônticas." ${ }^{\text {139 }}$ (RITTEL, 1972a/2010, p.161, tradução nossa). Deste modo:

[...] quando você desenvolve uma solução para um problema capcioso, a cada único passo é feito um julgamento que não é baseado em conhecimentos científicos. Há sempre uma declaração 'deveria-ser-assim' envolvida. Para cada etapa há uma conclusão que termina com 'fazer isto e aquilo'. Esta é a chamada 'premissa deôntica', ou seja, uma premissa pessoal de natureza do 'deveria-ser' que não se justifica pela experiência profissional, mas é apenas uma indicação de atitudes éticas, morais gerais e políticas. Portant, se você olhar apenas o resultado do proœsso de planejamentb, você não pode reœnstruir as declarações deônticas que entraramna argumentação levando a solução. [...] há a necessidade de olhar para os métodos que mostram alguma transparência do processo de planejamento. Esses métodos devem levar a uma situação em que cada passo do processo é compreensível e comunicável ou 'transparente'. ${ }^{140}$ (RITTEL, 1972a/2010, p.160, tradução nossa)

A segunda geração do movimento de métodos em design, como proposta por Rittel (1972aR2010, p.161), deveria, portanto, atentar à exteriorização e registro das 'premissas deônticas' dos envolvidos no processo de planejamento, de modo que os julgamentos conformados por estas premissas fossem passíveis de 'objetificação'141, isto é, assumissem uma configuração formal determinada. Retoma-se aqui o sentido original proposto por Alexander (1964) e Jones (1970) do método como facilitador da comunicação e crítica do processo projetual, porém foca-se na elaboração de estruturas concernidas às premissas deônticas dos agentes deste processo, e não à imposição de ordens baseadas nos princípios da racionalidade. Consequentemente, Rittel avança na formulação da concepção

\footnotetext{
139 Do origin al em inglês: "There is no scientific planning. Dealing with wicked problems is always political. There is not that detached, scientific, objective attitude in planning; it is always political becaus e of these deontic premises."

140 Do original em inglês: "[...] when you develop a solution to a wicked problem, at every single step a judgment is made that is not based on scientific expertise. There is always a 'ought-to-be' statement involved. For each step there is a conclusion that ends with 'do this and that'. This is so-called 'deontic premise' i.e. a personal premise of the 'ought-to-be' nature that is not justified by professional expertise but is only an indication of political and general moral and ethical attitude. Therefore, if you look only at the outcome of the planning process, you cannot reconstruct the deontic statements have enter ed into the argument leading to solution. [...] there is the need to look for methods which show some transparency of the planning process. These methods should lead to a situation where every step of the planning process is understandable and communicable or 'transpar ent' ".

141 Rittel ressalta a distinção no emprego do termo 'objetificação' e o sentido tradicional de obj eti vidade científica: "Isso é diferente de fazer algo objetivo, porque fazer algo objetivo no sentido científico significa que você inventar um proc edi mento, cujo res ultado torna-se independente da pess oa que o realiza [...] F alamos de uma situação objeti va ou uma operação levando a proposições objetivas: o quanto menos faz diferença quem realiza o mais obj etivo o resultado seria. Mas como vimos, aqui importa quem julga, ou quem faz a declaração, ou quem passa pelo processo de planejamento." (RITTEL, 1972a/2010, p.160 traduçãonossa)
} 
do processo projetual propondo o redirecionamento dos esforços de pesquisa sobre métodos sistêmicos no sentido de auxílio ao planejamento, entendido como processo compartilhado de negociação, em que os argumentos que definem posicionamentos e compreensões distintas são ponderados e discutidos entre seus representantes:

Considerando que o processo de planejamento da primeira geração pode ser conduzido em confinamento solitánio, com longas sequências de passos onde você pode proceder de acordo com as regras da are, o processo de planejamento da resolução de problemas capciosos deve ser entendido como um processo argumentativo: um que levante questões e controvérsias para o qual voœê pode assumir diferentes posições, com as evidêndias coletadas e argumentos construídos a favor e contra estas diferentes posições. As várias visões são discutidas, e depois uma decisão é tomada e proœde aḱ que a próxima questão surge dentro do proœsso. [...] Cada questionamento de decisão pode ser combinado com umargumento e na verdade fazemos isso o tempo todo: nós deliberamos nosso julgamento, e qual é a deliberação que não identificação e ponderação de prós e contras, simulando debates e argumentos em sua cabeça? Métodos sistêmicos de segunda geração estão tentando tomar esta deliberação explícita, para apoiá-la e encontrar meios para tomar este processo mais poderoso e para tê-lo sob melhor controle. O planejamento é um proœsso argumentativo. ${ }^{142}$ (RITTEL, 1972a/2010, p.162, tradução nossa)

É através desta caracterização de uma perspectiva sistêmica de ênfase nos processos argumentativos que Rittel (1972a) delineou a abordagem conhecida como 'segunda geração de métodos' em distinção à 'primeira geração de métodos', como observou Cross (1992):

A primeira geração (dos anos 1960) foi baseada na aplicação de métodos sistemáticos, racionais e 'científicos'. A segunda geração (do começo dos anos 1970) se afastou das tentativas de otimização e da onipotência do designer (especialmente com relação à problemas capciosos), em direção do reconhecimento de tipos de soluọões satisfatórias ou apropriadas (Simon em 1969 tinha introduzido a œncepção de 'satisfatório') e um proœsso 'argumentativo' participativo em que designers são parœiros dos 'donos' dos problemas (clientes, consumidores, usuários, a comunidade). ${ }^{143}$ (CROSS, 1992, p.17, tradução nossa)

\footnotetext{
142 Do original em inglês: "Whereas the planning process of the first generation can be carried out in solitary confinement with long sequences of steps where you can proceed according to the rules of the art, the planning process of wicked problem solving must be understood as an argumentative process: one of raising questions and issues tow ards which you can assume different positions, with the evidence gathered and arguments built for and against these different positions. The various positions are discuss ed, and after a decision is taken one proceeds until the next question arises within the process. [...] Each question of decision can be combined with an argument and actually we do this all the time: we deliberate our judgment and what is deliberation other than identifying and weighing pros and cons, simulating debates and arguments in your head? Systems methods of the second generation are trying to make this deliberation explicit, to support it and to find means in order to make this process more powerful and to get it under better control. Planning is an argumentative process."

143 Do original em inglês: "The first generation (of the 1960s) was based on the application of systematic, rational, 'scientific'
} 
Desta forma colocou-se um novo horizonte para a pesquisa sobre o processo projetual, de especial relevância para a arquitetura. A visão de design como argumentação possibilitou a compreensão de aspectos do projetar então eclipsados pelas propostas anteriores dos métodos em design, em favor dos quais Rittel contemplou o desenvolvimento de sistemas de planejamento, ferramentas para a visualização e registro de informações a partir das premissas deônticas dos agentes do processo projetual, e dos caminhos abertos por seus julgamentos, decisões e posicionamentos, como apresentaremos na sequência.

\subsubsection{Argumentação e sistemas de Plane jamento}

De acordo com a concepção de Rittel de design como argumentação (1967/1971; 1972a; 1972b; 1987), podemos nos referir ao projetar como um processo decisório, onde posicionamentos distintos originam múltiplas possibilidades concorrentes em busca de soluções para problemas, que são aceitas ou negadas através de negociações em diversas escalas de amplitude, culminando no estabelecimento de acordos e comprometimentos necessários às coordenações de ações envolvidas na efetivação do plano ou projeto, o produto deste processo de design. Deste modo:

O raciocínio do designer apareœ como um processo de argumentação. Ele debate consigo mesmo ou co m outros; questões surgem, posições que competem são desenvolvidas em resposta a elas, e uma procura é feita sobre seus respectivos prós e contras, finalmente, ele faz sua opinião em favor de alguma posição, com frequênda após revisão profunda das posições. Neste modelo de design como argumentação, as várias questões estão interligadas de forma complexa, normalmente várias delas são 'abertas' simultaneamente, outras são adiadas ou reabertas. Ele se encontra em um campo de posições com argumentos concorrentes que ele deve avaliar de forma a assumir sua própria posição. ${ }^{144}$ (RITTEL, 1987/2010, p.189, tradução nossa)

methods. The second generation (of the early 1970s) moved away from attempts to optimize and from the omnipotence of the designer (especially for wicked problems), towards recognition of satisfactory or appropriate sol ution-types (Simon 1969 had introduced the notion of 'satisficing') and an 'argumentative', participatory process in which designers are partners with the problem 'owners' (clients, cus tomers, users, the community).

144 Do original em inglês: "The designer's reas oning appears as a process of argumentation. He debates with hims elf or with others; issues come up, competing positions are developed in respons e to them, and a search is made for their respective pros and cons; ultimately he makes up his mind in favor of some position, frequently after thorough modification of the positions. In this model of design as argumentation, the various issues are interconnected in intricate ways; us ually several of them are "open" simultaneously, others ar e postponed or reopened. He finds hi ms elf in a field of positions with competing arguments with he must ass ess in order to assume his own position" 
Observamos que os apontamentos de Rittel (1972a) acerca de princípios fundamentais para uma 'segunda geração de métodos' basearam-se na compreensão de que a formulação de um problema capcioso dependia essencialmente das chamadas 'premissas deônticas', e que esta formulação é constantemente revista à medida que as premissas deônticas são também revistas, pelo desenvolvimento igualmente dinâmico da compreensão do problema, e portanto, "não há uma separação clara das atividades de definição, s íntese e avaliação de problema. Todos estes ocorrem o tempo todo. [...] Aprender o que é o problema $E$ o problema." ${ }^{145}$ (RITTEL, 1987/2010, p.188-189, tradução nossa). O projetar envolve, portanto, a revisão contínua de posicionamentos, à medida que, por exemplo, julga-se como apropriada a posição do outro: este processo depende da formalização da argumentação de seus participantes, a 'objetificação', proposta por Rittel (1972a, p.161), que "significa o intercâmbio de informações entre os interessados, a fim de chegar a um entendimento mútuo." ${ }^{146}$ (RITTEL, 1972b/2010, p.171, tradução nossa).

Por 'informação', Rittel compreendeu o processo pelo qual transformações são produzidas no conhecimento do indivíduo (RITTEL, 1967/1971, p.19). O autor distinguia dois tipos de informação: 'interna', atribuída ao raciocínio na mente do planejador e 'externa', que é a informação compartilhável (através de 'objetificação') obtida pela exteriorização do raciocínio dos agentes do planejamento e também pelo lidar com as situações problemáticas (RITTEL, 1972b, p.174). Sobre este último tipo, observou ainda a possibilidade de elaboração de 'sistemas de informação', estruturas de suporte ao registro, visualização e manipulação de informação. Retomando a premissa fundamental da interdependência entre formulação do problema-solução, o autor afirmou que:

O planejamento pode ser entendido como um processo no qual as informações relevantes de problemas podem ser produzidos e processados. Um dos pontos era que a formulação do problema é idêntica à resolução do problema. Segue-se que, do ponto de vista do pesquisador de sistemas da 'segunda geração', o projeto de um sistema de planejament é 0 mesmo que o projeto do sistema de informação de planejamento. ${ }^{147}$ (RITTEL, 1972b/2010,

\footnotetext{
145 Do original em inglês: "There is no clear separation of the activities of problem definition, synthesis, and evaluation. All of thes e occur all the time. [...] Learning what is the problem IS the problem."

146 Do original em inglês: "objetification in planning means exchanges of infor mation among those concerned in order to reach mutual understanding."

147 Do original em inglês: "Planning can be understood as a process in which problemrelevant infor mation can be produced and processed. One of the points was that problem formulation is identical with problem resolution. It follows that, from the viewpoint of the 'second generation' system researcher, the design of a planning system is the same as the design of the
} 
p.171, tradução nossa)

A partir dos anos 1970, Rittel dedicou parte de seus esforços de pesquisa ao desenvolvimento de sistemas de informações de planejamento ${ }^{148}$, que também podem ser compreendidos como sistemas de gestão de conhecimento de design (PROTZEN; HARRIS, 2010, p.168). Para Rittel, estes sistemas diferem de outros sistemas 'técnico-científicos' compostos de informações factuais e explanatórias, uma vez que incorporam informações deônticas visando à obtenção de conhecimento ${ }^{149}$ desta ordem: "[...] o que é necessário acima de tudo, e é postulado pela abordagem de sistemas de segunda geração, é que o conhecimento deôntico deveria ser muito mais explícito e externalizado no sistema de planejamento que tem sido o caso até ag ora." ${ }^{\text {150 }}$ (RITTEL ,1972b/2010, p.176, tradução nossa). Um exemplo neste sentido é o IBIS, Sistema de Informação Baseado em Assuntos - 'Issue Based Information System', uma classe de sistemas de informação desenvolvida por Rittel para a documentação e visualização de informações organizadas em 'assuntos', que são questões controversas, ou seja, que possuem mais de uma resposta e, portanto, podem ser contestadas por posições distintas (RITTEL, 1972b/2010, p.178). É um sistema para capturar e gravar as deliberações de design, para o reconhecimento e colocação de todas as questões que foram suscitadas em seu processo:

IBIS é essencialmente uma ajuda mnemônica. Não é uma tentativa de fomeœr uma representação completa do conhecimento [...] Nem é semelhante a sistemas expertbs - IBIS não tenta fazer sugestões para o usuário, não diz qual é a coisa certa a fazer, simplesmente tenta apresentar todas as questões, posições e argumentos que o designer pode pensar, todos os argumentos e posições que olham para os lados distintos de uma determinada questão. ${ }^{151}$ (PROTZEN; HARRIS, 2010, p.169, tradução nossa)

planning infor mation system"

148 Protzen e Harris (2010, p. 168) relatam que Rittel, ao longo de sua pesquisa, trabalhou em uma série de sistemas de informação em auxílio a processos de planejamento e design, como o caso do sistema APIS - 'Argumentative Planning Information System' des envolvi do no projeto de Infor mação Tecnológica e Científica da Comunidade Europeia do Diretório Geral da Comissão da Comunidade Europeia; e também o sistema UMPLIS - 'Umweltplanungs-informationsystem' desenvolvido para a coordenação de atividades ambientais e políticas de várias agências governamentais, e os poderes executivo e legislativo do Governo alemão na década de 1970.

149 A partir deste referencial, o autor reformul a o enunciado que descreve o raciocínio do projetar, afirmando que o designer "começa com uma discrepância entr e o conheci mento factual e o deôntico, procura por explicações de como as coisas são e como deveriam ser, e estas explicações Ihe dão dicas sobre o conhecimento instrumental que ele precisa para superar esta discrepância" (RITTEL, 1972b/2010, p.176, tradução nossa).

150 Do original em inglês: "[...] what is needed above all, and is postulated by the sys tems approach of the second generation, is that deontic knowledge should be much more explicit and externalized in the planning system than was the case until now."

151 Do original em inglês: "IBIS is essentially a mnemonic aid. It is not an attempt to provide a full representation of 
Observa-se assim, como característica importante dos sistemas de informação de planejamento como o IBIS a possibilidade de acomodação de contradições: "Uma pessoa diz que uma cidade é superpovoada enquanto a outra diz que é despovoada. Desde que nós dissemos que aceitamos a 'simetria de ignorância', nós deixamos ambas as opiniões em nosso sistema de informação." ${ }^{152}$ (RITTEL, 1972b/2010, p.177, tradução nossa). Desta forma, ao invés de evitar ou procurar resolver a dimensão do conflito inerente ao projetar, Rittel propõe sua incorporação e explicitação através do sistema de planejamento, representando assim uma inovação com relação à postura dos métodos de design dos anos 1960. Esta postura vincula-se diretamente com a concepção de argumentação, conforme observaram Protzen e Harris:

[...] Rittel quis dizer argumentação para levantar dúvidas, questionar suposições, para frustrar patologias, para descobrir conflitos de interesse, para desafiar meios propostos e fins, para contestar argumentos, em outras palavras, não para chegar a um consenso, mas para ativar os confitos não vistos e ditos. [...] 0 modelo de planejamento como argumentação fomece a base na qual os conflitos entre as partes envolvidas se articulam $e$ avenidas que podem levar a resoluções são abertas. ${ }^{153}$ (PROTZEN; HARRIS, 2010, p.228229 , tradução nossa)

É com base nesta compreensão que reconhecemos o modelo de argumentação de Rittel como pertencente ao horizonte da conversação, à medida que se apresentam os elementos típicos deste processo, a que nos deteremos de maneira pormenorizada na continuação de nosso trabalho. Aqui, convém sublinhar a relevância da concepção de liberdade epistêmica do projetar, com base nas observações tardias do autor ${ }^{154}$.

knowledge [...] Nor is it akin to expert systems -IBIS does not attempt to make sugges tions to the user; it does not say what the right thing to do is, it simply attempts to present all the issues, positions and arguments that the designers can think of it, all the arguments and positions that look at the different sides of a given issue."

152 Do original em inglês: "One person says a town is overpopulated whereas another says it is underpopulated. Since we have said that we accept the 'symmetry of ignorance', we leave both opinions in our information system." De forma complementar o autor obser va que é importante saber quem são os res ponsáveis pelas ass erti vas.

153 Do original em inglês: "[...] Rittel also meant argumentation to raise doubts, to question assumptions, to frustrate pathologies, to uncover conflicts of interest, to challenge proposed means and ends, to contest arguments, in other words, not to reach cons ens us, but to activate uns een and unspoken conflicts. [...] The model of planning as argumentation provides the grounds on which conflicts among the involved parties get articulated and avenues are opened that may lead to resolutions."

154 Embora fundamental a todo o raciocínio de Horst Rittel, a concepção de liberdade epistêmica é apontada pelo mes mo em artigo de 1987, poucos anos antes de sua morte. (RITTEL, 1987/2010) 


\subsubsection{A liberdade epistêm ica no projetar}

A fim de ilustrar a natureza argumentativa do racioc ínio envolvido no projetar, Rittel (1987/2010, p.189) propôs a Figura 13, que apresenta uma estrutura hipotética de raciocínio de um designer, uma rede de cursos alternativos de respostas a partir da proposição de um assunto típico (no caso 'deveria 'A' ser incorporado no plano?'). O autor observou que basicamente o designer pode adotar três posições: uma afirmativa, uma negativa e uma de questionamento: assim as escolhas conduzem à adoção de um de três caminhos para cada tomada de decisão; em contrapartida, em qualquer ponto de tomada de decisão na estrutura de raciocínio em que surja um questionamento, abre-se a possibilidade de expansão de um número indeterminado de estruturas em paralelo, que podem tanto conduzir a novos desdobramentos como retroceder de maneira que o designer adote um dos outros caminhos iniciais como abandonar 'A', incorporar ' $A$ ' ou mes mo o desenvolvimento de todo um novo assunto 'B' vinculado a esta estrutura de raciocínio original (RITTEL, 1987/2010, p.191).

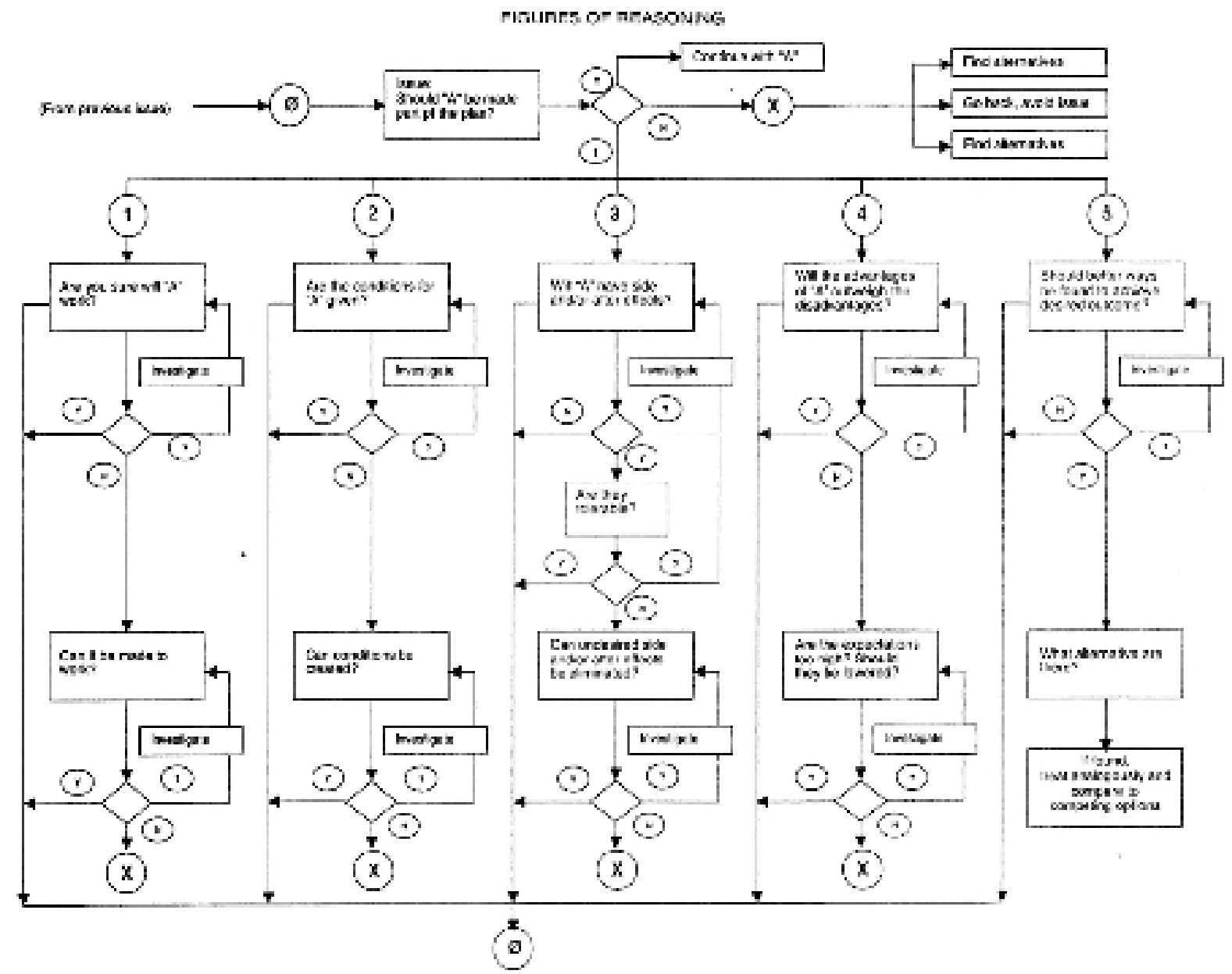

Figura 13 - Estrutura de raciocínio de um designer sobre a consideração do assunto: "Devo incorporar 'A' como parte do plano?" . Fonte: (Rittel, 1987/2010, p.189). 
Rittel (1987/2010, p.191) observou que nesta estrutura, o processo de raciocínio configura-se essencialmente como um de formação de juízos, no qual a compreensão da situação muda conforme o designer percorre os diferentes caminhos alternativos, à medida que, por exemplo, novas informações são incorporadas na estrutura como fatos ou premissas deônticas vinculadas à meios para a obtenção de fins estipulados. Em consequência disto, o percurso de deliberações realizado influencia nos juízos subsequentes da mesma forma, acumulando uma rede complexa de dependências deônticas ou fatuais de modo que "[...] todas as deliberações terminam com julgamentos (ex. 'bom o suficiente!') que podem ser baseados nas deliberações, mas não são derivados delas. Olhando para os vários prós e contras, o designer tem 'feito sua cabeça'. Como isso acontece, está além do raciocínio." ${ }^{155}$ (RITTEL, 1987/2010, p.192, tradução nossa). Neste sentido, o autor afirmou que:

\begin{abstract}
A análise revela a incrivel liberdade epistêmica em projetar: não há restrições lógicas ou epistemológicas ou regras que prescrevam qual dos vários passos significativos deva-se tomar em seguida. Não há 'algoritmos' para guiar o processo. É deixado para o julgamento do designer como proœder. Não há lógica ou outra necessidade de querer fazer algo em especial em resposta a uma questão. Nada tem de ser ou permanecer œmo está ou como se parece ser, não há limites para o concebível. Há uma falta de 'razão suficiente', que ditaria tomar um curso partiaular de ação e não outro.156 (RITTEL, 1987/2010, p.192, tradução nossa)
\end{abstract}

A liberdade epistêmica é uma das características determinantes do raciocínio de projeto: "Projetar depende decisivamente e em cada passo do raciocínio da visão de mundo do designer. Não existe design objetivo, neutro." ${ }^{157}$ (RITTEL, 1987/2010, p.192, tradução nossa) Com base nesta premissa, retomamos as obsenações levantadas por Rittel (1972aR210, p.153-155) com relação às restrições no emprego da racionalidade nos processos de resolução dos problemas de design, pela afirmação de que "não há algoritmo que pode ser usado para

\footnotetext{
155 Do original em inglês: "[...] all deliberations ter minate with judgments (E.g. "Good enough!") which may be "based on the deliberations, but are not derived from them. Looking at the various pros and cons, the designer has "made up his mind". How this happens is beyond reasoning.

156 Do original em inglês: "The analysis reveals the awesome epistemic freedom in designing: there are no logical or epistemological constraints or rules that would prescribe which of the various meaningful steps to take next. There are no "algorithms" to guide the process. It is left up to the designer's judgment how to proceed. There is no-logical or other necessity to want or to do something particular in response to an issue. Nothing has to be or to remain as it is or as it appears to be; there are no limits to the conceivable. There is a lack of "sufficient reas on" which would dictate to take a particular course of action and no other."

157 Do original em inglês: "Designing depends decisively and at every step of reas oning on the world view of the designer. There is no neutral, objective design"
} 
determinar todas as formulações possíveis de problemas. [...] Por que não? Racionalidade é limitada por certos paradoxos que não podem ser evitados." 158 (PROTZEN; HARRIS; CAVALLIN; 2000 , p.50, tradução nossa). Isto deve-se à seguinte questão:

Para fazer um modelo que capture todas as informações relevantes que o designer usa para tomar decisões, nós precisaríamos capturar informações não só sobre o mundo físico, mas também informações sobre as mentes do designer e sobre os outros participantes importantes no processo de design, tudo o que seria significativo para delinear as possibilidades do que o designer poderia considerar. Algo significante neste esforço seria incluir um modelo do modelo que está sendo usado - porque claramente este modelo é uma parte significativa do mundo da tomada de decisão. E nisso reside o paradoxo: o modelo deve incluir a si mesmo. 0 modelo do modelo deve incluir um modelo do modelo do modelo, e assim por diante, em regressão infinita. ${ }^{159}$ (PROTZEN; HARRIS; CAVALLIN, 2000, p.50 tradução nossa)

Nesta perspectiva Protzen, Harris e Cavallin (2000) corroboraram com os dilemas acerca dos 'paradoxos da racionalidade' apontados por Rittel (1972a/2010), observando que do ponto de vista prático podemos construir um modelo incluindo a maior parte possível das escolhas do designer, mas não há certeza de que o mesmo não irá ou não desejará atravessar os limites impostos por este modelo (PROTZEN, HARRIS, CAVALLIN, 2000, p.51). Aqui, evidencia-se a relação entre o conceito de liberdade epistêmica e uma das premissas fundamentais do pensamento de Horst Rittel (1972a/2010), que diz respeito à configuração dos problemas capciosos, à medida que "O designer tem que tomar uma decisão sobre o que é importante. Em um nível muito básico, seus juízos de valor determinam qual é a formulação do problema. O problema de projeto é que o designer reconhece que ele é" ${ }^{160}$ (PROTZEN, HARRIS, CAVALLIN, 2000, p.51, tradução nossa). Esta é uma colocação elementar de ser observada: por exemplo, se o designer é particularmente atento à eficiência energética, medidas em prol desta questão provavelmente serão capturadas na formulação do problema de design, entretanto, outras

\footnotetext{
158 Do original em inglês: "Despite the existence of procedures like systematic doubt, there is no algorithm that can be used to deter mine all possible problem for mulations. [... Why not? Rationality is limited by certain paradoxes that cannot be avoided."

159 Do original em inglês: "To make a model which would capture all the relevant infor mation which the designer us es to makes decisions, we would need to capture not only infor mation about the physical world, but also infor mation about the minds of the designer and about the other significant players in the design process, all of which would be significant in delineating the possibilities which the designer could consider. Significant in this effort would be to include a model of the model that is being used-because clearly that model is a significant part of the decision-making world. And in this lies the paradox: the model must include itself. The model of the model must include a model of the model of the model, and so on in infinite regression."

160 Do original em inglês: "The designer has to make a decision about what is important. At a very basic level, his value judgments deter mine what the for mulation of the problem is. The design problem is what the designer recognizes it to be."
} 
questões que o designer considere menos importantes, ou mes mo as quais ele ignore, ou não pense, de qualquer modo, não são capturadas. Portanto, é correto afirmar que, de acordo com a diversidade de visões e modos de projetar:

O que o designer conheœ, acredita, teme, deseja, entra em seu raciocínio em cada etapa do processo, e afeta su uso da liberdade epistêmica. Ele - é claro - cmpromete-se com as posições que correspondem à suas crenças, conviç̧ões, preferências e valores, a menos que seja persuadido ou convencido por alguém mais ou uma outra ideia sua. ${ }^{161}$ (RITTEL, 1987/2010, p.193, tradução nossa)

Bazjanac (1974) corroborou com Rittel (1987/2010) reafirmando o sentido de negociação assumido na argumentação em detrimento da perspectiva sistêmica dos anos 1960 de 'otimização' do processo decisório, referindo-se à conformação deste conjunto de préentendimentos e 'visão de mundo' dos designers a que referem-se Protzen, Harris e Cavallin $(2000$, p.51) pelo emprego do termo alemão 'Weltanschauung'162.

É importante notar que os argumentos não podemnão ser fundados, em seguida, a decisão reflete a posição mais forte no argumento. Efetivamente, a maioria das decisões são negociadas. Isto significa que o processo de se chegar a melhores decisões não é um processo de otimização, no sentido das pesquisas operacionais, mas sim um processo de negociação e compromisso entre as partes com diferentes Weltanschauungen. ${ }^{163}$ (BAZJANAC, 1974, p.11, tradução nossa).

Aqui a observação de Bazjanac (1974) implica novamente no sentido político ${ }^{164}$ que Rittel carrega em sua concepção de design, cujo desdobramento no planejamento em escala

\footnotetext{
161 Do original em inglês: "What the designer knows, believes, fears, desires enters his reasoning at every step of the process, affects his use of epistemic freedom. He will - of course - commit hims elf to those positions that match his beliefs, convictions, preferences and values, unless he is persuaded or convinced by someone else or his own insight."

162 Segundo o dicionário online Cambridge o termo al emão 'Weltanschauung' significa opini ão, crença ou ideia ou um modo de pensar sobre algo, ou o conjunto da visão de mundo de um indivíduo. Cambridge Dictionary Online. Disponível em: <http://dictionar y.cambridge. org/dictionar y/british/view_1>. Acess o em: 12/08/2011.

163 Do original em inglês: "It is important to note that arguments may not be settled the decision then reflects the strongest position in the argument. Most decisions in effect are negotiated. This means that the process of arriving at better decisions is not a process of optimization in the operations research sense; it is rather a process of negotiation and compromise between parties with different Weltanschauungen."

164 De acor do com o comentário de Rittel sobre o sentido empregado para o termo 'político': "De acor do com o Dicionário Oxford 'política' significa 'conduta prudente, e sagacidade'. Pelas origens gregas não significa nada além de cidadania, e o opos to grego para um político, um não-político é um 'idiota.' (Idiota significado próprio e privado). Se eu falo sobre políticos não tenho pal avra melhor aqui - Quero dizer, no sentido aristotélico, tendo o homem como um animal político." (RITTEL, 1964 apud. PROTZEN; HARRIS, 2010, p.140 tradução nossa)
} 
governamental representa, conforme abordamos anteriormente, um dos principais concernimentos do autor: "design está associado a poder. Designers planejam no comprometimento de recursos e portanto af etam a vida de muitos. Designers são atores na aplicação do poder." ${ }^{165}$ (RITTEL, 1987/2010, p.193 tradução nossa). Neste sentido, Rittel sublinhou ${ }^{166}$ que o estabelecimento de planos implica necessariamente em consequências e que por isso mes mo dentre os agentes do planejamento de design devem figurar pessoas de opiniões diferentes ou mesmo contraditórias, de modo que as resultantes dos planos efetivam-se como compromissos: "O designer é parte nestes processos, ele toma partido. Concepção implica um compromisso político - embora muitos designers prefiram ver-se como especialistas neutros, imparciais e benevolentes que servem a abstração do bem comum." ${ }^{167}$ (RITTEL, 1987R2010, p.194, tradução nossa) Isto significa que:

É preciso que o designer esteja plenamente consciente dos inescapáveis dilemas produzidos por suas tentativas de projetar de forma responsável. Ele deve saber que seus resultados são 'políticos' por necessidade, porque eles são baseados emimagens suas e de outros de como o mundo é e como ele deveria ser. Quanto mais um projeto importa mais cruciais se tornarão suas implicações políticas ('político' sem a conotação americana depreciativa, mas no sentido Aristotélio: todo ato é político se isso afeta os assuntos da comunidade, se ela atinge além dos limites da privacidade).168 (RITTEL, 1967/1971, p.25, tradução nossa)

Compreendemos assim que a abordagem de Rittel representa uma concepção do processo projetual bastante distinta da abordagem de primeira geração dos métodos em design, reposicionando a atividade do design com relação a outros questionamentos e problematizações, redefinindo assim também de forma conjunta, o escopo dos esforços necessário para o desenvolvimento desta prática:

\footnotetext{
165 Do original em inglês: "Design is associated with power. Designers plan to commit resources and thereby affect the lives of many. Designers are actors in the application of pow er."

${ }^{166}$ Rittel comenta a este respeito, de uma maneira complementar, que "Felizmente par a todos nós, a mai oria dos designers não tem sucesso em moldar o mundo do seu jeito. O design ocorre em um contexto social. Praticamente todos os planos afetam muitas pessoas de diferentes maneiras. Fazer planos visa a distribuição de vantagens e desvantagens." (RITTEL, 1987/2010, p.194, tradução nossa)

167 Do original em inglês: "The designer is party in these processes; he takes sides. Designing entails political commitment although many designers would rather see themselves as neutral, impartial, benevol ent experts who serve the abstraction of the common good."

168 Do original em inglês: "It requires that the designer be fully aware of the inescapable dilemmas produced by his attempts to design responsibly. He must know that his results are 'political' by necessity because they are based on his and other's images of how the world is and how it ought be. The more a project matters the more crucial its political implications will become ('political' without the derogative American connotation but in the Aristotelian sense: every act is political if it affects the affairs of the community, if it reaches beyond the boundaries of privacy)."
} 
Rittel nos ensinou que a abordagem a problemas e a abordagem ao design deveriam ser através de interação social. E isso em si mesmo, é uma mudança radical a partir de modos bastante arraigados de pensar. Design não é sobre a manipulação de materiais e o objeto resultante, mas sim sobre as pessoas que são afetadas por estes. A lição de Rittel sobre os problemas e argumentação baseada em questionamento é que 0 design repousa sobre 0 domínio social, e assim é lá que as melhores respostas serão encontradas. Todo conhecimento, Rittel diria, é político. ${ }^{169}$ (PROTZEN; HARRIS, 2010, p.234-235 tradução nossa)

Apesar da nítida ruptura com a abordagem da primeira geração de métodos em design, notamos em nosso percurso pelas concepções de Horst Rittel, a integridade de seu comprometimento com a proposta original da gênese dos métodos em design no início dos anos 1960, a respeito da elaboração de estruturas sistemáticas em auxilio ao projetar capazes de conferir a seus usuários clareza de discernimento e compreensão mútua dos diversos procedimentos, valores e juízos estabelecidos nesta prática. Com relação a esta concordância, sublinha-se a adequação da proposta do próprio Rittel quanto ao estabelecimento de 'gerações', onde há simultaneamente um sentido de renovação e continuidade. Esta passagem de gerações, em nossa compreensão, sugere duas considerações importantes: 1. Ao refutar a abordagem da primeira geração, demonstrando a inadequação dos valores e procedimentos tradicionais da ciência no trato com problemas sociopolíticos, afirma-se a necessidade subjacente de revisão do sentido na aplicação da epistemologia científica e das técnicas fundamentadas em seus conhecimentos na prática projetual. 2. As concepções do processo projetual baseiam-se nas 'premissas deônticas' de seus proponentes; há a necessidade, portanto, de promover uma investigação sobre como as próprias (pré-)concepções afetam estes processos, afim de contribuir assim para a compreensão desta dimensão relevante do projetar. Ambas as considerações, que norteiam nosso raciocínio na condução deste estudo, são contempladas nas abordagens que visitaremos adiante neste trabalho.

\footnotetext{
169 Do original em inglês: "Rittel taught us that the approach to problems and the approach to design must be through social interaction. And this, in its elf, is a radical departure from heavily entrenched ways of thinking. Design is not about the materials manipulated and the resulting object, but rather it is about the people who are affected. Rittel's lesson of wicked problems and issue-based argumentation is that design lies in the social realm, and it is there that the best answers will be found. All Knowledge, Rittel would say, is political."
} 

Capítulo 2

O projetar como conversação 



\section{O PROJETAR COMO CONV ERSAÇÃO}

\subsubsection{O projetar como conversação reflexiva}

Nesta primeira parte do capítulo, apresentamos a abordagem de Donald Schön sobre a conversação do projetar, que segundo o autor se estabelece através da reflexão por parte do designer acerca de seus 'modos de ver' e agir junto às situações da prática projetual. Nossa referência central é a obra 'The Reflexive Pratitioner: How Professionals Think in Action' de 1983, em que Schön conduziu uma extensa investigação sobre como profissionais de diversas áreas de atuação lidam com os problemas encontrados em suas respectivas práticas, empregando um tipo de conhecimento diferente daquele vinculado à teorias e axiomas científicos. Nesta obra, a arquitetura é o primeiro dos cenários elencados pelo autor, que encontrou na análise de protocolo entre mestre e aluno no contexto do estúdio de projeto arquitetônico um exemplo significante do processo de 'reflexão-em-ação' que descreve como 'uma conversação reflexiva com os materiais da situação' (SCHÖN, 1983, p.78). No artigo 'The architectural studio as an Exemplar of Education for Reflection-in-Action', de 1984, Schön apontou novamente a prática do projetar arquitetônico como exemplo de investigação reflexiva, que se presta como modelo educacional para outros campos profissionais de acordo com a dinâmica das trocas dialógicas exercidas no estúdio de projeto. A contribuição de Schön à pesquisa de design é referenciada por Dorst e Dijkhuis (1996, p.254-255) como uma resposta efetiva à visão paradigmática de Simon (1969) e suas teorias de resolução de problemas pelo emprego de instrumental técnico e epistemologia científica. 


\subsubsection{Donald Schön e a busca por uma epistem ologia da prática}

Preocupado com a condição da prática profissional no contexto norte-americano no início dos anos 1980, o filós ofo norte-americano Donald Alan Schön (1931-1997) expôs em sua obra 'The Reflective Pratictioner: how professionals think in action' (SCHÖN, 1983), de 1983, princípios para o que denominou 'uma epistemologia da prática', uma investigação sobre como arquitetos, planejadores, engenheiros e gestores, entre outros profissionais (a que o autor refere-se de modo geral como 'praticantes ${ }^{, 170}$ ) lidam com situações problemáticas ${ }^{171}$ no desempenho de suas respectivas atribuições (SCHÖN, 1983, p.VIII). Esta investigação foi motivada pelo entendimento de que o conhecimento profissional fornecido pelas instituições de ensino superior (universidades e escolas profissionalizantes) era insuficiente em proporcionar às profissões a devida obtenção de seus propósitos, especialmente quanto ao atendimento das demandas sociais mais urgentes (SCHÖN, 1983, p.13). Na compreensão do autor, as universidades "[...] são instituições comprometidas, em sua maior parte, a uma epistemologia particular, uma visão de conhecimento que fomenta desatenção seletiva à competência prática e mestria profissional." ${ }^{172}$ (SCHÖN, 1983, p.VII, tradução nossa). Esta epistemologia particular, que Schön denominou 'epistemologia da racionalidade técnica' (SCHÖN, 1983, p.21) foi considerada pelo autor um dos principais fatores de uma 'crise de confiança' nas profissões configurada nos anos $1960^{173}$, caracterizada pela redução na credibilidade profissional por parte da opinião pública norte-americana à medida que "[...] soluções para os problemas públicos criadas por profissionais tiveram consequências inesperadas, às vezes piores do que os problemas que eles foram projetados para resolver." ${ }^{174}$ (SCHÖN, 1983, p.4, tradução nossa).

\footnotetext{
170 Do original em inglês: 'Practitioners'

171 Schön comenta o emprego do conceito de situação problemática a partir de Dewey: "Em seu Lógica: a Teoria da Investigação, Dewey propôs que problemas são construídos a partir de situações de indeterminação, situações problemáticas, que nós apreendemos através da experiência da preocupação, confusão ou dúvida." (SCHÖN, 1983, p.357, tradução nossa)

172 Do original em inglês: "They are institutions committed, for the most part, to a particular epistemology, a view of knowledge that fosters selective inattention to practical competence and professional artistry."

${ }^{173}$ Como obser vamos anteriormente, com relação às agitações soci ais e culturais do contexto norte- americano pela crescente insatisfação com ações governamentais como a guerra do Vi etnã, a produção tecnológica armamentista, di versos os conflitos fomentados por incompati bilidades entre interess es ci vis e i nstituci onais etc.

174 Do original em inglês: "[...] professionally designed solutions to public problems have had unanticipated consequences, someti mes worse than the problems they were designed to solve."
} 
Afirma-se que, de acordo com o modelo de 'racionalidade técnica', a atividade profissional consiste na resolução instrumental de problemas pela aplicação rigorosa de teorias e técnicas derivadas do conhecimento científico especializado, bem delimitado e padronizado (SCHÖN, 1983, p.21-23). Para o autor, a racionalidade técnica é a epistemologia positivista da prática, institucionalizada no bojo da fundação da universidade moderna do final do século XIX quando o positivismo esteve em seu auge e nas escolas profissionalizantes vinculadas às universidades nas primeiras décadas do século XX (SCHÖN, 1983, p.31). Schön observou que o ideário positivista, caracterizado pela doutrina do filósofo francês August Comte (1798$1857)^{175}$, esteve relacionado a uma apologia tecnológica que ascendeu com o avanço da Revolução Industrial do século XIX, fundamentada pela crença no poder da ciência na superação das dificuldades encontradas no curso do progresso humano ${ }^{176}$. No entanto, esta crença começou a ceder nos anos 1960, com o agravamento de problemas sociopolíticos cuja aplicação do conhecimento instrumental da epistemologia da racionalidade técnica pareceu não ser capaz de resolver (SCHÖN, 1983, p.37-39). Observamos que este é o mesmo contexto da crítica de Rittel e Webber (1973) quanto à inviabilidade de um sistema geral de planejamento, e de Horst Rittel (1972a/2010) em particular, sobre a inadequação da abordagem de resolução de problemas ${ }^{177}$ da primeira geração de métodos em design, conforme sua conceituação dos problemas capciosos (RITTEL, 1972a/2010; RITTEL; WEBBER, 1973).

A partir de um raciocínio bastante similar ao de Rittel $(1972 a, 1987)^{178}$, Schön procurou apontar deficiências na proposta de resolução de problemas da racionalidade técnica,

\footnotetext{
175 Segundo Schön (1983, p.32), as doutrinas do positi vismo apoi ado no ideário do filós ofo August Comte relacionam-se com: 1. A convicção de que a ciência empírica seria a única fonte de conheci mento positi vo do mundo. 2. A intenção de li mpar a mente humana do misticismo, superstição e outras formas de pseudoconhecimento. 3. O programa de estender o conhecimento científic o e o control e téc nico à sociedade humana, no senti do de des envolver tec nol ogias políticas e morais.

176 O autor comenta a este res peito que: "Como a vis ão de mundo científica ganhou domi nância, assim também a ideia de que o progresso humano poderia ser alcançado utilizando-se ciência na criação de tecnologia para a obtenção de fins humanos. Este Programa Tecnológico, que foi primeiro largamente expressado nos escritos de Bacon e Hobbes, se tornou um tema maior para os filósofos do lluminismo no sécul o XVIII, e no final do século XIX já se encontra consolidado como um pilar de sabedoria corrente." (SCHÖN, 1983, p.31, tradução nossa)

177 Segundo o comentário bem humorado de Schön: "Existiu um ponto avançado na década em que parecia que o slogan para os anos sessenta deveria ser 'Problemas são nosso mais importante produto'. Profissionais pareciam ter descoberto a saliência de situações incertas e problemáticas, de instabilidade, unicidade e conflito de valores." (SCHÖN, 1984, p.2, tradução nossa)

178 Protzen e Harris (2010, p.150) obser varam que Rittel e Schön, compartilhavam de ideias muito semel hantes, mas "por conta do destino" desconheciam o trabalho um do outro e não havi am se encontrado até 1987, pouco antes da morte de Rittel.
} 
argumentando que na dimensão da prática, problemas não se apresentam como dados, mas precisam ser construídos pelo indivíduo "a partir dos materiais de situações problemáticas, que são enigmáticas, confusas e incertas. Para converter uma situação problemática em um problema, precisa-se realizar certo tipo de trabalho. Ele precisa présentir uma situação incerta que inicialmente não faz sentido" ${ }^{\prime 19}$ (SCHÖN, 1983, p.40, tradução nossa). Da mes ma forma que Rittel (1972a/2010, p.153) teceu suas ponderações quanto à ef etividade restrita dos métodos sistemáticos e técnicas baseadas no conhecimento científico na resolução de problemas, Schön procurou delimitar o emprego restrito da racionalidade técnica junto aos problemas da prática profissional ${ }^{180}$, justamente pelo reconhecimento da necessidade de se 'enquadrar' as situações como problemáticas, um processo que o autor afirmou não ser de ordem técnica:

É este tipo de situação que profissionais esão cada vez mais começando a enxergar como central à suas práticas. Eles estão começando a reconheœr que, enquantb a configuração de problemas é uma condição necessária para resolução de problemas técnions, ela em si não é um problema técnico. Quando configuramos um problema, nós selecionamos o que iremos tratar œmo as 'coisas' da situação, nós estabelecemos os limites de nossa atenção comele, e impomos uma coerência que nos permite dizer o que é errado e em que direções a situação precisa ser modificada. A configuração de problemas é um proœsso em que interativamente, nós nomeamos as coisas que iremos atender e enquadramos o contextb em que nos referenciaremos a elas. ${ }^{181}$ (SCHÖN, 1983, p.40, tradução nossa)

Percebemos também a correspondência ${ }^{182}$ da visão de Schön (1983) e Rittel (1972b/2010) com

179 Do original em inglês: "[...] from the materials of problematic situations which are puzzling, troubling, and uncertain. In order to convert a problematic situation to a problem, a practitioner must do a certain kind of work. He must sense of an uncertain situation that initially makes no sense."

180 Com relação ao caso do proj eto arquitetônico, Schön observa: "[...] o praticante aborda o problema da prática como um caso único. [...] A situação é complexa e incerta, e existe um problema em encontrar o problema. [...] Como cada pr aticante trata seu caso como único, ele não pode lidar com ele pela aplicação de teorias ou técnicas padronizadas." (SCHÖN, 1983, p.129, tradução nossa)

181 Do original em inglês: "It is this sort of situation that professionals are coming increasingly to see as central to their practice. They are coming to recognize that although problem setting is a necess ary condition for tec hnic al problem solving, it is not itself a technical problem. When we set the problem, we select what we will treat as the "things" of the situation, we set the boundaries of our attention to it, and we impose upon it a coherence which allows us to say what is wrong and in what directions the situation needs to be changed. Problem setting is a process in which, interactively, we name the things to which we will attend and frame the context in which we will attend to them."

182 Protzen, Harris e Cavallin $(2000$, p.48) corroboraram com esta afirmação, obser vando que a indeter minação dos problemas de design, permite aos designers escolherem qual o probl ema a resolver (pel a aplicação da liberdade epistêmica), de modo diretamente análogo a descrição de Schön de que o designer proc ede atr avés da defi nição de enquadramentos. 
relação a esta configuração de problemas, que Rittel descreveu como o processo pelo qual o designer reconhece o problema como "[...] uma discrepância entre o conhecimento factual e o deôntico, procura por explicações de como as coisas são e como deveriam ser, e estas explicações the dão dicas sobre o conhecimento instrumental que ele precisa para superar esta discrepância."183 (RITTEL,1972b/2010, p.176, tradução nossa). Deste modo, ambos os autores concordaram que o processo de configuração de problemas é anterior e fundamental para o emprego dos meios instrumentais prescritos pela epistemologia da racionalidade: "é mais através do processo não-técnico de enquadrar a situação problemática que nós podemos organizar e clarificar ambos os fins a serem alcançados e os possíveis meios para alcançálos”" ${ }^{184}$ (SCHÖN, 1983, p.41, tradução nossa). O autor observou outro aspecto importante do processo de resolução dos problemas na prática profissional (que se remete diretamente à concepção de problemas capciosos), apontando como os desdobramentos das ações conduzidas neste processo tendem à conformação de novas situações problemáticas:

Quando profissionais consideram que estrada a construir, por exemplo, eles lidam usualmente com uma situação complexa e mal definida em que assuntos geográficos, topológioos, financeiros e políticos são todos misturados. Uma vez eles têm algo como u ma estrada a construir e vão considerar a melhor forma de construí-la, é que eles têm um problema que pode ser resolvido pela aplicação de técnicas disponíveis; mas quando a estrada que eles construíram leva inesperadamente à destruição de uma vizinhança, eles podem encontrar-se novamente em uma situação de inœrteza. ${ }^{185}$ (SCHÖN, 1983, p.40 tradução nossa).

Deste modo, o emprego do instrumental da racionalidade técnica para a realização das ações também não provê garantias de que suas consequências não ocasionarão outros problemas, ainda maiores. Evidencia-se, portanto, a insuficiência da epistemologia da

\footnotetext{
183 Do original em inglês: "[...] a discrepancy between factual and deontic knowledge, seeks out explanations why things are so and how they should be, and thes e explanations give him hints about the instrumental knowledge he needs to overcome this discrepancy." Aqui percebemos coloc ada de maneira i mplícita a conc epção de design em Simon (1969/1996).

184 Do original em inglês: "It is rather through the non-technical process of framing the problematic situation that we may organize and clarify both the ends to be achieved and the possible means of achieving them."

185 Do original em inglês: "When professionals consider what road to build, for example, they deal us ually with a complex and ill-defined situation in which geographic, topological, financial, economic and political issues are all mixed up together. Once they have some-how decided what road to build and go to consider how best to built it, they have a problem they can solve by the application of available techniques; but when the road they have built leads unexpectedly to the destruction of a neighbor hood, they may find themselves again in a situation of uncertainly." Aqui percebemos exemplificada a ess ência do raciocínio de Rittel (1972a/2010, p.153-155) sobre os 'paradoxos da racionalidade'.
} 
racionalidade técnica em prover meios adequados para lidar com os problemas da prática profissional: “[...] nós podemos entender assim, portanto, não só porque incerteza, unicidade, instabilidade e conflito de valores são tão incômodos à epistemologia positivista da prática, mas também porque profissionais vinculados a esta epistemologia encontram-se pegos em um dilema." ${ }^{186}$ (SCHÖN, 1983, p.42, tradução nossa). Este dilema coloca-se à medida que atender a condição de rigor ${ }^{187}$ na aplicação do conhecimento e instrumental técnico-científico para a resolução de problemas significa limitar-se à resolução de uma gama reduzida de problemas (os 'problemas domesticados' na caracterização de Rittel e Webber (1973, p.160)). Caracterizase assim o que o Schön chamou de 'dilema do rigor ou relevância':

Na geografia da prática profissional, há um plano muito seco e alto, onde você pode praticar as técnicas e usar as teorias em que você tem o seu doutoramento. Abaixo, existe um pântano onde os problemas reais vivem. A dificuldade é decidir se quer permaneœr no terreno mais elevado, onde você pode ser rigoroso, mas lidar com problemas de menor importância, ou desœr para o pântano para trabalhar em problemas que voœe realmente se preocupa, mas de uma maneira que você vê œmo irremediavelmente não rigorosa. É o dilema de rigor ou relevância. Você não pode ter ambos, e a maneira pela qual as pessoas escolhem entre eles define 0 curso de suas vidas profissionais. ${ }^{188}$ (SCHÖN, 1984, p.3 tradução nossa)

Diante deste dilema, assim, o autor sublinhou a relevância na concepção de uma epistemologia efetiva da prática, que permitisse a seus praticantes conduzir ações rigorosas diante dos problemas enfrentados nas profissões e, visando este propósito, buscou o desenvolvimento de uma abordagem distinta do modelo da racionalidade técnica, baseada em seus estudos sobre o raciocínio reflexivo conduzido nas ações e experimentações práticas e do conhecimento derivado desta reflexão. Ou seja, Schön procurou suprir a

\footnotetext{
186 Do original em inglês: "[...] we can understand, therefore, not only why uncertainty, uniqueness, instability, and value conflict are so troublesome to the Positivist epistemology of practice, but also why practitioners bound by this epistemology find themselves caught in a dil emma."

187 De modo similar com os princípios de rigor na condução de um experimento científico, por exemplo, no contexto da racionalidade e da objeti vidade, legitimando assi mo mesmo.

188 Do original em inglês: "In the geography of professional practice, there is a very dry, high ground where you can practice the techniques and uses the theories on which you got your PhD. Down below there is a swamp where the real problems live. The difficulty is to decide whether to stay on the high ground, where you can be rigorous but deal with problems of lesser importance, or go down into the swamp to work on problems you really care about but in a way you see as hopelessly unrigorous. It is the dilemma of rigor or relevance. You can't have both, and the way in which people choose between them sets the course of their professional lives."
} 
demanda por bases epistemológicas mais amplas à aplicação do instrumental científico na prática, diante da insuficiência deste proceder frente à configuração dos problemas capciosos conforme Rittel e Webber (1973) os descreveram.

\subsubsection{Reflexão-em-ação e arquitetura}

No intuito de responder a este dilema, demonstrou-se a importância do reconhecimento de que "em um sentido existencial tácito, nosso conhecimento vem de existência, de experiência, de simples mente 'ser/estar no mundo.' Em suas interações cotidianas, pessoas exibem conhecimento e habilidades, ou 'saber-fazer'."189 (SCHMDT, 2000, p.269, tradução nossa). Segundo Schön (1983, p.50), na prática do dia a dia, as pessoas emitem julgamentos sem que se consiga estabelecer critérios adequados, e também recorrem a habilidades as quais existe alguma dificuldade em expor em regras e procedimentos. Mesmo quando faz-se o uso consciente e explícito de técnicas baseadas em pesquisa e teorias científicas, ainda assim se é dependente de julgamentos, desempenhos de habilidade e de conhecimentos tácitos: "[...] nosso conhecer é geralmente tácito, implícito em nossos padrões de ação e em nossa sensibilidade com as coisas as quais nós estamos lidando. Parece correto afirmar que nosso conhecer está em nossa ação.” ${ }^{190}$ (SCHÖN, 1983, p.49, tradução nossa). Da mes ma forma, o autor propôs que, enquanto configura-se a problemática da situação pela manipulação do conhecimento tácito que confere sentido às suas ações, o praticante submete-se a um processo paralelo de questionamento e consciência destas próprias ações, ou seja, "enquanto Ele tenta estabelecer um sentido nisso, ele também reflete acerca dos entendimentos implícitos em sua ação, entendimentos que ele aflora, critica, reestrutura e incorpora em uma nova ação.”191 (SCHÖN, 1983, p.50, tradução nossa). Schön (SCHÖN, 1983, p.54)

\footnotetext{
189 Do original em inglês: "In a tacit existential sense, our knowledge comes from existence, from experience, from simply being in the world. In their everyday inter actions, people exhibit knowledge and skills, or 'know-how."

190 Do original em inglês: "Our Knowing is ordinarily tacit, implicit in our patterns of action and in our feel for the stuff which we are dealing. It seems right to say that our knowing is in our action."

${ }^{191}$ Do original em inglês: "As He tries to make sense of it, he also reflects on the understandings which have been implicit in his action, understandings which he surfaces, criticizes, restructures, and embodies in further action." O que Schön denota nesta passagem é o caráter de continui dade e circularidade dos processos de compreensão. Na sequência da dissertação,
} 
denominou este processo como 'reflexão-em-ação', e ressaltou sua relevância junto ao proceder frente situações problemáticas: "é todo este processo de reflexão-em-ação que é central para a arte pela qual seus praticantes algumas vezes lidam satisfatoriamente com situações de incerteza, instabilidade, unicidade e conflito de valores." ${ }^{192}$ (SCHÖN, 1983, p.50, tradução nossa). Para Schön, conhecimento tácito e reflexão-em-ação correspondem aos fundamentos básicos de uma epistemologia apropriada à resolução dos problemas da prática, de modo que:

O dilema de rigor ou relevância pode ser dissolvido se nós desenvolvermos uma epistemologia da prática que situe a resolução técnica de problemas em um contexto mais amplo de investigação reflexiva, que mostre como a reflexão-em-ação pode ser rigorosa de seu próprio modo, e œnecte a arte da prática na unicidade e incerteza à arte da pesquisa científica. ${ }^{193}$ (SCHÖN, 1983, p.69, tradução nossa)

Sanyal (1997, p.5) observou que o filósofo pragmatista ${ }^{194}$ e educador norte-americano John Dew ey (1859-1952) foi uma forte influência para o pensamento de Schön, que se debruçou de modo aprofundado sobre a obra de Dewey, especialmente sua Teoria da Investigação ${ }^{195}$, assunto de sua dissertação de doutorado em filosofia pela Universidade de Harvard em 1955. Os interesses precoces de Schön sobre a aquisição do conhecimento e os procedimentos de aprendizagem através da prática profissional guiaram-no a desenvolver, a partir do trabalho de Dewey (1938), sua proposta para uma epistemologia da prática e

retornaremos a este tema, c aracterizando-o frente ao contexło do círculo her menêutico e no campo da cibernética de primeira ordem, no que diz respeito à circularidade em sistemas fechados e também à cibernética de segunda ordem, que trata da relação interati va entre a obser vação do observador sobre o sistema obs ervado através do estabel ecimento de ins tâncias de metalinguagem.

192 Do original em inglês: "It is this entire process of reflection-in-action which is central to the art by which practitioners sometimes deal well with situations of uncertainty, instability, uniqueness, and value conflict."

193 Do original em inglês: "The dilemma of rigor or relevance may be dissolved if we can develop an epistemology of practice which places technical problem solving within a broader context of reflective inquiry, shows how reflection-in-action may be rigorous in its own right, and links the art of practice in uniqueness and uncertai nty to the scientist's art of research."

194 O prag matis mo consiste em uma corrente filosófic a do final do século XIX e começo do século XX, repres entada pela obra de pensadores norte-americanos como William James (1842-1910), John D ewey (1859-1952) e Charles Sanders Pierce (1839-1914). Segundo Gavin Melles (2008, p.88-89), o pragmatismo representa uma perspectiva distinta sobre conhecimento, sentido e ver dade: "O pragmatis mo rel eva um conjunto de ideias como planos de ação que emprestam seus sentidos a partir de suas consequências práticas do mundo real. isto contrasta com posições filosóficas atuais, como as da filos ofia analítica, que propõem a consi deração de conheci mento abs trato e ideias abstr atas em correspondência à verdade e realidade objeti va."

195 Sobre a Teoria da Investigação de Dewey ver: DEWEY, J. Logic, the Theory of Inquiry. New York: Holt, Rinehart and Winston, 1938. 
posteriores teorias do ensino-aprendizagem em torno do conceito de reflexão-em-ação:

Por todo tempo Don manteve seu apego intelectual à filosofia do pragmatismo de Dewey. Especificamente, a noção deweyana de que todo o conhecimento deriva da prática mantevese no coração da formulação de Don da fundamentação epistemológica da prática efetiva. A formulação de Don, no entanb, não foi uma repetição dos argumentos de Dewey: Ele foi além de Dewey no desenvolvimento de uma teoria de aprendizagem que, ele argumentou, exigia reflexão-na-ação. Em outras palavras, nem todas as ações levam à aprendizagem: apenas quando a ação é informada por reflexão e, por sua vez, informa a reflexão, se é capaz de aprender e apereiçoar seu conhecimento. ${ }^{196}$ (SANYAL, 1997, p.5-6, tradução nossa)

Mais do que meramente reproduzir o pensamento de John Dew ey, Schön desenvolveu uma teoria da prática reflexiva própria, que segundo Waks (2001), expressa uma distinção essencial quanto ao locus do conhecimento afirmado na Teoria da Investigação de Dew ey (1938), em que a produção de conhecimento se daria majoritariamente pela reflexão proveniente da condução da investigação científica experimental:

Isto implica uma diferença fundamental entre Schön e Dewey sobre o que é prática reflexiva e como ela é aprendida. Para Dewey, continua a ser semelhante ao pensamento científico, e é aprendido fazendo - envolvendo-se eminvestigaçes cientificas, apartadas dos problemas práticos que as geram. Para Schön ela œrresponde às formas de pensamento específicas, por exemplo, das práticas profissionais, e se aprende no grosso da atividade profissional, não apartadas. Para Dewey, o lugar paradigma da educação é o laboratório científico, para Schön é o estúdio de de sign.197 (WAKS, 2001, p.40, tradução nossa)

O vínculo entre Schön e o ensino de design pode ser considerado deter minante para seu modo particular de pensar o processo de reflexão-em-ação, e seu desdobramento como

\footnotetext{
196 Do original em inglês: "All along Don retained his intellectual attachment to Dewey's philosophy of pragmatism. Specifically, the Deweyian notion that all knowledge derives from practice remained at the heart of Don's formulation of the epistemological foundation of effective practice. Don's formulation, however, was not a rehash of Dewey's arguments: He went beyond Dewey in developing a theory of learning which, he argued, required reflection-in-action. In other words, not all actions lead to learning: only when action is infor med by reflection and, in turn, infor ms reflection, is one able to learn and refine one's knowledge."

197 Do original em inglês: "This implies a fundamental difference between Schön and D ewey on what reflective pr actice is and how it is learned. For Dewey, it remains akin to scientific thinking, and it is learned by doing - by engaging in scientific inquiries at one remove from the practical problems generating them. For Schön it is the forms of thinking specific to e.g. professional practices, and it is learned in the thick of the professional activity, not at one remove. For Dewey, the paradigm site of educ ation is the scientific laboratory; for Schön it is the design studio."
} 
uma teoria epistemológica. Abdicando de seguir uma carreira estável de filósofo acadêmico $^{198}$, Schön foi consultor industrial, administrador em instituto governamental e presidente de organização de consultoria sem fins lucrativos, debruçou-se sobre questões acerca de inovação tecnológica e social ${ }^{199}$ e também a respeito da relação ensinoaprendizagem com relação à prática profissional na área do design arquitetônico. Em 1972, foi convidado a lecionar no Departamento de Estudos Urbanos e Planejamento e de Arquitetura do Instituto de Tecnologia de Massachusetts, nos Estados Unidos, onde foi titulado professor emérito ${ }^{200}$ em Estudos Urbanos e Educação, cargo que ocupou até sua aposentadoria em 1992 (WAKS, 2001, p.38). Em meados da década de 1970 e ao longo da década de 1980, Schön envolveu-se em uma série de estudos sobre educação em arquitetura junto a outros pesquisadores do MIT e da Universidade de Harvard, que incluíram a observação e a análise de protocolo do processo projetual pelos diálogos entre mestres e alunos em estúdio de projeto arquitetônico ${ }^{201}$, e a condução de experimentos sobre o projeto arquitetônico valendo-se de exercícios e jogos de design. É justamente através desta experiência junto do projetar na arquitetura que Schön reconheceu o processo investigativo do design no âmago da prática profissional (SCHMDT, 2000, p.267): Schön compreendeu que o processo pelo qual designers vêm a conhecer uma situação problemática, vinculado à intenção de transformar esta situação (em outra preferida), corresponde ao modo como alguns profissionais conseguem lidar efetivamente com situações problemáticas de sua prática, que se caracterizam assim como atividades de design (SCHÖN, 1983, p.147). Neste contexto, Schön observou a importância da arquitetura, a

\footnotetext{
198 Referindo-se frequentemente como um 'filós of o deslocado', segundo o depoimento de Mary R. Schmidt (SCHMIDT, 2000, p.267); e Leonard J. Waks, profess or do utor emérito da Temple Uni versity, Philadelphia, Estados Unidos (WAKS, 2001, p.38).

199 Waks $(2001$, p.38) relata que, após um breve período como profess or de filosofia na Universidade da Califórnia, Schön foi empregado na firma de consultoria ADL - Arthur D. Little na área de design de produto e inovação tecnol ógica; e em 1963, juntou-se ao departamento governamental de comércio dirigindo o Instituto para Tec nol ogia Aplicada no 'Bur eau of Standar ds'. Em 1966, deixa o governo e de volta a Cambridge funda a Organização para Inovação Social e Tecnológica, sem fins lucrativos, conduzindo pesquisa e inter venções nas ár eas de mor adia, saúde, educ ação e outros ser viços sociais.

200 Tradução da titulação no original em inglês: Ford Professor Emeritus on Urban Studies and Education and Senior Lecturer in the Department of Urban Studies and Planning and Architecture, Massachusetts Institute of Technology.

201 O estudo de protocolo sobre a passagem entre o mestre do estúdio Quist e a aluna de primeiro ano Petra que Schön (1983) utiliza para exemplificar o process o de refl exão- em-ação na prátic a do designarquitetônico deriva da pesquisa de Roger Simmonds sobre educação arquitetônica, dirigido pel os pesquis ador es Dean Maurice Kilbridge da Universidade de Har vard e Dean Willian Porter do MIT. Outros estudos citados por Schön em sua obra envol veram os pesquisadores William Porter, John Habraken e Glenn Wiggins do Departamento de Arquitetura, Jeanne Bamberger da seção de música, Edith Ackerman do laboratório de Mídi a e Tecnologia, e Larry Bucciarelli do programa de Ciência, tec nol ogia e s ociedade (SCHÖN, 1992, p.4).
} 
qual afirmou ser a mais antiga profissão de design reconhecida ${ }^{202}$ e, portanto, "[...] um protótipo para o design em outras profissões. Se existe um processo fundamental subjacente às diferenças entre profissões de design, é na arquitetura que estamos mais próximos de encontrá-lo"203 (SHÖN, 1983, p.77, tradução nossa). A este processo de 'vir a conhecer', entendido como a experimentação prática envolvida do projetar arquitetônico, foi proposta uma devida investigação: "a fim de entender o que designers arquitetônicos fazem, então, precisamos de uma visão especial de investigação; uma derivada da reflexão sobre o conhecimento-em-ação implícito no fazer arquitetônico.”204 (SCHÖN, 1984, p.4, tradução nossa). Através desta investigação, Schön propôs-se também a evidenciar este fazer, compreendido como a manifestação da 'arte' pela qual alguns profissionais obtêm sucesso frente situações problemáticas em suas práticas, pela produção e emprego de conhecimento-em-ação através do processo contínuo de reflexão-em-ação:

O processo de reflexão-em-ação [...] é uma parte essencial da artisticidade com que alguns profissionais, por vezes, lidam com incerteza, singularidade e conflito de valores em todos os domínios da prática profissional. Mas a arquitetura $\infty m$ a sua tradição especial de prática e educação, é uma das poucas ocupações em que o processo é manifestado, honrado e mantido. Mesmo aqui, eu imagino, o processo ainda é bastante implícito. Arquitetos pareœm refletir muito pouco sobre sua própria prática de reflexão-na-ação. No entanto sua prática, redescrita através da reflexão, pode servir como um exemplo poderoso para outras profissões. ${ }^{205}$ (SCHÖN, 1984, p.5, tradução nossa)

\footnotetext{
202 Schön observa que arquitetura é dotada de uma tradição de prática e ensino anterior ao regime da racionalidade técnica, por isso, oc upando uma posição diferenciada entre as profiss ões: "Arquitetura é uma profiss ão anômala. Se cristalizou como uma profissão antes da doutrina da racionalidade técnica entrar em bom curso. É uma profissão bi modal. É uma arte, não só porque é um ofício de design, mas também porque se preocupa com a dimensão estética da experiência humana. Mas também é uma pr ofissão dedicada à provisão de estruturas físicas funções soci ais criticamente importantes. Arquitetura vive tanto no mundo da arte e no mundo da performance tec nológica." (SCHÖN, 1984, p.4, tradução nossa)

203 Do original em inglês: "[...] as prototype for design in other professions. If there is a fundamental process underlying the differences among design professions, it is in architecture that we are most likely to find it."

204 Do original em inglês: "In order to understand what architectural designers do, then, we need a special view of inquiry; one derived from reflection on the spontaneous knowing-in-action i mplicit in architectural making."

Do original em inglês: "The process of reflection-in-action [...] is an essential part of the artistry with which some practitioners sometimes cope with uncertainty, uniqueness, and value-conflict in all domains of professional practice. But architecture with its special tradition of practice and education, is one of the few occupations in which the process is manifest, honored, and maintained. Even here, I think, the process is still largely implicit. Architects appear to reflect very little on their own practice of reflection-in-action. Yet their practice, redescribed through reflection, might serve as a powerful exemplar for other professions."
} 
Aqui, de acordo com nossa compreensão, a abordagem de Schön insere-se no contexto da pesquisa em design contemplando uma proposta radicalmente distinta à do movimento de métodos em design dos anos 1960, à medida que percebemos que o autor propõe-se justamente à investigação do 'domínio intuitivo' do processo investigativo projetual, repudiado pelos teóricos dos métodos racionais em sua busca pelo estabelecimento de modelos e procedimentos matemáticos lógicos, gerais e abstratos do projetar. Esta compreensão mostra-se válida ao observarmos que em sua proposta de uma epistemologia da prática efetiva, Schön descreveu este domínio como seu escopo de investigação:

\begin{abstract}
Vamos então repensar a questão do conhecimento profissional, vamos posicionar a questão em sua cabeça. Se o modelo da racionalidade técnica é incompleto, na medida em que não dá conta de competências práticas em situações 'divergentes', tanto pior para o modelo. Vamos procurar, em vez disso, por uma epistemologia da prática implícita nos processos intuitivos, artísticos, que alguns praticantes conduzem em situações de incerteza, instabilidade, singularidade e conflito de valores. ${ }^{206}$ (SCHÖN, 1983, p.49, tradução nossa)
\end{abstract}

Para além de seu concernimento epistemológ ico com a prática profissional e de suas teorias de ensino e aprendizagem, Schön promoveu uma significante contribuição também à pesquisa em design, ao recolocar diversas questões sobre a natureza do projetar influenciando o trabalho de diversos outros pesquisadores de design a partir dos anos $1980,{ }^{207}$ sendo que sua concepção do projetar é referenciada por Dorst e Dijkhuis (1996) como um verdadeiro 'paradigma' na descrição da atividade do design, que os autores contrapõem ao de Herbert Simon (1969). Esta concepção compreende o reconhecimento de um tipo especial de reflexão-em-ação central a esta artisticidade, através da qual, profissionais lidam com as situações problemáticas da prática (SCHÖN, 1983, p.62) em que o processo investigativo de design desenvolve-se segundo a forma metafórica de uma conversação.

206 Do original em inglês: "Let us then reconsider the question of professional knowledge, let us stand the question on its head. If the model of Technical Rationality is incomplete, in that it fails to account for practical competence in 'divergent' situations, so much the worse for the model. Let us search, instead, for an epistemology of practice implicit in the artistic, intuitive process es which some practitioners do bring to situations of uncertainty, ins tability, uniqueness and value conflict."

207 Como podemos observar pelo trabalho de Atwood, McCain e Williams (2002); D ownton (2003) ou na compreensão de Dorst e Dijkhuis (1996) da visão de Schön (1983) como um modo paradigmático de descrever a ativi dade do design. 


\title{
2.1.3 O projetar como convers ação com a situação do design
}

Em sua busca pela configuração de uma epistemologia da prática baseada no reconhecimento dos processos de reflexão-em-ação, Donald Schön aproximou-se assim da investigação reflexiva do design arquitetônico, reconhecendo neste processo o modo pelo qual é produzido um tipo de conhecimento "principalmente tácito, em vários sentidos da palavra: designers sabem mais do que eles podem dizer, eles tendem a dar descrições imprecisas do que eles sabem, e eles podem ganhar um melhor acesso ao (ou só acessam) seu conhecimento-em-ação colocando-se no modo de fazer."208 (SCHÖN, 1992, p.3). Este conhecimento permite que ao designer lidar com os problemas indeterminados do design à medida que interagem com a situação problemática através de suas ações transformadoras:

\begin{abstract}
Arquitetura é uma profissão enraizada na maestria de projetar, um processo que eu caracterizo como uma forma especial de reflexão-em-ação: conversação reflexiva $œ m$ materiais da situação do design. Neste sentido, eu sugiro, a arquitetura encama um tipo de maestria que tambémé por vezes praticada emoutras profissões, especialmente nas zonas indeterminadas da prática. ${ }^{209}$ (SCHÖN, 1984, p.9, tradução nossa)
\end{abstract}

Esta é a caracterização em que Schön vê a atividade prática do design como um processo especial de reflexão-em-ação, descrita como uma 'conversação reflexiva com os materiais da situação' (SCHÖN, 1983, p.78; 1984, p.9; 1992, p.4; SHÖN; WIGGINS, 1988/1992, p.135), uma espécie de troca que efetiva-se na interação entre o designer e a situação do design: "designers, será argumentado, estão em transação com uma situação de design; eles respondem às demandas e possibilidades de uma situação de design, que por sua vez, eles ajudam a criar." ${ }^{210}$ (SCHÖN, 1992, p.4, tradução nossa). O autor exemplifica este processo através da seguinte descrição:

\footnotetext{
208 Do original em inglês: "It is mainly tacit, in several senses of the word: designers know more than they can say, they tend to give inaccurate descriptions of what they know, and they can best (or only) gain access to their knowledge in action by putting themselves into the mode of doing."

209 Do original em inglês: "Architecture is a profession rooted in the artistry of designing, a process I have characterized as a special form of reflection-in-action: reflective conversation with materials of the design situation. In this sense, I suggest, architecture embodies a kind of artistry that is also sometimes practiced in other professions, especially in the indeterminate zones of practice."

210 Do original em inglês: "designers, it will be argued, are in trans action with a design situation; they respond to the demands and possibilities of a design situation, which in turn, they help to create."
} 
Um designer faz coisas. Às vezes Ele faz o produto final, mais frequentemente, Ele faz u ma representação - um plano, programa, ou imagem - de um artefab a ser construído por outros. Ele trabalha em situações específicas, utiliza materiais específicos e emprega um distinto meio e linguagem. Tipicamente, seu proœsso de fazer é complexo. Existem mais variáveis - tipos de movimentos possíveis, normas e inter-relações destes - que podem ser representados em um modelo finito. Por causa desta complexidade, os movimentos do designer tendem, feliz ou infelizmente, a produzir consequências outras que aquelas pretendidas. Quando isso aconteœ, o designer pode levar em conta as mudanças não intencionais que ele tem feito na situação formando novas apreciações e entendimentos e fazendo novos movimentos. Ele dá forma à situação e, em acordo com sua apreciação inicial da mesma, a situação 'diz algo em resposta', e ele responde à resposta da situação. Em u m bom processo de design, essa conversação coma situação é reflexiva. Em resposta à que a situação coloca, o de signer reflete-em-ação na construção do problema, nas estraḱgias para ação, ou na modelagem do fenômeno, que estão implíitos em seus movimentos. ${ }^{211}$ (SCHÖN, 1983, p.78-79, tradução nossa)

Podemos nos referir a este processo também como uma sequência subjacente de eventos, que inicia-se pelo reconhecimento do designer de uma situação complexa e incerta, em que há dificuldades em aplicar teorias ou técnicas padronizadas e assim compreende-se a situação como um caso único (SCHÖN, 1983, p.129). No desempenho do designer evidencia-se uma 'artisticidade', representada por sua capacidade de manter vários 'modos de ver' a situação, pela qual se configura um problema enquadrando a situação do design ao atribuir ou impor a ela uma coerência ou sentido (SCHÖN, 1983, p.40). O designer conduz então um experimento a partir deste problema formulado no intuito de investigar as consequências decorrentes deste enquadramento da situação, que o leva à descoberta de implicações não intencionais ou não previstas, que dão novos sentidos à situação, podendo ser compreendidas como outros problemas a serem resolvidos ou oportunidades a serem

\footnotetext{
211 Do original em inglês: "A designer makes things. Sometimes He makes the final product; more often, He makes a representation - a plan, program or image - of an artifact to be constructed by others. He works in particular situations, us es particular materials, and employs a distinctive medium and language. Typically, his making process is complex. There are more variables -kinds of possible moves, norms, and interrelations hips of these-that can be represented in a finite model. Because of this complexity, the designer's moves tend, happily or unhappily, to produce cons equences other than those intended. When this happens, the designer may take in account of the unintended changes he has made in the situation by forming new appreciations and understandings and by making new moves. He shapes the situation, in accordance with his initial appreciation of it, the situation "talks back" and he responds to the situation's back-talk. In a good process of design, this conversation with the situation is reflective. In answer to the situation's back talk, the designer reflects-in-action on the construction of the problem, the strategies of action, or the model of the phenomena, which have been implicit in his moves."
} 
exploradas (SCHÖN, 1983, p.131). A esta dinâmica, Schön referiu-se como u ma conversação com a situação: "A situação responde, o praticante ouve, e como aprecia o que ouve, ele reenquadra a situação novamente."212 (SCHÖN, 1983, p.131-132, tradução nossa). O desenvolvimento de uma nova experimentação através de ações e movimentos de um novo enquadramento leva à continuidade da conversação:

Nessa conversação reflexiva, o esforço do praticante para resolver o problema reenquadrado produz novas descobertas que exigem nova reflexão-na-ação. 0 processo espiraliza-se através de fases de apreciação, ação e reapreciação. A situação única e incerta passa a ser entendida através da tentativa de mudá-la, e transformada através da tentativa de ser compreendida. ${ }^{213}$ (SCHÖN, 1983, p.132, tradução nossa).

Descreveu-se, portanto, a estrutura básica de reflexão-em-ação na prática do design como um diálogo entre o designer e a situação do design, através de uma alternância entre 'modos de ver' e 'movimentos', que ocorrem em níveis locais e globais e de muitas maneiras diferentes (SHÖN; WIGGINS, 1988/1992, p.135). Desta forma, o projetar é essencialmente a interação entre fazer e ver, fazer e descobrir: "Um designer vê, se move e vê novamente. Trabalhando em algum meio visual [...] o designer vê o que está 'lá' em alguma representação de um lugar, desenha em relação a isto, e vê o que ele/ela desenhou, assim informando ainda mais projetar." ${ }^{214}$ (SCHÖN, 1992, p.5, tradução nossa). É importante observar que o termo 'ver' empregado pelo autor na configuração desta interação (a qual se pode referir de várias formas, como no caso, 'ver-desenhar-ver') corresponde a uma multiplicidade de sentidos, para muito além da apreensão visual literal, referindo-se a uma série de atividades perceptivas e cognitivas desempenhadas pelo designer em seu raciocínio, destacando-se, por exemplo, a construção de sentidos ${ }^{215}$ e sua atribuição à padrões identificados:

\footnotetext{
212 Do original em inglês: "The situation talks back, the practitioner listens, and as he appreciates what he hears, he reframes the situation once again."

213 Do original em inglês: "In this reflective conversation, the practitioner's effort to solve the reframed problem yields new discoveries which call for new reflexion-in-action. The process spirals through stages of appr eciation, action, and reappreciation. The unique and uncertain situation comes to be understood through the attempt to change it, and changed through the attempt to understand it."

214 Do original em inglês: "A designer sees, moves and sees again. Working in some visual medium [...] the designer sees what is 'there' in some representation of a site, draws in relation to it, and sees what he/she has drawn, ther eby infor ming further designing."

215 Deve-se observar a coloc ação pelo próprio autor da especificação deste 'ver como' em acordância com a proposta do
} 
Em todo esse 'ver', o designer não só registra visualmente informação, mas também constrói o seu significado, ele/ela identifica padrões, e dá-hes significados para além de si mesmos. Palavras œmo 'reconhecer', 'dectar', 'descobrir' e 'apreciar' denotam variantes de 'ver', assim como os termos 'ver que', 'ver como' e 'ver em..${ }^{216}$ (SCHÖN, 1992, p.5, tradução nossa)

Esta função de 'ver' associada à construção de sentidos determina assim o modo pelo qual os designers enquadram as situações problemáticas, 'vendo-as' de acordo com suas compreensões particulares das situações e configurando-as como problemas os quais tentam compreender e resolver (SCHÖN, 1983, p.134). Em outras palavras, a configuração de problemas pelo enquadramento das situações de design depende deste 'ver como', que incorpora as apreciações dos designers, como por exemplo, julgamentos de valor e qualidade: estes julgamentos estão vinculados, por sua vez, ao universo cultural, crenças e valores do designer, ou seja, todos os atributos e de juízo que conformam um 'sistema de apreciação' 217 (SCHÖN; WIGGINS, 1988/1992, p.137-138). Pode-se afirmar que é a partir de seus sistemas de apreciação que designers são capazes de estabelecer comparações entre as situações únicas do design com suas experiências passadas, 'vendo-as' com relação a seu repertório de exemplos, imagens, entendimentos e ações, ou seja, reconhecendo correlações que o permitem proceder com seus enquadramentos, problematizações e ações:

filósofo austríaco Ludwig Wittgenstein (1989-1951) confor me suas Investigações Filos óficas publicadas em 1953 (WITTGENSTEIN, 1953/1989)

216 Do original em inglês: "In all this 'seeing', the designer not only visually registers information, but also constructs its meaning; he/she identifies patterns, and gives them meanings beyond themselves. Words such as 'recognize', 'detect', 'discover' and 'appreciate' denote variants of seeing, as do such terms as 's eeing that', 'seeing as' and 'seeing in'."

217 Schön remete o sentido de 'sistemas de apreciação' colocado em concordância com o pensamento do cientista de sistemas Geoffrey Vic kers (1894-1982), conf orme suas obras: VICKERS, G. The Art of Judgment. New York: Basic Books, 1965;

Social Process. New York: Basic Books, 1968. Schön cita também Christopher Alexander, ao afirmar de maneira complementar que a observação do autor de que as apreciações expressas em atos de julgamentos podem ser conduzidas tacitamente, ou seja, sem nec essariamente o es tabeleci mento explícito de critérios para el es (SCHÖN; WIGGINS, 1988/1992, p.139). Finalmente, Schön observa que os "sistemas de apr eciação são variáveis no res peito que podem evoluir com o tempo [...]. De fato, o modo como o indi víduo des envol ve um tipo particul ar de sistema apreciati vo parec e ter muito em haver com o processo pelo qual aprende a ser tor nar um designer arquitetônico. E o modo como um sistema apr eciativo desenvol ve-se e vem a ser compartilhado por um grupo de designers parece ter muito a ver com o processo em que comunidades de design evol uem." (SCHÖN; WIGGINS, 1988/1992, p.139, tradução nossa) 
Vendo essa situação como aquela, pode-se também fazer nesta situação como o que foi feito naquela. [...] É a nossa capacidade de ver situaçoes desconhecidas como conhecidas, e realizar no seguinte o que fizemos no último, que nos permite trazer a nossa experiência do passado para suportar o caso único. É a nossa capacidade de 'ver-como' e 'fazer-como' que nos permite ter uma intuição para problemas nos quais não se encaixam regras existentes. ${ }^{218}$ (SCHÖN, 1983, p.139, tradução nossa)

Desta forma, sistemas de apreciação são essenciais para projetar, pelo modo com o qual designers aproximam-se das situações de design, as problematizam e avaliam a procedência destas problematizações através de ações, movimentos ou experimentos investigativos. Coloca-se aqui uma complementaridade entre instâncias, no sentido de que o processo de design não depende somente das apreciações e julgamentos dos designers, mas também de suas ações:

'Ver-como' como não é suficiente, no entanto. Quando um praticante vê uma situação nova como algum elemento de seu reperb́rio, ele obtém uma nova maneira de vê-la e uma nova possibilidade para a ação nela, mas a adequação e utilidade de sua nova visão ainda devem ser descoberbs em ação. Reflexão-em-ação envolve necessaniamente experimento. ${ }^{219}$ (SCHÖN, 1983, p.141, tradução nossa)

Expressa-se assim que a conversação é mais que a formulação e realização da intenção de transformação elaborada pelo designer, pois envolve a própria transformação do designer pela reflexão acerca das consequências de seus atos, ou seja, é dependente de que se reconheça uma resposta da situação, e por isso, dependente da experimentação prática desta situação(SHÖN; WIGGINS,1988/1992, p.139).

\footnotetext{
218 Do original em inglês: "Seeing this situation as that one, one may also do in this situation as in that one. (...) It is our capacity to see unfamiliar situations as familiar ones, and to do in the former as we have done in latter, that enables us to bring our past experience to bear on the unique case. It is our capacity to see-as and do-as that allows us to have a feel for problems that do not fit existing rules."

219 Do origin al em inglês: "Seeing as is not enough, however. When a practitioner sees a new situation as some element of his repertory, he gets a new way of seeing it and a new possibility for action in it, but the adequacy and utility of his new view must still be discovered in action. Reflection-in-action necessarily involves experiment."
} 


\subsubsection{A experimentação da prática reflexiva}

A contraparte de 'ver' no modelo da reflexão-em-ação de Schön apresenta-se como o 'fazer', que compreende a condução de uma ação, ou movimento, que pode ser uma transformação ou mudança em uma configuração do design, ou o ato de transformar em si (por exemplo, uma modificação entre o desenho de uma configuração formal com relação a outra ou a ação de desenhar pela qual a modificação é feita) (SCHÖN; WIGGINS, 1988/1992, p.137). Este 'fazer' pode ser compreendido também como um experimento, no sentido de que o designer procede à experimentação da situação que configurou como um problema, ao tentar resolvê-la (SCHÖN, 1983, p.134), e como investigação, decorrente à reflexão sobre as consequências e implicações subsequentes à própria ação (SCHÖN, 1983, p.131). Schön adverte que esta experimentação do design, no entanto, possui características distintas do modelo de experimento científico da racionalidade técnica (SCHÖN, 1983, p.147), observando a necessidade de expor categoricamente estas distinções, a partir da própria compreensão do significado de experimentar nestes dois casos (SCHÖN, 1983, p.152-153).

A princípio, é colocado que “ [...] no sentido mais genérico, experimentar é agir em ordem de ver no que a ação leva. A questão experimental mais fundamental é 'e se?' "220 (SCHÖN, 1983, p.145, tradução nossa). Para Schön, a experimentação na prática desenvolve-se em três níveis: 'experimentos exploratórios', quando a ação é conduzida sem uma previsão de seus resultados; 'testes de movimento', que corresponde à condução de uma ação em ordem de produzir uma modificação intencional; e 'teste de hipóteses', que corresponde às ações realizadas para avaliação do emprego de ideias ou para escolha de teorias competidoras (SCHÖN, 1983, p.145-147). O autor afirmou que quando o designer reflete-em-ação sobre uma situação problemática, manifestando sua compreensão intuitiva da mesma, "[...] sua experimentação é ao mes mo tempo exploratória, teste de movimento e teste de hipótese. As três funções são cumpridas pelas mesmas ações. E deste fato segue o caráter distintivo da experimentação na prática."221 (SCHÖN, 1983, p.147, tradução nossa). Esta distinção destacada pelo

\footnotetext{
220 Do original em inglês: "In the most generic sense, to experiment is to act in order to see what the action leads to. The most fundamental experimental question is, 'What if?' "

221 Do original em inglês: "[...] his experimenting is at once exploratory, move testing, and hypothesis testing. The three functions are fulfilled by the very same actions. And from this fact follows the distinctive character of experimenting in practice."
} 
autor remete às premissas da experimentação do modelo da racionalidade técnica, em que, "[...] há um mundo objetivamente conhecível, independente dos valores e pontos de vista do praticante. A fim de obter conhecimento técnico dele, o praticante deve manter uma clara fronteira entre si e seu objeto de investigação."222 (SCHÖN; WIGGINS, 1988/1992, p.163, tradução nossa). A esta afirmação Schön expôs a outra natureza da experimentação prática na qual os designers lidam com as situações problemáticas a que intencionam entender e transformar:

Seu experimento de teste de hipóteses é um jogo com a situação. Eles procuram fazer a situação conformar-se a suas hipóteses, mas permanecem abertos à possibilidade de que ela não irá. Assim, sua atividade de teste de hipóteses não é nem uma profecia autorrealizável, que assegura contra a apreensão de dados desconfortáveis, nem é o teste de hipóteses neutro do método de experimento controlado, que apela para que o pesquisador evite influenciar o objeto de estudo e que abrace dados desconfortáveis. A situação prática não é nem de argila a ser modelada à vontade, nem um independente e autossuficiente objeto de estudo do qual o investigador mantém sua distância ${ }^{223}$ (SCHÖN, 1983 , p.150, tradução nossa)

Neste ponto, o autor retorna ao cerne fundamental da caracterização da investigação do projetar como uma conversação ao afirmar que o designer "no entanto, reconhece que a situação, tendo uma animação própria distinta de suas intenções, pode frustrar seus projetos e revelar novos significados." ${ }^{224}$ (SCHÖN, 1983, p.163, tradução nossa), ou seja, estabelecese uma relação de reciprocidade: o designer intenciona transformar a situação e a situação responde ao resistir à intenção transformadora do designer, modificando, por sua vez, a apreciação do designer de suas próprias ações e da situação em si:

\footnotetext{
222 Do origin al em inglês: "[...] there is an objectively knowable world, independent of the practitioner's values and views. In order to gain technical knowledge of it, the practitioner must maintain a clear boundary between himself and his object of inquiry."

223 Do original em inglês: "Their hypothesis-testing experiment is a game with the situation. They seek to make the situation conform to their hypothesis but remain open to the possibility that it will not. Thus their hypothesis-testing activity is neither selffulfilling prophecy, which insures against the apprehension of disconfirming data, nor is it the neutral hypothesis testing of the method of controlled experiment, which calls for the experimenter to avoid influencing the object of study and to embrace disconfir ming data. The practice situation is neither clay to be modeled at will nor an independent, self-sufficient object of study fromwhich the inquirer keeps his distance."

224 Do original em inglês: "Yet he recognizes that the situation, having a life of its own distinct from his intentions, may foil his projects and reveal new meanings."
} 
A relação do investigador a esta situação é transacional. Ele molda a situação, mas em conversação com ela, de modo que seus próprios modelos e apreciações também são moldados pela situação. Os fenômenos que ele busca entender são emparte de sua própria criação, ele se encontra na situação que ele proaura entender.225 (SCHÖN, 1983, p.150-151, tradução nossa)

Ao configurar-se como uma conversação reflexiva com a situação, os atributos da investigação prática conduzida na atividade de projetar distinguem-se assim dos atributos vinculados ao paradigma de investigação científica correspondente ao modelo da racionalidade técnica, de modo que os valores de controle, distância e objetividade, centrais para este modelo, assumem novos significados na conversação, à medida que o investigador tenta controlar as variáveis para o bem do experimento de teste de hipóteses: "[...] sua hipótese é sobre o potencial da situação para transformação e no processo de avaliação ele entra na situação"226 (SCHÖN, 1983, p.166, tradução nossa). O conhecimento produzido neste processo é objetivo, no sentido que o designer alcança ou não uma mudança satisfatória, proporcionando a avaliação se ele deve realizar mudanças de ordem diferente na situação; mas também é "[...] pessoal, atrelado aos seus compromissos com o sistema apreciativo e teoria geral. É convincente apenas para membros de uma comunidade de investigação que partilham destes compromissos." ${ }^{227}$ (SCHÖN, 1983, p.166, tradução nossa).

Apesar destas distinções, deve-se observar que a experimentação prática pode e deve seguir de forma rigorosa, como o caso da experimentação científica ${ }^{228}$. Aqui, entretanto, para Schön, o rigor ef etiva-se na atenção do designer investigador com relação à resposta da situação ao seu movimento: "Ele experimenta rigorosamente quando se esforça para fazer a situação conformar-se com seu ponto de vista, enquanto, ao mes mo tempo

\footnotetext{
225 Do original em inglês: "The inquirer's relation to this situation is tr ansactional. He shapes the situation, but in conversation with it, so that his own models and appreciations are also shaped by the situation. The phenomena that he seeks to understand are partly of his own making; he is in the situation that he seeks to understand."

226 Do original em inglês: "[...] his hypothesis is about the situation's potential for transformation, and in the testing process he steps into the situation."

227 Do original em inglês: "[...] personal, bounded by his commitments to appreciative system and overarching theory. It is compelling only to members of a community of inquiry who share thes e commitments."

${ }^{228}$ Como já observado, com relação ao chamado "dilema do rigor ou relevância" da prática profissional, exposto no início deste capítulo.
} 
permanece em aberto para a evidência de seu fracasso em fazê-lo."229 (SCHÖN, 1983, p.153, tradução nossa). Desta forma, o designer deve ser capaz de reconhecer, através da reflexão sobre a resistência da situação, se sua hipótese é inadequada e de que maneira, ou que o seu enquadramento do problema é inadequado e de que maneira. Este é um processo dinâmico, à medida que "[...] ele joga o seu jogo em relação a um alvo em movimento, mudando o fenômeno enquanto o experimenta. Se ele deveria refletir-na-ação, e como ele deveria experimentar, dependerá das mudanças produzidas por seus movimentos anteriores." ${ }^{230}$ (SCHÖN, 1983, p.153, tradução nossa). Schön (1983, p.155-156) propôs quatro derivações possíveis de desfecho para uma experimentação prática (Tabela 3), contemplando se os resultados obtidos cumprem as expectativas do investigador e sua avaliação com relação a serem desejáveis ou não. A adoção de um destes quatro desfechos não termina o processo de investigação da prática, mas cria novas condições para a renovação do processo, levando a novos enquadramentos, entendimentos e compreensões:

Assim o praticante avalia seu experimento em reenquadrar a situação problemática não só pela sua capacidade para resolver o novo problema que ele configurou, mas por suas apreciações dos efeitos não intencionais da ação, e especialmente por essa capacidade, em conversação com a situação, para fazer um artefato que é coerente e uma ideia que é compreensivel. Mas a obtenção de coerência não põe um fimà investigação. Pelo contrário, o praticante também avalia a sua reformulação por esta habilidade [...] para manter a investigação em movimento. [...] U ma reformulação bem-sucedida da situação problemática leva a uma continuação da conversação reflexiva. ${ }^{231}$ (SCHÖN, 1983, p.136, tradução nossa).

\footnotetext{
229 Do original em inglês: "He experiments rigorously when he strives to make the situation conform to his view of it, while at the same ti me he remains open to the evidence of his failure to do so."

230 Do original em inglês: "[...] he plays his game in relation to a moving target, changing the phenomena as he experiments. Whether he ought to reflect-in-action, and how he ought to experiment, will depend on the changes produced by his earlier moves."

231 Do original em inglês: "Thus the practitioner evaluates his experiment in reframing the problematic situation not only by his ability to solve the new problem he has set but by his appreciations of the unintended effects of action, and specially by his ability, in conversation with the situation, to make an artifact that is coherent and an idea that is understandable. But the achievement of coherence does not put an end to inquiry. On the contrary, the practitioner also evaluates his reframing by its ability [...] to keep inquiry moving. [...] A successful reframing of the problematic situation leads to a continuation of the reflective conversation."
} 


\begin{tabular}{|c|c|c|}
\hline $\begin{array}{l}\text { Consequências em } \\
\text { relação à intenção }\end{array}$ & $\begin{array}{l}\text { 'Desej abil idade' de todas } \\
\text { as consequên cias, } \\
\text { intencionais ou não }\end{array}$ & Comentários \\
\hline $\begin{array}{c}1 . \\
\text { Surpresa }\end{array}$ & Indesejável & $\begin{array}{l}\text { O primeiro é um caso típico para a reflexão-na-ação. } 0 \text { movimento } \\
\text { falha em produzir o resultado pretendido, e suas consequências, } \\
\text { intencionais e não intencionais, são consideradas indesejáveis. O } \\
\text { movimento é negado e a teoria associada a ele é refutada. O } \\
\text { pesquisador então responde à negodação do movimento, } \\
\text { refletindo sobre sua teoria subjaœnte. }\end{array}$ \\
\hline $\begin{array}{c}2 . \\
\text { Surpresa }\end{array}$ & $\begin{array}{c}\text { Desejável } \\
\text { ou } \\
\text { Neutra }\end{array}$ & $\begin{array}{l}\text { No segundo caso, a expectativa do pesquisador é deœpcionada, } \\
\text { mas as consequências como um todo são consideradas } \\
\text { desejáveis. A teoria associada é refutada, mas o movimento é } \\
\text { afirmado. De acordo com a lógica de afirmação }{ }^{232} \text {, o movimento } \\
\text { foi bem sucedido. Não há necessidade de reflexão a menos que se } \\
\text { queira considerar o presente caso como uma preparação para } \\
\text { futuros casos }\end{array}$ \\
\hline $\begin{array}{c}3 . \\
\text { Não Surpresa }\end{array}$ & $\begin{array}{c}\text { Desejável } \\
\text { ou } \\
\text { Neutra }\end{array}$ & $\begin{array}{l}\text { No terceiro caso, o movimento produz o resultado pretendido e as } \\
\text { suas consequências são tomadas no seu conjunto como } \\
\text { desejáveis. Não há necessidade de uma reflexão-na-ação, a } \\
\text { menos que o investigador - de novo considerando o presente caso } \\
\text { como uma preparação para futuros casos - coloca-se a questionar } \\
\text { sobre os fatores de seu êxito atual. }\end{array}$ \\
\hline $\begin{array}{c}4 . \\
\text { Não Surpresa }\end{array}$ & Indesejável & $\begin{array}{l}\text { No quarto caso, o movimento produz os resultados esperados, } \\
\text { mas ta mbém provoca modificações não intencionais que são vistas } \\
\text { em geral, insatisfatórias. Aqui, haverá reflexão sobre a teoria } \\
\text { associada œm o movimento, mas se focará sobre o escopo da } \\
\text { relevância da teoria, emvez de sua veracidade. }\end{array}$ \\
\hline
\end{tabular}

Tabela 3 - Possibilidades de resultado de experimentação prática quanto o cumprimento das expectativas do investigador e a desejabilidade das consequências. Adaptado de Schön (1983, p.155-156).

\footnotetext{
232 A 'lógica da afir mação' remete a questão de que, no contexto da prática, é colocada uma prioridade no interesse de transfor mação, ou seja, a lógica da afir mação c onfigura os limites do rigor experi mental (SCHÖN, 1983, p. 155).
} 
Recordando o sentido de alternância entre apreciações, movimentos e novas apreciações, podemos representar de modo diagramático (Figura 14) o sentido de circularidade no processo de reflexão-em-ação da investigação do projetar, que se expressa de modo sequenciado na estrutura 'ver-mover-ver' (Figura 15). Apresentamos uma leitura desta estrutura em uma forma expandida, conforme nossa apreensão da concepção da conversação reflexiva pelo diagrama da Figura 16.

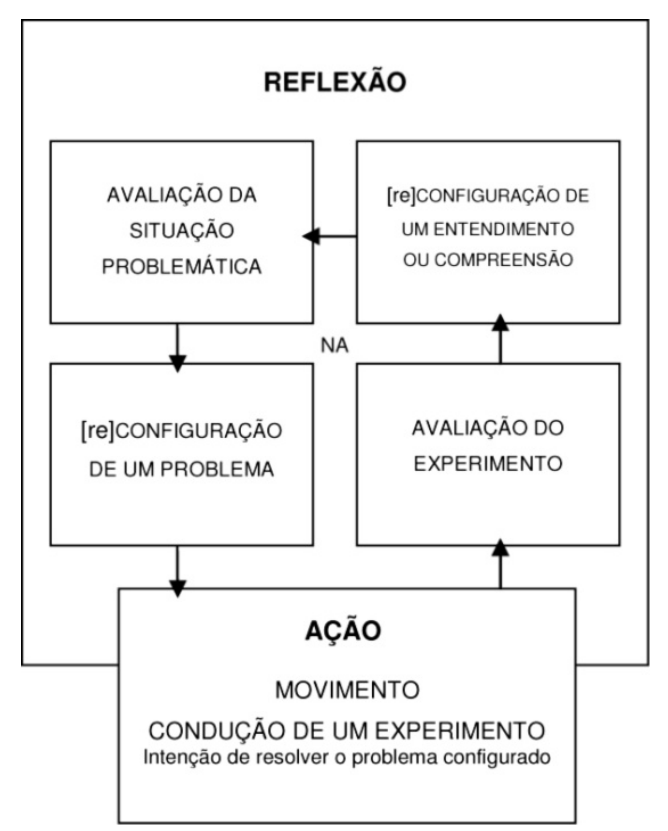

Figura 14 - Diagrama da estrutura de reflexão em ação na investigação projetual como uma conversação reflexiva.

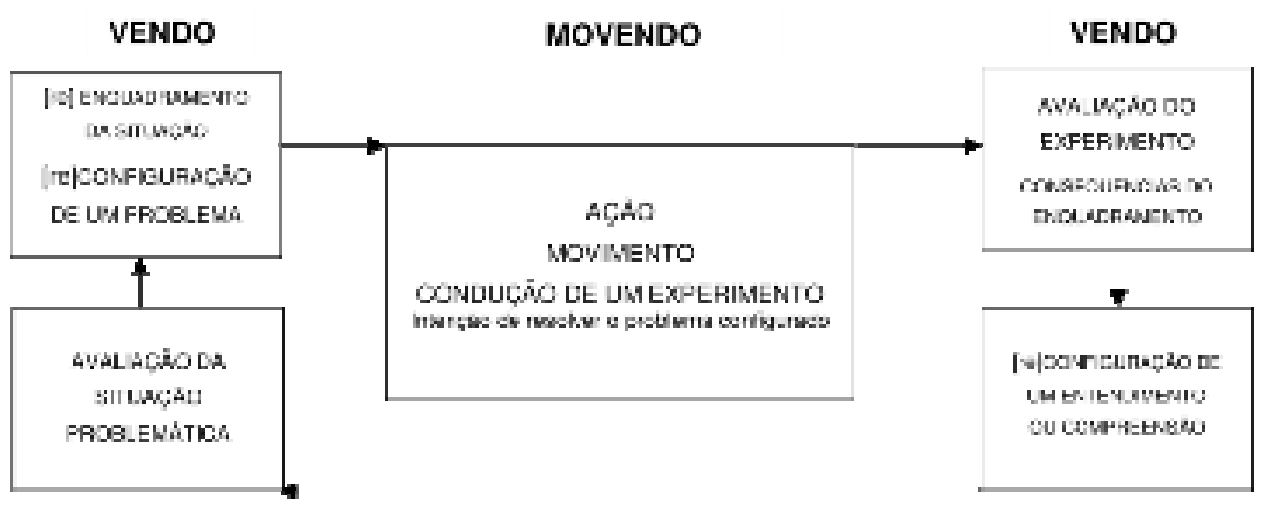

Figura 15 - Diagrama da estrutura 'ver-mover-ver' como uma conversação reflexiva. 


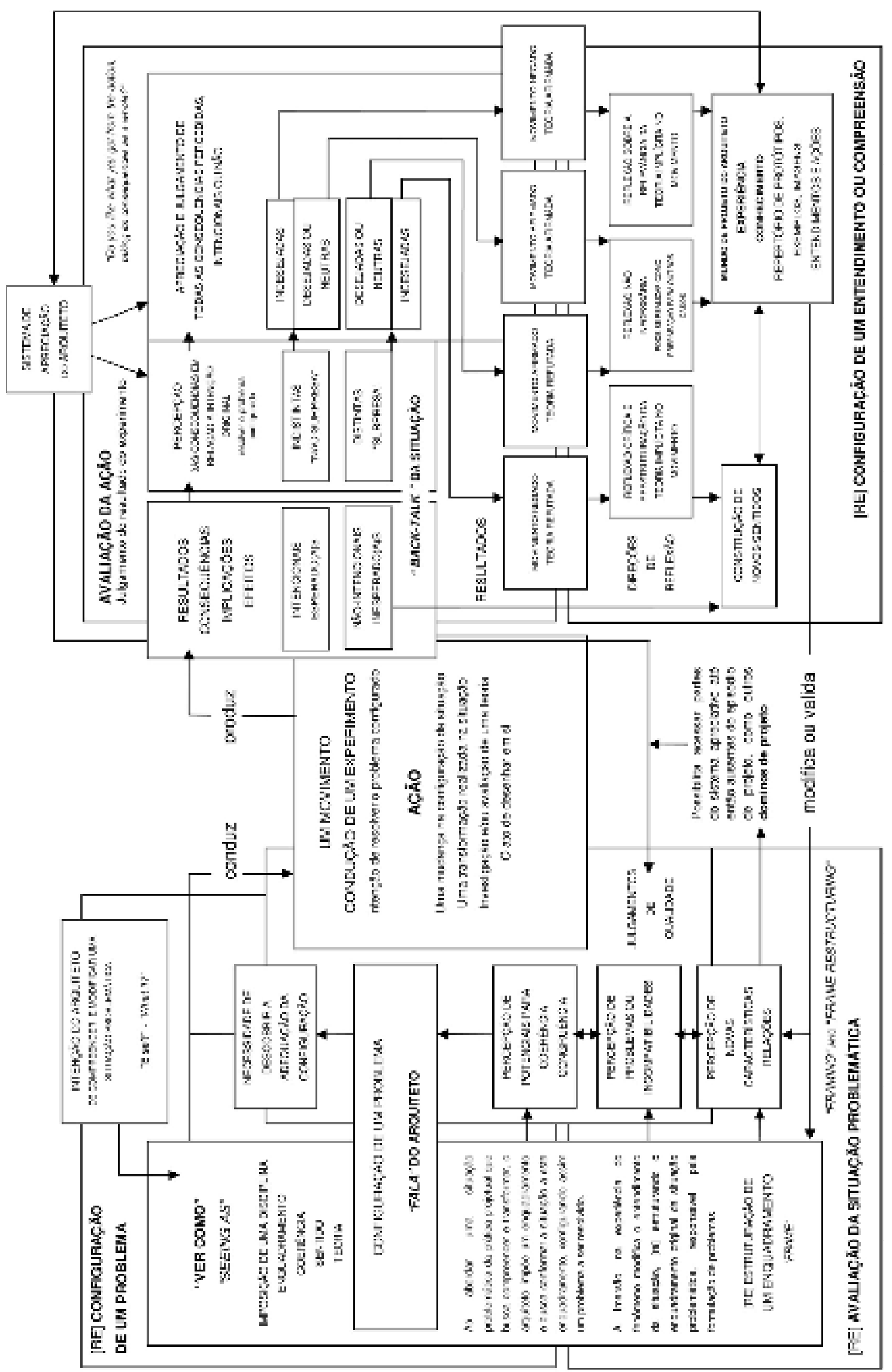

Figura 16 - Diagrama ex pandido da estrutura da conversação reflex iva conduzida na investigação projetual. 


\subsubsection{A transformação da compreensão pelo projetar}

Conforme observamos anteriormente, Schön promoveu o reconhecimento de que a situação do design é necessariamente conformada de propriedades e atributos próprios que oferecem 'resistência' às intenções e formulações de seus designers, e que é através da interação com estas propriedades que lida-se efetivamente com esta situação, sob a forma de conversação (SCHÖN, 1992, p.10-11). Essa interação pode ocorrer de modos distintos, ao passo de que o designer pode relacionar-se diretamente com elementos concretos da situação do design em si, como a manipulação de estruturas e elementos construtivos, por exemplo, ou através de representações, pela manipulação de ideias através de desenhos, pois a situação do projeto propriamente material, e assim, "[...] é apreendida, em parte, através da apreciação sensorial ativa. Isto é verdade tanto quando o designer está no lugar, e quando ele ou ela atua no mundo virtual de uma prancheta de desenho, modelo em escala ou tela de computador." ${ }^{233}$ (SCHÖN, 1992, p.4, tradução nossa). Este é o raciocínio subjacente à descrição 'conversação reflexiva com os materiais da situação' (SHÖN, 1983, p.78; 1984, p.5; 1992, p.4, SHÖN; WIGGINS, 1988/1992, p.135). Neste sentido, uma dimensão importante da conversação reflexiva no projetar diz respeito aos meios pelos quais o designer conduz suas ações e reflexões: a investigação do design arquitetônico, por exemplo, pode ser expressa em uma linguagem projetual que combina a produção de elementos gráficos como desenhos e a fala do designer (que pode se manifestar por escrito, ou de modo verbal, por exemplo) (SHÖN, 1983, p.95). Neste caso, desenho e fala articulam-se na condução de um raciocínio composto por elementos de diversas ordens de concernimento, como forma, escala, indicações de grandezas e de relações espaciais, de uso e funcionalidade etc., que podem ser agrupados de acordo com suas qualidades distintas, configurando o que Schön chamou de 'domínios de design'. No projetar, o designer interage com diversos domínios que são interdependentes e que se articulam, e, portanto, seus movimentos tendem a produzir consequências em mais que um domínio, e observa-se $e^{234}$ que, devido à sua capacidade limitada de processamento de informação, ele não é capaz de considerar todas as

\footnotetext{
233 Do original em Inglês: "[...] is apprehended, in part, through active, sensory appreciation. This is true both when the designer is on site, and when he or she operates in the virtual world of a sketchpad, scale model or computer screen."

234 Neste ponto Schön (1983) corroborou com as coloc ações de Simon (1969) sobre a capacidade limitada de gestão de informações dos designers frente à previsão das consequências de suas ações.
} 
consequências de seus movimentos em relação aos domínios envolvidos (SHÖN; WIGGINS, 1988/1992, p.143). O próprio movimento do designer também é limitado por sua capacidade reduzida de atender a vários domínios frente à complexidade das situações típicas do design (em um sentido similar ao proposto por Alexander (1964), Jones (1970) e Simon (1969)), e portanto, só após a realização do movimento, em sua apreciação reflexiva da transformação visando um certo domínio, ele é capaz de reconhecer consequências outras as quais anteviu, e este processo pode levar ao reconhecimento de novos domínios antes desconsiderados pela apreciação de novos sentidos e associações pelo 'modo de ver' do designer, como nos referimos anteriormente. Pode-se afirmar assim, que a estrutura sequencial de ver-mover-ver conforma-se em resposta às condições limitadas de compreensão da situação de design:

\begin{abstract}
Por esses dois motivos, então - razões que poderíamos denotar como 'consciência limitada' e 'habilidade limitada para gerenciar complexidade' - o projetar [...] tem a estrutura de conversação de ver-mover-ver, onde o segundo 'ver' envolve o reconhecimento de consequências não intencionais bem como intencionais, onde as consequências não intencionais caem em domínios outros do que aqueles em que o problema e sua solução contemplada são inicialmente formulados.235 (SCHÖN; WIGGINS, 1988/1992, p.143, tradução nossa)
\end{abstract}

Por outro lado, observa-se a relevância da conversação reflexiva como a forma pela qual o designer reconhece nas consequências de suas ações mais do que tinha se antecipado ou imaginado anteriormente, ou seja, o projetar avança desvelando aspectos então ocultos à respeito da situação problemática, e assim a estrutura sequencial de ver-mover-ver torna possível o manejo da complexidade desta situação (SCHÖN; WIGGINS, 1988/1992, p.143). Deste modo podemos conceber "o projetar como um processo acumulativo de descoberta cujo produto não é só uma intenção elaborada [...] mas uma compreensão enriquecida de relações entre movimentos, consequências e qualidades através de múltiplos domínios."236

\footnotetext{
235 Do original em Inglês: "For these two reasons, then - reasons we might shorthand as 'limited awareness' and 'limited ability to manage complexity' - designing [...] has the conversational structure of seeing-moving-seeing, where the second 'seeing' involves recognition of unintended as well as intended consequences, and where unintended consequences fall into domains other than those in which the problem and its prospective sol ution are initially for mul ated."

${ }^{236}$ Do original em Inglês: "[...] designing as a cumul ative process of discovery whose output is not an el abor ated intention [...] but an enriched understanding of rel ations hips among moves, consequences and qualities across multiple domains."
} 
(SCHÖN; WIGGINS, 1988/1992, p.144, tradução nossa). A partir desta concepção, a atividade do design corresponde também a um processo de aprendizado, conduzido de modo solitário pelo próprio designer em suas conversas reflexivas com os materiais da situação ou de modo compartilhado, como no caso do estúdio de projeto, em que este designer é exposto a famílias particulares de domínios de design e visões de interconexões cujo sentido ou coerência é acordado coletivamente (constituindo uma 'cultura de projeto', ou uma 'tradição' como referiu-se Alexander (1964)). Este sentido de design como aprendizado foi observado também por Alexander (1977) que ao começo dos anos 1970 abandonou os modelos e procedimentos formais pelos quais tinha advogado anteriormente na década de 1960 (BAZJANAC, 1974, p.12). Em sua obra 'A Pattern Language', de 1977, Alexander (1977) concebeu um outro modelo, em que descreve o processo projetual essencialmente como um processo de aquisição de conhecimento e de tomada de decisões que refletem este conhecimento, de modo que a tarefa mais importante para o projetar passa a ser a provisão de conhecimento 'apropriado' ao designer na resolução de seus problemas, a partir do estudo dos diversos 'padrões'. Para Schön, este processo de descoberta e conhecimento no projetar permite ao designer não só o desenvolvimento de compreensões da situação problemática, mas também a construção de seu próprio universo particular de investigação, em última instância redefinindo sentidos ontológicos, como verdadeiros 'criadores de mundos'237 (SCHÖN, 1992, p.9). O autor observou a distinção que esta concepção expandida de design implica com relação à sua abordagem tradicional como resolução de problemas:

Designers são, no termo de Nelson Goodman, criadores de mundos. Não só eles constroem os significados de suas situações, materiais e mensagens, mas também as ontologias de que esses significados dependem. Cada procedimento, e cada formulação de problema, depende de uma ontologia: a construção da totalidade das coisas e das relaçães que 0 designer toma co mo a realidade do mundo em que ele ou ela projeta. [...] isso deve ser contrastado com a imagem familiar de projetar como 'buscar dentro de um espaço do problema'. Na medida em que design se assemelha os exemplos que acabamos de descrever, é claro que um 'espaço do problema' não é dado com a apresentação da tarefa de design, o designer constrói o mundo do design em que ele/ela define as dimensões de sua/seu espaço do problema, e inventa os movimentos pelos quais ele/ela tenta encontrar

237 Schön utiliza a concepção de constr ução de mundos no sentido da construção de ontologias, referindo-se à obra do filósofo norte-americano Nelson Goodman (1906-1998). Ver: GOODMAN, N. Ways of Worldmaking. USA: Ed. Hackett, 1978. 
soluções. ${ }^{238}$ (SCHÖN, 1992, p.9-11, tradução nossa)

Schön procurou evidenciar assim que a construção de mundos de design desenvolve-se a partir da conversação na atividade do design, e de maneira recíproca o desenvolvimento destes mundos transforma o modo em que designers entendem e conduzem suas investigações de design, em um sentido evolutivo (SCHÖN, 1992, p.10-11). Da mesma forma, ao descrever design como um processo de aprendizagem, Bazjanac (1974, p.14) observou que durante a busca por definições do problema e da solução da situação do design, o designer aprende mais sobre os mesmos ao longo de todo o processo, originando novas ideias que redefinem continuamente sua compreensão. Desta forma, o projetar pode ser compreendido como a busca de uma solução que ajusta-se melhor ao conhecimento que se tem no momento do processo, ou seja, solução e conhecimento evoluem, sendo codependentes. Esta compreensão corrobora também com a descrição de Rittel (1967/1971) do processo argumentativo do design, ao afirmar que, "A imagem resultante do processo de design mostra o designer argumentando na direção de uma solução consigo mes mo e com outras partes envolvidas no projeto. O designer constrói um caso levando a uma melhor compreensão do que está a ser realizado.” ${ }^{239}$ (RITTEL, 1967/1971, p.19-20, tradução nossa). Este caso a que Rittel refere-se é informado pelos diferentes sentidos compreendidos pelo designer e por outros agentes sobre 'o que o problema deveria ser', que são discutidos e negociados e então, "[...] princípios de solução são desenvolvidos, avaliados e decididos em vista de seu desempenho esperado. [...] Desta maneira, formulações melhores do problema estão sendo desenvolvidas simultaneamente com uma imagem cada vez mais clara da solução." ${ }^{240}$

\footnotetext{
${ }^{238}$ Do original em inglês: "Designers are, in Nelson Goodman's ter m worldmakers. Not only do they construct the meanings of their situations, materials and messages, but also the ontologies on which these meanings depend. Every procedure, and every problem formulation, depends on such an ontology: a construction of the totality of things and relations hips that the designer takes as the reality of the world in which he or she designs. [...] this should be contrasted with the familiar image of designing as 'search within a problem space'. To the extent that designing resembles the examples just described, it is clear that a 'problem space' is not given with the presentation of the design task; the designer constructs the design world within he/she sets the dimensions of his/her problem space, and invents the moves by which he/she attempts to find solutions."

239 Do original em Inglês: "The resulting picture of the design process shows the designer arguing toward a solution with himself and with other parties involved in the project. He builds a case leading to a better understanding of what is to be accomplished."

240 Do original em Inglês: "[.. .] sol ution principles are developed, ev aluated in vi ew of their expected perfor mance and decided upon. [...] In this way, better formulations of the problem are being developed simultaneously with a clearer and clearer image of the solution."
} 
(RITTEL, 1967/1971, p.19-20, tradução nossa). Para Schön (1992) a construção dos sentidos da situação de design e dos próprios mundos de design derivam da conversação reflexiva dos designers com os materiais da situação, para Rittel (1967/1971), a condução de cursos específicos de ação pelo comprometimento das partes (o propósito do design) depende do acordo sobre as premissas deônticas de seus agentes, pela argumentação e negociação. Percebemos aqui, que esta transformação da compreensão dos designers ou dos agentes em geral do projetar (com relação à situação problemática do design ou assumindo um sentido mais profundo, de ordem ontológica) é a contraface do processo projetual 'obscurecida' pela concepção de design como resolução de problemas:

\begin{abstract}
Pensar no projetar como resolução de problemas é usar uma metáfora morta para um processo vivo e esquecer-se que o design não é tanto uma questão de ajustar o status quo quanto de perceber novas possibilidades e descobrir as nossas reaçoes a elas. Fazer ou inventar algo novo não é só mudar os arredores de alguém, mas mudar um pouco a realidade. Por esta razão creio ser, acredito umerro começar a projetar pensando apenas no problema, como o chamamos, e deixar para pensar em como ele está sendo resolvido, para estágios posteriores. A mente do indivíduo, embora não sua obra, é mantida emuma mistura constante de ambos problema e solução emque a interdependência de cada umé evidente por toda parte. A expressão inicial de objetivos, ou neœssidades, indiferente do quão abstratos e absolubs estes possam parecer, é, penso eu, cheio de assunções ocultas sobre como a pessoa que os afirma pensa em como os mesmos podem ser satisfeitos, por exemplo, a declaração 'resolver o problema do desemprego' poderia implicar que estamos a engajar-nos em uma procura por empregos de algum tipo, mas u ma resposta imaginativa pode muito bem sugerir maneiras de viver sem trabalho em que desemprego não é mais o problema. Se realizada, a solução inspirada muda nossas mentes. ${ }^{241}$ (JONES, 1970/1992, p.XXIX, tradução nossa)
\end{abstract}

\footnotetext{
241 Do original em inglês: "To think of designing as 'problemsolving' is to use a rather dead metaphor for a lively process and to forget that design is not so much a matter of adjusting the status quo as of realizing new possibilities and discovering our reactions to them To make or invent something new is to change not only one's surroundings but to change reality a little. For this reason it is, I believe, a mistake to begin designing by thinking only of the problem, as we call it, and to leave thinking of how it is to be solved to later stages. One's mind, though not one's paper-work, is best kept in a constant inter mingling of both problem and solution so that the interdependency of each is evident throughout. The initial expression of objectives, or needs, however abstract and absolute it may seem is, I think, full of hidden assumptions about how the person stating it thinks it can be satisfied, eg. the statement 'solve the unemployment problem' could imply that we are to become engaged in a search for jobs of some kind, but an imaginative response may well suggest ways of workless living in which unemployment is no longer the problem If realized, the ins pired solution changes our minds."
} 
Reconhecemos, portanto, que a abordagem de design como uma conversação reflexiva evidencia o modo fundamental em que o projetar está vinculado ao processo de constante revisão da compreensão e dos sentidos das ações e movimentos conduzidos em sua investigação, e que este processo, por sua vez, depende da interação com as qualidades próprias e materiais da situação projetual, bem como, da interação com as premissas deônticas e modos de ver alheios, provenientes dos demais agentes envolvidos no projetar. De acordo com esta concepção, nenhuma ação projetual é fruto da formulação de uma intenção ou vontade, a pura 'subjetividade' do designer, exigindo sempre uma negociação cujo propósito final a se atingir é um acordo, que permite tanto o estabelecimento de coordenações de ações projetuais e o desenvolvimento do processo, quanto à validação dos próprios sentidos destas ações ao longo do mes mo.

\subsection{O projetar como conversação hermenêutica}

Na sequência de nossa investigação, apresentaremos a abordagem dos pesquisadores e arquitetos Adrian Snodgrass e Richard Coyne, que, no contexto da década de 1990, publicaram uma série de $\operatorname{artigos}^{242}$ revisitando a problemática da natureza da atividade e dos processos de design, a partir da crítica à concepção racionalista cientificista do projetar, de modo correlato a Schön (1983). Snodgrass e Coyne (1995, p.47; 1997/2006, p.45) corroboraram com o pensamento de Donald Schön $(1983,1992,1988 / 1992)$ e sua caracterização do design arquitetônico como uma conversação com a situação, porém através de uma compreensão própria, baseada em um referencial teórico-filosófico fundamentado na fenomenologia ${ }^{243}$

\footnotetext{
242 Ao longo da década de 1990, Coyne e Snodgrass publicaram uma série de artigos criticando a posição racionalista e positivista cientificista da pesquisa em design e revisitando a natureza dialógica da prática do design sob a perspectiva filosófico-teórica da fenomenologia hermenêutica com base nas obras dos filós ofos alemães Martin Heidegger (1889-1976) e Hans-Georg Gadamer (1900-2002); dentre os artigos, des tac amos: SNODGRASS; COYNE,1992,1997 2006; e COYNE; SNODGRASS, 1995. 243 Para Snodgrass e Coyne, a fenomenol ogia compreende uma corrente filos ófica contemporânea dotada de uma ontologia pós-racionalista, que: "[...] é um r etorno à primazi a da experiência. A fenomenologia de Huss erl defende um retorno à forma como as coisas aparecem. Heidegger modifica e desenvol ve este tema, começando com um apelo à primazia (primordial) da experiência do envol vi mento irrefletido em um mundo em que não há sujeito ou objeto. Com Hei degger, mesmo o conc eito de estar em (como em "no mundo") é transitório, derivado, contextual e até mesmo cultur al. Outros entendimentos de ser, como aquele em que podemos distinguir um sujeito separado de um 'mundo objetivo', são construídos sobre essa experiência." (SNODGRASS; COYNE, 1995, p.45, tradução nossa)
} 
hermenêutica do filósofo Martin Heidegger ${ }^{244}$ (1889-1976) e principalmente na orientação da hermenêutica contemporânea desenvolvida pelo filósofo Hans-Georg Gadamer (1900-2002). ${ }^{245}$ Para os autores, a reflexão-em-ação de Schön (1983) corresponde essencialmente a um processo interpretativo, em que a compreensão do designer desenvolve-se por uma investigação dialética junto à experienciação da situação do design, a qual considera-se um evento hermenêutico ${ }^{246}$ (SNODGRASS; COYNE, 1997/2006, p.45-46).

\subsubsection{Filosofia hermenêutica e metáforas do processo proje tual}

Snodgrass e Coyne observam a relevância da crítica acerca da abordagem científica do projetar nos anos 1990, mes mo então passadas cerca duas décadas da crise da primeira geração de métodos, pela constatação da perseverança dos modelos lógico-formais e da concepção de uma ciência do design ${ }^{247}$ junto à pesquisas de computação em auxílio ao

244 O filósofo alemão Martin Heidegger (1989-1976), que lecionou nas uni versidades de M arburg (1923-27) e Frei burg (192744), tem seu pensamento comumente associado à fenomenologia e ao existencialismo, embora caiba ressaltar que o mes mo deva ser identificado como parte de tais movimentos filosóficos apenas com extremo cuidado e qualificação. Suas ideias têm exercido uma influência seminal sobre o des envol vimento do pens amento filosófic o contemporâneo Europeu, contribuindo par a campos di versos como, a hermenêutica, a teoria política, psicologia e teologia. Enciclopédia Stanford de Filosofia, disponível em: <http://plato.stanford.edu/entries/heidegger/> e Enciclopédia Internet de Filosofia IEP, disponível em: $<$ http://www.iep.utm. edu/heidegge/> Acess o em: 12/08/2011.

245 O filós ofo alemão Hans-Georg Gadamer (1900-2002) lecionou na Alemanha em Kiel em 1934-35, e depois, em 1939, assumiu a Diretoria do Institu to Filosófico da Uni versidade de Leipzig, tornando-se decano da Faculdade, em 1945, e reitor em 1946, antes de regressar ao ensino e pesquisa em Frankfurt, em 1947 e em Heidel berg em 1949, onde veio oficial mente se aposentar (tornando-se Professor Emérito) em 1968. Estudioso da filologia clássica e do pensamento neo-kantiano, e profundamente afetado pela filosofia de Martin Heidegger, Gadamer desenvolveu uma abordagem distinta baseada na dialógica pl atônico-aristotélica, bem como no pens amento heideggeriano, que rej eitou o subjeti vismo e o relativis mo, evocando a ess encialidade da inter pretação para a compreensão. O caráter dialógico da abordagem de Gadamer é evidenciado no papel teórico centr al que ele dá ao conceito de diálogo em seu pens amento. Enciclopédia Stanfor d de Filos ofia. Disponível em: <http://plato.stanford. edu/entries/gadamer/> Acess o em: 12/08/2011.

246 Segundo breve panorama do doutor e pesquisador norte-americano Robert Sokolowsk, da Escola de Filosofia da Universidade Católica da América em Washington, Estados Unidos: "A hermenêutica começou como um movimento especific amente alemão, com Friedrich Schleier macher (1768-1834) e especialmente Willhel m Dilthey (1833-1911) que foi contemporâneo de Edmund Husserl. A hermenêutica ressaltou originalmente as estruturas de ler e interpretar textos do passado e apresentou seu trabalho como uma filosofia da interpretação bíblica e literária e de pesquisa histórica. Heidegger expandiu a compreensão de hermenêutica do estudo de textos e documentos para a autoi nterpretação da existência humana como tal. A pessoa primariamente associada à hermenêutica é, naturalmente, Has-Georg Gadamer, que não foi só um estudioso de Heidegger, mas também outro intérprete de Platão, Aristóteles e textos poéticos. [...] Gadamer foi infl uenciado por Heidegger, sob cuja orientação estudou em Marburgo, mas menos influenciado por Husserl, com quem também estudou em Friburgo." (SOKOLOWSKI, 200012010, p.235-236)

247 De acor do com a conc epção em Herbert A. Simon (1916-2001) em seu 'As Ciências do Artificial' de 1969. 
processo projetual neste contexto, conforme exposto na apresentação do artigo '/s Designing Hermeneutical?', escrito pelos autores em 1991 e publicado em 1997:

\begin{abstract}
Antes do mo mento da escrita, pensamos que o debate sobre se você poderia, ou precisava, aplicar os métodos da ciência no estudo do projeto arquitetônico havia retroœdido, e não mais provocado interesse. Filósofos da ciência já haviam estabelecido que o funcionamento contingente, cultural e contestado das humanidades proporcionavam um 'modelo' melhor que os métodos de laboratório científico em todo o caso. A prática arquitetônica há muito tinha decidido que não havia necessidade de recorrer à ciência para legitimar suas atividades, e o método de ensino de estúdio, com suas práticas abertas, dialógicas e materialmente baseadas, tinha reafirmado-se como um modelo altamente respeitado da eduçção. [...] Mas havia umoutro fator que influenciava a pesquisa em design. Em 1991, 0 otimismo sobre o computador estava em seu apogeu. Preocupados com suas agendas técnicas, com pouco tempo ou inclinação para absorver os debates mais amplos ou exerciar as suas implicações, foi fácil para os pesquisadores orientados à œmputação caírem na fórmula simples de pesquisa: uma ciência de design?248 (SNODGRASS; COYNE, 1997/2006, p.23, tradução nossa)
\end{abstract}

Para Snodgrass e Coyne (1992, p.56), a ciência do design baseia suas pesquisas sobre o processo projetual em modelos derivados de teorias pertencentes às ciências lógicoempíricas. Por sua vez, metodologias do design são baseadas em resolução de problemas, análise, síntese e avaliação e outros modelos que representam o processo projetual como um problema matemático a ser solucionado através de passos lógicos prescritos. Os autores sublinham que estes modelos não são de modo algum periféricos, como parte de um expediente didático, pedagógico ou meramente explanatório, mas "[...] eles são fundamentais para o empreendimento científico, e os pesquisadores da ciência do design têm enfatizado a importância de modelos científicos explicitamente formulados baseados em

\footnotetext{
248 Do original em inglês: "Prior to the time of writing, we thought the debate about whether you could, or needed to, apply the methods of science to study in architectural design had receded, and no longer provoked interest. Philos ophers of science had already established that the contingent, cultural and contested workings of the humanities provided a better 'model' of the methods of labor atory science in any case. Architectural practice had long decided that there was no need to appeal to science to legitimate its activities, and the studio teaching method, with its open-ended, dialogical and materially-based practices, had reasserted its elf as a highly respected model of education. [...] But there was another factor that influenced design res earch. In 1991 optimism about the computer was at its zenith. Preoccupied with its technical agenda, with little time or inclination to absorb the wider debates or work out their implications, it was an easy matter for computer-oriented researchers to fall into simple res earch for mula: a science of design."
} 
uma metodologia rigorosa para os estudos de design",249 (SNODGRASS; COYNE, 1992, p.57, tradução nossa). Segundo os autores, a utilização de modelos científicos para descrever e explicar o processo projetual baseia-se em dois pressupostos: 1. é assumido que o projetar procede como um processo lógico que pode ser expresso em linguagens formais como a matemática ou lógica simbólica; 2. é assumido que estes modelos correspondem ao processo projetual de uma maneira lógico-dedutiva. Snodgrass e Coyne (1992, p.59-62) refutaram esta premissa, afirmando que as funções semânticas e reveladores de modelos não são fundamentadas em suas estruturas lógicas, mas em suas estruturas metafóricas ${ }^{250}$. Para eles, a metáfora não é apenas uma figura de linguagem, mas uma figura de pensamento ${ }^{251}$, um tipo de estrutura cognitiva inerente a to da transposição de conceitos, seja entre palavras e imagens, entre texto e seu contexto, entre partes e o todo de algum sentido ou sistemas complexos (SNODGRASS; COYNE, 1992, p.62). De acordo com esta concepção, Snodgrass e Coyne (1992) afirmaram que os modelos científicos do projetar são também metáforas, que procuram transferir os conceitos envolvidos nas relações estruturais de teorias científicas em relações de estruturação do referente, de modo que uma estrutura é vista como a outra. Neste sentido, aponta-se novamente a questão do insucesso dos modelos científicos de design quanto a sua aplicabilidade nas situações da prática, e a configuração de uma lacuna entre as promessas vinculadas em suas elaborações e sua efetiva realização: "[...] a razão para esta lacuna não está em uma suposta inércia ou preconceito anticientífico da parte dos designers, mas uma falta de correspondência entre os modelos do processo de design e o processo em si como experimentados pelos designers em sua prática"252 (SNODGRASS; COYNE, 1992, p.71, tradução nossa). Outra questão colocada diz respeito à observação de que as metáforas ao mesmo tempo permitem certas compreensões enquanto negam outras: "Metáforas revelam ao mes mo tempo que ocultam. Jogam luz sobre certos aspectos de um

249 Do original em inglês: "[...] they are pivotal to the scientific enter prise, and design science res earchers have emphasized the importance of explicit for mulated scientific models based on a rigorous methodology for studies of designing."

250 Snodgrass e Coyne (1992, p.62) observam que a palavra grega metaphora significa 'transferência', portanto, metáf ora pode ser compreendi da como a transferência de um conceito para outro.

251 Schön corrobora com esta compreensão acerca da importância das metáforas como processos cognitivos próprios do pens amento humano, conforme podemos obs ervar em suas obras: SCHÖN, D. Displacement of concepts. London: Tavistok, 1963; e SCHÖN, D. Generative metaphor: A perspective on problem-setting in social policy. In: ORTONY, A. (ed.) Metaphor and thought. Cambridge Press, p.137-162.

252 Do original em inglês: "[...] The reas on for this gap lies not in some suppos ed inertia or antiscientific prejudice on the part of designers, but in lack of correspondence between models of the design process and the process its elf as experienced by designers in their practice". 
conceito e obscurecem outros, como um holofote ressalta objetos contra um fundo de escuridão e esconde todo o resto." ${ }^{253}$ (SNODGRASS; COYNE, 1992, p.71, tradução nossa). Diante desta premissa, os autores obsenaram a relevância no estabelecimento de uma abordagem alternativa às metáforas e modelos científicos do design: "[...] ao enfatizar a reflexão, experiência, julgamento, interpretação, práticas culturais e metáfora, estamos alargando consideravelmente o âmbito da compreensão do design, e trazendo estas áreas da experiência do design excluídas pelo racionalis mo no discurso."254 (COYNE; SNODGRASS, 1995, p.48, tradução nossa). Estas são algumas das considerações pelas quais Snodgrass e Coyne justificaram a adoção dos princípios colocados na concepção projetual de Schön $(1983,1984$, 1988/1992, 1992) em correspondência com as metáforas hermenêuticas, em detrimento às metáforas do pensamento científico:

Aplicando as ideias de Schön, podemos prontamente encontrar metáforas hermenêuticas para substituir os modelos baseados em lógica que têm dirigido à pesquisa em design ao longo dos últimos cinquent anos. Modelos como o círculo hermenêutico de compreensão, a troca dialógica de pergunta e resposta, a metáfora do jogo, e a metáfora da metáfora em si mesma pode preencher adequadamente a lacuna deixada pela metáfora de resolução de problemas, a metáfora de análise/síntese/avaliação, a metáfora da linguagem atômica, e várias outras metáforas que a ciência de design tem extraído das ciências naturais. ${ }^{255}$ (SNODGRASS; COYNE, 1992, p.74 tradução nossa)

Conforme observamos, Snodgrass e Coyne (1992) consideram os modelos científicos como metáforas que descrevem o processo projetual em termos de um conjunto logicamente consistente e coerente de relações extraídas de base teórico-científica pela linguagem matemática (SNODGRASS; COYNE, 1992, p.72). Para os autores, o poder das metáforas baseadas na lógica está em sua capacidade de concentrar-se em características específicas e bem

253 Do original em inglês: "Metaphors reveal at the same time that they conceal. They throw light on certain aspects of a concept and obscure others, just as a spotlight picks out objects against a background of darkness and hides everything els e."

254 Do original em inglês: "[...] by emphasizing reflection, experience, judgment, interpretation, cultural practices, and metaphor, we are considerably widening the scope of design understanding, and bringing those areas of design experience excluded by rationalis m into the discourse".

255 Do original em inglês: "Applying Schön's ideas, we can readily find her meneutical metaphors to replace the logic-based models that have driven design research over the last fifty years. Models such as the her meneutical circle of understanding, the dialogical exchange of question and answer, the metaphor of play, and the metaphor of metaphor its elf can appropriately fill the gap vacated by the problemsolving metaphor, the analysis/synthesis/evaluation metaphor, the atomic language metaphor, and the various other metaphors design science has drawn from the natural sciences". 
definidas do projetar, permitindo a estruturação destas características para propósito de pesquisa, por exemplo (SNODGRASS; COYNE, 1992, p.73). Porém, pela mesma caracterização, elas acabam fechando-se em si mesmas e em suas definições restritivas e assim permanecem limitadas em seus próprios horizontes. Em contraposição, afirma-se que a qualidade essencial das metáforas hermenêuticas está em sua abertura para interpretações, permitindo a compreensão do processo projetual à medida que ele muda de situação para situação, fomentando a geração de outras metáforas: "Quanto maior a ambiguidade, mais questões a metáfora levanta e, portanto, ela concede um ímpeto ainda maior para uma troca dialógica de pergunta e resposta. A metáfora hermenêutica não dá explicações rigorosas de seu referente, mas incita o diálogo e, assim, amplia horizontes." ${ }^{256}$ (SNODGRASS; COYNE, 1992, p.72, tradução nossa). Com base nesta comparação, Snodgrass e Coyne (1992) reiteram seu argumento a favor da adoção das metáforas hermenêuticas na concepção do projetar:

\begin{abstract}
Uma metáfora hermenêutica [...] é u ma que é ampla e flexível o suficiente para dar conta do processo de design tant como um todo e como um complexo de partes interagentes. Por exemplo, a metáfora do círculo hermenêutico, que vê o processo de design como uma troca dialógica entre o designer e a situação do design, tem tolerância conœitual o bastante para preservar a totalidade daquilo que ele modela, ao mesmo tempo que descreve 0 funcionamento das partes. 0 círculo hermenêutico não quebra o projetar em fragmentos; destrói a complexidade, a sutileza e singularidade da situação do projeto, ou privilegia ou exclui aspectos do processo, mas sim respeita a sua interdependência e interação. Essa metáfora é hermeneuticamente rica; como o processo que modela, ela leva a interpretações ilimitadas aplicáveis em situações únicas e sem preœdentes.257 (SNODGRASS; COYNE, 1992, p.72, tradução nossa)
\end{abstract}

Através deste viés, damos continuidade à nossa investigação sobre o projetar arquitetônico,

\footnotetext{
256 Do original em inglês: "The greater the ambiguity, the more questions the metaphor raises and, hence, the greater impetus it gives to a dialogical exchange of question and answer. The hermeneutical metaphor does not give rigorous explanations of its referent, but prompts dial ogue and, thereby, expands horizons."

257 Do original em inglês: "A her meneutical metaphor [...] is one which is broad and flexible enough to give an account of the design process both as a whole and as a complex of interacting parts. For example, the metaphor of the her meneutical circle, which sees the design process as a dialogical exchange between the designer and the design situation, has enoughconceptual tolerance to preserve the wholeness of what it models, even as it describes the functioning of the parts. The hermeneutical circle does not break designing into fragments; destroy the complexity, subtlety and uniqueness of the design situation; or privilege or preclude aspects of the process, but rather respects their interdependence and interaction. Such a metaphor is hermeneutically rich; like the process it models, it leads to limitless interpretations applicable in unique and unprecedented situations."
} 
aproximando-nos da filosofia hermenêutica e de suas formas metafóricas como uma abordagem alternativa aos modelos sistemáticos do processo projetual, evidenciando sua correspondência com a concepção de conversação de Schön (1983).

\subsubsection{O círculo hermenêutico e a onipresença do projetar}

Segundo Snodgrass e Coyne (1997/2006), a questão da interpretação recebeu um tratamento sistemático na obra do teologista e filologista alemão Friedrich Schleiermacher ${ }^{258}$ (1768-1834), que formulou sua 'Hermenêutica Geral' em 1810, na qual caracterizou o objetivo da hermenêutica desvendar os processos da compreensão de textos e obras literárias afins (SNODGRASS; COYNE, 2006, p.8). Nesta versão da hermenêutica, Schleiermacher postulou em favor da analogia de que a interpretação seria uma reconstrução, no sentido de que só poder-se-ia compreender algo desde que fossem reconstruídas todas as suas relações de acordo com seu contexto originário, o que implica na deter minação uma certa orientação ou posicionamento, de modo que "interpretar algo é posicioná-lo dentro de um conjunto de relações"259 (SNODGRASS; COYNE, 2006, p.8, tradução nossa). Os autores observam a correspondência entre os termos 'posicionar' e 'apontar' na compreensão de Gadamer (1975/1997) para o qual a interpretação implica apontar em uma direção particular. Termos familiares à arquitetura, como 'apontar', 'orientar', 'posicionar', 'conectar', 'localizar', 'relacionar' etc., deste modo dizem respeito à interpretação: "posicionar e apontar constituem a base de sinais e sistemas de significação, os primórdios da linguagem e interpretação."260 (SNODGRASS; COYNE, 2006, p.9, tradução nossa). Afirma-se uma relação fundamental entre a arquitetura e interpretação, uma vez que o interpretar ou posicionar compreende o estabelecimento de relações de significados, pelas quais originariam-se as coerências, ordens, razões, partes e proporções, elementos ancestrais na constituição arquitetônica:

\footnotetext{
${ }^{258}$ Friedrich Schleier macher (1768-1834) foi um teól ogo e filól ogo alemão a quem é atribuído o projeto de uma her menêutica geral e universal aplicável a qualquer evento de interpretação, fundamentando-a assim em uma dimensão filosófica. Para um entendi mento aprofundado ver: RICOUR, P. Interpretação e Ideologias. Rio de J aneiro: Ed. Forense, 1988.

259 Do original em inglês: "To interpret something is to position it within a set of relationships."

260 Do origin al em inglês: "Positioning and pointing constitute the basis of signs and systems of signification, the beginnings of language and interpretation."
} 
Começamos com a proposição de que a arquitetura é interpretacional na medida em que envolve posicionamento. Posicionar é invocar um momento arquitetônio primário. Ser posicionado é também manter um ponto de vista, uma interpreação, ou talvez o início de uma interpretação. [...] esse entendimento rudimentar de interpretação implica coerência, uma visão importante do antigo legado Vitruviano, que dominou os tratados de arquitetura do Renascimentb e dos primeiros Modemos. Este é também um argumento sobre a parte e 0 todo. Hermenêutica, o estudo da interpretação, agarra a problemática da parte e do todo como fundamental. A fim de compreender uma parte de um tex to é preciso entender o todo. O todo só pode ser entendido como uma amálgama de muitas partes. 0 mesmo vale para a forma de um edifício, de acordo $\infty m$ a tradição clássica. À maneira que cada elemento deveria ser posicionado e proporcionado de modo a formar uma unidade que é o edifício. 0 edifício também imita uma unidade mais ampla ou de ordem universal. Coerência entre as partes é concomitante com a coerência de entendimento?261 (SNODGRASS; COYNE, 1997/2006, p.22, tradução nossa).

A relação entre as partes e o todo, e o estabelecimento de coerências na medida em que a compreensão do sentido do todo passa pela compreensão das partes e vice-versa diz respeito a uma observação sobre a circularidade dos processos de interpretação central à hermenêutica do filósofo alemão Wihelm Dilthey ${ }^{262}$ (1833-1911), que sucedeu Schleiermacher no desenvolvimento do pensamento hermenêutico e providenciou uma base teórica na qual Heidegger e Gadamer elaboraram a teoria contemporânea da interpretação (SNODGRASS; COYNE, 2006, p.13). Este conceito de circularidade comum à obra destes filósofos e que corresponde à acomodação e reacomodação da compreensão de acordo com a relação

261 Do original em inglês: "We began with the proposition that architecture is interpretational in so far as it involves positioning. To position is to invoke a primary architectural moment. To be positioned is also to hold a point of view, an interpretation, or is perhaps the start of an interpretation. [...] this rudimentary understanding of interpretation implicates coherence, a major insight of the ancient Vitruvian legacy, which dominated the architectural treatises of the Renaissance and the early moderns. This is also an argument about the part and the whole. Hermeneutics, the study of interpretation, grasps the problematic of the part and the whole as pivotal. In order to understand a part of a text one needs to understand the whole. The whole can only be understood as an amalgamation of so many parts. The same applies to the for m of a building, according to the classical tradition. It was though that each element must be positioned and proportioned so as to form a unity that is the building. The building also imitates a wider unity or universal order. Coherence between the parts is concomitant with the coherence of understanding."

262 O filósofo al emão Wihelm Dilthey (1833-1911), responsável pela formalização da circularidade her menêutica, é também conhecido por promover a distinção entre ciências naturais e humanas, consider ando que a tarefa primor dial das ciências naturais é chegar a explicações baseadas em leis, a tarefa principal das ciências humanas seria a compr eens ão da história e vida do homem. Es te compreender, par a Dilthey, exigia tanto uma artic ulação interna das estr uturas temporais de nossa própria experiência quanto a inter pretação de objetivações externas dos outros. Enciclopédia Stanford de Filosofia, disponível em: <http://plato.stanford. edu/entries/dilthey/> Acesso em: 12/08/2011. 
entre partes e todo, é denominado 'círculo her menêutico' (SNODGRASS; COYNE, 2006, p.35). Para a teoria hermenêutica, conforme expressa na obra de Gadamer (1975/1997; 1976/2002), a compreensão é um processo dinâmico que se realiza pela formulação do círculo hermenêutico da interpretação, cuja concepção axiomática remeteria originalmente à antiga retórica grega ${ }^{263}$ :

A regra hermenêutica, segundo a qual devemos compreender o todo a partir do singular e 0 singular a partir do todo, provém da retórica antiga e foi transferida, pela hermenêutica moderna, da arte de falar para a arte de compreender. Em a mbos os casos, estamos às voltas com uma relação circular prévia. A antecipação de sentido, que comporta o todo, ganha uma compreensão explícita através do fato de as partes, determinadas pelo todo, determinarem por seu lado esse mesmo todo. (GADAMER, 1976/2002, p.72)

Snodgrass e Coyne (1997/2006, p.36) observaram a colocação de uma questão lógica preliminar quanto ao fenômeno da circularidade hermenêutica, pela configuração de um paradoxo: uma vez que necessita-se de uma compreensão geral para a compreensão das partes e por sua vez a compreensão geral depende da compreensão das mesmas partes, como resultado da aplicação deste postulado o processo em si não poderia ser iniciado. A resposta a esta questão, segundo os autores, depende de dois entendimentos essenciais sobre o funcionamento do círculo hermenêutico: 1. que os processos interpretativos são situados em nossa experiência de vida e não podem ser desconsiderados de um sentido existencial contextualizado a partir do qual 2. projetamos sentidos em nossas expectativas sobre as coisas, ou seja, "a interpretação traz consigo uma antecipação, ainda que vaga e informal, do sentido do todo, e a luz desta antecipação ilumina de forma retroativa as partes."264 (SNODGRASS; COYNE, 1997/2006, p.37, tradução nossa). Em outras palavras, para entendermos de fato a formulação hermenêutica devemos apreender um sentido de 'projetar' que é essencial a este processo, ou seja, projeta-se um significado do todo e esta projeção preliminar é continuamente revisada: "A projeção, em primeiramente incerta e só

\footnotetext{
263 Gadamer traça as origens da regra das partes e do todo com relação à retórica clássica, porém sublinha a distinção própria da hermenêutica: "Toda a história do pens amento confir ma ess a antiga proxi midade entre a retórica e a hermenêutica. No entanto, a hermenêutica contém sempre um elemento que ultrapassa a mera retórica: inclui sempre um encontro com as opiniões do outro, que vem, por sua vez, à fala. [...] Por isso a hermenêutica é filos ofia porque não pode ser restrita a uma teoria da arte, que 'apenas' compreende as opini ões do outro. A hermenêutica implica, antes, que toda compreensão de algo ou de um outro vem precedida de uma autocrítica. Aquele que compreende não postula uma posição superior. Confessa, antes, a necessidade de col ocar à prova a verdade que supõe própria." (GADAMER, 1976/2002, p.140-141)

264 Do original em inglês: "Inter pretation brings with it an anticipation, albeit vague and infor mal, of the meaning of the whole; and the light of this anticipation plays back to illuminate the parts."
} 
existente em linhas gerais, volta-se para a interpretação das partes, exigindo a sua revisão, mes mo que o significado que se projetou seja continuamente revisto à luz da interpretação e crescente compreensão das partes."265 (SNODGRASS; COYNE, 1997R2006, p.37, tradução nossa). Assim, como resultado deste processo de reacomodação reflexiva, a compreensão do todo emerge gradualmente. Este 'projetar' representa uma noção essencial à hermenêutica moderna, cuja contribuição, segundo Snodgrass e Coyne, remete-se ao pensamento ontológico heideggeriano: "Não só jogamos para frente nossas pré-compreensões em cada ato de interpretação, diz Heidegger, mas os pré-entendimentos em si são 'jogados' em nossa situação presente a partir da experiência passada."266 (SNODGRASS; COYNE, 1997/2006, p.39, tradução nossa). Com base neste entendimento, os autores afirmam não ser possível conceber a existência humana como algo 'objetivo', à medida que somos "[...] lançados no meio de uma rede de entendimentos de práticas, instituições, convenções, objetivos, instrumentos, expectativas e uma infinidade de outros fatores que fazem de nós o que somos."267 (SNODGRASS; COYNE, 1997/2006, p.39, tradução nossa). A este respeito, cabe citar o próprio Heidegger (1927/1989) que sublinhou a necessidade de atenção sobre os pré-entendimentos que são vinculados naturalmente ao processo de interpretação pelo círculo her menêutico:

O círculo não deve ser rebaixado a um vitiosum, mesmo que apenas tolerado. Nele se esconde a possibilidade positiva do conhecimento mais originário que, de cerb modo, só pode ser apreendida de modo autêntico se a interpretação tiver compreendido que sua primeira, única e última tarefa é de não se deixar guiar, na posição prévia, visão prévia e concepção prévia, por conceitos ingênuos e 'chutes'. Ela deve, na elaboração da posição prévia, da visão prévia e da concepção prévia, assegurar o tema científico a partir das coisas elas mesmas. (HEIDEGGER, 1927/1989, p.201)

\footnotetext{
265 Do original em inglês: "The projection, at first unclear and only existing in outline, plays back into the interpretation of the parts, requiring their revision even as the projected meaning itself is continually revised in the light of the interpretation and increasing understanding of the parts." Em outras palavras, segundo a descrição de Gadamer (1976/2002) sobre a interpretação textual: "Quem quiser compreender um texto deverá sempre realizar um projeto. El e projeta de antemão um sentido do todo, tão logo se mostre um primeiro sentido no texto. Ess e primeiro senti do somente se mostra porque lemos o texto já sempre com certas expectativas, na perspectiva de um determinado sentido. A compreensão daquilo que está no texto consiste na elaboração desse projeto prévio, que sofre uma constante revisão à medida que aprofunda e amplia o sentido do texto." GADAMER (1976/2002, p.75)

266 Do original em inglês: "Not only do we throw forward our pre-understandings in every act of interpretation, says Heidegger, but the pre-understandings themselves have been 'thrown' into our present situation from pas texperience."

267 Do original em inglês: "[...] thrown into the midst of a network of understandings of practices, institutions, conventions, aims, tools, expectations and a multitude of other factors that make us what we are."
} 
Afirma-se nesta passagem a necessidade de uma concretização da consciência dos sentidos históricos que conformam a compreensão prévia de algo, por parte do indiv íduo, de maneira a evitar a obstrução de sentidos legítimos da compreensão por suas opiniões prévias e preconceitos, e assim "realizar a compreensão guiada pela consciência histórica, de forma que a apreensão da alteridade histórica e o emprego que ali se faz dos métodos históricos não consista simplesmente em deduzir o que a ela se atribuiu de antemão" (GADAMER, 1976/2002, p.77). Gadamer referiu-se a estes pré-entendimentos atrelados a um sentido histórico como 'preconceitos' (pré-conceitos) ou mesmo prejuízos (pré-juízos, juízos prévios), inerentes aos processos interpretativos pela sua natureza ontológica, e portanto, desvelados de conotações negativas ou pejorativas: "todo entendimento, diz ele, necessariamente envolve prejuízo, sentidos prévios que não são totalmente objetificáveis." ${ }^{268}$ (SNODGRASS; C OYNE, 1997/2006, p.38, tradução nossa). Segundo Gadamer (1976/2002), todo preconceito ou prejuízo a princípio pode permitir ou negar a interpretação de algo, caracterizando um processo interpretativo complexo em que cada revisão da projeção prévia de um pré-juízo pode lançar uma outra projeção de sentido, projeções conflitantes ou concorrentes podem posicionar-se lado a lado na elaboração de uma interpretação até que se confirme de modo mais inequívoco um sentido, "que a interpretação começa com conceitos prévios substituídos depois por conceitos mais adequados" (GADAMER, 1976/2002, p.75). Com base nesta premissa, Gadamer ressaltou assim como Heidegger (1927/1989, p.201) a necessidade de se questionar a adequação do projetar, cuidando para que o mesmo possa se confirmar ou não no objeto de interpretação:

Em suma, esse constante projetar de novo é o que perf́z o movimento semântico de compreender e de interpretar. Quem procura compreender está sujeito a errar por causa das opiniões prévias, que não se confirmamnas coisas elas mesmas. Dessa forma, a constante tarefa do compreender consiste em elaborar projebs corretos, adequados às coisas, isto é, ousar hipóteses que só devem ser confirmadas 'nas coisas elas mesmas'. (GADAMER, 1976/2002, p.75)

Esta colocação indica a necessidade da adoção de um 'proceder' frente à interpretação visando a superação de pré-direcionamentos recorrentes em nossas opiniões capazes de

268 Do original em inglês: "All understanding, he says, necessarily involves prejudice, foremeanings that are not fully objectific able." 
desabilitar os sentidos próprios e originais, legítimos da 'coisa em si', a qual se interpreta, ou seja, o desenvolvimento de uma maneira de acessar a validação ou adequação das interpretações (GADAMER, 1976/2002). Porém, segundo a observação de Heidegger (1927/1989), não é possível se colocar à parte do círculo de interpretações e estabelecer métodos "[...] pelos quais possamos nos referenciar para acessar a verdade ou falsidade de nossas interpretações. Nós já estamos nele, em todos os nossos pensamentos e ações, inclusive no ato de estabelecer critérios científicos de validação"269 (SNODGRASS; COYNE, 1997/2006, p.39, tradução nossa). Desta forma, nossas interpretações, adequadas ou não, baseiam-se em interpretações que da mesma forma apelam a outras interpretações em uma regressão incessante, de forma que "[...] essa falta de certeza final e absoluta é o predicamento epistemológico inescapável que é construído sobre a condição humana. É uma condição da nossa própria finitude"270 (SNODGRASS; COYNE, 1997/2006, p.40, tradução nossa). Esta abordagem da compreensão, entendida como um processo de acomodação de significados em um sentido histórico, contrapõe-se fundamentalmente à dicotomia sujeito-objeto pressuposta no pensamento cartesiano, subjacente à validação de hipóteses por estruturas lógico-racionais, como as tradicionalmente empregadas no pensamento científico:

O significado não é fixo e firme, mas é histórico, muda com o tempo e como a situação muda. $O$ entendimento está em fluxo perpétuo. Significado não é um objeto imutável que está defronte de nós, mas é parte em constante mudança de uma situação em constante mudança. Não é um objeto, mas também não é subjetivo. Não é algo que nós pensamos primeiro e depois lançamos sobre umobjeto externo. Sabe-se de dentro e só se pode saber assim: não podemos dar a volta em frente do significado, não mais do que podemos dar a volta na frente da linguagem. Esta mos e mbutidos em estruturas de significado, e assimnão podemos vê-las como objetos que podem ser testados pelos critérios da lógica. Significado existe antes de qualquer separação entre sujeito e objeto. № ab interpretativo, a dicotomia cartesiana sujeib-objeto dissolve-se. ${ }^{271}$ (SNODGRASS; COYNE, 1997/2006, p.40, tradução

\footnotetext{
269 Do original em inglês: "[...] to which we can refer to ass ess the truth or falsity of our interpretations. We are already in it, in all our thinking and actions, incl uding the act of establishing scientific criteria of validation."

270 Do original em inglês: "[...] this lack of final and absolute certainty is the inescapable epistemological predicament that is built into the human condition. It is a condition of our own finitude."

271 Do original em inglês: "Meaning is not fixed and firm but is historical; it changes with time and as the situation changes. Understanding is in per petual flux. Meaning is not an immutable object that stands over against us but is an ever-changing part of an ever-changing situation. It is not an object, but neither is it subjective. It is not something we think first and then throw over onto an external object. It is know from within and can only be so known: we cannot get around in front of meaning, any more than we can get around in front of language. We are embedded in meaning structures, and so cannot view them as objects that
} 
nossa).

Diante desta aferição sobre a natureza her menêutica da compreensão e da necessidade de validação das interpretações, conforme observou Gadamer (1975/1997;1976/2002), é pressuposto que o intérprete seja capaz de questionar seus pré-entendimentos, interrogar-se, à luz das situações e do horizonte $^{272}$ a que ela implica, modificando sua compreensão através de uma relação dialética: "saber quer dizer sempre entrar ao mesmo tempo no contrário. Nisso consiste sua superioridade frente ao deixar-se levar pela opinião, que sabe pensar possibilidades como possibilidades. O saber é fundamentalmente dialético." (GADAMER, 1975/1997, p.538). Este é o modo pelo qual posiciona-se a metáfora da conversação no pensamento hermenêutico de Gadamer, entendida como uma forma dialética genuína, para a descrição da natureza hermenêutica da compreensão, como veremos logo mais.

\subsubsection{A natureza conversativa do e vento herme nê utico}

Em sua obra, 'Verdade e Método', Gadamer recorreu à dialética clássica para elucidar a natureza do evento her menêutico, distinguindo o modelo platônico de diálogo como detentor de uma 'primazia especial' na busca da verdade ${ }^{273}$ : "quando duas pessoas se encontram e trocam experiências, trata-se sempre do encontro entre dois mundos, duas visões e duas imagens de mundo" (GAD AMER, 1976/2002, p.246). O filósofo obsenou que este reconhecimento é comunicado pela elaboração teórica e esforço conceitual dos grandes pensadores clássicos como Platão, que não comunicou sua filosofia em diálogos escritos só por reconhecimento ao mestre do diálogo, Sócrates, mas porque "viu ali um princípio da verdade, segundo o qual a palavra só encontra confirmação pela recepção e aprovação do outro e que o pensamento que não viesse acompanhado do pensamento do outro seria inconsequente e

can be tested by the criteria of logic. Meaning exists prior to any separation of subject and objects. In the interpretative act the Cartesian subject-obj ect dic hotomy dissolves."

272 Para Gadamer (1975/1997, p.452): "Nós determinamos o conceito da situação justamente pelo fato de que repres enta uma posição que li mita as possibilidades de ver. Ao conc eito da situação pertence ess encial mente, então, o conc eito do horizonte. Horizonte é o âmbito de visão que abarca e encerra tudo o que é visível a partir de um determinado ponto."

273 Gadamer (1976/2002, p.245) cita os filós of os Friedrich Schl eiermacher e Friedrich Schlegel (1772-1829) no sentido de precederem como advogados da dialética platônica através da exaltação do diálogo e da modalidade da conversação interpess oal com relação a uma maior val orização quanto a sua função filos ófica atribuída. 
sem força vinculante" (GADAMER, 1976/2002, p.246). Uma vez observada a natureza de constante mudança e transformação dos significados em um sentido histórico, e a necessidade de afirmação da adequação das interpretações em um sentido de verdade, podemos entender a compreensão como um acordo ou desacordo entre os sentidos desvelados em um processo hermenêutico, dialógico: "É tarefa da hermenêutica esclarecer o milagre da compreensão, que não é uma comunicação misteriosa entre as almas, mas participação num sentido comum.” (GAD AMER, 1976/2002, p.73). É neste sentido de coparticipação com relação a um sentido comum, que Gadamer exalta o diálogo ou sua versão especial, referida como 'conversação ${ }^{274}$, como o evento hermenêutico quintessencial (SNODGRASS; COYNE, 1997/2006, p.41). Esta concepção de conversação ou diálogo no pensamento de Gadamer pode ser esboçada nos seguintes termos:

A conversação é um processo pelo qual se procura chegar a um acordo. Faz parte de toda verdadeira conversação 0 atender realmente ao outro, deixar valer os seus pontos de vista $e$ pôr-se em seu lugar, e talvez não no sentido de que se queira entendê-lo como esta individualidade, mas simno de que se procura entender o que ele diz. O que importa que se acolha é o direito de sua opinião, pautado na coisa, através da qual podemos chegar a nos por de acordo com relação à coisa. (GADAMER, 1975/1997, p.561)

Como conversação entende-se um diálogo genuíno no qual indivíduos são imersos em discussão, ambos interessados em ampliar suas compreensões de um determinado assunto, assim como o é na dialética socrática ${ }^{275}$, através de um processo de interrogação e

\footnotetext{
274 Sobre a concepção de conversação, coloca-nos Gadamer (1976/2002, p.247): "O que é uma conversação? De certo que com isso pensamos num processo entre pessoas, que apesar de toda sua amplidão e infinitude potencial poss ui uma unidade própria e um âmbito fechado. Uma conversação é, para nós, aquilo que dei xou uma marca. O que perfaz uma verdadeira conversação não é termos experimentado algo de novo, mas termos encontrado no outro algo que ainda não havíamos encontrado em nossa própria experiência de mundo. Aquilo que movia os filós ofos a criticar o pensamento monológico é o mes mo que experimenta o indi víduo em si mesmo. A convers ação possui uma força tr ansformadora. Onde uma conversação teve êxito ficou algo para nós em que nos transformou. A convers ação possui, assim, uma grande proximidade com a amizade. É só na conversação (e no 'rir juntos', que funciona como um entendimento tácito transbordante) que os amigos podem encontrar-se e construir aquela espécie de comunhão onde cada qual continua sendo o mesmo para o outro porque ambos encontram o outro e encontram a si mesmos no outro" Observação: Nesta passagem optamos pela tradução de Manuel Olsagasti na versão espanhola de 1992 de 'Verdade e Método' publicado pela editora Sígueme, a despeito da versão em português que utiliza o ter mo 'diálogo' no lugar de 'conversação'. D e ac ordo com uma análise preliminar do sentido de emprego dos termos no pensamento de Gadamer nesta obra, a princípio parece correto admitir-se a utilização dos mesmos como sinôni mos.

275 Segundo a observação de Gadamer (1975/1997, p.542): "A produtividade maiêutica do diálogo socrático, sua arte de parturiente da palavra orienta-se, obviamente, às pess oas humanas que constituem os companheiros de diál ogo, porém limitase a manter-se nas opiniões que estes exteriorizam e cuja cons equência i manente e obj eti va desenvol ve-se no diálogo. O que
} 
apropriação, envolvendo o reconhecimento e assimilação do que não é familiar (SNODGRASS; COYNE, 1997/2006,p.41). O verdadeiro diálogo é marcado pela transformação de seus participantes, pelo qual chega-se a um acordo sobre determinados sentidos: "o objetivo de todo entendimento e compreensão é o acordo quanto à coisa. Dessa forma, a her menêutica teve, desde sempre, a tarefa de suprir a falta de acordo ou de restabelecer o acordo, quando perturbado" (GADAMER, 1976/2002, p.73). Este acordo implica um desvelar de uma compreensão para além das intenções iniciais individuais ${ }^{276}$, e, portanto, a conversação assume uma dinâmica própria, com seus próprios direcionamentos e desdobramentos, de forma a dificultar ou mes mo impedir seu controle ou condução por parte de seus envolvidos:

Costumamos dizer que 'levamos' uma conversação, mas a verdade é que, quanto mais autêntica é a conversação, menos possibilidade têmos interlocutores de 'levá-la' na direção que desejariam. De fato, a conversação autêntica não é nunca aquela que teríamos querido levar. Antes, em geral, seria até mais correto dizer que chegamos a uma conversação, quando não nos enredamos nela. Como uma palavra puxa a outra, como a conversação dá voltas para ć e para lá, encontra seu curso e seu desenlace, tudo isso pode ter talvez alguma espécie de direção, mas nela os dialogantes são menos os que dirigem do que os que são dirigidos. O que 'sairá' de uma conversação ninguém pode saber por antecipação. 0 acordo ou o seu fracasso é como um acontecimento que tem lugar em nós mesmos. Por isso, podemos dizer que algo foi uma boa conversação, ou que os astros nos foram favoráveis. São formas de expressar que a conversação tem seu próprio espírito e que a linguagem que nela discorre leva consigo sua própria verdade, isto é, 'revela' ou deixa aparecer algo que desde este momento é. (GADAMER, 1975/1997, p.559)

É esta a caracterização da conversação como processo dialético que a distingue fundamentalmente da retórica clássica enquanto arte do discurso, em que existe uma intenção subjacente de convencimento ou imposição das ideias próprias através da

vem à tona, na sua verdade, é o logos, que não é nem meu nem teu, e que por isso sobrepuja tão amplamente a opinião subjeti va dos companheiros de diálogo, que inclusi ve aquele que o conduz per manece sempre como aquele que não sabe. A dialética, como arte de conduzir uma conversação, é ao mesmo tempo a arte de ol har juntos na uni dade de uma perspecti va [...] isto é, a arte da for maç ão de conc eitos como elaboração da intenção comum."

276 Neste sentido afirmam Snodgrass e C oyne: "As c ondições são favoráveis quando o intérprete é entregue ao di álogo, como acontece quando estamos absortos em uma conversa estimulante. Nesta situação eu não escolho minhas palavas com cuidado, eu não planejo o que vou dizer, mas falo espontaneamente. Eu ouço as mi nhas próprias palavras, como eu pr oferi-las e, ao mesmo tempo como meu ouvinte ouve, e elas podem ser tão reveladoras para mim como el as são para o outro. A conversa transcende a separação entre sujeito e objeto. Eu interpr eto as perguntas do outro e objeções de maneiras de um modo distinto da intencionalidade do outro, quando proferidas. A conversa tem uma vida própria, levando os envol vidos em áreas que são novas para eles, e indo além de suas intenções iniciais e interess es." (SNODGRASS; COYNE, 1997/2006, p.44, tradução nossa). 
argumentação: "A arte da dialética não é a arte de ganhar de todo mundo na argumentação. Pelo contrário, é perfeitamente possível que aquele que é perito na arte dialética, isto é, na arte de perguntar e buscar a verdade, apareça aos olhos de seus ouvintes como o menos indicado a argumentar" (GADAMER, 1975/1997, p.540). Assim, a dialética depende da abertura ao questionamento, isto é, manter-se como uma investigação, uma experimentação, e deste modo, podemos afirmar que "a arte de perguntar é a arte de continuar perguntando; isso significa, porém, que é a arte de pensar. Chama-se dialética porque é a arte de conduzir uma autêntica conversação" (GAMADER, 1975/1997, p.540). A experiência hermenêutica é, portanto, uma investigação dialógica: "É claro que em toda experiência encontra-se pressuposta a estrutura da pergunta. Não se fazem experiências sem a atividade do perguntar" (GAMADER, 1975/1997, p.534). Por sua vez, a estrutura dialética de pergunta e resposta também é uma forma do círculo hermenêutico, pois toda pergunta posiciona-se de maneira preliminar a um determinado 'modo de ver' (SNODGRASS; COYNE, 1997/2006, p.42). A pergunta então vincula um direcionamento, o 'horizonte do perguntar, ${ }^{277}$, em contrapartida deixa em aberto a resposta, proporcionando o novo: "quando se pergunta, deixam-se abertas as possibilidades de sentido, de maneira que aquilo que tenha sentido possa ser introduzido na própria opinião" (GADAMER, 1975/1997, p.552). Deste modo "a estreita relação que aparece entre perguntar e compreender é a única que dá à experiência hermenêutica sua verdadeira dimensão" (GADAMER, 1975/1997, p.551), à medida que reconhece algo não como verdadeiro, mas simplesmente como algo com sentido, de maneira que a possibilidade de verdade fique em suspenso: "esse pôr-em-suspenso é a verdadeira essência original do perguntar. Perguntar per mite sempre ver as possibilidades que ficam em suspenso." (GADAMER, 1975/1997, p.551). Gadamer observou que esta qualidade de 'por em suspensão' do perguntar permite a revelação de novos sentidos sobre algo que se queira compreender, através da estrutura dialética de pergunta e resposta que se realiza nas verdadeiras conversações:

[...] acaba-se reconhecendo que para todo conhedimento e discurso, em que se queira conhecer o conteúdo das coisas, a pergunta toma a dianteira. Uma conversação que queira chegar a explicaralguma coisa predisa romper essa coisa através de uma pergunta. Esta é a razão pela qual a dialética realiza nos moldes de perguntas e respostas, ou melhor, que todo

277 Gadamer observa que: "É essencial a toda pergunta que tenha um sentido. Sentido quer dizer, todavia, sentido de orientação. O s enti do da pergunta é si multaneamente a única direção que a res posta pode adotar se quiser ser ad equada, com sentido. Com a pergunta, o interrogado é colocado s ob uma determinada perspec tiva." (GADAMER, 1975/1997, p. 534) 
saber passa pela pergunta. Perguntar quer dizer colocar no aberto. A abertura do perguntado consiste emque não está fixada a resposta. [...] o sentido de perguntar consiste em colocar em aberto o perguntado em sua questionabilidade. Ele tem que ser colocado em suspenso de maneira que se equilibremo pró e o contra. 0 sentido de qualquer pergunta só se realiza na passagem por essa suspensão, na qual $₫$ converte em uma pergunta aberta. (GADAMER, 1975/1997, p.535).

Devemos finalmente observar que a dialética dos processos de compreensão apresenta-se como uma experimentação pela estrutura de questionamento, porém de modo distinto da experimentação metodológica científica: "No método o investigador controla e manipula, na dialética, o assunto da discussão coloca questões a que o investigador responde. $O$ assunto interroga o investigador. O processo dialético é introduzido de modo que o assunto pode revelar-se."278 (SNODGRASS; COYNE, 1997/2006, p.42, tradução nossa). Afirma-se que a experiência tem a sua realização dialética não no conhecer, mas na própria abertura para a experiência, que é em si mesmo um estar em 'livre jogo' com a experiência (SNODGRASS; COYNE, 1997/2006). É neste sentido em que Gadamer reclamou a primazia da investigação dialética sobre o método científico junto à questão da busca da verdade, situando a ciência no contexto hermenêutico da condição humana:

No conjunto da nossa investigação evidencia-se que, para garantir a verdade, não basta 0 gênero de œrteza, que o uso dos métodos científicos proporáona. Isso vale especialmente para as ciências do espinito, mas não significa, de modo algum, uma diminuição de sua cientificidade, mas antes, a legitimação da pretensão de um significado humano especial, que elas vêm reivindicando desde antigamente. 0 fato de que, em seu conhecimento, opere também o ser próprio daquele que conhece, designa certamente o limite do 'método', mas não o da ciência. O que a ferramenta do método não alcança tem de ser conseguido e pode realmente sê-lo através de uma disciplina do perguntar e do investigar, que garante a verdade. (GADAMER, 1975/1997, p.709)

Afirma-se, portanto, o caráter fundamental da compreensão junto à percepção, pensamento e ações humanas, de modo que "[...] o processo hermenêutico é mais básico e anterior ao uso de lógica, linguagens formais e método científico, portanto forma a fundação para toda a

\footnotetext{
278 Do original em Inglês: "In method the inquirer controls and manipulates; in dialectic the subject matter of the discussion poses questions to which the inquirer responds. The subject matter interrogates the inquirer. The dial ectical process is entered into so that the subject matter can reveal its elf."
} 
racionalidade" ${ }^{279}$ (SNODGRASS; COYNE, 1997/2006, p.44, tradução nossa). Neste sentido, complementaram os autores, "[...] a hermenêutica é fundamental ao nosso modo de ser. Compreender não é uma de nossas atividades no mundo, mas é básico para tudo o que fazemos e somos."280 (SNODGRASS; COYNE, 1997/2006, p.44, tradução nossa). Nas palavras de Gadamer, [...] "compreender é o caráter original do ser da vida humana em si." ${ }^{281}$ (GADAMER, 1975 apud SNODGRASS; COYNE, 1997/2006, p.44, tradução nossa). Esta é a premissa fundamental para a formulação do projetar como um evento her menêutico da compreensão.

\subsubsection{O projetar arquitetônico como evento hermenêutico}

Observamos até o presente momento o modo pelo qual a filosofia hermenêutica coloca a questão da compreensão como um fenômeno inerente à existência humana, de acordo com a circularidade das interpretações que se estabelecem na estrutura de questionamento por perguntas e respostas (GADAMER, 1975/1997; 1976R2002; SNODGRASS; COYNE, 1997/2006). A partir daqui, podemos então retomar a descrição de Schön da atividade prática do design arquitetônico como uma conversação reflexiva com a situação (SCHÖN, 1983; 1984; 1988/1992; 1992) estabelecendo uma leitura deste processo à luz dos conceitos da hermenêutica, uma vez que [...] "mesmo um exame superficial dos estudos de protocolo de Donald Schön indica que o processo de design que ele descreve funciona de acordo com a dinâmica do círculo hermenêutico, procedendo por meio de uma troca dialógica com a situação do design.,282 (SNODGRASS; COYNE, 1997/2006, p.45, tradução nossa). Em sua caracterização da atividade prática do design como um processo de reflexão-em-ação, Schön (1983, p.79-104; 1984, p.4-8; 1988/1992, p.136145; 1992, p.5-8) procedeu à análise de um estudo de caso em arquitetura ${ }^{283}$ que trata da

\footnotetext{
279 Do original em inglês: "The hermeneutical process is more basic than and prior to the use of logic, formal languages and scientific method, and therefore forms the foundation for all rationality."

280 Do original em inglês: "[...] her meneutics is fundamental to our mode of being. Understanding is not one of our activities in the world, but is basic to everything we do and are."

281 Do original em inglês: "Understanding is the original character of the being of human life itself."

282 Do original em inglês: "Even a cursory examination of the protocol studies of Donald Schön indicates that the design process he describes works according to the dynamics of the her meneutical circle, proceeding by way of a dialogic exchange with the design situation."

283 Este é um dos princi pais estudos de caso a que Schön recorre (em diversos trabalhos e apresentações) para exemplificar sua caracterização da prática do design, como uma conversação reflexi va com a situação. Schön (1988/1992, p. 156) reporta que o caso teria sido observado e registrado por Roger Simmonds como parte de uma pesquisa sobre educação em arquitetura realizada em meados da década de 1970, dirigidos por Dean Killbridge da Uni versidade de Harvard e Dean Porter
} 
interação entre um professor de estúdio de projeto (Quist) e uma aluna de primeiro ano (Petra). Neste estudo de caso, a aluna reporta seu progresso ao professor, explicando que seu projeto para a escola encontra-se 'emperrado' devido à impossibilidade de superar um problema configurado por ela mesma: uma inadequação entre a forma preliminar da edificação proposta, com relação aos contornos acidentados do terreno (SCHÖN, 1983, p.83-84). Esta forma preliminar representa o avanço de sua ideia inicial de agrupar seis pequenas salas de aula em uma progressão escalar ao longo do terreno: Petra julgou a área das salas como muito reduzidas e propôs uma nova configuração em forma de letra 'L' para as mesmas, a qual considerou mais significante (conforme ilustrado na Figura 17, porém a partir daí, questiona seu movimento com relação a sua necessidade de adequação junto aos contornos topográficos do terreno (SCHÖN, 1983, p.82-83). Neste ponto, o professor Quist inicia sua interlocução, traçando um diagrama de orientação norte-sul e reenquadrando o problema de Petra: ao invés de procurar uma adequação da forma da edificação no terreno, Quist sugere a imposição de uma geometria aos contornos de nível, conformando a topografia a favor da elaboração das configurações em 'L' propostas: "Quist: Você deveria começar impondo uma disciplina, mesmo arbitrária, uma vez que o terreno é muito acidentado - você pode sempre abrir mão dela mais tarde." ${ }^{284}$ (SCHÖN, p.85, tradução nossa) Desta forma, torna-se possível conduzir o processo de desenvolvimento da proposta, inclusive em benefício a outros aspectos até então não observados por Petra, como a utilização de desníveis e relação de alturas com a acomodação da funcionalidade dos espaços (SCHÖN, 1983, p.85-87), de acordo com a Figura 17. Sobre o desempenho de Quist, Schön comentou:

O principal problema, na visão de Quist, não é que inserir a forma do edifício na encosta, o terreno é muito 'acidentado' para isso. Em vez disso, coerência deve ser dada ao local na forma de geometria - uma 'disciplina' - que pode ser imposta sobre ele. No restante desta fase do probcolo, Quist joga œm as consequências de tal movimento. A demonstração de Quist vai centrar-se agora no novo problema de coordenar a geometria construída em relação aos contomos inconstantes da encosta. Mas a geometria pode ser 'quebrada' novamente. Acho que isso significa que voœê pode dissolver a disciplina de origem para tentar outra, e que voce pode mais tarde fazer novas violações conscientes da geometria inicial. Na metáfora de Quist, a geometria é uma espécie de armadura que pode ser aberta e retirada em lugares de que fora construída. Ele vai falar muitas vezes da neœssidade de

do Instituto de Tecnologia de Massac hus etts - MIT.

284 Do original em inglês: "Quist: You should begin with a discipline, even if it is arbitr ary, bec ause the site is so screwy -you can always break it open later" 
'atenuar' uma disciplina consistente, afastando-se dela conscientemente. ${ }^{285}$ (SCHÖN, 1983,

p.85, tradução nossa)
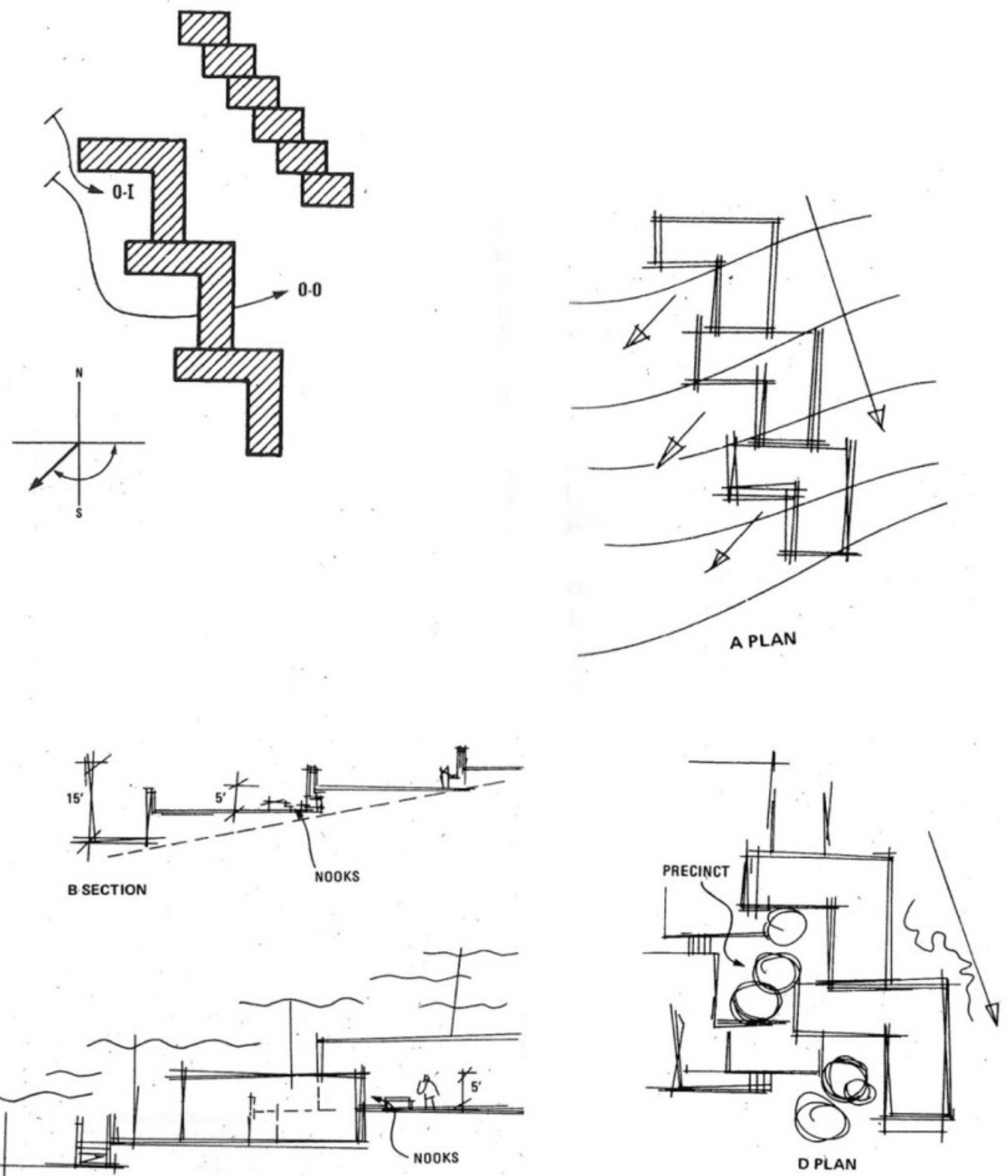

Figura 17 - Croquis de estudo da aluna Petra mostrando seu desenvolvimento projetual para uma escola, com a conformação de salas em 'L' e sua relação com a topografia acidentada. Fonte: (SCHÖN, 1983, p.86-87).

\footnotetext{
285 Do origin al em inglês: "The main problem, in Quist's view, is not that of fitting the shape of the building to the slope; the site is too "screwy" for that. Instead, coherence must be given to the site in the for m of a geometry -a 'discipline' - which can be imposed upon it. In the remainder of this phase of the protocol, Quist plays out the consequences of such a move. Quist's demonstration will now center on the new problem of coordinating the constructed geometry with the 'screwy' contours of the slope. But the geometry can be 'broken open' again. I think this means that you can dissolve the original discipline in order to try another one, and that you can later make knowing viol ations of the initial geometry. In Quist's metaphor, the geometry is a sort of armor which can be broken open in places, once it has been constructed. He will speak often of the need to 'soften' a consistent discipline by consciously departing fromit."
} 
Segundo Snodgrass e Coyne (1997R2006), o processo que Schön (1983) descreveu corresponde ao funcionamento do c írculo her menêutico, pois compreende-se que "[...] 'começar com uma disciplina, mesmo que arbitrária', em termos hermenêuticos, é a projeção de um préentendimento. Esta disciplina projetada, diz Schön, é um 'e se' a ser adotado em ordem de descobrir suas consequências, e pode sempre ser revista mais tarde." ${ }^{286}$ (SNODGRASS; COYNE, 1997/2006, p.45, tradução nossa), ou seja, à luz de reinterpretações e novas compreensões. Em outra passagem, Schön relatou a seguinte observação do professor Quist à Petra sobre o processo de design: "Quist: O princípio é que você trabalhe simultaneamente a partir da unidade e do total e então vá em ciclos - para trás e à frente, atrás e à frente, que é o que você tem feito de modo hesitante." ${ }^{287}$ (SCHÖN, 1983, p.92, tradução nossa). Novamente o autor analisa o comentário de Quist explicitand o seu entendimento do mo do como o professor lida com a atividade do design neste caso:

Ele [Quist] também demonstra como o todo está assegurado em cada movimento pardal. Uma vez que uma ideia geral foi criada, uma má implantação do espaço da administração pode arruiná-la. Portanto, o designer deve oscilar entre a unidade e o total, e como Quist aponta em um de seus raros metacomentários - ele deve oscilar entre o envolvimento e 0 desapego. Quist, por vezes, torna-se tão envolvido no desenvolvimento local de formas que o projeto parece estar fazendo-se a si mesmo. Mas ele também dá um passo atrás a partir da experiência projetada de passagematravés do espaço, a fim de to mar nota das relações mais amplas que as qualidades de que $o$ todo da ideia vai depender. Finalmente, enquanto percorre ciclos através de iterações de movimentos e apreciações dos resultados de movimentos, Quist muda da adoção provisória de uma estratégia para o compromisso final. [...] Ele descobre na resposta da situação toda uma nova ideia que gera um sistema de implicações para mais movimentos. Seu experimento global é também uma conversação reflexiva œma situação. ${ }^{288}$ (SCHÖN, 1983, p.102, tradução nossa).

\footnotetext{
286 Do original em inglês: "[...] 'begin with a discipline, even if it is arbitrary', which, in her meneutical ter ms, is the projection of a pre-understanding. This projected discipline, says Schön, is a 'what if to be adopted in order to discover its consequences, and can always be broken open later."

287 Do original em inglês: "Quist:The principle is that you work simultaneously from the unit and from the total and then go in cycles - back and forth, back and forth - which is what you've done a couple of times stutteringly."

288 Do original em inglês: "He also demonstrates how the whole is at sake in every partial move. Once a whole idea has been created, a bad placement of the administration can ruin it. Hence the designer must oscillate between the unit and the total, and - as Quist points out in one of his infrequent meta-comments - he must oscillate between involvement and detachment. Quist becomes at times so involved in the local development of for ms that the design appears to be making its elf. But he also steps back from the projected experience of pass age through the space in order to take note of the larger relationships on which the qualities of the whole idea will depend. Finally, as he cycles through iterations of moves and appreciations of the outcomes of moves, Quist shifts from tentative adoption of a strategy to eventual commitment. [...] He discovers in the situation's back talk a whole new idea which generates a system of implications for further moves. His global experiment is also a reflexive conversation with the situation."
} 
Em sua leitura particular da atividade prática projetual descrita no estudo de caso apresentado por Schön (1983, p.102), Snodgrass e Coyne (1997/2006, p.45) evidenciaram o modo pelo qual designers desenvolvem sua compreensão da situação do design de acordo com a abordagem hermenêutica. Para os autores, os designers procedem por meio de um contínuo inter-referenciamento do todo e do particular que compõem a situação de design, sob a forma do círculo hermenêutico: "[...] eles projetam o sentido do todo e trabalham as implicações desta projeção, referindo-se de volta para as partes individuais, que são então reinterpretadas. A compreensão surge por um processo de revisão constante."289 (SNODGRASS; COYNE, 997/2006, p.46, tradução nossa). Devemos atentar ao modo como, a partir desta abordagem, os autores referem-se às ações dos designers com relação ao 'projetar' no sentido hermenêutico presente no pensamento de Heidegger (1927/1989) e Gadamer (1975/1997), e como este sentido vai de encontro ao termo 'projetar' ao qual nos referimos usualmente com relação à atividade de concepção em arquitetura:

As associações são refletidas nas etimologias. Nós falamos de 'projeb' do design, palavra que significa literalmente um 'lançar diante'. 'Projeb' é usado para traduzir o termo Entwurf de Heidegger, que significa 'jogar algo fora ou longe de algo', com um forte sentido de 'Iançar' maior do que temo equivalente eminglês. Emseu uso co mum, no entanto, Entwurf significa 'desenhar' ou 'esboçar' algum 'projeto' pretendido. Ele também é usado no sentido de 'projeção', como quando dizemos que um geômetra 'projeta' um círculo em uma superfície plana.290 (SNODGRASS; COYNE, 1997/2006, p.268, tradução nossa)

Baseados nesta compreensão, Snodgrass e Coyne (1997/2006, p.269) consideraram o termo 'projeto' ${ }^{291}$ como mais apropriado para descrever a tarefa de design e seu objetivo, do que a palavra 'problema', pelo transporte de conotações da matemática e da física, inadequadas à descrição da natureza da prática projetual por implicarem um sentido cientificista subjacente. Por outro lado, observam que '[...] a etimologia da própria palavra 'problema' traz associações com 'projeto', vem do Grego problema, -matos, de pro-ballô, 'lançar perante’,

\footnotetext{
289 Do original em inglês: "[...] they project the meaning of the whole and work out the implications of this projection by referring it back to the individual parts, which are then reinterpreted. Understanding arises by a proc ess of constant revisions."

290 Do original em inglês: "The associations are refl ected in ety mologies. We speak of the design 'project', which word literally means a 'throwing before'. 'Project' is us ed to translate Heidegger's Entwurf, which means 'throwing something off or away from one', with a stronger sense of 'throwing' than has the English equivalent. In its common usage, however, Entwurf means 'designing' or 'sketching' some intended 'project'. It is also used in the sense of 'projection' as when we say that a geometer 'projects' a circle onto a place surface."

291 Do original em inglês: "project" (SNODGRASS \& COYNE, 1997/2006, p269)
} 
isto é, 'jogar à frente'."292 (SNODGRASS; COYNE, 1997/2006, p.269, tradução nossa). A partir desta abordagem com base na leitura de Snodgrass e Coyne (1997/2006), consideramos a correspondência entre a concepção de conversação reflexiva de Schön (1983; 1984; 1988/1992; 1992) e a conversação hermenêutica que efetiva-se na estrutura dialética de perguntas e respostas à medida que ambas as visões supõem essencialmente a transformação das compreensões e entendimentos do designer sobre uma deter minada situação de design em questão:

\begin{abstract}
0 ato hermenêutico de projetar segue uma estrutura dialética de pergunta e resposta. 0 designer projeta uma realização antecipada do trabalho, e então entra em diálogo com ela, questionando sua validade à luz dos fatores particulares que compõema situação do design. O designer, então, permite à situação de projeto fazer perguntas, por sua vez. As respostas dadas pela situação e as questões que ela levanta evocam ainda mais respostas e perguntas, e o design prossegue por um movimento de para frente e para trás, de ida e vinda, de pergunta e resposta.293 (SNODGRASS; COYNE, 1997/2006, p.46-47, tradução nossa)
\end{abstract}

Nesta conversação, a situação do design questiona os prejuízos, preconceitos e préentendimentos, ou seja, valores e atitudes que o designer traz consigo para a situação em questão (SNODGRASS; COYNE, 1997/2006, p.47), onde este percebe suas propriedades e particularidades, e interage com as consequências não intencionais de suas ações transformadoras (SCHÖN, 1988/1992, p.143). Este entendimento baseia-se na premissa de que "a situação de design é capaz de questionar o designer porque podemos entrar em diálogo com as coisas, assim como com as pessoas. O projeto e a situação do design são autorrepresentantes e funcionam à maneira de textos, que engajam os leitores e os questiona." ${ }^{294}$ (SNODGRASS; COYNE, 1997/2006, p. 47, tradução nossa). Cabe observar novamente que a efetivação desse diálogo depende da capacidade do designer em 'escutar a fala da

\footnotetext{
292 Do original em inglês: "[...] the etymology of the word 'problem' itself carries ass ociations with 'project', it comes from the Greek problema, - matos, from pró-ballô, 'to throw before', that is, 'fore-throwing'."

293 Do original em inglês: "The hermeneutic act of designing follows a dialectical structure of question and answer. The designer projects an anticipated completion of the work, and then enters into a dialogue with it, questioning its vality in the light of the particular factors that make up the design situation. The designer then allows the design situation to ask questions in its turn. The answers given by the situation and the questions it raises evoke further answers and questions, and the design proceeds by a back-and-forth, to-and-fro movement of query and response."

294 Do original em inglês: "[...] the design situation is able to question the designer because we can engage in dial ogue with things as well as people. The project and the design situation are self-representing and function in the manner of texts, which engage readers and question them."
} 
situação', permitindo-se ser questionado pela situação do design, o que significa ao mesmo tempo desvelar estruturas do pensamento arraigadas em nossos preconceitos, e contemplar a possibilidade de revisão e transformação destas pré-estruturas de significados frente aos sentidos que a situação coloca:

Ao projetar, designers estão continuamente sendo questionados. Eles podem facilitar esse processo colocando-se abertos para as perguntas, deixando-se vulneráveis, em situação de risco, tomando as perguntas como uma provação de seus pré-julgamentos [...]. No primeiro caso, há uma revelação no desvelar de configuraçoes mentais inconscientes, e essa revelação faz do processo de projeto não só um des-cobrir (a descoberta) do artefato como ele revela a si mesmo no processo do discurso (à maneira pela qual ideias revelam-se aos participantes de uma conversa), mas também é autorreveladora, um processo de autodescoberta ou de edificação 295 (SNODGRASS; COYNE, 1997/2006, p. 47, trad. nossa).

Este é o sentido transformador característico da conversação a que refere-se Gadamer: "A conversação possui uma força transformadora. Onde uma conversa teve êxito ficou algo para nós em nós que nos transformou." (GADAMER, 1976/1997, p.247). O sentido de revelação, de descoberta recíproca da conversação é ressaltado pelo filósofo em sua asserção de que "é só na conversação [...] que pode-se construir aquela espécie de comunhão onde cada qual continua sendo o mesmo para o outro porque ambos encontram o outro e encontram a si mes mos no outro." (GADAMER, 1976/1997, p.247). Este sentido pode ser apreendido da mesma forma, no projetar: "na forma de uma conversa animada, que ao longo transporta seus falantes, a situação de projeto leva o designer em seu fluxo. Boa conversa absorve os falantes, assim também a ação de projetar, quando se está procedendo como deveria, absorve o designer."296 (SNODGRASS; COYNE, 1997/2006, p.48, tradução nossa). A conversação absorve os designers quando estão verdadeiramente projetando, sendo que envolvem-se tanto na tarefa a ponto de não perceberem mais que estão projetando, ou que a situação do projeto é um objeto para além de si mesmos (SNODGRASS; COYNE, 1997/2006). Evidencia-se novamente, a

\footnotetext{
295 Do original em inglês: "When designing, designers are continually being questioned. They can facilitate that process by laying themselves open to the questions, leaving themselves vulnerable, at risk, by taking the questions as a probing of their prejudgments [...]. In the for mer case there is a revelatory disclos ure of unconscious mind sets, and this disclosure renders the design process not only a dis-covery (an uncovering) of the artifact as it reveals itself in the process of discourse (in the manner in which insights reveal thems elves to participants in a conversation), but it is also self-revelatory, a process of self-discovery or of edification."

296 Do original em inglês: "In the manner of a spirited conversation, which carries the speakers along, the design situation carries the designer in its flow. Good conversation absorbs the speakers; so likewise the action of designing, when it is proceeding as it should, absorbs the designer. [...]"
} 
qualidade da conversação apontada por Schön (1983, p.136) em criar as condições para a renovação contínua do próprio processo projetual, levando ao desvelar de novos entendimentos, novas compreensões e também um novo ímpeto para a transformação.

\subsubsection{Jogos, linguagem e dois entendimentos dissonantes}

Em nosso percurso sobre a natureza da atividade do design, de acordo com a caracterização de Schön (1983; 1984; 1988/1992; 1992) e Snodgrass e Coyne (1992; 1995; 1997/2006), observamos o processo de conversação no qual designers interagem com a situação do design que buscam entender e transformar, a partir de interpretações e revisões constantes de sentidos que desvelam-se à luz de novas compreensões e entendimentos. Esta interação, por sua vez, manifesta-se por meio da linguagem: "Toda conversação pressupõe uma linguagem comum, ou melhor dito, constitui, a partir de si, uma linguagem comum." (GADAMER, 1975/1997, p.556). A linguagem representa o meio de expressão das intenções, pensamentos e ações vinculadas à compreensão de algo nos processos interpretativos, assim como "todo compreender é interpretar, e todo o interpretar se desenvolve por meio de uma linguagem que pretende deixar falar o objeto e é, ao mesmo tempo, a linguagem própria de seu intérprete.” (GADAMER, 1975/1997, p.666). Assim, o compartilhamento de uma linguagem em comum faz-se condição fundamental para o desenvolvimento da conversação: "Percebemos agora que todo este processo é um processo linguístico" (GADAMER, 1975/1997, p.559). Com relação a este entendimento, para além da metáfora da conversação, Gadamer utilizou-se também da metáfora de 'jogo' em sua obra para descrever a forma pela qual o processo dialógico her menêutico realiza-se na linguagem:

[...] a forma em que se realiza todo dálogo pode ser descrita a partir do conceito de jogo. Para isso é necessário livrar-se de um hábib de pensar que define a essência do jogo a partir da consciência do jogador. [...] Jogo é, na verdade, um processo dinâmico (cinétio) que abarca os jogadores ou o jogador. Quando falamos de jogo do navio ou de jogo cênico ou do livre jogo das articulações, não se trata de uma mera metáfora. Pelo contrário, a fascinação do jogo para a consciência que joga repousa justamente nessa saída estática de si próprio para umnexo dinâmico que desenvolve sua própria dinâmica. Dá-se jogo quando o jogador individual leva a sério o jogo, isto é, quando entra seriamente no jogo, sem 
considerar-se apenas um jogador. [...] Penso que a estrutura fundamental do jogo de estar impregnado de seu espírito - espírito de leveza, de liberdade, do prazer do logro - e nisso impregnar o jogador é aparentada coma estrutura do diálogo, onde se dá a linguagem real. A vontade de o indivíduo reservar-se ou abrir-se já não é determinante para o modo de entrarmos em diálogo mútuo e de sermos levados por ele. 0 determinante é a lei da coisa em questão (Sache) no diálogo, que provoca a fala e a réplica e acaba conjugando a ambas. Assim, quando se dá o diálogo sentimo-nos plenos. 0 jogo da fala e da réplica prolonga-se para um diálogo interior da alma consigo mesma, como Platão já havia tão bem qualificado o pensamento. (GADAMER, 1976/2002, p.180)

Gadamer (1976/2002, p.180) exaltou o sentido pelo qual no jogo seus participantes encontram satisfação pela liberdade de movimento em se jogar, no desempenho de diferentes escolhas e ações com relação ao reconhecimento e interação com o alheio, representado pelos outros jogadores e a dinâmica do jogo em si. É este sentido de jogo, contido essencialmente na utilização da linguagem que, segundo o autor, absorve seus jogadores assumindo uma vida própria (GADAMER,1975/1997, p.707-708). Coloca-se desta forma a inerência do jogar em toda a compreensão, que efetiva-se por meio da linguagem, configurando-se como u ma condição da qual participa-se impreterivelmente: "a compreensão é um jogo [...] aqui não se dá, de modo algum, a liberdade da autopossessão, que é inerente ao poder abster-se assim e é isso o que pretende expressar, a aplicação do conceito do jogo à compreensão." (GADAMER, 1975/1997, p.708). Esta leitura da linguagem pela tônica do jogo em Gadamer (1975/1997) encontra uma correspondência com relação à concepção de linguagem expressa na obra tardia do filósofo Ludwig Wittgenstein (1889-1951) $)^{297}$, que atenta aos diferentes modos com que o sentido dos elementos da linguagem articulam-se e com relação às variadas funções que desempenham em seus empregos particulares em jogos de linguagem que, imbuídos de uma perspectiva histórica e contextual ${ }^{298}$, são assumidos como verdadeiras formas de vida:

\footnotetext{
297 Ludwig Joseph Johann Wittgenstein (1889-1951), filósofo austríaco, naturalizado britânico, cuja obra é considerada de grande relevância ao pensamento filosófico do século XX. Seu trabalho é frequentemente dividi do entr e seu período inicial, exemplificado pelo Tratado Lógico Filosófico (Tractatus lógico-filosophicus, 1921), e último período, representado pelas Investigações Filosóficas (Philosophical Investigations, 1953) publicado postumamente, que rejeitou muitas das conclus ões do Tractatus. Enciclopédia Internet de Filos ofia IEP. Disponível em: <http://plato.stanford.edu/entries/wittgenstein/> Acesso em: 12/08/2011.

298 Neste sentido Wittgenstein lança mão de uma metáfora arquitetônica ao observar que: "Nossa linguagem pode ser considerada como uma vel ha cidade: uma rede de ruelas e praças, cas as novas e velhas, e cas as construídas em diferentes épocas; e isto tudo cercado por uma quantidade de novos subúrbios com ruas retas e regulares e com casas uniformes." (WITTGENSTEIN, 1953/1989, p. 15)
} 
Quantas espécies de frases existem? Afirmação, pergunta e comando, talvez? - Há inúmeras de tais espédies: inúmeras espécies diferentes de emprego daquilo que chamamos de 'signo', 'palavas', 'frases'. E essa pluralidade nãoé nada fixo, um dado para sempre; mas novos tipos de linguagem, novos jogos de linguagem, como poderíamos dizer, nascem e outros enveheœm e são esquecidos. [...] 0 termo 'jogo de linguagem' deve aqui salientar que o falar da linguagem é uma parte de uma atividade ou de uma forma de vida. (WITTGENSTEIN, 1953/1989, p.18)

Snodgrass e Coyne destacaram a relevância do pensamento de Wittgenstein (1953) em demonstrar que a linguagem em sua constituição assemelha-se à formas de vida como também dá forma à vida, por ser constitutiva do mundo que é experienciado "[...] e portanto, a linguagem não pode ser um objeto que podemos inventar ou criar. Nossa relação com a linguagem não é uma de sujeito e objeto, uma vez que estamos dentro da linguagem e fazemos parte de seu processo."299 (SNODGRASS; COYNE, 1997/2006, p.33-35, tradução nossa). Os autores apontaram (SNOD GRASS; COYNE, 1997/2006, p.23), entretanto, para a difusão de u ma visão antagônica a esta concepção de linguagem, oriunda do contexto de pesquisa em design arquitetônico e computação, que por sua vez, embasa o modelo em que o processo de design é visto como conjunto de procedimentos lógicos e algorítmicos cujo desdobramento semântico se dá através de gramáticas lógico-formais:

É comu mente suposto que a atividade de design pode ser descrita, codificada e explicada em termos de um modelo de lógica algorítmica derivado da teoria da linguagem. O modelo, exemplificado no trabalho de Stiny, Knight, Mitchell, Kalay e Coyne et al., te msido a base de muita pesquisa em metodologia de projeto arquitetônico e CAD. [...] Mitchell dá uma descrição elegante do modelo. [...] ele afirma que o design pode ser descrito em palavas que compõem uma linguagem crítica em que as descriçoes das palavras podem ser formalizadas usando a notação de cálculo de predicados de primeira ordem. Mundos de projeto, diz ele, consistem em 'sinais gráficos que, como palavras, podem ser manipulados de acordo com certas regras gramaticais'. Ele vê os processos de design como 'cálculos no mundo do design com o objetivo de satisfazer os predicados de forma e função declarados emuma linguagem crítica'. ${ }^{300}$ (SNODGRASS; COYNE, 1997/2006, p.29, tradução nossa)

\footnotetext{
299 Do original em inglês: "[...] and therefore language cannot be an object that we can invent or create. Our rel ationship with language is not one of subject and object, since we are within language and part of its process."

300 Do original em inglês: "It is commonly supposed that design activity can be described, codified, and explai ned in ter ms of an algorithmic logic model derived fromlanguage theory. The model, exemplified in the work of Stiny, Knight, Mitchell, Kalay and Coyne et al., has been the basis of much res earch in architectural design methodol ogy and CAD. [...] Mitchell gives an elegant description of the model. [...] he ass erts that design can be described in words that make up a critical language and such word descriptions can be formalized using the notation of first-order predicate calculus. Design worlds, he says, consist of 'graphic tokens which, like words, can be manipulated according to certain grammatical rules'. He sees design processes 'as
} 
Os autores observaram que este modelo ${ }^{301}$ pressupõe que o processo projetual é análogo ou equivalente ao processo pelo qual usamos a linguagem, fundamentado em uma concepção derivada de uma teoria positivista de linguagem, baseada no emprego de lógica formal e da manipulação de elementos primários (por exemplo, formas geométricas), que correspondem semanticamente a objetos reais (SNODGRASS; COYNE, 1997/2006, p.30). Por sua vez, estes elementos se combinam para formar segmentos maiores de informações, como sentenças, cujo significado é prescrito por um conjunto de regras lógicas: "Para serem significativas, dizem os positivistas, essas combinações de símbolos verbais ou átomos de palavra devem ser montadas de acordo com as regras da lógica formal. Se não estão de acordo com estas regras, eles são sem sentido e as declarações que transmitem são falsas'302 (SNODGRASS; COYNE, 1997/2006, p.30, tradução nossa). Enfatiza-se assim, a existência de duas concepções opostas de linguagem como metáforas do processo de design: a primeira, o modelo lógico da linguagem formal, em que unidades elementares são combinadas de acordo com regras lógicas conformando estruturas dotadas de sentido; e a segunda, o modelo dialógico correspondente à metáfora da conversação e do jogo, que corresponde à linguagem da interpretação (SNODGRASS; COYNE, 1997/2006, p.48-49). Para os autores, estas duas concepções baseiam-se em perspectivas antagônicas e mutuamente exclusivas sobre linguagem: neste sentido eles citam a afirmação do filósofo Jürgen Habermas $(1929-4)^{303}$ de que "[...] o caráter inequívoco das linguagens formalizadas é comprado à custa de qualquer possibilidade de diálogo. Cálculos formais, diz ele, têm uma estrutura monadológica, uma que exclui conversação, eles permitem implicações, mas não comunicações, eles substituem o diálog o com uma mera troca de informações"304 (HABERMAS, 1977 apud. SNODGRASS; COYNE, 1997/2006, p.49; tradução nossa). É com respeito a este caráter redutivo que Snodgrass e

computations in design world with the objec tive of satisfying predicates of for mand function stated in a critical language'."

301 Para um maior aprofundamento, ver: MITCHELL,W.J. A lógica da arquitetura. Projeto, computação e cognição. Campinas: Editora Unicamp, 2008.

302 Do original em inglês: "To be meaningful, say the positivists, these combinations of verbal tokens or word atoms must be assembled according to the rules of formal logic. If they not conform to these rules, they are meaningless and the statements they convey are false".

303 Jürgen Habermas (1929-) é um filósofo e sociólogo alemão, cujo pensamento e trabalho atenta aos processos comunicativos no contexto da sociologia. Dentre suas obras a este respeito podemos citar: HABERMAS, J. The theory of communicative action: Reason and the rationalization of society. Cambridge: v. 1 e 2, 1981/1986; HABERMAS, J. On the pragmatics of communication. Cambridge: ed. Maeve C ooke, 1998.

304 Do original em inglês: "[...] the unequivocal char acter of for malized languages is purchased at the cost of any possibility of dialogue. Formal calculi, he says, have a monadological structure, one that excludes conversation; they permit implications, but not communications, they replace dialogue with a mere exchange of infor mation." Ver: HABERMAS, J. A review of Gadamer's truth and method. In: DALLM AYR, F.R.; MCCARTHY, T. (eds.) Understanding and Social Inquiry. Notre Dame: Uni versity of Notre Dame Press, p. 335- 363, 1977. 
Coyne (1997/2006) pontuaram sua crítica à concepção de linguagem formal empregada no contexto das pesquisas computacionais baseadas em gramáticas da forma:

Enquanto a linguagem formal é uma a disposição do usuário, a linguagem do diálogo autêntio não pertence aos æus falantes, mas sim os possuem e guiam. Sua função não é instrumental, mas reveladora, que revela o entendimento de dentro de si mesma, e assim serve como um meio que transmite entendimentos entre os falantes. Nós não usamos a linguagem em uma conversa como um conjunt pré-determinado de significados atômicos acompanhados por um conjunto de regras para sua combinação. Ao contrário, como vimos, o significado das palavras depende da situação em que elas são usadas, e a lógica da linguagem não é a lógica do lógiœ, mas a lógica da pergunta e resposta. A linguagem utilizada na conversação não pode ser reduzida à lógica formalizável de regras gramaticais ${ }^{305}$ (SNODGRASS; COYNE, 1997/2006, p.49, tradução nossa)

Seguindo esta distinção crítica, os autores retomam o sentido de jogo conforme apresentado no pensamento de Gadamer (1975/1997) e Wittgenstein (1953/1989) ao colocarem que: [...] "linguagem não é um sistema de signos, uma linguagem de símbolos, nem é um sistema de informação. Éum jogo, e como tal, ele rompe com os limites que qualquer sistema simbólico necessariamente implica." ${ }^{306}$ (SNODGRASS; COYNE, 1997/2006, p.35, tradução nossa). Deste modo, portanto, não pode ser entendida como um conjunto de símbolos atômicos que representam ou correspondem a elementos em um mundo extralinguístico, ou seja, "não pode ser forçada em uma camisa-de-força de gramáticas formais sem que se altere o que ela realmente é." ${ }^{307}$ (SNODGRASS; COYNE, 1997R2006, p.35, tradução nossa). Contrapõe-se o modelo lógico do projetar à concepção dialógica da conversação hermenêutica:

Se, como tem sido argumentado aqui, o proœsso de design pertence ao domínio da troca dialógica, está firme mente embutido emuma situação humana, e é um nexo focal dentro de uma rede de estruturas prévias de entendimento, então ele não deve ser entendido em termos de uma linguagem de lógica precisa que manipula elementos atômicos em um

\footnotetext{
305 Do original em inglês: "Whereas formal language is one at the disposal of the user, the language of authentic dial ogue does not belong to the speakers, but rather possess es and guides them Its function is not instr umental, but disclosive; it reveals understanding from within its elf, and thereby serves as a medium that trans mits understandings between the speakers. We do not us e language in a conversation as a set of pre-given atomic meanings accompanied by a set of rul es for their combination. On the contrary, as we have seen, the meaning of words depends on the situation in which they are used, and the logic of language is not the logician's logic but the logic of question and answer. The language us ed in convers ation cannot be reduced to logically for malisabl e rule-grammars."

306 Do original em inglês: "Language is not a sign system, a language of symbols; nor is it an information system It is a game, and such it breaks out of the li mits that any symbolic system nec essarily implies."

307 Do original em inglês: "[...] it cannot be forced into the straitjacket of for mal grammars without altering what it really is."
} 
sistema exato de signos, œmo em modelos œmputacionais de design, mas sim em termos da linguagem da conversação diária. Projetar não é computacional, mas hermenêutico. ${ }^{308}$ (SNODGRASS; COYNE, 1997/2006, p.55, tradução nossa)

O que se coloca novamente é, por um lado, a impossibilidade de tradução da interação que ocorre no contexto situacional em que o jogo da linguagem realiza-se, que é dialógica e transformativa, em um processo lógico formal ou descrição algorítmica, e por outro lado, no jogo das interpretações os sentidos são plurais, dinâmicos e contextuais, não se permitindo serem fixados como fatos atômicos ${ }^{309}$ em um sistema de representação objetivo. Snodgrass e Coyne (199712006, p.54) atentaram que a própria elaboração de gramáticas formais deve ser entendida como atrelada à processos interpretativos que ocorrem em uma situação contextual determinada, ou seja, linguagens formais são criadas a partir das interpretações e compreensões de seus criadores, ou seja, através de processos hermenêuticos. É desta maneira que se reafirma a universalidade do evento hermenêutico da compreensão que se desenvolve à maneira de conversações por meio da linguagem (GADAMER 1975/1997; SNODGRASS; COYNE, 1997/2006, p.44), e com base nesta compreensão que caracteriza-se a natureza do projetar como um processo interpretativo, e portanto her menêutico.

\footnotetext{
308 Do original em inglês: "If, as has been argued here, the design process bel ongs to the domain of dial ogical exchange, is firmly embedded in a human situation, and is a focal nexus within a network of forestructures of understanding, then it is to be understood not in terms of a language of precise logic that manipulates atomic tokens in an exact sign system, as in computational models of design, but rather in terms of the language of everyday conversation. Designing is not computational, but hermeneutical."

309 Os autores são enfáticos ao afirmarem que: "O mundo do design, como o mundo em geral, não consiste em um conjunto de fatos atômicos cuja rel ação pode ser expressa em proposições lógicas. Nós não experienciamos nenhum desses mundos como um conjunto de fatos objetivos. 'Fatos' inter-relacionam e se interpenetram com outros 'fatos', eles não podem ser considerados isol adamente, nem são separáveis. Nós temos já sempre interpretado 'fatos' no contexto das nec essidades, expec tati vas, preoc upações, preconceitos e intimações humanas. Assim que fazemos um 'fato' explícito, isol ado e rasgado do seu contexto, perdemos a sua riqueza de significado. Dar um significado único e preciso para o 'fato' é emasculá-lo. Cada fato é polissêmico." (SNODGRASS; COYNE, 1997/2006, p.49, tr adução nossa)
} 
Capítulo 3

Horizonte em expansão 



\section{HORIZONTE EM EXPANSÃO}

\subsection{O projetar como conversação cibernética}

Nesta primeira parte do capítulo realizamos uma aproximação à cibernética, observando a caracterização da atividade projetual como conversação tratando-se de uma interação comunicativa entre sistemas. A cibernética é um campo transdisciplinar que se originou na segunda metade do século XX, pela reunião de pesquisadores concernidos com relações de regulação, organização, comunicação e controle em diversos sistemas e organismos. Não faz parte do escopo do trabalho uma abordagem pormenorizada dos complexos aspectos teóricos e conceitos vinculados a esta área de investigação, considerando sua grande abrangência e a exigência de conhecimentos avançados em diversas disciplinas como matemática, física, química, biologia, neuropsicologia, etc., os quais estão evidentemente fora de nossos méritos de pesquisa. Nos reservamos assim a realizar uma breve introdução sobre o tema a partir do direcionamento de nosso interesse específico sobre o projetar arquitetônico e a conversação. Neste sentido, aproximamo-nos da leitura de ciberneticistas contemporâneos como Ranulph Glanville, Paul Pangaro e Hugh Dubberly, que desempenharam estudos tanto sobre cibernética quanto em arquitetura e design em geral, que referenciam-se por sua vez na obra do cientista inglês, psicólogo e ciberneticista Gordon Pask e sua Teoria da Conversação, que manteve uma reconhecida proximidade ao ensino e prática arquitetônica no contexto inglês das décadas de 1960 e 1970. Fazemos também uma introdução ao pensamento teórico de Pask, demonstrando a possibilidade de derivação de seus conceitos para com a compreensão do processo projetual, especialmente com relação à configuração de um desenvolvimento próprio da cibernética conhecido como 'cibernética de segunda ordem'. 


\title{
3.1.1 Introdução à cibernética
}

\begin{abstract}
Esta é a coisa fascinante sobre a cibernética. Você pede a algumas pessoas para dar-lhe uma definição e, apesar de você não chegar a saber muito sobre cibernética a partir deles, você descobre muito sobre a pessoa forneœndo a definição, incluindo a sua área de especialização, sua relação com o mundo, seu desejo de jogar com metáforas, o seu entusiasmo para administração, e seu interesse em comunicações ou teoria da mensagem. ${ }^{310}$ (VON FOERSTER, tradução nossa)
\end{abstract}

É de comum acordo entre pesquisadores ciberneticistas (HEYLIGHEN; JOSLYN, 2001, p2; SCOTT, 2004, p.1366; GLANVILLE, 2007b, p.1180), a associação da origem do termo 'cibernética' ao grego 'Kybernetes', significando 'timoneiro'311, sentido empregado na antiguidade clássica pelo filósofo Platão (HEYLIGHEN; JOSLYN, 2001, p.2) e posteriormente no século XIX pelo filósofo e cientista francês André-Marie A mpère (1775-1836) com relação à "arte de governar ou a ciência do governo" ${ }^{312}$. Também é de praxe a observação de que sua reintrodução no contexto moderno deveu-se ao matemático norte-americano Norbert Wiener ${ }^{313}$ (1894-1964) pelo emprego do termo em sua obra de 1948 'Cibernética - Controle e comunicação no animal e na máquina', dedicada a aspectos como coordenação, regulação e controle em sistemas biológicos e mecanis mos em geral (WIENER, 1948/1970). Segundo os pesquisadores Francis Heylighen e Cliff Joslyn (2001, p.2), Wiener buscou em seu trabalho o desenvolvimento de uma teoria geral das relações sistêmicas de controle e organização, inspirado principalmente pelos resultados militares em sistemas mecânicos de artilharia servo-controlados empregados na Segunda Grande Guerra, bem como pelo desenvolvimento da teoria matemática da comunicação de Claude Shannon. Assim como Wiener (1948/1970), o

\footnotetext{
310 Do original em inglês: "That is the fascinating thing about cybernetics. You ask a couple of people to give you a definition and although you don't get to know much about cybernetics from them, you find out a lot about the person supplying the definition, including their area of expertise, their relation to the world, their desire to play with metaphors, their enthusias mfor management, and their interest in communications or message theory." Esta é uma das citações sobre definições de cibernética de acordo com a página el etrônica da American Society for Cybernetics - Disponível em: <http://www. asccybernetics.org/foundations/definiti ons. htm> Acess o em: 12/08/2011.

311 Tradução dos termos originais em inglês: 'Steer man' (HEYLIGHEN; JOSLYN, 2001, p.2; SCOTT, 2004, p.1366) ou 'Helms man' (GLANVILLE, 2007b, p. 1180).

312 Do original em inglês: “Cybernetique - the art of governing or the science of government". Sociedade Americana de Cibernética - ASC. Disponível em: < http://www.asc-cybernetics. org/foundations/definitions.htm> Acess o em 01/05/2010.

313 Norbert Wiener (1894-1964) foi um renomado matemático norte-americano, considerado um dos fundadores da cibernética, pioneiro na formalização da concepção sistêmica de 'feedback', com muitas implicações para a engenharia, controle de sistemas, ciênci a da computação, biologia, filos ofia e da organização da sociedade.
} 
psiquiatra inglês Ross Ashby ${ }^{314}$ (1903-1972), outro pioneiro da cibernética, foi responsável pela associação entre o significado do termo cibernética, 'a arte da timonagem' ('the art of steermanship'), à relação entre controle e comunicação em mecanis mos sistêmicos em geral, ou seja, de uma maneira independente da 'materialidade', 'condição existencial' ou mes mo da epistemologia por trás do conhecimento destes sistemas, de modo que "[...] as verdades da cibernética não são condicionais à sua existência derivada de outros campos da ciência. A cibernética possui suas próprias fundações”315 (ASBHY, 1956, p.1, tradução nossa). É neste sentido, que a cibernética distingue-se como "a ciência que estuda os princípios abstratos de organização em sistemas complexos. Preocupa-se não tanto sobre no que consiste o sistema, mas como ele funciona." ${ }^{316}$ (HEYLIGHEN; JOSLYN, 2001, p.2, tradução nossa). Deste modo:

Cibemética concentra-se em como sistemas utilizam informação, modelos e controlam ações no sentido de orientar e manter seus objetivos, enquanto contrariam diversas perturbaçoes. Sendo inerentemente transdisciplinar, o raciocínio cibemético pode ser aplicado para entender, modelar e projetar sistemas de qualquer tipo: físicos, tecnológicos, biológicos, ecológicos, psicológions, sociais, ou qualquer combinação entre estes.317 (HEYLIGHEN ; JOSLYN, 2001, p.2, tradução nossa).

A cibernética emergiu formalmente como um campo específico de estudos pela reunião interdisciplinar de diversos intelectuais ${ }^{318}$ do pós-Segunda Guerra Mundial, em uma série de

314 William Ross Ashby (1903-1972) foi um psiquiatra inglês, Doutor em Psiquiatria pel a Uni versidade de Cambridge, diretor de pesquisa do hos pital de Barnwood House em Glouc ester de 1947 a 1959, e em 1960 tornou-se professor e pesquis ador do Departamento de Biofísica e Engenharia Elétrica da Universidade de Illinois em Urbana Champaign, Estados Unidos. É considerado um dos pi oneiros da ciber nética, entre suas principais obras sobre o tema podemos citar 'Design for a Brain', de 1950 e 'An Introduction to Cybernetics', de 1956. Ashby também é conhecido pelo des envol vimento do Homeostato, em 1948.

315 Para Ashby, a cibernética não trata das coisas em si, mas sim de modos de comportamento. Do original em inglês: 'Cybernetics, too, is a theory of machines', but it treats, not things but ways of behaving. It does not ask 'what is this thing?' but 'what does it do? [...] The truths of cybernetics are not conditional on their being derived from other branch of science. Cybernetics has its own foundations."

${ }^{316}$ Do original em inglês: "The science that studies the abstract principles of organization in complex systems. It is concerned not so much with what system consist of, but how they function."

317 Do original em inglês: "Cybernetics focuses on how systems us e infor mation, models, and control actions to steer towards and maintain their goals, while counteracting various disturbances. Being inherently transdisciplinary, cybernetic reas oning can be applied to understand, model and design systems of any kind: physical, technological, biological, ecological, psychological, social, or any combination of those."

318 Dentre os quais o matemático norte-americano Norbert Wiener (1894-1964), o matemático húngaro-americano John Von Neumann (1903-1957), o neuropsicologista norte-americano Warren McCulloch (1898-1969), o matemático norte-americano Claude Shannon (1916-2001), o psiquiatra inglês W. Ross Ashby (1903-1972), o biólogo, antropólogo e cientista social inglês Gregory 
dez conferências patrocinadas pela Fundação Josiah Macy Jr. ${ }^{319}$ entre os anos 1946-1952, nos Estados Unidos, as chamadas 'Conferências Macy ${ }^{320}$, sob o título 'Cibernética causalidade circular e feedback em sistemas biológicos e sociais' ${ }^{321}$. O ciberneticista e arquiteto Ranulph Glanville (2007), recorrendo a uma exemplificação sobre um sistema cibernético, apontou que mesmo nos sistemas mais simples, como o de um termostato, o controle efetiva-se através de um circuito (em inglês 'loop') de 'feedback' ${ }^{322}$, ou seja, o sensor do mecanis mo regula/controla a temperatura ambiente ativando e desligando a fonte de calor (como ilustrado na Figura 18). Por outro lado, o sensor em si é controlado pela oscilação da temperatura do ambiente, assim "[...] o que é relevante aqui é que a forma (organizacional) de controle é circular - como sua causalidade." ${ }^{323}$ (GLANVILLE, 2007b, p.1182, tradução nossa). Pode-se observar assim que:

Como afirmado no tema da Conferência Macy, a característica central e distintiva dos sistemas cibernétions, em contraste com os sistemas mais tradicionais da ciência, é circularidade: sistemas cibeméticos são circulares, enquanto sistemas científicos têm tradicionalmente sido dirigidos à linearidade. ${ }^{324}$ (GLANVILLE, 2007b, p.1184, tradução nossa)

Bates on (1904-1980), a antropóloga norte-americana Margaret M ead (1901-1978), o cientista austro-americano Heinz Von Foerster (1911-2002), entre outros nomes.

319 A fundação filantrópica Josiah Macy Jr. é sediada em Nova Iorque, nos Estados Unidos, cujas ati vidades envovem o suporte e patrocínio de educação profissional e pesquisa na área de saúde pública desde os anos 1930, segundo o site da fundação. Disponível em: < http://www.j osiahmac yfoundation.org/> Acesso em 01/05/2011.

320 Para uma leitura aprofundada sobre as Conferências Macy em cibernética ver: PIAS, C.; VON FOERSTER, H. (eds) Cybernetics: the Macy-Conferences 1946-1953 = Kybern etik. Zurich-Berlim, Germany: ed Diaphane, 2004.

321 Do original em inglês: "Cybernetics - Circular Caus al and Feedback Mechanis ms in Biological and Social Systems". Devese obser var que, a incorpor ação do ter mo 'Cibernética' ao título das conferências ocorreu somente pela ocasião da sétima edição, em 1950. Sociedade Americana de Cibernética - American Society of Cybernetics - ASC. Dispinível em: $<$ <ttp://www. asc-cybernetics.org/foundations/de finitions .htm> Ac esso em 01/05/2011.

322 A enciclopédia online 'Principi a C ybernética' descreve o termo 'feedback' como "um fluxo de informações de volta par a sua origem. Um processo circular causal no qual a infor mação saída de um sistema é devolvi da à sua entrada, possivelmente envol vendo outros sistemas no circuito. Podem ser de dois tipos: 'feedback negati vo ou feedback de redução de desvio', que diminui as informações de entradas e é inerente à estabilização sistêmica, por exemplo, o controlador de um motor a vapor; 'feedback positi vo ou feedback de ampliação de des vio' que aumenta as entradas e é inerentemente deses tabilizador e vicioso, por exemplo, o crescimento de uma cidade quando as pessoas criam novas oportunidades que por sua vez atraem mais pessoas a viver lá.", tradução nossa. Disponível em:<http://www.i mprint.co. uk/thesaurus/feedbackhtm> Acesso em 12/08/2011. 323 Do original em inglês: "[...] what is relevant, here, is that the (organizational) form of control is circular - as is the causality."

324

in contrast with more traditional systems of science, is circularity: cybernetic systems are circular, whereas scientific systems have traditionally ai med at being linear." 


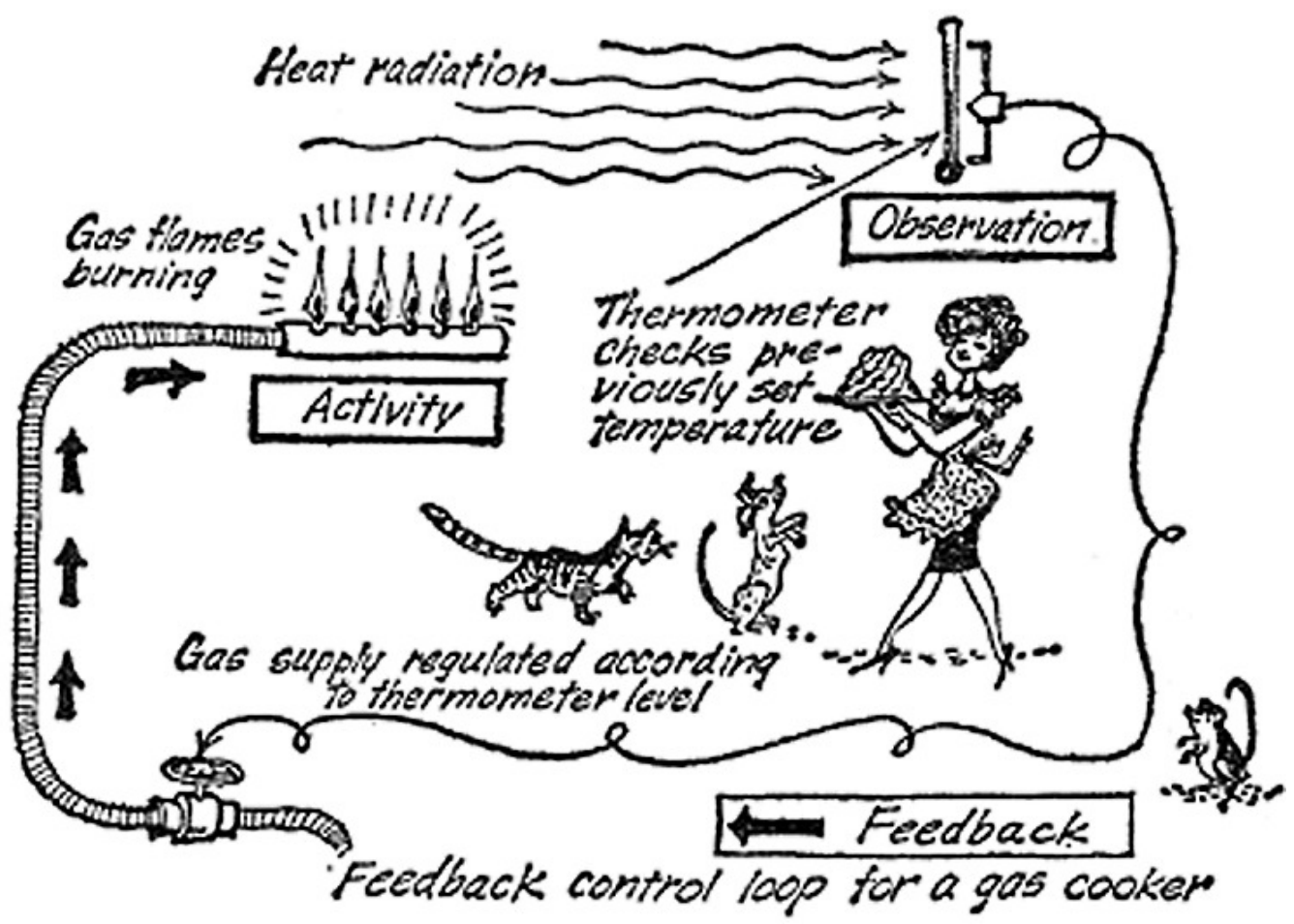

Figura 18 - Diagrama de um aquecedor controlado por mecanismo de 'feedback loop'. Fonte: (LOHBERG;LUTZ, 1965) http://www.lauftex t.de/cybemetic-computer/feed-backs.htm acesso em: 12/08/2011

Segundo o ciberneticista Bernard Scott (2004), o conceito de controle por feedback loop pode ser aplicado a vários domínios distintos, fato de maior importância para a concepção da cibernética como um campo de estudo transdisciplinar, à medida que seus fundadores, "[...] engenheiros, antropologistas, neurologistas, psicólogos e economistas (para citar alguns) estavam construindo modelos similares, embora em diferentes domínios de aplicação e terminologia." ${ }^{225}$ (SCOTT, 2004, p.1367, tradução nossa). Glanville (2007b, p.1181) observou que 'controle' implica em algum objetivo ou intenção (propósito) e meios pelo qual a intenção possa ser comunicada a um atuador ou ator: neste sentido, talvez a contribuição mais fundamental da cibernética neste, seja a explicação de intencionalidade ou comportamento dirigido por objetivo em termos de controle e informação, uma vez que feedback loops como mecanis mos para a obtenção ou manutenção de estados e objetivos eram vistos como modelos básicos para a autonomia característica dos organ ismos vivos e processos mentais em geral (HEYLIGHEN; JOSLYN, 2001, p.3).

\footnotetext{
325 Do original, em inglês '[...] Engineers, anthropologists, neurologists, psychol ogists and economists (to name some) were constructing 'similar' models, albeit with differ ent domains of application and ter minol ogy."
} 
A partir de uma perspectiva cibernética, Scott (2004, p.1367) observou que organis mos como cérebros e sociedades podiam ser modelados como sistemas determinados por processos hierárquicos ou heterárquicos de controle, seriais ou paralelos, síncronos ou assíncronos, desde que respeitassem a 'Lei da Variedade Requerida' ('Law of Requisite Variety, no original) de Ashby (1956) de que "[...] para que um sistema seja controlado, [...] a variedade (número de estados) do controlador deve exceder a variedade no sistema a ser controlado" ${ }^{326}$ (GLANVILLE, 2007b, p.1187, tradução nossa). Variedade de estados, isto é, a capacidade de 'perceber' e 'distingu ir' perturbações no ambiente, é assim um atributo deter minante para o controle sistêmico de forma que "[...] todos os organis mos dotados de auto-organização das amebas às sociedades humanas adaptam-se e evoluem para tornarem-se 'informados' das restrições em seus mundos - ou perecem" ${ }^{327}$ (SCOTT, 2004, p.1367, tradução nossa). Como apontamos anteriormente, sistemas cibernéticos encerram-se de maneira circular: a este respeito que Ashby (1956) descreveu a cibernética como "[...] o estudo de sistemas que são abertos a energia, mas fechados à informação e controle - sistemas informacionalmente

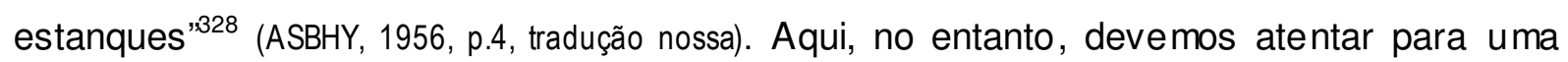
compreensão especial do conceito de 'informação' desta definição, como apontou Scott (2004):

É importante notar que este uso do termo 'informação' é claramente diferente do uso em ciência da computação ('proœssamento de informação' significando, estritamente, processamento de dados, a transmissão de dados e a transformação de um padrão de dados em outro) [...] Em resumo, um organismo não recebe 'informação' como algo transmitido a ele, mas como um sistema circularmente organizado que interpreta perturbações como sendo informativas. Nesta definição de Ashby podemos ver a emergência do conceib chave que leva à preocupação de segunda ordem sobre a epistemologia do observador. ${ }^{329}$ (SCOTT, 2004, p.1369, tradução nossa.)

\footnotetext{
${ }^{326}$ Do original em inglês: "[...] for any system to be controlled, [...] the variety (number of states) in the controller must exceed the variety in the system to be controlled."

327 Do original em inglês: "[...] All of self-organizing systems from amoebae to human societies adapt and evolve to become 'infor med' of the constrai nts in their worlds - or perish."

${ }^{328}$ Do original em inglês: "[...] the study of systems that are open to energy but closed to information and control - systems that are 'infor mation-tight'."

329 Do original em inglês: "It is important to notice that this use of the term 'infor mation' is clearly different from the usage in computer science ('infor mation processing' meaning, strictly, data processing, the trans mission of data and the transfor mation of one data 'patter n' into another) [...] In brief, an organis m does not receive 'infor mation' as something trans mitted to it, rather, as a circularly organized system it inter prets pertur bations as being infor mative."
} 
Referindo-nos novamente sobre o exemplo do termostato, o sensor do sistema pode ser compreendido como um observador, que se 'informa' das perturbações na temperatura do ambiente, o sistema observado, no caso. Por outro lado, o sensor ativa o mecanis mo do termostato que regula a temperatura ambiente ao acionar e desligar uma fonte de calor, influenciando assim no comportamento deste sistema observado, ao atuar sobre ele (GLANVILLE, 2007b, p.1182). A circularidade desta relação implica no reconhecimento de que, o modo pelo qual o observador está situado em uma relação de atuação ao sistema o qual observa e modela, está fundamentalmente atrelado ao modo como o mesmo o compreende (percebe e se informa), e vice-versa: segundo Scott $(2004, p .1370)$, esta era uma das preocupações presentes desde os primeiros debates cibernéticos que dizia respeito a uma dimensão reflexiva particular da cibernética, caracterizada pelos (meta) questionamentos acerca do modo como os próprios entendimentos sobre sistemas influenciavam as observações sistêmicas, ou seja, "entendeu-se que a epistemologia do observador, como ele, entendido como um sistema, vem a observar e conhecer o seu mundo e os sistemas nele, era uma questão complexa"330 (SCOTT, 2004, p.1370, traduçãonossa). Em outras palavras:

\begin{abstract}
Eles [ciberneticistas] começaram a reconhecer que todo o conhecimento de sistemas é mediado por nossas representações simplificadas - ou modelos - dos mesmos, que necessariamente ignoram aqueles aspectos dos sistemas que são irrelevantes aos propósitos para os quais o modelo é construído. Assim, as propriedades dos sistemas e m si precisam ser distinguidas daquelas dos seus modelos, que dependem de nós como seus criadores.31 (HEYLIGHEN; JOSLYN, 2001, p.3, tradução nossa).
\end{abstract}

São estas as inquietações fundamentais que levaram a cibernética a distanciar-se de sua abordagem original 'mecanicista' e desenvolver-se em torno de temas como 'autonomia', 'auto-organização' e 'cognição', no final dos anos 1960 e começo dos anos 1970, caracterizando-se como o movimento conhecido como 'Cibernética da Cibernética', ou 'Cibernética de Segunda Ordem.'

\footnotetext{
330 Do original em inglês: "[...] It was understood that the epistemology of the observer, how she, as a system comes to observe and know her world and the systems therein, was a complex matter"

331 Do original em inglês: "They began to recognize that all our knowledge of systems is mediated by our simplified representations -or models- of them, which necessarily ignore those as pects of the system which are irrelevant to the purposes for which the model is constructed. Thus the properties of the systems themselves must be distinguished from those of their models, which depend on us as their creators."
} 


\subsubsection{Cibernética de segunda ordem}

O direcionamento da pesquisa sobre o papel do observador e das observações sobre sistemas nos anos 1960 e começo dos 1970 levou ao desenvolvimento de uma revisão da perspectiva cibernética, preconizada pela sugestão da antropóloga Margaret Mead (1901-1978) em $1968^{332}$, da aplicação da teoria cibernética com relação ao próprio pensamento cibernético: a cibernética da cibernética, ou 'Cibernética de Segunda Ordem', conforme sua formalização pelo ciberneticista Heinz Von Foerster (1911-2002) que promoveu a distinção entre uma primeira e segunda ordem para a cibernética ao afirmar que "[...] a cibernética dos sistemas observados podemos considerar como sendo a cibernética de primeira ordem, enquanto a cibernética de segunda ordem é a cibernética dos sistemas observadores"333 (VON FOERSTER, 1979/2003, p.285, tradução nossa). A cibernética de segunda ordem compreende assim o estudo da interação entre elementos sistêmicos, de maneira que:

Um ciberneticista de segunda ordem, trabalhando com um organismo ou um siste ma social, reconheœ este sistema como um agente à sua maneira, interagindo com outro agente, 0 observador. Como a mecânica quântica tem nos ensinado, observador e observado não podem ser separados, e o resultado de observações irão depender de suas interações. 0 observador também é um sistema cibernético, tentando construir um modelo de outro sistema cibernético. Para entender este proœsso, nós precisamos de uma 'cibemética da cibemética', por exemplo, uma 'meta' ou cibernética 'de segunda ordem' ${ }^{334}$ (HEYLIGHEN ; JOSLYN, 2001, p.3-4, tradução nossa.)

Com sua vinda para os Estados Unidos, Heinz Von Foerster conduziu, no Laboratório de Computação Biológica da Universidade de Illinois, uma série de pesquisas em que procurou

\footnotetext{
332 Margaret Mead (1901-1978) foi uma antropóloga norte-americana que desempenhou pesquisa sobre a cultura moderna ocidental e estudos sociocomportamentais em sociedades primitivas asiáticas. Glanville (2007, p.1182-1183) comenta que Mead teria proporcionado os primeiros questionamentos para uma virada reflexi va da cibernética ao sugerir que se tratasse a então emergente sociedade cibernética como um sistema cibernético, ou seja, aplicar consistentemente conhecimentos e ideias sobre os sistemas cibernéticos à própria cibernética. Para uma melhor compreensão ver: MEAD, M. Cybernetics of Cybernetics. In: VON FOERSTER et al. (eds.). Purposive Systems. Spartan Books, 1968.

333 Do original em inglês: "[...] the cybernetics of observed systems we may consider to be first-order cyber netics; while second-order cybernetics is the cybernetics of observing systems."

334 Do original em inglês: "A second-order cyberneticist working with an organism or social system, on the other hand, recognizes that system as an agent in its own right, interacting with another agent, the observer. As quantum mechanics has taught us, observer and observed cannot be separated, and the result of observations will depend on their interaction. The observer too is a cybernetics system, trying to construct a model of another cybernetic system. To understand this process, we need a 'cybernetics of cybernetics', i.e. a 'meta' or 'second-order' cybernetics."
} 
estabelecer fundamentos para a compreensão de como um sistema torna-se um sistema observador (SCOTT, 2004, p.1372), baseado nos trabalhos então realizados sobre sistemas autoorganizados (derivados das concepções cibernéticas e das conferências organizadas por ele mes mo sobre o tema na década de 1960) e influenciado pela obra de pensadores como o etimologista Jean Piaget, o filósofo Ernst Von Glaserfeld e pelo polímata Spencer Brow $n$ (GLANVILLE, 2004). Ainda nos anos 1960, Von Foerster publicou uma série de trabalhos sobre a presença inevitável do observador (de acordo com o conceito piagetiano) como um construtor de 'objetos', sendo ele mes mo seu 'objeto definitivo' construído (SCOTT, 2004, p.1372), o que evocou um entendimento epistemológico essencialmente construtivista: "[...] o conhecimento não pode ser absorvido passivamente a partir do ambiente, mas precisa ser construído ativamente pelo sistema ele próprio” ${ }^{335}$ (HEYLIGHEN; JOSLYN, 2001, p.21, tradução nossa). Nas palavras do próprio Von Foerster, “[...] o ambiente não contém informação; o ambiente é como ele é." ${ }^{336}$ (VON FOERSTER, 1974/2003, p.252, tradução nossa). É neste sentido que afir ma-se que ao construir seu conhecimento, inclusive de si mesmo como um objeto, o observador constrói também sua realidade ${ }^{337}$ :

A realização de Von Foerster foi importante: ele mostra que à medida que recorremos à nossa ciência para explicar como nós mesmos funcionamos nos encontramos emu m círculo hermenêutico de explicação. Como ele œlocou, 'precisamos de um cérebro para explicar o cérebro'. Se o cérebro é um construtor de mapas e modelos, cabe-nos a reconheœr que todas as nossas teorias e explicações são construções. Nossa experiência de fazer parte de uma 'realidade' é tambémuma construção ${ }^{338}$ (SCOTT, 2004, p.1372, tradução nossa)

Glanville (2004) observou que um dos principais interesses da pesquisa de Von Foerster constituiu-se na possibilidade de computar 'realidades estáveis' (os chamados objetos) a partir de observação recursiva, continuamente redistinguindo distinções: para tanto, Von

\footnotetext{
${ }^{335}$ Do original em inglês: "[...] knowledge cannot be passively abs orbed from the environment, it must be actively cons tructed by the system itself"

336 Do original em inglês: "[...] The environment contains no infor mation; the environment is as it is."

337 Glanville obs erva a este res peito que "[...] em seu trabalho, o observador de Von Foerster explica-se a si mesmo, evitando assim que um ciberneticista de segunda ordem seja associado com o nilismo irracional inerente no pós-modernismo." (GLANVILLE, 2004, tradução nossa)

338 Do original em inglês: "Von Foerster's achievement was momentous: he shows that as we draw on our science to explain how we ourselves work we find ourselves in a her meneutic circle of explanation. As he puts it 'we need a brain explain a brain'. If a brain is a constructer of maps and models, it behoves us to acknowledge that all our theories and explanations are constructions. Our experience of being part of a 'reality' is also a construction."
} 
Foerster encontrou um modelo matemático baseado em funções eigen ${ }^{339}$ que uma vez aplicadas recursivamente, atingiam estabilidade e estados autoperpetuados dinamicamente, formando elementos autorreferenciados ${ }^{340}$ em sistemas eigen, seus objetos. De acordo com Glanville (2004), Von Foerster estudou o modo como estes mecanis mos relacionavam-se com o funcionamento do sistema nervoso, em correspondência com a concepção do neurobiólogo chileno Humberto Maturana (1928-) que compreende o sistema nervoso como um sistema circular autônomo e organizacionalmente fechado (dotado de 'clausura organizacional' ${ }^{341}$, em termos biológicos). Maturana é bastante referenciado no contexto da Cibernética de Segunda Ordem por ser responsável, junto do pesquisador chileno Francisco Varela (1946-2001) pela proposição da 'Teoria da Autopo iese'342 (autocriação ou autoprodução), que descreveu os seres vivos como organizações sistêmicas ontogenéticas e autopoiéticas, sistemas que mantém-se a si mesmos por processos recursivos e circulares autorreferenciados e de contínua autoprodução, ou seja, mantém sua estabilidade pela sua habilidade dinâmica de reproduzir-se, renovar-se (GLANVILLE 2004; 2007b, p.1184). A relevância do trabalho de Maturana e Varela com relação à cibernética deve ser ressaltada à medida que "[...] os conceitos de autopoiesis, clausura organizacional e a noção associada de 'autonomia', originários na biologia, têm se tornado por extensão análoga alguns dos mais desenvolvidos e poderosos conceitos da Cibernética de segunda ordem."343 (GLANVILLE, 2004, tradução nossa).

\footnotetext{
339 Funções eigenou 'Eigenfunctions' são funções matemáticas empregadas no campo da mec ânica quântica.

340 Esta autorreferenciação é evidenciada em sua apr esentação de 1974 sobre a 'Cibernética da Cibernética', em que atesta como seu cor olário número um: "Tudo o que é dito é dito para um observador", em acordo e complementaridade com o postulado do neurologista e biólogo chileno Humberto Maturana "Tudo o que é dito é dito por um observador" (VON FOERSTER, 1979/2003, p.283, tradução nossa).

341 Tradução do termo em inglês: "Organizational Closure".

342 Maturana e Var ela (1987, p.47-48, tradução nossa) descrevem os sistemas autopoi éticos como "Uma classe de sistemas mec ânicos em que cada membro da cl asse é um sistema dinâmico definido como uma unidade por rel ações que a constituem como uma rede de processos de produção de componentes que: (a) recursivamente participar através de suas interações na geração e realização da rede de processos de produção de componentes como uma uni dade no es paço em que eles (os componentes) existem pela realização de seus limites. [...] a autonomia em sistemas vivos é uma característica de autoprodução (autopoiesis), a básica cons equência da organização au topoiética é que tudo o que ac ontece em um sistema autopoi ético é subor dinada à realização de sua autopoi ese, caso contrário el e se desi ntegra."

343 Do original, em inglês: "[...] the concepts of autopoi esis, organizational closure, and the associated notion 'autonomy', originating in biology, have become by anal ogical extension some of the most powerful and developed concepts in second order Cybernetics."
} 
Assim como Heinz Von Foerster e Humberto Maturana, outro relevante pesquisador do contexto da Cibernética de Segunda Ordem cujo trabalho abrangeu de modo significativo estes conceitos (incorporados de modo especial em uma perspectiva de ênfase na interação sistêmica) foi o ciberneticista inglês Gordon Pask (1928-1996) ${ }^{344}$. Instigado desde cedo pelo modo o qual os sistemas circulares relacionam-se por meio de interações comportamentais, Pask (1975a, 1976) dedicou extensos esforços de pesquisa no desenvolvimento da chamada 'Teoria Cibernética da Conversação', em que descreveu as estruturas formais das interações sistêmicas a que se referiu como 'conversações', os eventos de produção e distinção de sistemas 'psicossociais' através do meio de linguagem (SCOTT, 2004, p.1372). Bernard Scott $(2004$, p.1371), um dos colaboradores no desenvolvimento da Teoria da Conversação por muitos anos, citou a correspondência conceitual entre Pask e Maturana observada na ocasião da 'Conferência Internacional sobre Sistemas Auto-Referenciais'345 em Londres no final dos anos 1960:

Destaca-se nas discussões em torno do tema da conferência a observação de que os sistemas biológicos e psioossociais, enquanto logicamente distintos, poderiam ser ambos caracterizados como sendo organizacionalmente fechados e, portanto, neœssariamente autorreferenciais, embora o senso de aubrreferência seja diferente no que diz respeito às ontologias diferentes. Na terminologia de Pask, os sistemas biológicos são 'sistemas taciturnos'. O observador externo infere clausura organizacional a partir de observạ̃oes sobre o œmportamento dos sistemas e da persistência de uma organização estável. Os sistemas psicossociais são 'sistemas orientados por linguagem'. Com isto então o observador é um observador participante e pode conversar pró-nominalmente, usando as

344 O ciberneticista inglês Andrew Gordon Pask (1928-1996) tornou-se mestre em Ciências Naturais pela Uni versidade de Cambridge em 1928, Doutor em psicol ogia pela Uni versidade de Londr es em 1964 e posteriormente Doutor em Ciências pela Universidade Li vre do Reino Uni do. Em sua extensa carreira acadêmica, Paskconduziu pesquisas no Reino Unido, na Escol a de Arquitetura da Architectural Association e na Uni versidade de Brunel, em Londr es; nos Estados Unidos na U niversidade de Illinois em Chicago e em Urbana-Champaign (junto do BCL de Von Foerster), Universidade de Concórdia, Instituto de Tecnol ogia da Geórgia, Uni versidade de Oregon e Instituto de Tecnologia de Mass achusetts; também na U niversidade Nacional Autônoma do México e Universidade de Amsterdam, na Holanda. Pask é responsável pelo desenvolvimento de diversos conceitos e as pectos fundamentais da cibernética, em especial a Teoria Ciber nética da Conversação, confor me suas obr as Conversation Theory, with applications in education (Conversation, Cognition and Learning), Amsterdam: Elsevier, 1975; Conversation Theory: Applications in Education and Epistemology, Amsterdam: Elsevier, 1976.

345 Do original em inglês: "International Conference of Self-Referential Systems", encontro organizado pelo empr esário filantropo Oliver Wells, dono e editor do periódico Artorga. Bernard Scott, que participou pessoal mente da conferência como parte da equipe de Pask conta que essencialmente a confer ência era um encontro entre membros do BCL (notadamente Humberto Maturana e o filós ofo Gottard Gunther (1900-1984), Von Foerster não pode comparecer) e da equipe da organiz ação Systems Research Ltd. de Pask em Richmond, Surrey, (no cas o Pask, Dionysius Kallikourdis, e o próprio Scott) (SCOTT, 2004, p.1371). 
anáforas 'eu', 'você', 'nós'. ${ }^{346}$ (SCOTT, 2004, p.1372, tradução nossa).

Outro colaborador de Pask, o ciberneticista Paul Pangaro, promoveu uma síntese desta compreensão cibernética de segunda ordem sobre sistemas vivos, atestando a compatibilidade entre visão de Heinz Von Foerster, Gordon Pask e Humberto Maturana e contextualizando a concepção de conversação de Pask (1975a, 1976):

Von Foerster, Pask, e Maturana compartilham a visão do sistema nervoso como um circuito fechado. Eles compartilhama posição construtivista que o sistema nervoso de umorganismo constrói um repertório de interações estáveis 'com' e 'através' do ambiente que são compatíveis e ressonantes, e essas interações ajudama manter a viabilidade do sistema. $\mathrm{E}$ eles compartiham o entendimento de que essas interações constituem o 'viver juntos' nas relaçoes sociais tedidos pela conversação, de modo que objetivos comuns sejam possiveis, de forma colaborativa e produtiva. ${ }^{347}$ (PANGARO, 2007, p.178-179, tradução nossa)

Nesta passagem esboça-se o modo pelo qual a conversação de Pask integra-se com os conceitos anteriormente apresentados aqui, de acordo com o comentário de Glanville (2004) de que Pask sempre intencionou uma aplicabilidade universal de seu trabalho. Para Glanville (2007b, p.1185, p.1199), assim como Pangaro foi aluno e outro colaborador das pesquisas de Pask, a conversação é um tipo essencial de sistema cibernético de segunda ordem, uma abordagem sobre a interação entre sistemas pela qual Pask contextualizou elementos como compreensão e consciência, sentido e linguagem, diálogo e aprendizado (GLANVILLE, 2004). Na sequência, faremos uma leitura pormenorizada da Teoria da Conversação de Gordon Pask (1975a, 1976), a que nos referenciamos na caracterização da atividade prática do design arquitetônico pela chave da conversação cibernética.

\footnotetext{
346 Do original em inglês: "Highlights in the discussions around the conference theme included noting that biological and psycho-social systems, while logically distinct, could both be characterized as being organizationally closed and hence, necess arily self-referential, although the sense of self-reference is different with respect to the different ontologies. In Pask's terminology, biological systems are 'taciturn systems'. The external observer infers organizational closure from observations about the systems behavior and the persistence of a stable organization. Psycho-social systems are 'language oriented systems'. With then the observer is a participant observer and may converse with them pro-nominally, using the anaphors ' $l$ ', 'you', 'we'."

347 Do original em inglês: "Von Foerster, Pask, and Maturana share the view of the nervous system as a closed loop. They share the constructivist position that an organis mis nervous system builds a repertoire of stable interactions with and through the environment that are compatible and resonant, and these interactions help the system mai ntain viability. And they share the understanding that these interactions constitute 'living together' in social relations, woven by conversation, whereby common goals are possible, collaboratively, and productive."
} 


\subsubsection{Teoria cibernética da conversação}

O que quero dizer com uma conversa? Bem, em primeiro lugar uma conversa é uma interação linguística ativa entre atores, isto é, os participantes (como voœê e eu) por quem conceitos pessoais são trocados e, em parte, compartilhados. ${ }^{348}$ (PASK, 1987, p.19, tradução nossa)

Segundo Gordon Pask, a Teoria Cibernética da Conversação é uma teoria reflexiva que trata do compartilhamento de 'conceitos' entre 'participantes' acerca de sua concordância ${ }^{349}$ e incapacidade em concordar (PASK, 1980, p.1002). Define-se conversação como um tipo de interação comunicativa sistêmica: "Conversação é transferência de informação entre sistemas organizacionalmente fechados (aliás, autônomos). É um mecanis mo de resolução de conflitos, que também gera uma distinção entre indivíduos autônomos em suporte à conversação'350 (PASK, 1980, p.1006, tradução nossa). Pask ressaltou a relevância deste aspecto especial da conversação que a distingue de um mero processo comunicativo colocando que para além da transferência de informação, "[...] algo como compreensão mútua, ou coerência entre os participantes deve ser incluído." ${ }^{351}$ (PASK, 1987, p.19, tradução nossa). O estabelecimento desta coerência, por sua vez, depende do câmbio dialógico de conceitos através da linguagem: "Os eventos de uma interação conversacional são trocas de conceitos, ocasião em que são produzidos conceitos compartilhados ou conceitos públicos, representados em LP'. ${ }^{352}$ (PASK, 1987, p.19, tradução nossa). Pask utilizou aqui a no menclatura 'LP' referindo-se a uma 'protolinguagem', um tipo de linguagem primitiva comum aos participantes da conversação, dotada dos atributos básicos de uma linguagem natural:

\footnotetext{
348 Do original em inglês: "What do I mean by a conversation? Well, first of all a conversation is an active linguistic interaction between actors, namely, the participants (such as you and l) by whom personal concepts are exchanged and in part, shared."

349 Pas kc hama de concordância uma compreensão mútua c oerente entre participantes, porém enf atiza que es ta conc ordância raramente representa um acordo completo. Esta concordância contemplaria também a instância do desacor do, como uma "concordância da discordância ou em discordar". Assim, a conversação certamente pode promover tanto a emergência de conflito quanto sua res olução. (PASK, 1987, p.19).

350 Do original em inglês: "Conversation is infor mation tr ansfer between organizationally closed (alias autonomous systems). It is a mechanism of conflict resolution, which also generates a distinction between autonomous individuals to support a conversation."

351 Do original em inglês: "[...]something like mutual comprehension, of coherence between the participants must be included."

352 Do original em inglês: "The events of a convers ational interaction are concept exchanges, on occasion producing shared concepts or public concepts, often represented in LP."
} 
LP é chamada de primitiva ou protolinguagem porque não tem o refinamento de determinadas línguas naturais, mas, mesmo que suas frases sejam comportamentos simbólicos, ela tem as qualidades essenciais de uma linguagem natural. [...] a linguagem utilizada pelos participantes interagindo não precisa ser, e muitas vezes não é, verbal. Pode ser gráfica, por exemplo, ou enão a linguagem da pantomima ou de comportamento simbólico. Deve, no entanto, ter o poder de uma linguagemnatural para expressar comandos e perguntas, obediências (ou não), respostas, solicitações, narrativas e metáforas, bem como descrições e declarações assertivas. ${ }^{353}$ (PASK, 1987, p.21, tradução nossa)

Pask afirmou que pode se compreender um 'conceito' como o sentido de uma entidade ou um s ímbolo como uma palavra, por exemplo (PASK, 1980, p.1002). O autor observou, no entanto, que o sentido de conceitos representados pela mes ma entidade (uma palavra, no caso) variava conforme as noções particulares de determinados indivíduos: o conceito de 'casa' para um indivíduo 'A' supostamente não é o mes mo para um indivíduo 'B', porém pode-se admitir que existam similaridades entre os conceitos à medida que 'A' e 'B' concordam entre si em um entendimento, configurando-se assim conceitos compartilhados ou mesmo públicos, que podem corresponder a sentidos comuns atribuídos às entidades em questão, em deter minado contexto social (PASK, 1980, p.1002). De modo correlato a esta compreensão, pela Teoria da Conversação o termo 'conceito' assume uma caracterização cibernética própria, representando uma unidade estável de configuração ${ }^{354}$, composta por procedimentos (como, por exemplo, um conjunto de instruções), cuja execução originam processos, que por sua vez, geram produtos, ou seja, define-se um conceito como "[...] um conjunto de procedimentos coerentes (que se atraem por lógica) capazes de serem aplicados como um processo no intuito de produzir um produto: este produto pode ser uma

\footnotetext{
353 Do original em inglês: "Lp is called a primitive or protolanguage because it lacks the refinement of particular natural languages but, even though it phrases are symbolic behaviours, it does have the essential qualities of a natural language. [...] the language us ed by the interacting participants need not be, and often is not, verbal. It may be graphical, for example, or else the language of pantomime or of symbolic behaviour. It must, however, have the power of a natural language to express commands and questions, obediences (or not), answers, requests; stories and metaphors as well as descriptions and ass ertoric statements."

354 Na Teoria da Conversação de Pask, uma unidade estável é um sistema organizacional mente fechado, em um sentido equivalente ao do domíni o bi ológico, do qual os sistemas 'autopoiéticos' seriam um caso específico (PASK, 1980, p.1003). Segundo a descrição de Pask: "Um arranjo é organizacionalmente fechado se existe alguma construção (biológica, molecular, conceitual, social) sobre as quais produções (enzi mas DNA, conceitos produti vos, operações soci ais produti vas) atuam par a produzir produtos. entre estes produtos, estão as próprias operações de produção. Organismos vivos, as células dos organismos vivos, ecol ogias compostas de organis mos são assi m. Também o são os participantes, atores e as sociedades que eles habitam." (PASK, 1987, p.22, tradução nossa)
} 
imagem, uma descrição, ou um comportamento, muitas vezes todos estes juntos. ${ }^{355}$ (PASK, 1987, p.21, tradução nossa).

Com base neste entendimento, afirma-se que através da execução de um conceito pessoal produz-se comportamentos pessoais (como, por exemplo, andar em uma bicicleta), implicando neste caso, um desdobramento do conceito no contexto físico do indivíduo, ou então a execução pode proceder apenas na mente deste mes mo indivíduo produzindo uma descrição do comportamento em questão (como a imaginação de andar de bicicleta) (PASK, 1980, p.1002). A manifestação deste produto, em uma mente como uma imaginação ou descrição ou como desdobramento comportamental implica na execução do conceito, ou seja, "há, de fato, uma complementaridade de processo-produto. Se um existe, então, o outro também" ${ }^{356}$ (PASK, 1987, p.21). Pask colocou ainda que, por determinar comportamentos qualificados, e entendendo que o indivíduo possui habilidades baseadas em conceitos (como andar de bicicleta), pode-se afirmar que conceitos podem também ser compreendidos como habilidades (PASK, 1980, p.1002). Segundo o autor, quando conceitos desenvolvem estabilidade, tendem a se fixar, às vezes, se enraizando ou ossificando-se em estruturas conceituais (PASK, 1987, p21), podendo evoluir conforme se revisam (pela sua reprodução) ou se enriquecem (pela agregação coerente de outros conceitos produzidos), conservando estabilidade à medida que são produtivos e reproduzidos (PASK, 1980, p.1002). Assim, para Pask, produção e reprodução são as operações vinculadas à estabilidade dos conceitos, em correspondência à noção sistêmica de 'autonomia', ou 'encerramento organizacional', o que significa a compreensão de um 'conceito' como um indivíduo, especificamente um 'Indiv íduo Ps icológico' (Indiv íduo P) nos termos de Pask, em distinção a indiv íduos ou sistemas cibernéticos mecânicos em geral (Indivíduos M) como os organis mos biológicos e sistemas ambientais ${ }^{357}$ (PASK, 1975b, p.9). Bernard Scott (2001) pontuou esta distinção de Pask como uma das propriedades fundamentais da Teoria da Conversação:

\footnotetext{
355 Do original em inglês: "[...] a bunde of coherent (logically sticking together) procedures capable of being applied as a process in order to produce a product; this product may be an image, a description, or a behaviour, often all of them."

356 Do original em inglês: "There is, in fact a process-product complementarity. If one exists, then does the other."

357 Sobre a natureza dos indi víduos M, Pask observa que um "Indi víduo M distingue-se pelos métodos conhecidos da física clássica e behavi orismo. Por exemplo, um homemé uma coisa, por isso é um ani mal, por isso é uma máquina única. Tem uma localização espaço-temporal que geral mente é justaposta com um outro indivíduo M chamado seu ambi ente." (PASK, 1975b, p.9, tradução nossa)
} 
O aspecto principal da Teoria da Conversação que a distingue da conta de Maturana e Von Foerster de cognição e comunicação é que Pask escolhe distinguir entre o 'biológion' ou 'biomecânico' e o 'psicológico' ou 'conceitual'. Assim como a individualidade dos organismos biológioos como 'máquinas' cibernéticas autoprodutivas, 'autopoiéticas' (termo de Maturana), Pask distingue a individualidade de sistemas conceituais, processos de $\infty$ nhecer e vir a conhecer, que são œerentes, autoprodutivos e, portanto, 'organizacionalmente fechados'. Pask refere-se a estes sistemas como o indivíduos (p-) psicológicos. ${ }^{358}$ (SCOTT, 2001, p.347, tradução nossa)

Um participante da conversação pode ser considerado também um Indivíduo P, como um sistema estável que contém em si outros sistemas estáveis/indivíduos $P$, conceitos ou conjunto de conceitos, configurando-se como um 'acoplamento estrutural' ${ }^{359}$ (BOYD, 2004, p.183,184). Pask apontou também que "O participante é organizacionalmente fechado, mas informacionalmente aberto. Um participante é apto e propenso a tratar, dar e receber, entrar em coerência com outros participantes, em suma, conversar. ${ }^{\prime 360}$ (PASK, 1987, p.23, tradução nossa). De fato, "[...] Indivíduos P são reconhecidos pela existência de conversações, e a conversação em si é, em dada ocasião, também um Indivíduo P (o broto)." ${ }^{361}$ (PASK, 1975b, p.12, tradução nossa). Ou seja, novos Indivíduos $\mathrm{P}$ podem ser originados como resultado de

\footnotetext{
${ }^{358}$ Do original em inglês: "The major aspect of Conversation Theory that distinguishes it from Maturana's and von Foerster's accounts of cognition and communication is that Pask chooses to distinguish between the 'biological' or 'bio-mechanical' and the 'psychological' or 'conceptual'. As well as the individuality of biological organisms as self-producing, 'autopoietic' (Maturana's ter m), cybernetic 'machines', Pask distinguis hes the individuality of conceptual systems, process es of knowing and coming to know, that are coherent, self producing, and hence 'organizationally closed'. Pask refers to such systems as psychol ogical (p-) individuals."

${ }^{359}$ Acoplamento estrutural é o termo sistêmico utilizado para designar o envol vimento es trutur almente determinado e também determinante de uma dada unidade com seu ambiente ou outra unidade. Segundo Humberto Maturana (1928-) e Francisco Varel a (1946-2001), o processo de engajamento afeta um histórico de interações recorrentes que conduzem à congruência estrutural entre dois (ou mais) sistemas, em outras palavras, é um processo histórico que conduz à coincidência espaçotemporal entr e as mudanças de estado nos participantes. Des te modo, acoplamento estr utural tem conotações de coordenação e coevol ução. Durante o curso de ac opl amento estrutural, cada sistema participante é, com relação ao outr o(s), uma fonte (e um alvo) de perturbações, ou seja os sistemas que participam reciprocamente servem como fontes de perturbações compens áveis entr e si. Es tes são 'compensáveis' nos senti dos que (a) há uma série de 'compensação' definida pelo li mite além do qual cada sistema dei xa de ser um todo funcional e (b) cada iteração da interação recíproca é afetada anteriormente. Acoplamento estrutural, então, é o processo através do qual as transformações estruturalmente deter minadas em cada uma das unidades sistêmicas induz (para cada) uma trajetória de mudança recíproca. Encyclopedia Autopoiética - Cybernetics \& Human Knowing Thesaurus. Disponível em:<http://www.imprint.co.uk/thesaur us/structural_coupling.htm> Acesso em 12/08/2011.

360 Do original em inglês: "The participant is organizationally closed but 'informationally open'. A participant is able to converse, willing to attend, give and rec eive, to enter into coherency with other participants, in short, to converse."

${ }^{361}$ Do original em inglês: " $P$ Individuals are recognized by the existence of conversations, and the conversation itself is, on a given occasion, a further $P$ Individual (the sprout)."
} 
conversações como novo conjunto de procedimentos capazes de engajar-se em outras conversações (BOYD, 2004, p.185). Como resultado destes processos, os Indivíduos P podem configurar sistemas sociais complexos dotados de 'consciência intelectual', em distinção aos sistemas mecânicos M:

Para Pask, 'consciênda' é uma propriedade de um indivíduo-P, um sistema que potendalmente pode 'conheœr sobre si mesmo' que é um sistema. Não é uma propriedade de um 'indivíduo mecânico' (indivíduo M). Os participantes de uma conversa são indivíduos P. A conversa é em si um indivíduo P. Note o poder da distinção: indivíduos Pe M não estão necessariamente em correspondência um para um. Um ' $M$ ' pode abrigar vários ' $P$ '; um ' $P$ ' pode ser alojado por vários 'M' ${ }^{362}$ (SCOTT, 2001, p.347, tradução nossa)

Um participante típico da conversação, por exemplo, é capaz de conversar consigo mesmo através de seu sistema conceitual de Indivíduos $\mathrm{P}$, e de comunicar-se com outro participante incorporado em um ambiente Individual $M$, que pode ser entendido como seu corpo biológico humano (PASK, 1975b, p.14), por sua vez, acoplado estruturalmente a outro Indivíduo M (o ambiente habitado por este corpo), e assim por diante, em relação a diversos níveis de organização. Do mesmo modo, a organização de Indivíduos $\mathrm{P}$ incorporados em Indiv íduos M conforma o domínio social em seus diversos níveis: "Típicos Indivíduos P são pessoas consideradas como personalidades-personagens executados por atores, o desempenho de papéis estáveis na sociedade, a organização de grupos coerentes, facções, os governos, culturas e ideias persistentes." 363 (PASK, 1975b, p.12, tradução nossa). Através desta compreensão expandida dos Indivíduos $\mathrm{P}$, podemos afirmar que as conversações também são passíveis de ocorrer em relação à diferentes níveis de organização como conversações entre pessoas (indivíduos), entre indivíduos e culturas, conversações entre sociedades e culturas e mes mo conversações entre culturas (PASK, 1987, p.20). Isto é possível toda vez que, ao conversar, os participantes reelaboram e compartilham interpretações pessoais de conceitos

\footnotetext{
362 Do original em inglês: "For Pask, 'consciousness' is a property of a p-individual, a system that potentially may 'know with itself' that it is a system. It is not a property of a 'mechanical individual' (m-individual). The participants in a conversation are $p$ individuals. The conversation is itself a $p$-individual. Do note the power of the distinction: $m$ and $p$-individuals are not necessarily in one to one correspondence. One ' $m$ ' may hous e several ' $p$ 's; one 'p' may be hous ed by several ' $m$ 's."

363 Do original em inglês: "Typical P Individuals are people regarded as personalities - characters (in plays) executed by any actors, the performance of stable roles in society, the organization of coher ent groups, factions, governments, cultures, and persistent ideas."
} 
que entram em acordo ou conflito, tornando-se 'tópicos' de conversação, no espaço ou domínio da conversação, que são os próprios participantes (PASK, 1980, p.1008). Pask utilizou-se de uma representação especial destes domínios sob a forma de 'malhas de vínculo' (no original 'entailment meshes'), uma espécie de formalização de estruturas do conhecimento, cujos elementos básicos são estes tópicos (PASK, 1980, p.1008). Na configuração de uma malha de vínculo, os tópicos são interconectados por coerências, um conjunto de outros tópicos cujos sentidos são interdependentes, ou seja, sobrepõem-se e condicionam-se em um entendimento complementar derivado. Em outras palavras, os tópicos em vínculos de coerência definem-se mutuamente durante as conversações (PASK, 1980, p.1008, 1009). Na sequência, apresentaremos a formalização da estrutura das conversações pelas quais estes processos desenvolvem-se.

\subsubsection{Arquitetura da te oria da conversação}

'Arquitetura da teoria da conversação' é como Pangaro (2002) referiu-se ao modelo formal empregado por Pask $(1975 a, 1976)$ na descrição e caracterização de interações sistêmicas envolvidas nos processos conversativos descritos na Teoria da Conversação. Segundo o autor, a estrutura representava também a proposta de Pask à Nicholas Negroponte para o desenvolvimento de uma aplicação computacional em auxílio ao processo de design arquitetônico:

Gordon foi soliciado por Negroponte à escrever um artigo que abordasse a œnstrução de uma 'máquina de arquitetura', umambiente computacional que interagisse comarquitetos no processo de design. 0 resultado seria como arquitetos trabalhando juntos em vez de arquitetos trabalhando com máquinas. Pask escreveu uma teoria que tinha perøolado em seu laboratório por alguns anos, chamada Teoria da Conversação. A primeira vez que deparei-me comela eu o chamei-a uma 'teoria de tudo'. 364 (PANGARO, 2007, p.175, tradução nossa).

\footnotetext{
364 Do original em inglês: "Gordon was asked by Negroponte to write a paper that would address the construction of an 'architecture machine', a computer environment that would interact with architects in the design process. The result would be like architects working together rather than architects working with machines. Pask wrote up a theory that had been percol ating at his I ab for a few years, called Convers ation Theory. When I first came across it, I called it a 'theory of everything'”.
} 


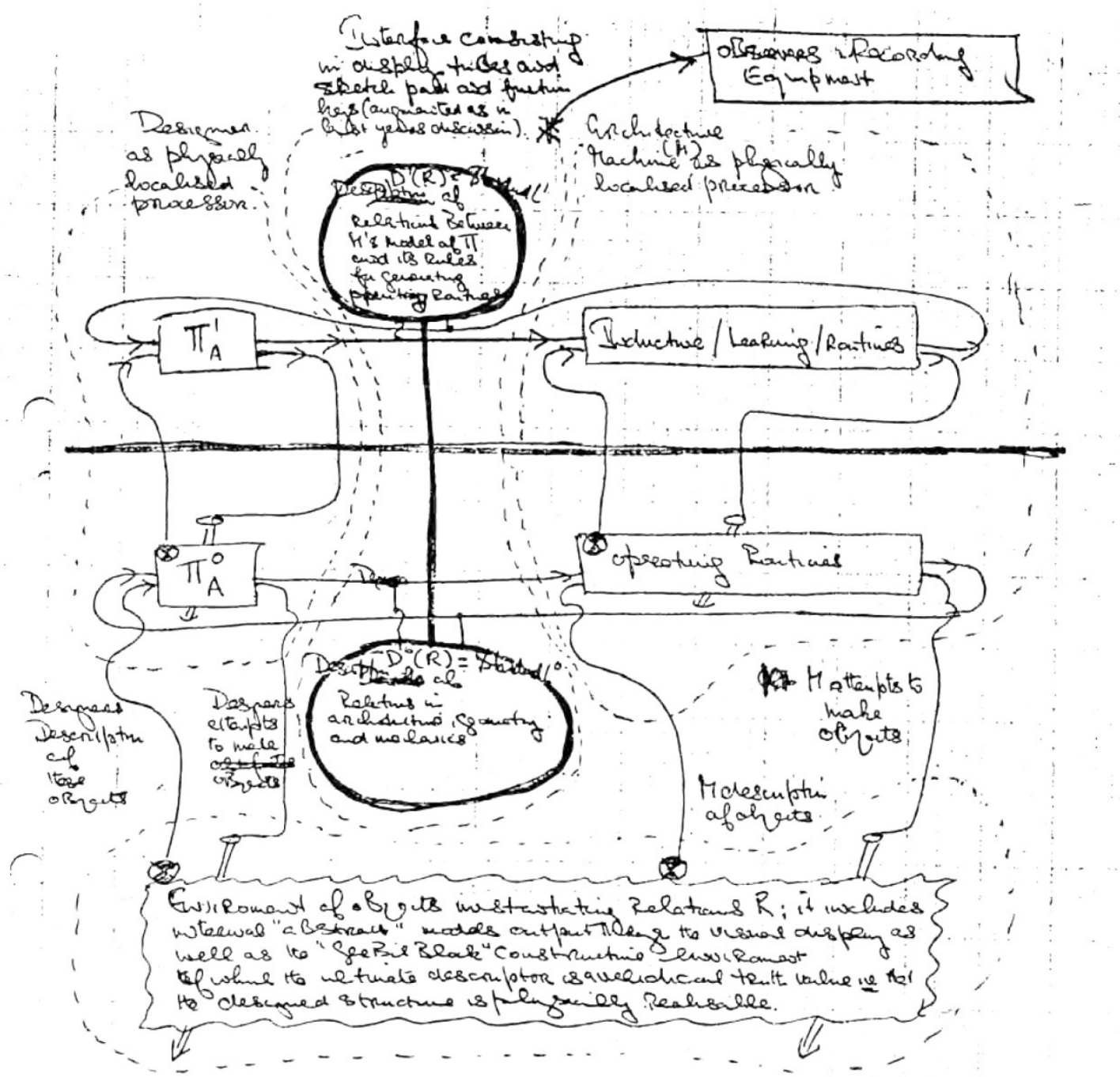

Figura 19 - Estrutura da conversação - proposta para um sistema computacional em aux ílio a arquitetos fonte: (PASK, 1975b, p.29)

As interações horizontais representadas no diagrama da Figura 19 e Figura 21 são denominadas 'Interações referenciadas - eu/você' (no original em inglês: 'I/you referenced interactions'), as interações em que os indivíduos ou sistemas conduzem quando entram em diálogo (PANGARO, 2002), nas quais ocorre o compartilhamento de conceitos (PASK, 1975b, p.22). Scott afirmou que a comunicação entre os participantes, que pode expressar-se como uma troca verbal, por exemplo, possui ao menos dois níveis lógicos ${ }^{365}$ para Pask, que podem ser

\footnotetext{
365 Boyd explica que es ta distinção de níveis corresponde ao teor ema do matemático John Von Neumann (1903-1957) de que o sistema automata que produz e se autorreproduz deve sempre possuir duas partes: o autômato produtivo em si e uma 'planta' ou um plano genético ou mi mético que o permita produzir a si mesmo (esta regra se aplica a seres vivos). Assim "Desde que são autoprodutivos e reprodutivos, o teorema de Von Neumann é o porquê os 'conjuntos de processos executáveis' que Pask chama de Indivíduos P, sempre tem ao menos dois níveis principais: procedimentos de resol ução de problemas $L_{0}$ e metaprocedimentos de aprendizagem ou programas-planos $L_{1}$ para guiar a escol ha dos procedimentos de resolução de pr oblemas durante a execução." (BOYD, 2004, p.184, tradução nossa)
} 
descritos pelos termos interrogativos 'como' e 'porquê', em que "o nível de 'como' relacionase com a forma de 'fazer' um tópico: como reconhecê-lo, construí-lo, mantê-lo e assim por diante; o nível de 'porquê' relaciona-se com explicar ou justificar o que um tópico significa em ter mos de outras tópicos. ${ }^{, 366}$ (SCOTT, 2001, p.351, tradução nossa). Voltando-nos ao diagrama da estrutura da conversação de Pask representado pela Figura 19, podemos identificar os dois níveis com relação aos campos acima e abaixo do eixo horizontal traçado ao centro da figura, em que a interação em 'loop' horizontal superior corresponde ao nível de 'porquê' ou 'o que pode ser entendido' no do mínio da conversação e a interação inferior corresponde ao nível de 'como' ou 'o que pode ser feito', a parte relacionada a 'prescrição-construção' da interação (PANGARO, 2007, p.176-177). A troca e execução de procedimentos conceituais nestes níveis distintos corresponderiam, por sua vez, à descrição formal básica de Pask a respeito da compreensão e aprendizagem de um tópico específico de conversação, conforme:

\begin{abstract}
Pask refere-se a aprender sobre 'o porquê' como aprendizagem de compreensão e aprender sobre 'œmo', como aprendizagem de operação, e concebe os dois como sendo aspectos complementares da aprendizagem efetiva. Estas distinções permitem a Pask dar uma definição formal do que significa a compreensão de um tópico. Para Pask, compreender um tópico significa que o aluno é capaz de 'ensinar de volta' o tema, fornecendo tanto demonstrações não-verbais e explicações verbais de 'como' e 'porquê', 367 (SCOTT, 2001, p.352, tradução nossa)
\end{abstract}

Scott observou ainda de maneira complementar que as conversações podem ter vários níveis acima de um nível básico de 'porquê', níveis em que justificativas conceituais são por sua vez justificadas, em uma relação de 'comentários sobre comentários' (SCOTT, 2001, p.351). Por sua vez, as interações verticais representadas no diagrama da Figura 19 e Figura 21, que apresentamos em detalhe na Figura 20 são denominadas 'Interações referenciadas em si' (no original em inglês: 'it-referenced interactions'), pois envolvem o controle de um processo por outro (PANGARO, 2002) no qual um inter-ator de um indivíduo ou sistema está agindo sobre outro, tratando o resultado da interação como um produto ou um objeto e não

\footnotetext{
366 Do original em inglês: "The level 'how' is concerned with how to 'do' a topic: how to recognize it, construct it, maintain it and so on; the 'why' level is concerned with explai ning or justifying what a topic means in ter ms of other topics."

367 Do original em inglês: "Pask refers to learning about 'why' as comprehension learning and learning about 'how' as operation learning, and conceives them both as being complementary aspects of effective learning. These distinctions allow Pask to give a formal definition of what it means to understanding a topic. For Pask, understanding a topic means that the learner can 'teac hback' the topic by providing both non-verbal demonstrations and verbal explanations of 'how' and 'why'."
} 
como um igual, um par (PANGARO, 2007, p.177). Estas interações correspondem à estrutura cibernética básica de controle por 'feedback-loop' ${ }^{368}$ em que processos controladores mandam instruções de execução para processos controlados cujo resultados são avaliados por comparação afim de se detectar a coerência da resposta (e a obtenção do procedimento desejado) ou a necessidade de correção, se detectada alguma incoerência ou erro (PANGARO, 2002; BOYD, 2004, p.182). Várias sequências destas instâncias de controle compreendem uma execução iterativa, um movimento contínuo que pode se caracterizar como 'inteligente' à medida que todos os aspectos e instâncias citadas encontram-se presentes, incluindo as modificações reguladoras baseadas em feedback nestas execuções iterativas (PANGARO, 2002).
A. Process os controladores
B. Process os controlados
C. Liminar de execução
D. Retorno de resultados de execução
E. Mecanismo comparador
F. Exec ução iterativa

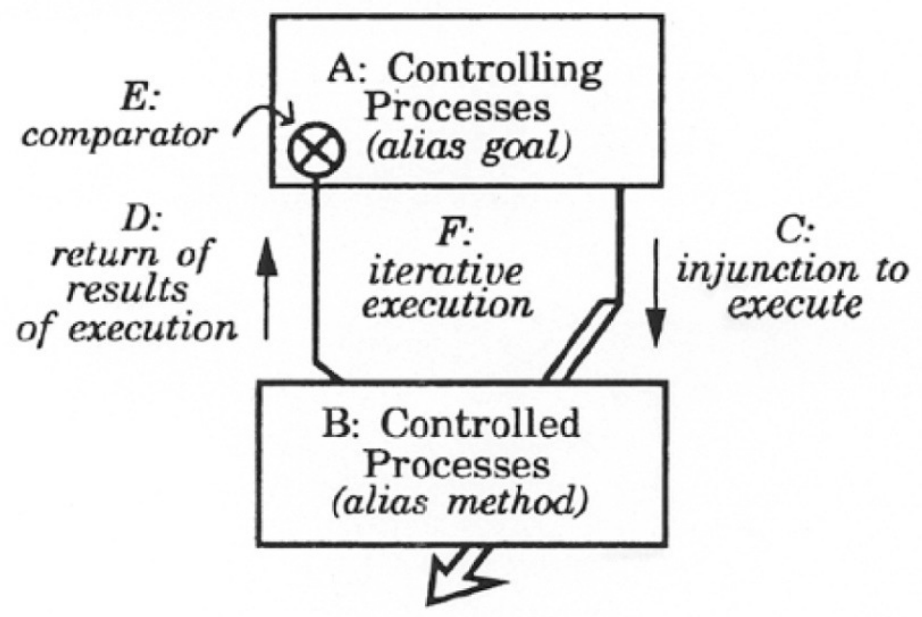

Figura 20 - Diagrama básico de controle e feedback entre dois níveis de organização. Fonte: PANGARO, 2002.

Esta colocação implica no reconhecimento do sistema como autônomo ${ }^{369}$, em que

\footnotetext{
${ }^{368}$ Confor me apres entamos anteriormente no exemplo do ter mostato.

369 Segundo a descrição de Boyd, "Os componentes da Teoria da Conversação são vários tipos de autômatos funcionando em paralelo. Autômatos são generalizações abstratas da ideia de máquina. Uma automação pode ser pensada como uma caixa com uma entrada (um 'input') alguma coisa dentro - parte disto pode envol ver regras de transformação de conteúdo - e uma saída (um 'output'). Se você entrar com um sinal, ele causará mudanças no estado interno de um autômato. Algumas vezes uma entrada também pode solicitar a um autômato a produção de uma saída. Por exemplo, se você digitar algum dado em um computador, ele pode simplesmente armazenar os dados. Então, se você digitar um comando para executar algum programa, o programa pode utilizar os dados para calcular e produzir uma saída para impressão, digo. O histórico de que programas e dados tem sido armazenados no computador determina o que ele fará com novas entradas. Isto é verdade para todos os autômatos mais trivi ais" (BOYD, 2004, p.183, tradução nossa).
} 
fechamento ou "clausura [sistêmica] ocorre quando o comparador confirma a execução de processos controlados de modo coerente com os processos controladores (como quando um objetivo é alcançado pela execução de um método de sucesso),370 (PANGARO, 2002). Do mes mo modo como com as interações horizontais, estas interações de controle podem ocorrer em diversos outros níveis, em uma corrente hierárquica verticalizada (PANGARO, 2002). Finalmente, à medida que conceitos são compartilhados, eventualmente os participantes da conversação podem desenvolver uma compreensão em comum que thes permita chegar então a um acordo (PASK, 1980, p.1002; 1987, p.19; PANGARO, 2007, p.177). Neste momento especial, um determinado participante pode estabelecer controle sobre um procedimento do outro participante, de modo consensual, uma vez que estes compartilhem o mes mo objetivo, por exemplo, como observou Pangaro (2007, p.177) ao associar esta instância da conversação à metáfora da dança, remetendo-se às interações da Figura 21:

Outro exemplo que explica a figura é dançar, talvez o melhor exemplo de todos e umusado por Gordon. Eu estou dançando $\infty \mathrm{m}$ minha parceira e eu a empurro dessa maneira particular enquanto nós dançamos. Ela não pensa, 'Como você se atreve?!' Ela pensa: 'Bem, por que ele está fazendo isso? Ah! Porque nós estamos dançando.' E, de fato, quando ela é empurrada por mim e percebe que até aqui o meu objetivo é dançar (quadrante superior esquerdo) e ela também tem esse objetivo (quadrante superior direito), e empurra-me de volta! Por mim tudo bem! Estou disposto a ser empurrado, porque eu estou disposto a participar disto para o objetivo comum. E, no final este cruzamento [...] este para trás e para frente, este é o entrelaçament de dois sistemas, u m Ae u m B, u malfa e beta, concordando em ter um objetivo comum e se comportar como um único sistema. Nesta mistura está 0 acordo, cooperação, e uma vontade de abrir mão da minha individualidade. ${ }^{371}$ (PANGARO, 2007, p.177-178, tradução nossa)

\footnotetext{
370 Do original em inglês: "Closure occurs when comparator confir ms execution of controlled processes is coherent with controlling processes (as when agoal is achieved by ex ecuting a successful method)."

371 Do original em inglês: "Another example that explicates the figure is dancing, perhaps the best example of all and one used by Gordon himself. I' $m$ dancing with my partner and I shove her this particular way as we dance. She doesn't think, 'How dare you?!' She thinks, 'Well, why is he doing that? Ah! Because we are dancing.' And, in fact, when she gets shoved by me and realizes that up here my goal is to dance (upper-left quadrant) and she also has that goal (upper-right quadrant), she shoves me back! Fine with me! l' $m$ willing to be shoved, becaus e l' $m$ willing to engage in this for the common goal. And in the end this crisscrossing [...] this back and forth, this intertwining is two systems, an $A$ and a $B$, an alpha and a beta, agreeing to have a common goal and to behave like a single system. In that merging is agreement, cooperation, and a willingness to give myself up my individuality."
} 


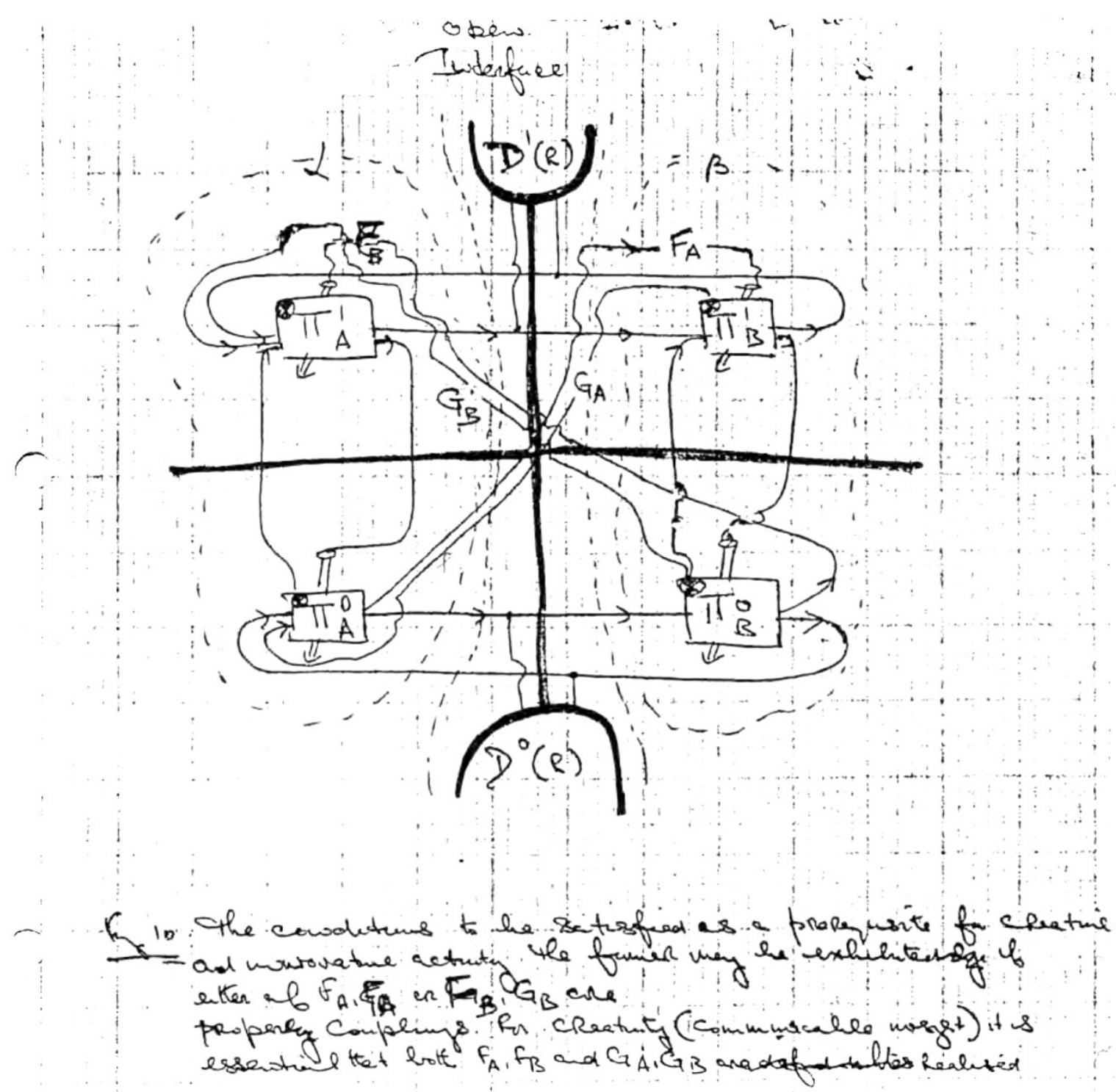

Figura 21 - 0 'esqueleto’ da estrutura da conversação. Fonte: PASK,1975, p.29.

Pask apontou que, neste estado específico, não se pode mais distinguir a estratificação da conversação em níveis de linguagem ' $L$ ' (descritos anteriormente como protolinguagens $L^{0}$, $L^{\prime}$ etc.) que convergem para uma linguagem $L^{*}$ natural aos indivíduos (como a linguagem verbal da fala de deter minado indivíduo) e neste momento o sistema é capaz de distinguir a si mesmo do outro ${ }^{372}$ (PASK, 1975 p.29). É neste mes mo contexto, que se estabelecem então as conexões interativas $F_{a}, F_{b}, G_{a}, G_{b}$ descritas conforme a FIGURA 21 (PASK, 1975b, p.29-30; PANGARO, 2007, p.177), responsáveis pela sincronização ${ }^{373}$ entre Indivíduos $\mathrm{Pe}$, entre Indiv íduos

\footnotetext{
372 Retomando o sentido da afirmação de Pask da conversação como um mecanismo de resol ução de conflitos que também gera distinção entre i ndi víduos autôno mos em suporte à própria conversação ( PASK, 1980, p.1006).

373 Pangar o (2007, p.169) utiliza o termo 'sincroniz ação' em referência ao processo de chegada a um acordo na conversação, remetendo-se à visão de Pasks obre a conversação como um proc esso de sincroniz ação de pr ocessos à priori assíncr onos.
} 
P e Indivíduos $M$, ou seja, que determinam a gênese de um novo sistema pela conjugação dos anteriores, cujo comportamento, em se tratando de seres humanos, por exemplo, atribui-se 'inteligência':

As conexões $F_{a}, F_{b}, G_{a}, G_{b}$, que permitem $A$ ter $B$ como seu ambiente e/ou $B$ tomar $A$ como seu ambiente, são cruciais a toda maneira de criatividade e inovação; pois, se estas conexões podem ser feitas, então, um Indivíduo P (o broto de uma conversa, pelo menos) é um observador ... de si mesmo. Uma vez que essas conexões são estabelecidas, a condição de fechamento é removida, e o domínio pode expandir (embora não de forma ilimitada), e ao mesmo tempo, perde-se a estratificação de $L$, de modo que $L$ pode também ser $L$ *. Se $A$ e $B$ representam os cérebros dos seres humanos, este truque ocorre frequentemente, e por causa disso, Indivíduos P são raras vezes totalmente correlacionados com Indivíduos M. Não vejo nenhuma razão, em princípio, por que esse truque não possa realizar-se com mecanismos, também. Mas se fosse, o mecanismo não seria inanimado. Sobre esta disposição, prefiro evitar o qualificador 'artificial' ao se falar de inteligência. ${ }^{374}$ (PASK,1975b, p.30, tradução nossa)

Pask esboçou, portanto, toda uma estrutura teórica cibernética própria para o desenvolvimento de recursos computacionais capazes de desenvolver conversações com seus usuários, a partir de uma concepção bastante distinta das abordagens sobre Inteligência Artificial e Ciência da Cognição conduzidas em sua época. A Teoria da Conversação de Pask ofereceu um modo de pensar nas conversações como uma comunicação interativa natural que efetiva-se em um contexto de trocas e compartilhamentos sistêmicos, promovendo um pano de fundo teórico sólido para sua compreensão e para experimentações práticas sobre sua dinâmica. Na sequência, apresentamos uma aproximação entre cibernética e o processo projetual referindo-nos particularmente à Teoria da Conversação de Pask como a interação cibernética fundamental pela qual $\mathrm{o}$ ato de projetar pode ser entendido como um processo cibernético de conversação.

\footnotetext{
${ }^{374}$ Do original em inglês: "The connections $F_{a}, F_{b}, G_{a}, G_{b}$, which allow $A$ to take $B$ as A's environment and/or $B$ to take $A$ as $B$ 's environment, are crucial to all manner of creativity and innovation; for, if these connections can be made, then a $P$ Individual (the sprout of a conversation, at least) is an obs erver ... of its elf. Once these connections are established, the clos ure condition is removed, the domain can expand (though not in an unlimited fashion), and, at the same moment, the stratification of $L$ is lost, so that $L$ may as well be $L^{*}$. If $A$ and $B$ stand for the brains of human beings, this trick is often played, and because of it, $P$ Individuals are seldom fully correlated with M Individuals. I see no reas on, in principle, why that trick should not be played with mechanisms, also. But if it were, the mechanis m would not be inanimate. Having this disposition, I prefer to avoid the qualifier 'artificial' when speaking of intelligence."
} 


\subsubsection{O projetar como conversação cibernética}

[A] Cibernética toma-se uma 'janela para o mundo'. Por onde olhe, o ciberneticista vê o fenômeno ubíquo do controle e comunicação, aprendizado e adaptação, autb-organização e evolução. Suas 'lentes cibeméticas' permitem a este ver algum domínio particular do conhecimento e seus sistemas como casos especiais de formas cibernéticas gerais e abstratas. ${ }^{375}$ (SCOTT, 2004, p.1367, tradução nossa).

Este é o contexto pelo qual justificamos a aproximação ao pensamento cibernético para nossa pesquisa sobre a natureza conversativa da atividade do design arquitetônico, assumindo de antemão a existência de uma correlação entre a cibernética e o processo de design em geral ${ }^{376}$. Neste sentido, Glanville (2007a, p.1156) apontou uma paralelo inicial sobre a condição do design e da cibernética de segunda ordem:

Margaret Mead (1968), um dos membros fundadores da cibemética, ao propor uma cibemética da cibernética (que mais tarde ficou conhecido como a cibernética de segunda ordem), nos lembrou que a cibernética é concebida œmo uma linguagem, possibilitando a pessoas de diferentes áreas falar de forma significativa uns com os outros. A cibernética é, portanto, não primariamente uma tecnologia ou mesmo uma ciência, mas um metatema e uma abordagem. Também é argumentado que o design é o mesmo: que é um modo de pensar que se situa na posição de um metatema para outros temas: daí a sua aplicabilidade geral, como mostrado em seu uso como 'sufixação' para outros assuntos. ${ }^{377}$ (GLANVILLE, 2007a, p.1156, tradução nossa.)

\footnotetext{
375 Do original em inglês: "Cybernetics becomes a 'window on the world'. Wherever he looks, the cybernetician sees the ubiquitous phenomena of control and communication, learning and adaptation, self-organization and evol ution. His 'cybernetics spectacles' allow him to see any particular knowledge domain and the systems within it as a special cas es of abs tract, general cybernetic for ms."

376 Conforme o exemplo do periódico Kybernetes: The International Journal of Systems, Cybernetics and Management Science, publicado pelo Emerald Group Publishing Limited, Universidade de Bradford, Reino Unido, é um jornal oficial, reconhecido pela UNESCO, da Organização Mundial de Sistemas e Cibernética - World Organization of Systems and Cybernetics WOSC; que em 2007, dedicou uma edição dupla sobre Cibernética e Design (ISSN: 0368-492X, v.36, n.9/10, 2007) composta de 27 artigos sobre o tema, quantia esta citada por Glanville (2009, p.431), que é membro da comissão editorial da revista. Disponível em: <http://www.emeral dinsight.com/j ournals.htm?iss n=0368-492x\& volume=36\&issue=9> Acesso em 12/08/2011.

377 Do original em inglês: "Margaret Mead (1968), one of the founders of cybernetics, in proposing a cybernetics of cybernetics (which later became known as second order cybernetics) reminded us that cybernetics is intended as a language, making it possible for people from different disciplines to talk meaningfully with each other. Cybernetics is, therefore, not primarily a technology or even a science, but a meta-subject and an approach. It is often argued that design is the same: that it is a way of thinking that sits in the position of a meta-subject to other subjects: hence its general applicability as shown in its suffixation to other subjects."
} 
Ciberneticistas contemporâneos como Ranulph Glanville e Paul Pangaro que atuam tanto no campo da cibernética, arquitetura e design, defendem a existência de uma relação estreita entre estas áreas, onde a conversação desempenharia um papel bastante relevante. Segundo Glanville (2007b, p.1185), a palavra conversação foi escolhida pelo ciberneticista Gordon Pask (1975) por referir-se a uma forma de comunicação e experimentação comum, envolvendo $o$ ato de falar e escutar uns aos outros, em uma forma essencialmente circular. Para o autor, a conversação representa uma das formas "[...] essenciais dos sistemas cibernéticos, que incorpora os recursos da cibernética de segunda ordem. Como Pask a descreve, a conversação é a forma básica de interação genuína, e por isso é tão importante, tão bom modelo para o design"378 (GLANVILLE, 2007b, p.1185, tradução nossa.) Gordon Pask é referenciado (GLANVILLE, 2007a, p.1153;2007b, p.1177) como precursor no estabelecimento explícito de uma conexão entre a cibernética, o design e a arquitetura, conforme expressou em seu artigo 'The Architectural Relevance of Cybernetics', publicado em 1969 (PASK, 1969). Glanville (2009) observou que este trabalho, por sua vez, foi resultado de uma série de debates centrados em torno do tema dos limites para uma abordagem cientifica no design arquitetônico, apresentado na Escola de Arquitetura da Associação de Arquitetos de Londres ${ }^{379}$, onde Pask foi tutor por vários anos: "[...] ele não só argumentou a relevância arquitetônica da cibernética, ele viveu em um ambiente onde isto era aceito e posto em prática. $\mathrm{O}$ argumento central de Pask envolvia a conversação. Três anos antes, ele havia publicado oficialmente a teoria da conversação.’380 (GLANVILLE, 2009, p.423, tradução nossa). Como forma de contextualizar a referenciação da conversação, Glanville comentou sobre o emprego do termo metafórico por Schön (1983) e Gordon Pask (1975) em um sentido cronológico:

\footnotetext{
378 Do original em inglês: "Conversation is the fourth essential circular cybernetic system that embodies the features of second order cyber netics. As Pask describes it, the conversation is the basic formof genuine interaction: and it is this which makes it so important, such a good model for design."

${ }^{379}$ A Archtiectural Association School of Architecture, conhecida como AA, é uma escol a independente de arquitetura, sediada em Londres, Reino Unido. Enquanto um dos tutores da escola, Pask certamente influenciou vários al unos, dentre el es Cedric Price, Peter Cook e Ranulph Glanville, este último que tornou-se seu colaborador e reconhecido pesquisador ciberneticista. Dentre os alunos que frequentar am a AA cuja obra arquitetônica apresenta notório reconheci mento podemos citar John Ruskin, George Gilbert Scott, D aniel Libes kind, Richard Rogers, Zaha Hadid e Rem Koolhaas.

380 Do original em inglês: "[...] He not only argued the architectural relevance of cybernetics, he lived in an environment where this was accepted and acted upon. Pask's central argument concerned conversation. Three years before he published officially on conversation theory."
} 
Quatorze anos depois, Donald Schön [...] examinou o conhecimento que profissionais desenvolvem e utilizam na prática de suas profissões. Ele se referiu a isso como prática reflexiva. Suas ideias foram retomadas por arquitetos (uma das profissões que ele examinou) e outros designers. Ele também analisou o ambiente em que arquitetos e designers são educados e trabalham: o estúdio. Schön emprestou a ideia de conversação (uma conversa reflexiva $\infty m$ a situação) para explicar 0 ato central do designer: manter uma conversa consigo mesmo através de papel e lápis. Esta não era uma nova ideia: muitos professores de arquitetura, incluindo Pask e eu, estavam usando essa metáfora, uma metáfora apresentada a mim quando eu era estudante (o que o desenho está dizendo a você?). Então pode-se ver que há uma razão para supor uma conexão crítica entre cibernética, arquitetura e design 381 (GLANVILLE, 2009, p.423-424, tradução nossa)

Ao conceber uma teoria que trata do desenvolvimento das interações entre conceitos (indivíduos psicológicos), entidades que caracterizam-se de modo semelhante aos organismos vivos conforme a concepção biológica de Maturana e Varela (1987), Gordon Pask propiciou uma estrutura teórica ontológica sobre o comportamento dialógico do ser, pela compreensão do indivíduo humano como a incorporação (em um corpo 'M-individual') de diversos indivíduos psicológicos ('Indivíduos P’), que reconfiguram-se dinamicamente a partir do contexto interativo correspondente determinando assim variações comportamentais, conforme sugeriu Ranulph Glanville: "Pask não afirma que seres humanos sofrem de transtorno de personalidade múltipla. Ele aponta para o que muitos de nós percebemos: em diferentes ocasiões, nos comportamos de maneiras diferentes, como se fôssemos pessoas diferentes. ${ }^{382}$ (GLANVILLE, 2009, p.429, tradução nossa). O autor exemplificou este raciocínio observando o modo pelo qual para muitos, falar e ouvir exigem a assunção de personas diferentes, de modo que pode-se assumir o papel do locutor em conduzir o diálogo ou do ouvinte que o segue: "quando eu mudo de locutor para ouvinte, eu não só mudo o que estou fazendo, mas aspectos de quem eu sou (o papel que eu estou tomando).

\footnotetext{
381 Do original em inglês: "Fourteen years later, Donald Schön [...] examined the knowledge pr ofessionals dev elop and use in the practice of their professions. He referred to this as reflexive practice. His insights were taken up by architects (one of the professions he examined) and other designers. He also examined the environment in which architects and designers are educ ated and work: the studio. Sc hön borrowed the idea of conversation (a reflexive conversation with the situation) to explain the central act of the designer: holding a conversation with oneself through paper and pencil. This was not a new insight: many teachers of architecture, including Pask and myself, were using this metaphor - a metaphor presented to me when I was a student (What is the drawing telling you?). So it can be seen there is a reason for assuming a critical connection between cybernetics and architecture and design."

382 Do original em inglês: "Pask does not argue humans suffer from multiple personality disorder. He points to what many of us realize: On different occ asions, we behave in different ways, as if we wer e different people."
} 
Reconhecemos a nossa capacidade de assumir personagens diferentes em expressões como 'vestindo o meu chapéu de ciberneticista' "383 (GLANVILLE, 2009, p.429, tradução nossa). Amparados por esta compreensão, regressamos ao contexto da prática projetual de acordo com a leitura de Glanville (2009), em que conversações são conduzidas, por exemplo, no ato de investigação pelo desenhar:

O designer, desenhando ou rabiscando, alterna entre os papéis (personas) de marcador e espectador [...]. A marca é muitas vezes feita sem intenção: não é a forma de alguma coisa, é uma exploração, uma pergunta vaga. Fazer uma marca, visualizá-la, refazer (mudar) a marca, revisá-la. Este é um tipo de jogo, cheio de perguntas 'e se ?' não ditas, a forma de uma conversa mantida consigo mesmo: afirmação proferida, afirmação ouvida, afirmação reiterada. $O$ ponto de uma conversação é que ela permite a comunicação entre personas (Indivíduos P) que constroemo mundo de forma diferente. Não significa presumir que algum sentido é comunicado: em vez disso cada persona constrói sua compreensão (portanto significado), permitindo que ele comporte-se em conjunto $\infty m$ seus parceiros na conversação. Dentro do mesmo corpo, Eu-o-desenhista e Eu-oespectador, vendo de forma diferente o que é considerado como sendo o mesmo (as marcas), ofereço ideias para seu parceiro participante que são diferentes, por meio desta não-correspondência, do que foi anteriormente entendido. Em outras palavras, personas criam novidade para/um com 0 outro: desenhar/rabiscar leva, inevitavelmente, à mudança. ${ }^{384}$ (GLANVILLE, 2009, p.429, tradução nossa)

Este é o sentido de correspondência estabelecido entre a concepção de Schön (1983, p.78; 1984, p.9; 1988/1992, p.135; 1992, p.4) do design arquitetônico como uma conversação reflexiva de acordo com a estrutura básica 'ver-mover-ver' e a concepção da conversação cibernética expressa por Glanville (2009): "[...] este ato circular de conversar consigo mesmo (normalmente através de um meio como papel e lápis), com a mudança concomitante entre

\footnotetext{
383 Do original em inglês: "When I switch from talking to listening, I switch not only what l'm doing, but as pects of who I am (the role l'm taking). We recognize our ability to assume different personae in expressions such as 'wearing my cybernetician's hat'."

${ }^{384}$ Do original em inglês: "The designer, sketching or doodling, switches between the roles (personae) of marker and viewer [...]. The mark is often made without intention: it's not the shape of something, it's a exploration, a vague question. Make a mark, view it, remake (change) the mark, review it. This is a type of play, full of unspoken 'what if' questions, the form of a conversation held with oneself: statement uttered, statement heard, statement restated. The point of a conversation is that it allows communication between personae ( $p$-ind's) that construe the world differently. It does not presume meaning is communicated: rather each persona constructs its understanding (hence meaning), allowing it to behave in concert with its partners-in-conversation. Within the same body, I-the-drawer and l-the-viewer, seeing differently what is taken to be the same (the marks), offer insights to their partner participant that are different, through this mismatch, from what was previously understood. In other words, personae create novelty for/with each other: Sketc hing/doodling leads, inevitably, to change."
} 
personas (muitas vezes tão rápido que estas ef etivamente coexistem), é a atividade central ao projetar"385 (GLANVILLE, 2009, p.430, tradução nossa). Certamente, podemos expandir a escala desta concepção elevando os processos de conversação a uma posição geral ainda mais fundamental, de acordo com a observação de Paul Pangaro (2008), que comentou a conexão entre a prática do design e a conversação colocada por Glanville $(2007 ; 2009)$ com base na obra de Pask (1975a, 1976), sendo enfático ao afirmar que "[...] conversação é design, e design é conversação"386 (PANGARO, 2008, p.2, tradução nossa). Segundo o autor:

Conversação efetiva ocorre quando crenças são negociadas através de interação e evoluem em uma estrutura de objetivos. Objetivos são negociados e evoluem através de interação. Estas conversações são proœssos de design. Similarmente, design - onde construọoes propostas são negociadas e evoluem em objetivos, enquanto objetivos para o design são negociados e também evoluem-é u m processo de conversação ${ }^{387}$ (PANGARO, 2008, p.2, tradução nossa.)

Esta afirmação de Pangaro (2008) é baseada na compreensão essencial de que como seres observadores, interagimos cognitivamente com as propriedades dos sistemas que compõem a realidade a qual observamos, através de processos conversativos, à medida que de uma maneira metafórica, conversamos com tudo em nosso ambiente: “[...] nós 'oferecemos nossa visão' enquanto agimos, reagimos e pensamos. O ambiente 'fala conosco' no sentido em que nós o interpretamos. Nós respondemos ao que escutamos, vemos e sentimos, em uma troca que possui a estrutura de um diálogo na linguagem" 388 (PANGARO, 1996, tradução nossa). Uma vez que sentidos não são transmitidos ${ }^{389}$, mas construídos pelos observadores a partir

385 Do original em inglês: "[...] this circular act of conversing with ones elf (normally through a medium such as paper and pencil), with the concomitant switch between personae (often achieved so fast that both effectively co-exist), is the central activity in designing."

${ }^{386}$ Do original em inglês: "[...] conversation is design, and design is conversation."

387 Do original em inglês: "Effective conversation occurs when beliefs are negotiated through interaction and evolve in a framew ork of goals. Concurrently, goals are negociated and evolve through interaction. Such conversations are process es of design. Similarly, design - where proposed constructions are negociated and evolve towards goals, while goals for the design are negociated and evolve -is a process of conversation."

388 Do original em inglês: '[...] We 'offer our views' as we act, re-act and think. The environment 'speak to us' in the sense that we interpr et it. We respond to what we hear and see and feel, in an exchange that has the structure of a dialogue in language."

389 Confor me comentário de Glanville (2007b, p.1190, tradução nossa): "Uma assunção básica de uma conversação é que participantes não transmitem ou compartilham sentidos (este é um dos pontos em que a teoria da conversação é mais poderosa e mais acurada ao repres entar experiência que a teoria da infor mação)". Desta maneira, é correto afirmar que em uma c onvers ação, s egundo obs erva o ciberneticista Heinz Von Foes ter (1974/2003, tradução nossa): "o ouvi nte, não o locutor, determina o sentido de uma fala". 
de suas experiências cognitivas ${ }^{390}$, a linguagem é um meio de experienciação de perturbações em que ressonâncias podem emergir sob a forma de consensos, ou acordos sobre entendimentos, em termos metafóricos e formais: "[...] esta perspectiva é consonante com o conceito de Maturana da linguagem como 'coordenação consensual de coordenação consensual de ações'. É na linguagem, via conversação, que vivemos juntos" ${ }^{391}$ (PANGARO, 1996, tradução nossa). Afirma-se, portanto, que é nesta vivência, através de acordos, que compartilham-se perspectivas em comunidades de relações, amigos, clubes, escolas de pensamento e culturas inteiras: "[...] na medida em que nós compartilhamos nossas semelhanças e (por um momento) ignoramos nossas diferenças, nos fundimos com outros participantes em conversação e perdemos a nossa individualidade em troca de tornar-se um com os outros', pelo menos no domínio cognitivo"392 (PANGARO, 1996, tradução nossa). Ebenreuter (2007) apresentou uma leitura da relevância da Teoria Cibernética da Conversação de Pask (1975a, 1976) que corrobora com esta compreensão de Pangaro (1996), atentando para a relevância do acordo e cooperação da dimensão colaborativa do projetar:

[...] design pode ser visto como uma forma de œnversação em que elementos da situação do projeto são negociados entre duas partes para desenvolver um resultado desejável. Assim, o desenvolviment colaborativo da situação do design facilita o aprendizado coletivo de objetivos requisitados entre 0 designer e as partes interessadas através de um proœsso cíclico de negociação e compreensão mútua. Como resultado, o projeto torna-se um processo compartilhado, ou œcriativo, que deve œnsiderar a intração do designer com os participantes no processo de design e a compreensão individual que cada um traz para a situação design. Da mesma forma que o planejamento œm base em diálogo facilita um processo compartilhado de aprendizagem, entendimento e negociação, a teoria de conversação desenvolvida por Gordon Pask serve para fazer um novo conhecimento explícito através de conversa, aprendizagem e acordo mútuo. ${ }^{393}$ (EBENREUTER, 2007,

\footnotetext{
390 Paul Pangaro (2008, p.6, tradução nossa) observa o acordo com esta posição e a compreensão expressa no trabalho de Humberto Maturana que, segundo o autor, afirma que "[...] loc uções (palavras, sentenças, parágrafos, imagens, gráficos em movi mento) não podem conter senti do porque o sistema ner vos o é um sistema fechado que não ac eita 'inputs'. Ao invés disso, palavras, sentenças e i magens são gatilhos de conheci mento adquirido anterior mente que conjuram o s enti do - e o ouvinte faz o sentido".

391 Do original em inglês: "[...] This perspective is consonant with Maturana's concept of language as "consensual coordination of consensual coordi nation of actions'. It is in language, and via conversation, that we live together."

392 Do original em inglês: "[...] ins ofar as we share our similarities and (for a moment) ignore our differences, we merge with other participants in convers ation and lose our individuality in exchange for 'becoming one with others', at least in the cognitive domain."
}

393 Do original em inglês: "[...] design can be seen as a form of convers ation in which elements of the design situation are 
p.1323, traduçãonossa)

A cibernética constitui-se, assim, uma abordagem transdisciplinar que permite a compreensão da atividade prática do design arquitetônico de acordo com seus conceitos sistêmicos, cujo especial interesse encontra-se na Teoria da Conversação de Gordon Pask (1975a, 1976), caracterizada por Glanville (2007b, p.1185) como a forma sistêmica quintessencial da Cibernética de Segunda Ordem, a interação comunicativa pelo meio de linguagem em que efetiva-se por seus acordos (ou acordos sobre desacordos), coordenações mútuas de comportamentos entre indivíduos vivos, o convívio. Apesar de tratar-se de uma abordagem que desenvolveu-se no bojo da pesquisa científica e que fundamenta-se em diversas teorias e fundamentos complexos de diversos campos disciplinares como, a física, matemática, biologia, psicologia cognitiva, entre outros, reconhecemos que diversas colocações e observações sobre a questão particular da conversação apresentam uma correspondência com preceitos afirmados pelas teorias epistemológicas de Schön (1983), e no contexto da filosofia hermenêutica de Gadamer $(1975 / 1997,1976,2002)$ conforme a leitura de Snodgrass e Coyne $(1992,1995,1997 / 2006,2006)$ sobre a condição interpretativa (e portanto hermenêutica) do processo projetual. Particularmente a descrição da circularidade dos sistemas cibernéticos e a circularidade do evento hermenêutico da interpretação apontam para uma convergência entre compreensões nas duas visões do projetar e sua estrutura dialógica. Na segunda parte deste capítulo, procuramos uma aproximação entre as diferentes visões de que tratamos no corpo deste trabalho, cuidando em evidenciar aspectos em comum que permitam esboçar uma paisagem deste horizonte da conversação que nos propomos a construir e investigar, através de sua caracterização.

negotiated between two parties to develop a desirable outcome. Hence, the collabor ative devel opment of the design situation facilitates the collective learning of required objectives between the designer and stakeholders through a cyclical process of negotiation and mutual understanding. As a result, design becomes a shared or co-creative process, which must consider the designer's interaction with the participants in the design process and the individual understanding they each bring to the design situation. In the same way that dialogue-bas ed planning facilitates a shared process of learning, understanding and negotiation, conversation theory developed by Gordon Pask serves to make new knowledge explicit through conversation, learning and mutual agreement." 


\subsection{O projetar como convers ação em expansão}

Nesta parte de nosso trabalho, apresentamos uma leitura coletiva das visões contempladas em nosso horizonte da conversação (Tabela 04), contrapondo aspectos centrais levantados ao longo de nosso percurso de pesquisa, a fim de evidenciar correspondências e distinções que nos permitam uma melhor compreensão das diversas implicações em se conceber o projetar como um processo essencialmente dialógico. Procuramos organizar esta leitura em certos assuntos que permearam as abordagens, como ontologia e epistemologia; a interdependência das instâncias projetuais; as qualidades de design como participação; colaboração e aprendizagem pela conversação e seus desdobramentos como um processo social; e finalmente uma antítese à concepção de resolução de problemas, em que especulamos as derivações de uma concepção de design como um livre vaguear, refletindo sobre o design de nosso próprio processo de pesquisa.

\begin{tabular}{|c|c|c|c|c|}
\hline Conc epção do pr ojetar & $\begin{array}{c}\text { Principal(is) } \\
\text { Autor(es) Referenciado(s) }\end{array}$ & $\begin{array}{c}\text { Principal(is) } \\
\text { Referência(s) dos Autores }\end{array}$ & Orientação & $\begin{array}{l}\text { Contexto } \\
\text { Cronológico }\end{array}$ \\
\hline $\begin{array}{l}\text { Processo racional } \\
\text { de busca por } \\
\text { soluções }\end{array}$ & $\begin{array}{l}\text { 1a. Geração } \\
\text { Métodos em Design }\end{array}$ & $\begin{array}{l}\text { Teorias de Sistemas } \\
\text { Herbert Simon }\end{array}$ & $\begin{array}{l}\text { Racionalismo cartesiano } \\
\text { Positivismo científico }\end{array}$ & 1960 's \\
\hline $\begin{array}{c}\text { Processo } \\
\text { Argumentativo }\end{array}$ & Horst Rittel & $\begin{array}{l}\text { Teorias de Sistemas } \\
\text { Karl R. Popper }\end{array}$ & Pragmatismo & 1970 's \\
\hline $\begin{array}{c}\text { Conversação } \\
\text { reflexiva }\end{array}$ & Donald Schön & John Dewey & Pragmatismo & 1980 's \\
\hline $\begin{array}{l}\text { Conversação } \\
\text { hermenêutica }\end{array}$ & $\begin{array}{l}\text { Adrian Snodgrass } \\
\text { Richard Coyne }\end{array}$ & $\begin{array}{c}\text { Hans-Georg Gadamer } \\
\text { Martin Heidegger } \\
\text { Ludwig Wittgenstein }\end{array}$ & $\begin{array}{l}\text { Filosofia Hermenêutica } \\
\text { Fenomenologia }\end{array}$ & 1990 's \\
\hline $\begin{array}{l}\text { Conversação } \\
\text { Cibemética }\end{array}$ & $\begin{array}{l}\text { Ranulph Glanville } \\
\text { Paul Pangaro }\end{array}$ & $\begin{array}{l}\text { Gordon Pask } \\
\text { Humberto Maturana } \\
\text { Heinz Von Foerster }\end{array}$ & $\begin{array}{c}\text { Cibernética de } \\
\text { Segunda Ordem } \\
\text { Biologia da Cognição } \\
\text { Teoria da Conversação }\end{array}$ & 2000 's \\
\hline
\end{tabular}

Tabela 04 - Horizonte da conversação - Recorte proposto 


\subsubsection{Ontologia e epistem ologia em transformação}

Em nosso estudo sobre as mudanças nos modos de se conceber o processo projetual e a atividade do projetar na segunda metade do século $X X$, observamos como as propostas originais do movimento de métodos em design dos anos 1960 sobre 'o que o design deveria ser' passam por uma revisão crítica a partir dos anos 1970, pela qual estudiosos e teóricos do design particularmente vinculados à arquitetura e ao planejamento urbano aproximaramse em suas distintas abordagens do reconhecimento da dimensão dialógica da prática projetual, utilizando-se de metáforas como a conversação na caracterização da natureza do projetar. A leitura pormenorizada das diferentes concepções dos autores que compõe nosso autodenominado 'horizonte da conversação' indica nitidamente o modo pelo qual suas visões estão profundamente atreladas às premissas ontológicas e epistemológicas dos mes mos: desta forma, procuramos elucidar diversos aspectos conceituais relacionados em cada abordagem, tratando de embasar devidamente o raciocínio subjacente a cada concepção do projetar. Na sequência, apresentaremos um percurso sobre as transformações envolvendo estas premissas procurando construir uma perspectiva panorâmica da investigação sobre o recorte proposto. Como já observado ${ }^{394}$, o surgimento do movimento de métodos em design foi influenciado pelo desenvolvimento de técnicas e conhecimentos científicos a partir das demandas militares das Grandes Guerras, com relação às pesquisas operacionais e teorias de tomada de decisão e resolução de problemas dos anos 1950. Broadbent (1973/1988) corroborou com estas assunções, mas também procurou explicitar um outro sentido subjacente à adoção das distintas abordagens para com o design a partir dos anos 1960:

Há verdade em tudo isso, mas os motivos, enfim, de abordar o design de novas maneiras são mais profundos que qualquer uma delas; eles são determinados por mudanças em atitudes filosóficas que não são exclusivas para a arquitetura, mas permeiam toda a nossa cultura e, mais especificamente, a sua ciência e tecnologia ${ }^{395}$ (BROADBENT, 1973/1988, p.56)

\footnotetext{
394 De acordo com Broadbent (1973/1988), Bazjanac (1974), Rowe (1987), Cross (1992; 2001), Downton (2003), Bayazit (2004).

395 Do original em inglês: "there is truth in all this, but the reasons, finally, for approaching design in new ways are deeper than any of it; they are determined by shifts in philos ophical attitudes which are not exclusive to architecture, but pervade the whole of our culture and, most specific ally, its science and technology."
} 
De modo similar, Buchanan (1995) argumentou sobre a diversidade de concepções sobre o design na segunda metade do século passado observando que "[...] de fato, o pluralis mo de design no século XX é inteligível porque repousa no pluralis mo de assunções filosóficas de que lhe é familiar. A exploração do design é, portanto, uma contribuição à filosofia da cultura de nosso tempo" 396 (BUCHANAN, 1995, p.55-56, tradução nossa). O autor indicou de modo sucinto algumas das correntes filosóficas influentes sobre o pensamento do design no contexto dos anos 1990:

Neopositivismo, pragmatismo, e várias formas de fenomenologia influenciaram o ensino e a prática de design no século XX. Se a teoria de design tende frequentemente a favor do neopositivismo, a prática do design tende para o pragmatismo e pluralismo, com fenomenologistas emambas as áreas. ${ }^{397}$ (BUCHANAN, 1992, p.6, tradução nossa)

Esta passagem acorda com a observação de Dorst e Dijkhuis (1996, p.253) de que ainda na década de 1990 muito do ideário positivista do design apresentava-se arraigado nas concepções e abordagens vinculadas às pesquisas sobre o projetar. Para Coyne e Snodgrass (1995), este ideário representou uma manifestação evidente das premissas do racionalis mo cartesiano originário ainda no século XV II pelo legado do filósofo francês René Descartes (1596-1650). Segundo os autores, a influência do pensamento cartesiano podia ser sumarizada em ter mos de sua ontologia, baseada na assunção da separação entre o sujeito pensante do mundo dos objetos e da primazia da experiência do ser, independente inclusive de seu corpo; e de sua epistemologia, que afirma a independência da razão (COYNE; SNODGRASS, 1995, p.43). O pensamento de Descartes afirmava assim a possibilidade de desligar-se de prejuízos e concernimentos pessoais a fim de chegar à verdade, conquistada pela condução do racioc ínio objetivo e prescrições de seu método: dividir as dificuldades no maior número de partes que for necessário e ordená-las das mais simples para as mais complexas para então resolvê-las, cuidando das devidas enumerações e revisões que certificam que nada foi omitido neste processo (COYNE; SNODGRASS, 1995, p.44; BROADBENT 1973/1988, p.60; MUNARI,1981, p.11). Coyne e Snodgrass (1995, p.44) afirmaram que crenças como a

\footnotetext{
396 Do original em inglês: "Indeed, the pluralism of design in the twentieth century is intelligible because it rests on a pluralis m of philosophic ass umptions which are familiar. The exploration of design is therefore, a contribution to the philos ophy of culture in our time."

397 Do original em inglês: "Neo-positivism, pragmatism, and various forms of phenomenology have str ongly influenced design education and practice in the twentieth century. If design theory has often tended toward neo-positivis m, design practice has tended tow ard pragmatis $m$ and pluralis $m$, with phenomenologists in both areas."
} 
independência da razão ou a 'transparência da mente' permearam tanto os pensamentos racionalistas quanto empiristas como o dos filósofos John Locke (1632-1704) e David Hume (1711-1776), entre outros, ao longo dos séculos XVII, XV III e XIX, constituindo a base para a objetividade da ciência moderna. Para os autores, esta base correspondia também à concepção epistemológica tradicional "[...] que vê o conhecimento como acumulação de proposições, fundadas em outras proposições para formar uma única 'edificação' "398 (COYNE; SNODGRASS, 1995, p.44, tradução nossa).

Esta base racionalista e esta concepção de 'avanço' do conhecimento perpetuaram-se assim, atingindo o bojo do positivismo no século XIX e início do século $\mathrm{XX}$, conformando o sentido positivista de progresso humano pela ciência (SCHÖN, 1983, p. 31), e que ter mina por se manifestar sobre os métodos de design nos anos 1960: "esta tambémé a base da teoria do design racionalista, que opera em objetividade, método e lógica"399 (COYNE; SNOD GRASS, 1995, p.44, tradução nossa). Protzen e Harris (2010) corroboraram com Coyne e Snodgrass (1995), observando que a crítica e revisão dos métodos em design nos anos 1970, por sua vez, esteve relacionada à influência de desenvolvimentos paralelos sobre a filosofia da ciência em que esta objetividade racionalista foi desafiada primeiramente por Popper (1959/1972), seguido pelo físico Thomas Kuhn (1962) que em sua obra 'The Structure of Scientific Revolutions' argumentou de modo convincente que as visões de mundo predominantes, os chamados 'paradigmas', são deter minantes para o trabalho científico (PROTZEN; HARRIS, 2010, p.5). Protzen e Harris (2010) citam ainda a influência neste contexto do trabalho do polímata Michael Polanyi (1958) que expôs o modo pelo qual o trabalho científico não é um empreendimento puramente racional, mas guiado por assunções não mencionadas; e também o pensamento do filósofo da ciência Paul Feyerabend (1975) que contestou a existência de métodos específicos ou de qualquer tipo para a descoberta científica e argumentou que a verdade emerge de muitos aspectos da existência, em detrimento do pensamento racional. Neste sentido, Coyne e Snodgrass $(1995, p .45)$ observaram que ataques significantes contra o cartesianismo e o legado iluminista foram conduzidos por filósofos do século XX como John Dew ey, Edmund Husserl, Martin Heidegger e Ludwig Wittgenstein,

\footnotetext{
${ }^{398}$ Do original em inglês: "[...] That views knowledge as the accumulation of propositions, each founded on prior propositions to for m a single 'edifice'."

399 Do original em inglês: "It also is the basis of rationalistic design theory which trades in objectivity, method and logic."
} 
entre outros, que desafiaram a ontologia cartesiana e sua distinção entre sujeito-objeto, a favor de uma ontologia pós-racionalista. Os autores destacam a contribuição fenomenológica do pensamento de Heidegger com relação a esta colocação:

\begin{abstract}
Uma ontologia pós-racionalista é um retomo à primazia da experiência. A fenomenologia de Husserl defende um retorno à forma como as coisas aparecem. Heidegger modifica e desenvolve este tema, começando com um apelo à experiência primária (primordial) do envolvimento irrefletido em um mundo em que não há sujeito ou objeto. Com Heidegger, mesmo o conceito de estar 'em' (como em 'no mundo') é transitório, derivado, contextual e até mesmo cultural. Outros entendimentos do ser, œmo aquele em que podemos distinguir um sujeito separado de um 'mundo objetivo', são construídos sobre esta experiência. ${ }^{400}$ (SNODGRASS; COYNE, 1995, p.45, tradução nossa)
\end{abstract}

Segundo Terry Winograd e Fernando Flores (1990, p.30), o pensamento de Heidegger contrapôs-se fundamentalmente ao dualismo mente-corpo vinculado à tradição filosófica ocidental, expresso na assunção da existência de dois domínios fenomenológicos distintos, um mundo objetivo real e físico e o mundo subjetivo mental composto dos pensamentos e sentimentos do indivíduo. Os autores cuidaram em ressaltar que Heidegger rejeitou a concepção de uma independência entre instâncias objetiva e subjetiva afirmando a impossibilidade de uma existir sem a outra, e exaltou a relevância da interpretação: "existência é interpretação e interpretação é existência. Pré-juízo não é uma condição em que o sujeito é levado a interpretar o mundo falsamente, mas é a condição necessária de ter um contexto para interpretação (portanto Ser)." (WINOGRAD; FLORES, 1990, p.31-32). Afirmar a nãoprimordialidade da separação entre sujeito-objeto implica, da mesma forma, desafiar a tradição epistemológica cartesiana da independência da razão e da possibilidade de se chegar à verdade através do pensamento livre de pré-juízos e do conhecimento objetivo (COYNE; SNODGRASS, 1995, p.44). Este é o contexto em que se expressa o pensamento hermenêutico de Gadamer (1975/1997, 1976/2002):

\footnotetext{
400 Do original em inglês: "A post-rationalist ontology is a return to the primacy of experience. The phenomenology of Husserl advocates a return to the way things appear. Heidegger modifies and develops this theme, beginning with an appeal to the primacy (primordial) experience of unreflective involvement in a world in which there is no subject or object. With Heidegger, even the concept of being 'in' (as in 'in the world') is transient, derived, contextual and even cultural. Other understandings of being, such as that in which we distinguish a subject separated from an 'objective world', are built upon this experience".
} 
A visão cartesiana do conhecimento objetivo é abandonada por escritores como Gadamer. Ao apelar para a experiência comum de como surge a compreensão, Gadamer estabelece a impossibilidade de uma 'mente sem prejuízos', desabilitando assim o pensamento iluminista e seu 'preconceito contra o preconœito'. Conhecimento não procede a partir de proposiọões lógicas derivadas através de longas cadeias de raciocínio, nem depende de proposições fundacionais. Gadamer explica a compreensão coma metáfora do círculo hermenêutico, que implica o sujeib e o objeto emumjogo de interpretação (hermenêutica) que não favoreœ um sobre o outro e, de fato, 'funde' sujeit e objeto ${ }^{401}$ (SNODGRASS; COYNE, 1995, p.46, tradução nossa)

Como observaram Coyne e Snodgrass (1995, p.46), uma epistemologia pós-racionalista apresenta ceticismo sobre esquemas de legitimação do conhecimento, reconhecendo a inconsistência da compreensão, de modo que paradoxos lógicos ${ }^{402}$ providenciam evidências da fragilidade da relação entre lógica e raciocínio ${ }^{403}$ e que os princípios do racionalis mo assim vistos conduzem a um desnorteamento: "Não podemos mais agir como se o conhecimento crescesse em incrementos. O conhecimento muda. A compreensão acontece através do diálogo." 404 (COYNE; SNODGRASS, 1995, p.46, tradução nossa). Para Winograd e Flores (1990, p.74-75, tradução nossa), "Conhecimento é sempre o resultado de interpretação, que depende de toda a experiência prévia do intérprete, e de sua contextualização em uma tradição. Não é nem 'subjetivo' (particular do indivíduo) nem 'objetivo' (independente do indivíduo)" ${ }^{405}$. Ambos Coyne e Snodgrass (1995, p.46) e Winograd e Flores (1990, p.10) reconheceram assim a relevância da investigação sobre a primazia da experiência para a compreensão das implicações de uma epistemologia pós-racionalística, apontando os estudos de Humberto Maturana e Francisco Varela (1980) no campo das ciências biológicas

\footnotetext{
401 Do original em inglês: "The Cartesian view of objective knowledge is abandoned by writers such as Gadamer. In appealing to the common experience of how understanding arises, Gadamer establishes the impossibility of an 'unprejudiced mind', thereby disabling Enlightenment thought and its 'prejudice against prejudice'. Knowledge does not proceed as of logical propositions derived through long chains of reasoning, nor does it depend on foundational propositions. Gadamer explains understanding with the her meneutical circle metaphor, which implicates the subject and the object in a game of interpretation (her meneutics) that does not favor one over the other and in fact, 'fuses' subject and object".

402 Como demonstramos ac erca das ponderações de Rittel (1972a/2010) e Protzen, Harris e Cavallin (2000) no capítulo 1.

403 Aqui observamos uma correspondência às colocações e análises de Rittel (1987) sobre a liberdade epistêmica do designer.

404 Do original em inglês: "No longer can we behave as if knowledge grows in increments. Knowledge changes. Understanding comes about through dial ogue."

405 Do original em inglês: "Knowledge is always the result of interpretation, which depends on the entire previous experience of the interpreter and on situatedness in a tradition. It is neither 'subjective' (particular to the individual) nor 'objective' (independent of the individual)."
} 
como outro significante referencial para esta empreitada. Winograd e Flores (1990), que basearam parte das premissas de sua obra 'Understanding Computers and Cognition: a New Foundation for Design' no trabalho de Maturana, ressaltaram as assertivas do biólogo sobre o fechamento ou clausura do sistema nervoso que, como um sistema estruturalmente fechado, experiencia o ambiente exterior como perturbações que acionam padrões de atividade do organis mo e tem o potencial de causar transformações estruturais neste, e assim alterando seu comportamento futuro (WINOGRAD; FLORES, 1990, p.71). Retoma-se aqui um dos preceitos fundamentais da ontologia da cibernética de segunda ordem: o indivíduo constrói seu mundo (sua realidade), e constrói a si mesmo pela reconfiguração estrutural em resposta às perturbações do outro sistema (no caso o ambiente), em última instância construindo a percepção de si mesmo como um observador em distinção de suas observações (VON FOERSTER, 1974/2003; MATURANA, 1990/2001). Da mes ma forma (FIGURA 22), o indiv íduo percebe o outro como perturbações que o 'in[formam]', e assim é possível que cada sistema construa suas compreensões através do outro por meio de linguagem (MATURANA, 1983/2001, p.88-92).

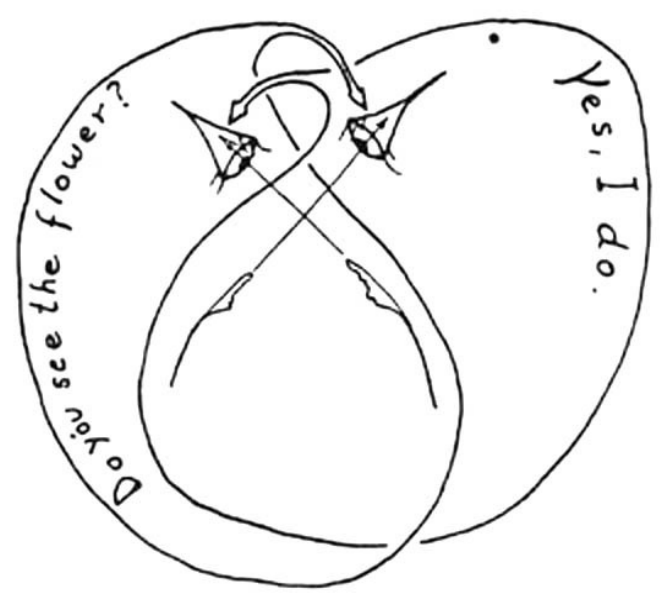

Figura 22 - Dança estrutural de dois organismos em interação com sistemas nervosos fechados que se perturbam estruturalmente Fonte: MATURANA, 1983/2001 p.92.

Percebemos que estas compreensões emergentes de ordem ontológica e epistemológica atreladas tanto à filosofia quanto às ciências do século $X X$ configuram, por sua vez, uma transformação nos modos de ver o projetar e a dinâmica do processo projetual, uma espécie de mudança de ethos segundo Dubberly (2008), que permeia os mais diversos domínios socioculturais da contemporaneidade, incluindo indubitavelmente a arquitetura bem como a 
prática do design em geral. ${ }^{406}$ Para o autor, do mes mo modo em que a compreensão da física transformou-se rapidamente no in ício do século $X X$, influenciada por uma série de desenvolvimentos tecnológicos e culturais, no final do século XX e começo do século XXI, uma transformação semelhante ocorreu no domínio da biologia, acarretando profundas mudanças no modo de se ver e compreender o mundo, um 'ethos orgânico-sistêmico', em que a prática do design assume aspectos distintos do contexto da modernidade, correspondente a um 'ethos mecânico-objetivo', conforme apresentado na Tabela 05 (DUBBERLY, 2008, p.1-3). Dentre os diversos aspectos listados por Dubberly (2008), como a recolocação do papel do designer e quanto às relações envolvidas no projetar, reconhecemos o es maecimento de concepção entre as dicotomias cartesianas e da filosofia ocidental tradicional em geral como referem-se Winograd e Flores (1990), em favor de um entendimento orgânico-sistêmico em que diversos sistemas e organismos interagem influenciando o comportamento uns dos outros e provocando transformações em um sentido evolutivo. Interação e transformação são propriedades intimamente associadas à metáfora da conversação, remetendo-se essencialmente à sua etimologia latina cum - que quer dizer 'com' e versare - 'dar voltas com' (MATURANA, 1988/2001). Concluímos assim que tanto a dissolução da concepção ontológica dualística manifesta nas dicotomias sujeito-objeto, subjetivo-objetivo, mente-corpo, etc., quanto o distanciamento da concepção de uma razão lógica, incólume de preconceitos e prejuízos e capaz de produzir conhecimento objetivo e edificante, em um desdobramento epistemológico correspondente, representam aspectos fundamentais que embasam as mudanças no modo de se conceber o projetar e suas diversas implicações e derivações manifestadas a partir dos anos 1960, proporcionando o reconhecimento da natureza do fazer do design como uma troca dialógica entre a situação do projeto e o designer, entre o designer e a sociedade em geral, bem como entre designers em sua colaboração. Esta troca dialógica eleva-se na compreensão contemporânea do projetar à medida que se reconhece a interdependência entre diversas instâncias: a liberdade epistêmica do designer que se reflete em sua compreensão transitória e dinâmica, o modo em que situações são concebidas como problemáticas e como se dirigem a elas as intenções transformadoras, a "resposta" da situação sob a forma de consequências, cuja reinterpretação e ressemantização pelo designer implica a continuidade do processo.

\footnotetext{
406 De ac ordo com noss a leitura de Broadbent (1973/1988), Buchanan (1992; 1995) Snodgrass e Coyne (1995), Coyne (2005), Dubberly (2008) e Pickering (2010).
} 


\begin{tabular}{|c|c|c|}
\hline & & $\begin{array}{r}\text { "Princípios de Organização" } \\
\text { Principles of Organization }\end{array}$ \\
\hline & $\begin{array}{c}\text { Mecânica objetiva } \\
\text { Mechanical-object }\end{array}$ & $\begin{array}{c}\text { Sistema orgânico } \\
\text { Organic-system }\end{array}$ \\
\hline $\begin{array}{l}\text { Época econômica } \\
\text { Economic era }\end{array}$ & $\begin{array}{l}\text { Era Industrial } \\
\text { Industrial age }\end{array}$ & $\begin{array}{l}\text { Era da Informação } \\
\text { Infor mation age }\end{array}$ \\
\hline $\begin{array}{l}\text { Autor paradigmático } \\
\text { Paradigm author }\end{array}$ & $\begin{array}{l}\text { Newton } \\
\text { Newton }\end{array}$ & $\begin{array}{l}\text { Darwin } \\
\text { Darwin }\end{array}$ \\
\hline $\begin{array}{l}\text { Metáfora } \\
\text { Metaphor }\end{array}$ & $\begin{array}{l}\text { Engrenagens } \\
\text { Clock-works }\end{array}$ & $\begin{array}{l}\text { Ecologias } \\
\text { Ecologies }\end{array}$ \\
\hline $\begin{array}{l}\text { Valores } \\
\text { Values }\end{array}$ & $\begin{array}{l}\text { Buscar simplicidade } \\
\text { Seek simplicity }\end{array}$ & $\begin{array}{l}\text { Abraçar a complexidade } \\
\text { Embrace complexity }\end{array}$ \\
\hline $\begin{array}{l}\text { Controle } \\
\text { Control }\end{array}$ & $\begin{array}{l}\text { De cima para baixo } \\
\text { Top-down }\end{array}$ & $\begin{array}{l}\text { De baixo para cima } \\
\text { Bottomup }\end{array}$ \\
\hline $\begin{array}{l}\text { Desenvolvimento } \\
\text { Development }\end{array}$ & $\begin{array}{l}\text { De fora } \\
\text { Fromoutside }\end{array}$ & $\begin{array}{l}\text { De dentro } \\
\text { Frominside }\end{array}$ \\
\hline & $\begin{array}{l}\text { Externamente montado } \\
\text { Externally-assembled }\end{array}$ & $\begin{array}{l}\text { Auto-organização } \\
\text { Self-organizing }\end{array}$ \\
\hline & $\begin{array}{l}\text { Feito } \\
\text { Made }\end{array}$ & $\begin{array}{l}\text { Crescido } \\
\text { Grown }\end{array}$ \\
\hline $\begin{array}{l}\text { Designer como } \\
\text { Designer as }\end{array}$ & $\begin{array}{l}\text { Autor } \\
\text { Author }\end{array}$ & $\begin{array}{l}\text { Facilitador } \\
\text { Facilitator }\end{array}$ \\
\hline $\begin{array}{l}\text { Papel do Designer } \\
\text { Designer's role }\end{array}$ & $\begin{array}{l}\text { Decidir } \\
\text { Deciding }\end{array}$ & $\begin{array}{l}\text { Construir acordo } \\
\text { Building agreement }\end{array}$ \\
\hline $\begin{array}{l}\text { Cliente como } \\
\text { Client as }\end{array}$ & $\begin{array}{l}\text { Proprietário } \\
\text { Owner }\end{array}$ & $\begin{array}{l}\text { Comissário } \\
\text { Steward }\end{array}$ \\
\hline $\begin{array}{l}\text { Relacionamento } \\
\text { Relations hip }\end{array}$ & $\begin{array}{l}\text { Demanda para proposta } \\
\text { Request for proposal }\end{array}$ & $\begin{array}{l}\text { Conversação } \\
\text { Conversation }\end{array}$ \\
\hline $\begin{array}{l}\text { Condição de Interrupção } \\
\text { Stopping condition }\end{array}$ & $\begin{array}{l}\text { Quase perfeito } \\
\text { Almost perfect }\end{array}$ & $\begin{array}{l}\text { Bom o suficiente para agora } \\
\text { Good enough for now }\end{array}$ \\
\hline $\begin{array}{l}\text { Resultado } \\
\text { Result }\end{array}$ & $\begin{array}{l}\text { Mais determinista } \\
\text { More deterministic }\end{array}$ & $\begin{array}{l}\text { Menos previsível } \\
\text { Less predictable }\end{array}$ \\
\hline $\begin{array}{l}\text { Estado final } \\
\text { End-state }\end{array}$ & $\begin{array}{l}\text { Concluído } \\
\text { Completed }\end{array}$ & $\begin{array}{l}\text { Adaptação ou evolução } \\
\text { Adapting or evolving }\end{array}$ \\
\hline $\begin{array}{l}\text { Ritmo } \\
\text { Tempo }\end{array}$ & $\begin{array}{l}\text { Edições } \\
\text { Editions }\end{array}$ & $\begin{array}{l}\text { Atualização contínua } \\
\text { Continuous updating }\end{array}$ \\
\hline
\end{tabular}

Tabela 05 - Princípios de organização da atividade do design em diferentes ethoi segundo Dubberly e Pangaro - tradução nossa. Adaptação a partir do original em: DUBBE RLY, 2008, p.3. 


\subsubsection{Interdependência e coevolução de Instâncias Projetuais}

Existiu um ponto avançado na década em que parecia que o slogan para os anos sessenta deveria ser 'problemas são nosso mais importante produto'. Profissionais pareciam ter descoberto a saliência de situações inœrtas e problemáticas, de instabilidade, unicidade e conflito de valores ${ }^{407}$ (SCHÖN, 1984, p.2, tradução nossa)

Podemos afirmar que um dos pontos centrais de nosso estudo abrange o modo pelo qual o projetar é visto no contexto da segunda metade do século $X X$ como um processo de busca por soluções, basicamente "uma atividade de resolução de problemas dirigida por objetivos" ${ }^{408}$ (ARCHER, 1965 apud. JONES, 1970/1992, p.3). Observamos que diversas propostas iniciais do movimento de métodos de design dos anos 1960 e 1970 partiram desta premissa ao focarem-se no estabelecimento de critérios, técnicas e métodos racionais para o design cujo modelo esteve atrelado aos desenvolvimentos científicos do pós-Segunda Guerra; cuidamos também de apontar como após cerca de uma década da formulação destas primeiras abordagens surgem manifestações sobre o reconhecimento de que o processo de determinação dos problemas, propósitos ou objetivos a serem resolvidos pelas ações de design representavam um aspecto crítico do processo projetual:

Em meados dos anos 1960, arquitetos e designers começaram a focar-se em métodos racionais de design, emprestados dos grandes e bem sucedidos projetos de engenharia militar durante a guerra e nos anos seguintes a ela. Embora estes métodos fossem eficazes para projetos militares com objetivos claros, eles muitas vezes provaram-se mal sucedidos

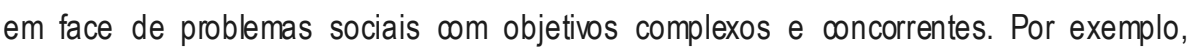
métodos elaborados para construção de mísseis foram aplicados a projetos de construção em grande escala no desenvolvimento urbano, mas estes métodos mostraram-se inadequados para a resolução dos problemas sociais subjacentes que os projetos de redesenvolvimento procuravam curar. ${ }^{409}$ (DUBBERLY, 2008, p.10, tradução nossa)

407 Do original em inglês: "There was a point late in the decade when it seemed that the slogan for the sixties must be 'Problems are our most important product'. Professionals seemed to have discover ed the salience of uncertain and problematic situations, of ins tability and uniqueness and value conflict."

408 Do original em inglês: "A goal-directed problemsolving activity." Ver: ARCHER, B. Systematic Method For Designers. London: Council of Industrial Design, 1965.

409 Do original em inglês: "In the mid-1960s, architects and designers began to focus on 'rational' design methods, borrowing from the successes of large military-engineering projects during the war and the years following it. While these methods were effective for military projects with clear objectives, they often proved unsuccessful in the face of social problems with complex and competing objectives. For example, methods suited to building missiles were applied to large-scale construction in urban development projects, but those methods proved unsuited to addressing the underlying social problems that redevelopment 
Como Rittel e Webber (1973, p.160) bem expressaram, definir o problema é o problema: a revelia de Alexander (1971) e Jones (1977) aos métodos sistemáticos pode ser entendida como um desacordo sobre as visões do que o design deveria ser e modo de obtenção efetivo de seus propósitos, tendo em vista as críticas sobre como a pesquisa sobre os métodos tornouse, em certa parte, um fim em si mesma e como o escopo de seu instrumental teórico científico mostrou-se insuficiente diante da configuração de problemas inerentes ao processo projetual:

Rittel e Webber se juntaram a um coro de dissidentes da tentativa de racionalização e argumentaram persuasivamente, e em termos compreensíveis para os sistematizadores, que o processo de design, e qualquer outra tarefa profissional, é muito mal explicado em termos de definição de objetivos, restrições, regras e busca emespaços de estado. A habilidade do profissional é melhor expressa no enquadramento real do problema a ser dirigido. Problemas de qualquer interesse profissional (problemas capciosos, como decidir uma política de saúde pública) já são 'resolvidos', e o logro profissional já está comprometido pelo tempo que o problema é identificado, conjecturado, e definido. Configuração de problemas é um processo contingente, pleno, e às vezes consensual para o qual não existe um conjunto oficial de regras, critérios ou métodos. ${ }^{410}$ (COYNE, 2005, p.6, tradução nossa)

Este foi o mote central de Rittel ao configurar a abordagem inicial dos métodos de design como um problema, posicionando a questão do projetar de acordo com um outro horizonte: “Horst Rittel propôs uma segunda geração de métodos de design, efetivamente reenquadrando o movimento, formulando o design como uma conversação sobre 'problemas capciosos"”411 (DUBBERLY, 2008, p.10, tradução nossa). A relevância do pensamento de Rittel é sublinhada por Rith e Dubberly (2008) para além da proposição de uma segunda geração, propiciando todo um outro repertório de concernimentos como pré-concepções, diálogo e política para a teoria do design (Tabela 06).

projects sought to cure."

410 Do original em inglês: "Rittel and Webber joined a chorus of dissenters from such attempted rationalization and ar gued persuasively, and in terms understandable to the systematizers, that the design process, and any other professional task, is only very poorly explained in terms of goal setting, constraints, rules and state-space search. The skill of the professional is better expressed in the actual framing of the problem to be addressed. Problems of any professional interest (wicked problems, such as deciding a public health policy) are already 'solved', and the hard professional graft is already committed by the time the problem is identified, conjectured, and defined. Problem setting is a contingent, fr aught, and sometimes consensual process for which there is no authoritative set of rules, criteria, or methods."

411 Do original em inglês: "Horst Rittel proposed a second-generation of design methods, effectively reframing the movement, casting design as convers ation about 'wicked problems'." 


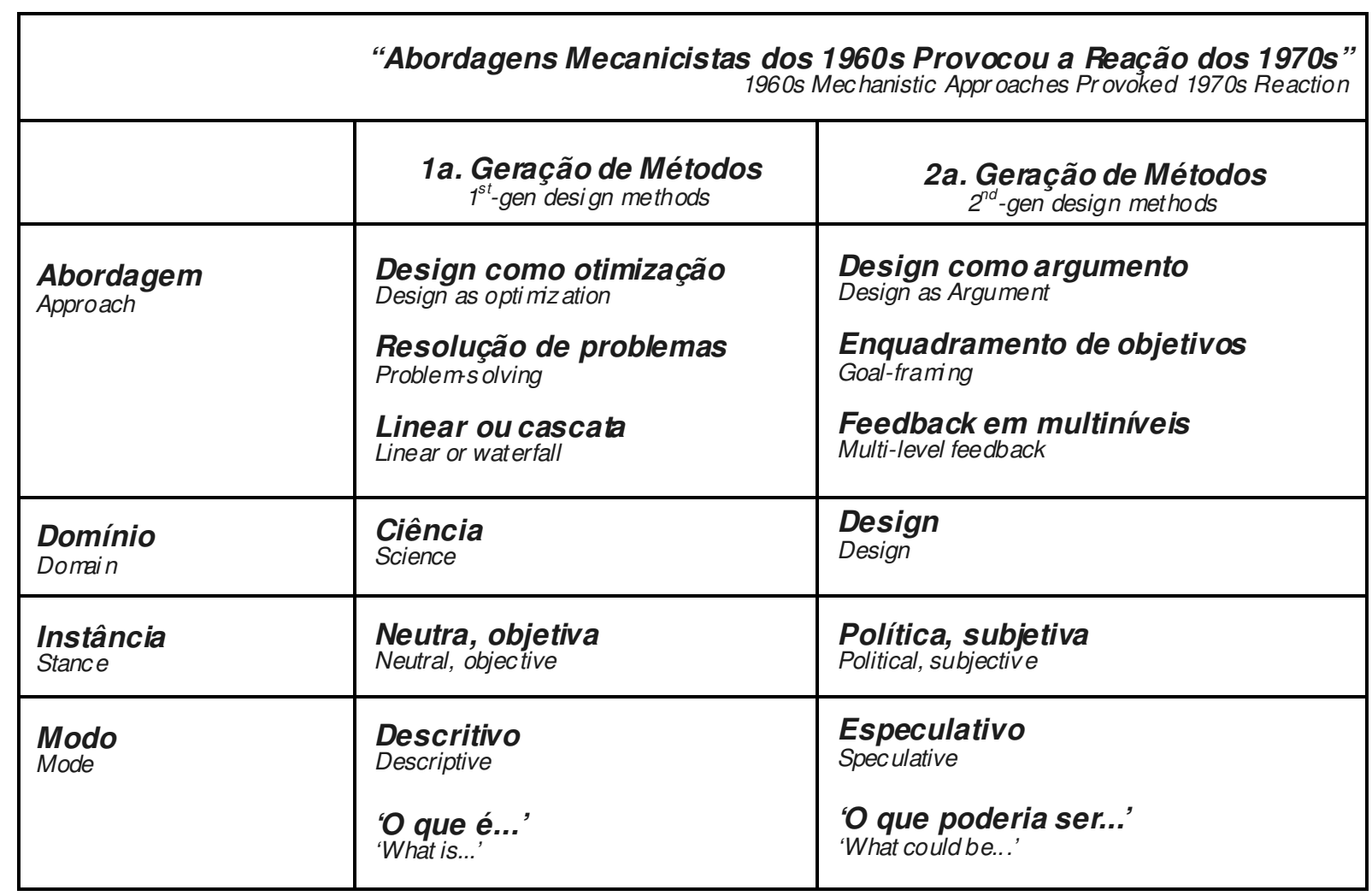

Tabela 06 - Comparativo entre gerações de métodos em design - Adaptação de Hugh Dubberly (2008) de esquema original de Chanpory Rith - tradução nossa. Fonte: DUBBERLY, 2008, p.10.

A afirmação da interdependência entre a formulação de um problema e sua solução, da mes ma forma, foi uma contribuição igualmente relevante de Rittel (1972a/2010) que encontra correspondência em trabalhos experimentais como o de Maher, Poon e Boulanger (1996) e os estudos empíricos conduzidos por Dorst e Cross (2001): "no design criativo, o designer está buscando gerar um par problema-solução correspondente, através da coevolução do problema e da solução."412 (DORST, 2006, p.10). Dorst (2006) apontou uma conclusão similar à expressa por Alexander (1974) e Bazjanac (1974): "a descrição de design como a coevolução de problema e solução leva à inquieta conclusão que, em descrever o design, nós não podemos pressupor que existe alguma coisa como um problema do design em qualquer ponto do processo projetual." ${ }^{413}$ (DORST, 2006, p.10). Neste sentido, podemos correlacionar esta instabilidade à natureza dinâmica da compreensão e do estabelecimento de sentidos pelo ‘jogo' da interpretação, ou seja, o modo como o designer percebe a discrepância entre a

\footnotetext{
412 Do original em inglês: "In creative design, the designer is seeking to generate a matching problem-solution pair, through a co-evolution of the problem and the solution."

413 Do original em inglês: "The description of design as the co-evolution of problem and solution leads to the uneasy conclusion that, in describing design, we cannot pres uppose that there is something like a set 'design problem' at any point in the design process."
} 
situação projetual e sua pré-compreensão do que esta situação deveria ser como algo dinâmico, à medida que aparentemente nenhuma destas instâncias é fixa em nenhum ponto do processo projetual, como bem observou Donald Schön $(1983$, p.85) sobre o protocolo de Quist e Petra. Este é o mes mo contexto das ponderações tardias de Rittel (1987/2010) sobre a liberdade epistêmica do designer: em nossa percepção, Schön (1983) avançou ainda mais que Rittel (1987/2010) no reconhecimento da incidência de resultados não intencionais e/ou imprevistos como 'resposta' às ações dos designers, cujo peso determinante sobre o processo projetual deve ser considerado. Schön demonstrou como a 'surpresa', o inesperado é parte efetiva da investigação projetual, implicando um forte sentido de descoberta (o 'descobrir' ou 'desvelar' apontado por Snodgrass e Coyne (1997/2006, p.47)), pela qual reacomodam-se os juízos, apreciações e decisões vinculados a compreensão momentânea do designer. Ao conferir uma 'objetificação' à situação problemática do design e elevá-la ao nível de interlocutor para com o designer, Schön (1983) estabeleceu o embasamento necessário para o entendimento de design como conversação: uma troca mútua e dinâmica de implicações transformativas, um movimento perpétuo de reposicionamento sobre sentidos, objetivos, ações e consequências pela interferência do 'outro' - novamente com-versare - 'dar voltas com' - Figura 23.

Condicionamento da

COMPREENSÃO

Sentidos. visōes de mundo JUíZOS. apreciações

Configuração de

PROBLEMAS

Objetivos .propósitos

enquadramentos
Transformação da

(re)SITUAÇÃO

cons equên cias

RESULTADOS desenvolvimento de (re)SOLUÇÕES

de problemas técnicas. métodos

Figura 23 - Movimento de transformação das instâncias projetuais em conversação. 
Reconhecemos que todas as concepções do projetar as quais nos atemos ao longo de nosso estudo remetem-se a estas quatro instâncias, interdependentes e dinâmicas: 1. A compreensão do designer, associada a seus juízos e apreciações, modos de ver e interpretações de sentidos. 2. A configuração de problemas, objetivos e propósitos, e de enquadramentos da situação problemática. 3. O desenvolvimento ou busca de soluções, técnicas e métodos para a obtenção dos propósitos do design, ou seja, a resolução de problemas. 4. As implicações práticas sob a forma de consequências intencionais ou não pela transformação das situações que são os 'objetos' do design, cujo reconhecimento pelo designer determina a renovação do ciclo. As conversações que se estabelecem entre estas instâncias apresentam-se em diferentes níveis e escalas da prática arquitetônica, por exemplo, entre designers ou agentes na discussão de conceitos ou aspectos de projeto, na interação do designer com seu meio de trabalho (desenho, modelos físicos, ou mes mo na elaboração de seu discurso), nos desdobramentos imprevistos da execução de elementos construtivos em canteiro, etc. As abordagens que compõem nosso horizonte de pesquisa demonstram uma clara distinção entre ênfases e compreensões sobre estas quatro instâncias, e acreditamos não ser possível estabelecer correspondências tomando umas como as outras (que a circularidade hermenêutica corresponde à circularidade cibernética de feedback loop, por exemplo) de acordo com a observação de Coyne (2005, p.15) sobre a inadequação de tal proceder. Neste sentido, entendemos as indicações apresentadas na Tabela 07 mais como uma sistematização de informações aos modos de Rittel (1972b/2010) a fim de incitar a reflexão, que uma tentativa de promover uma síntese conforme Alexander (1964) e outros. De qualquer modo, podemos afirmar que todas estas mesmas abordagens apresentam propostas para a investigação do design, posicionando uma questão em comum: a necessidade de investigação e validação das premissas incorporadas nas ações projetuais perante as propriedades específicas da situação projetual, de modo a proporcionar uma maior percepção e compreensão de estruturas de raciocínio e processos subjacentes ao projetar, atrelados ao modo como os designers lidam com suas respectivas práticas. Ou seja, todas as visões compartilham de concernimentos de 'Segunda Ordem', a ordem do observador, em termos cibernéticos. 


\begin{tabular}{|c|c|c|c|c|c|c|c|}
\hline 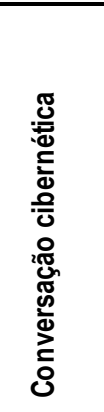 & 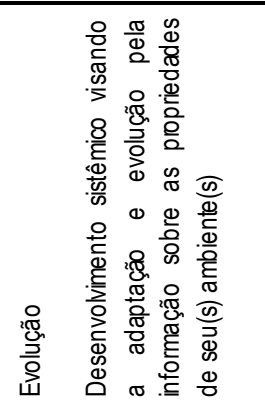 & 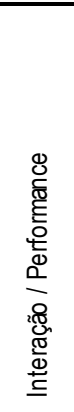 & 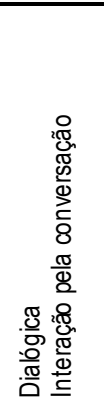 & 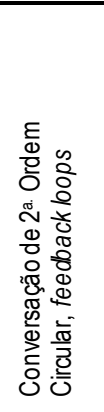 & 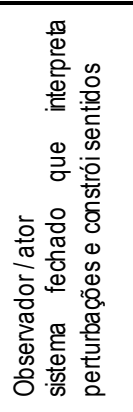 & 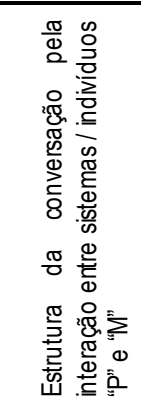 & 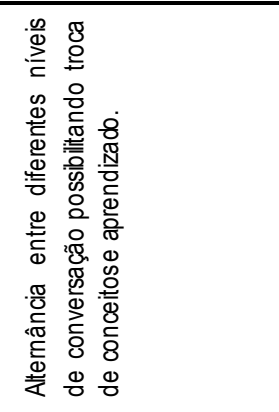 \\
\hline 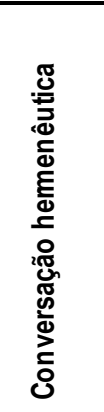 & 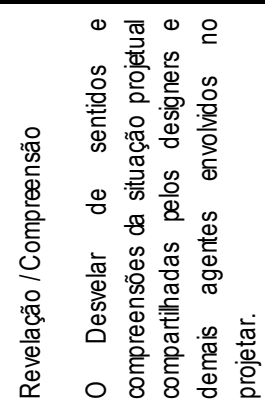 & 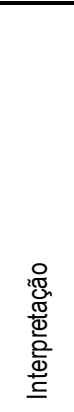 & 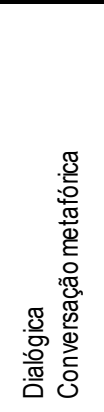 & 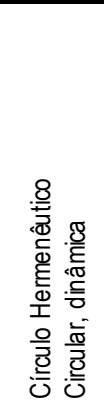 & 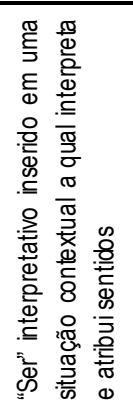 & 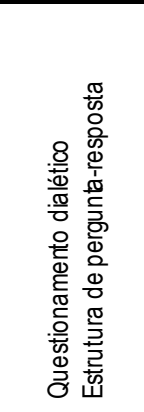 & 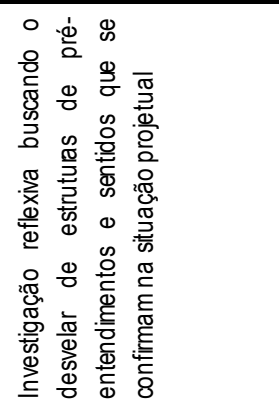 \\
\hline 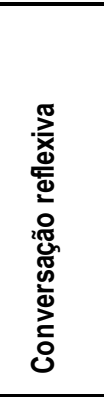 & 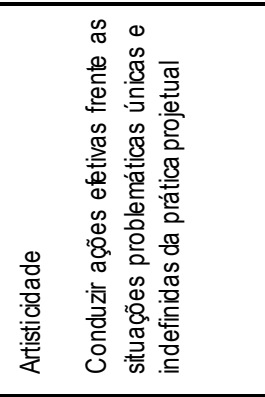 & 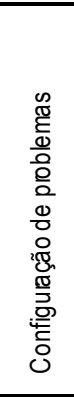 & 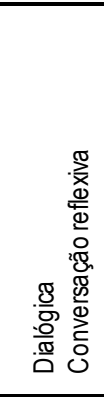 & 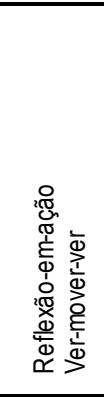 & 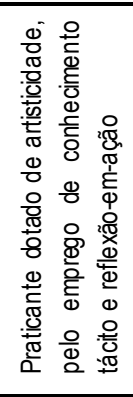 & 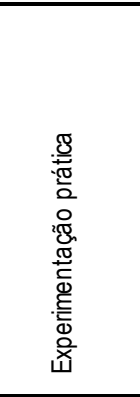 & 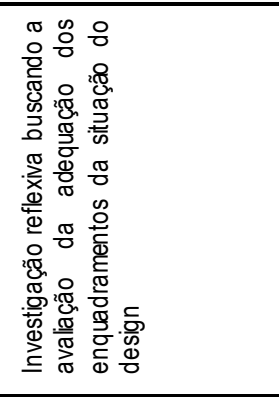 \\
\hline 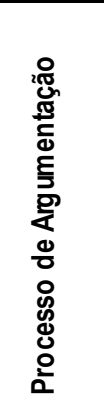 & 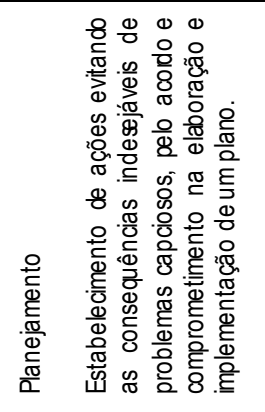 & 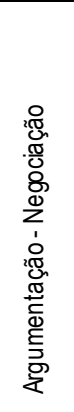 & 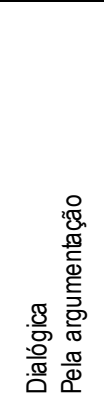 & 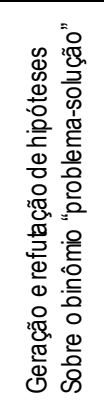 & 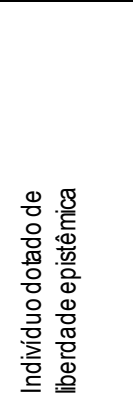 & 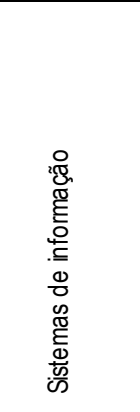 & 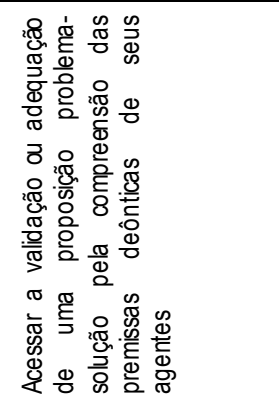 \\
\hline \multirow[t]{2}{*}{ 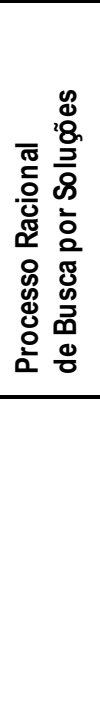 } & 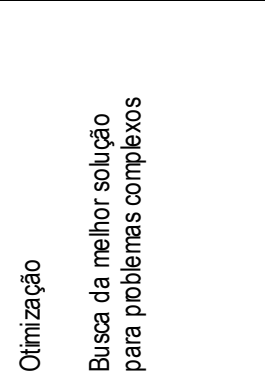 & 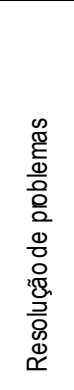 & 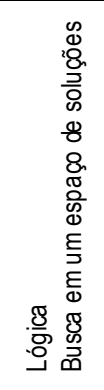 & 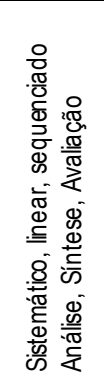 & 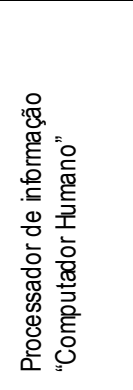 & $\begin{array}{l}\frac{0}{0} \\
\frac{.0}{20}\end{array}$ & 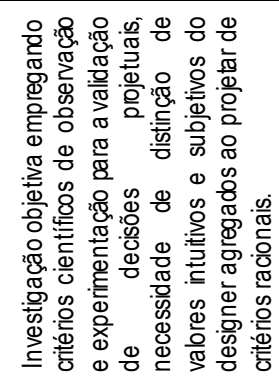 \\
\hline & 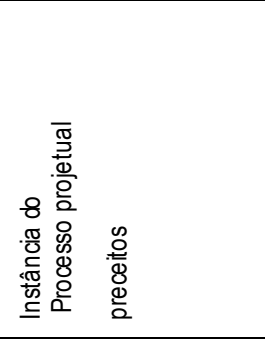 & 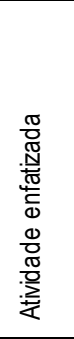 & 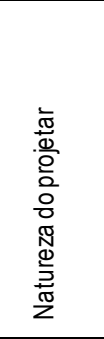 & 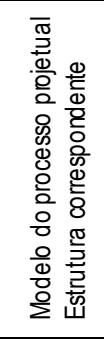 & 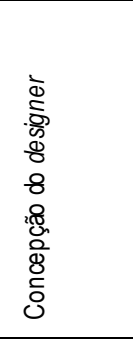 & 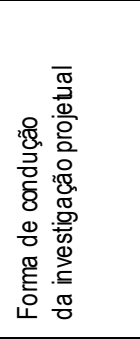 & 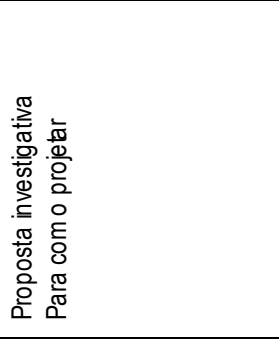 \\
\hline
\end{tabular}




\subsubsection{Concernimentos de segunda ordem sobre o processo projetual}

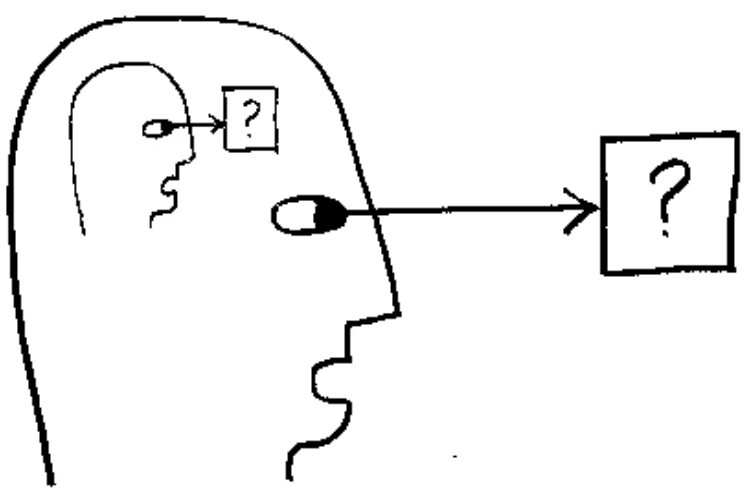

Figura 24 -Designercomo um sistema de Segunda Ordem. Fonte: (JONES, 1970/1992, p.55)

Em nossa compreensão, evidencia-se o modo como o pensamento em design a partir dos anos 1970 reconhece a necessidade de investigação sobre como o indivíduo percebe, constrói sentidos, interpreta e conduz suas ações transformadoras frente às situações problemáticas através da formulação dinâmica de problemas e soluções. Da mes ma forma, e no mes mo contexto cronológico, a cibernética passa por um processo semelhante pelo reconhecimento do indivíduo investigador como um sistema observador (Figura 24), cujas experimentações não poderiam mais ser entendidas pelos princípios científicos de neutralidade e objetividade, mas fazendo jus ao próprio referencial cibernético:

Na virada dos anos 1960 para a década de 1970 o movimento em direção à racionalidade científica explicita œmo o único gerador de 'soluções' objetivas de projeto (o termo está impregnado de ciência) começou a minguar e, por volta da mesma época, os pensadores na cibemética começaram a investigar o paradoxo de que a forma como os sistemas cibeméticos eram discutidos falhavam em refletir a natureza dos sistemas cibeméticos: sistemas cibernéticos eram apresentados utilizando-se o dispositivo tradicional científico do observador imparcial, mesmo apesar deles tratarem de sistemas em que 0 observador ( 0 sensor) é tudo menos imparcial: esse é o ponto do feedback! ${ }^{414}$ (GLANVILLE, 2007b, p.1176, tradução nossa)

\footnotetext{
414 Do original em inglês: "At the turn of the 1960s into the 1970s the movement towards explicit scientific rationality as the sole generator of objective design 'solutions' (the term is redolent of science) began to wane, and, at about the same time, thinkers in cybernetics began to investigate the paradox that the way cyber netic systems were discussed failed to reflect the nature of cybernetic systems: cybernetic systems were presented using the traditional scientific device of the detached observer, even though they spoke of systems in which the observer (the sensor) is anything but detached: that's the point of feedback!"
} 
Para Glanville (2007b) constituiu um fato curioso que o design e a cibernética tenham compartilhado do mesmo concernimento sobre a condição inerente do observador / designer e seu processo investigativo, e no entanto, o pensamento em design tenha se aproximado da cibernética de primeira ordem ao invés da cibernética de segunda ordem, a versão da cibernética que "[...] se preocupa especificamente com os sistemas de compreensão em que o resultado é imprevisível e individual, e o observador está sempre presente e nunca ignorável." ${ }^{415}$ (GLANVILLE, 2007b, p.1177). Dubberly (2008, p.9-10) concordou com Glanville (2007) afirmando que a passagem da primeira à segunda geração de métodos de design conforme o escopo da proposta de Rittel (1972a/2010) possui, é coerente com o 'amadurecimento' da cibernética original, de forte inclinação 'mecanicista', para a cibernética de segunda ordem, dirigida a compreensão das relações sistêmicas dos organismos vivos. Podemos distinguir aspectos centrais entre estas concepções de acordo com a Tabela 08:

\begin{tabular}{|c|c|}
\hline & $\begin{array}{c}\text { "Amadurecimento da Cibernética" } \\
\text { Cybernetics Matures }\end{array}$ \\
\hline $\begin{array}{l}\text { Cibernética de Primeira Ordem } \\
1^{\text {st }} \text { order cybernetics }\end{array}$ & $\begin{array}{l}\text { Cibernética de Segunda Ordem } \\
2^{\text {nd }} \text { order cybernetics }\end{array}$ \\
\hline $\begin{array}{l}\text { Loops Simples } \\
\text { Single-loop }\end{array}$ & $\begin{array}{l}\text { Volta Dupla } \\
\text { Double-loop }\end{array}$ \\
\hline $\begin{array}{l}\text { Voltas de Controle } \\
\text { Control loops }\end{array}$ & $\begin{array}{l}\text { Voltas de Aprendizagem } \\
\text { Learning loops }\end{array}$ \\
\hline $\begin{array}{l}\text { Regulação no Ambiente } \\
\text { Regulating in environment }\end{array}$ & $\begin{array}{l}\text { Participação na Conversação } \\
\text { Participating in conversation }\end{array}$ \\
\hline $\begin{array}{l}\text { Sistemas observados } \\
\text { Observed systems }\end{array}$ & $\begin{array}{l}\text { Sistemas observadores } \\
\text { Observing systems }\end{array}$ \\
\hline $\begin{array}{l}\text { Observador fora do Esquema } \\
\text { Observer outside frame }\end{array}$ & $\begin{array}{l}\text { Observador no Esquema } \\
\text { Observer in the frame }\end{array}$ \\
\hline $\begin{array}{l}\text { Observador descreve o Objetivo } \\
\text { Observer describes goal }\end{array}$ & $\begin{array}{l}\text { Participantes criam objetivos } \\
\text { Participants co-create goals }\end{array}$ \\
\hline $\begin{array}{l}\text { Assume objetividade } \\
\text { Assumes objectivity }\end{array}$ & $\begin{array}{l}\text { Reconhece Subjetividade } \\
\text { Recognizes Subjectivity }\end{array}$ \\
\hline
\end{tabular}

Tabela 08 - Comparativo entre ordens da cibernética - Adaptação de Hugh Dubberly (2008) de esquema original de Paul Pangaro tradução nossa. Fonte: DUBBERLY, 2008, p.10.

\footnotetext{
415 Do original em inglês: "[...] is specifically concerned with understanding systems in which the outcome is unpredictable and individual, and the obs erver is always present and never ignorable."
} 
Glanville refletiu que os ciberneticistas dos anos 1960, por sua vez, limitaram-se a perceber o design como "[...] uma atividade de resolução de problemas pertencente ao mundo do complexo mas ainda definível." ${ }^{416}$ (GLANVILLE, 2007b, p.1177, tradução nossa) Neste contexto, o autor apontou Gordon Pask e sua relação direta com o ensino de arquitetura como uma significante exceção. Embora o tema principal do trabalho de Pask (1975a, 1976) tenha se situado em torno dos mecanismos e processos de aprendizado em sistemas humanos e mecânicos, Boyd (2004, p.182) demonstrou como a Teoria da Conversação pode ser entendida em função da resolução e configuração de problemas, pela compreensão de que a estrutura mínima de um Indivíduo P pode ser descrita como um mecanis mo cibernético simples (um 'solucionador de problemas', como um termostato que regula a temperatura, como exemplificamos anteriormente) em interação com o sistema 'objeto' do problema (um modelo ou espaço de teste de soluções, ou o ambiente, no caso do termostato) adicionado de outro sistema cibernético 'aprendiz' (que atua no controle do primeiro), executando em algum(s) indiv íduo(s)-M, conforme a Figura 25.

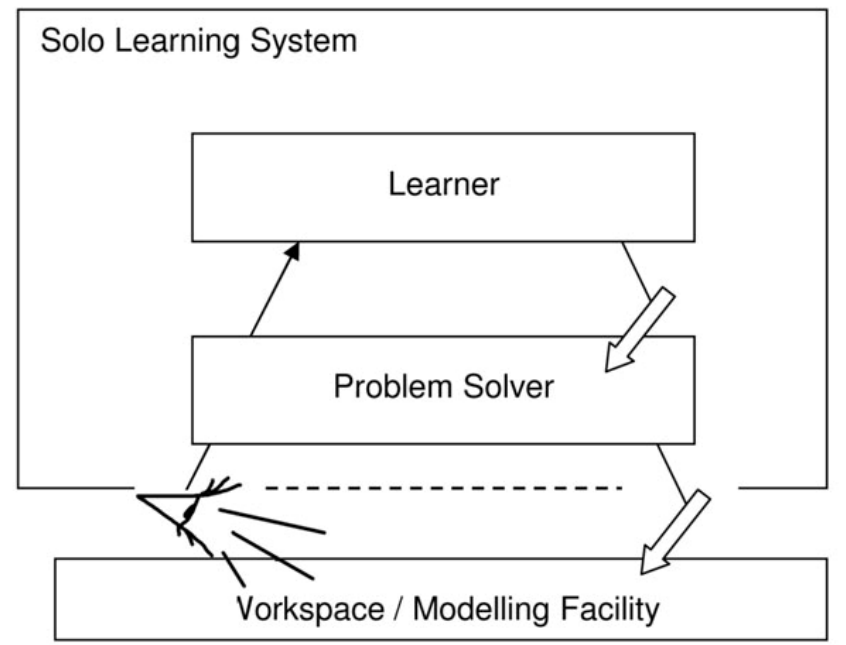

Figura 25. Sistema aprendiz simples 'solitário' Adaptado de (BOYD 2004 p.182)

Este é um modelo de sistema de segunda ordem, um sistema observador composto por uma volta dupla de feedback loop, onde a primeira volta (primeira ordem) representa a resposta em forma de informação que o sensor do sistema compara com a condição desejada (seu objetivo), no sentido de corrigir a diferença entre esta condição desejada e a

\footnotetext{
416 Do original em inglês: "[...] a problemsolving activity that lives in the world of the complex-yet-definable."
} 
condição atual do ambiente pela ação de atuadores: no caso do design, podemos entender este mecanismo como um processo de condução de ações para resolução de problemas (DUBBERLY, 2005, p.118), Figura 26. Por sua vez, uma segunda volta de feedback loop (segunda ordem) é aninhada sobre a volta inicial (Figura 27), que coleta a resposta da ação dos atuadores sobre o ambiente, a fim de determinar se o objetivo é adequado ou não, e proceder uma nova configuração para este objetivo (um processo que corresponde à configuração de problemas do design). Deste modo, o sistema da Figura 26 pode ser lido como um sistema autorregulador de primeira ordem, enquanto o segundo (Figura 27) é um sistema 'aprendiz', um sistema de segunda ordem, que aprende pela modificação de objetivos baseados na aferição do resultado de ações externas ao sistema (DUBBERLY, HAQUE, PANGARO, 2009, p.5). Múltiplos sistemas aprendizes podem se aninhar sobre um primeiro nível e escolher qual sistema de primeira ordem ativar com base em seus próprios objetivos, e assim, à medida que "[...] o sistema de segunda ordem persegue seu objetivo e testa opções, ele aprende como suas ações afetam o ambiente. 'Aprender' significa conhecer quais sistemas de primeira ordem podem enfrentar as perturbações ao se lembrar daquelas que se sucederam no passado." 417 (DUBBERLY, HAQUE, PANGARO, 2009, p.5, tradução nossa).

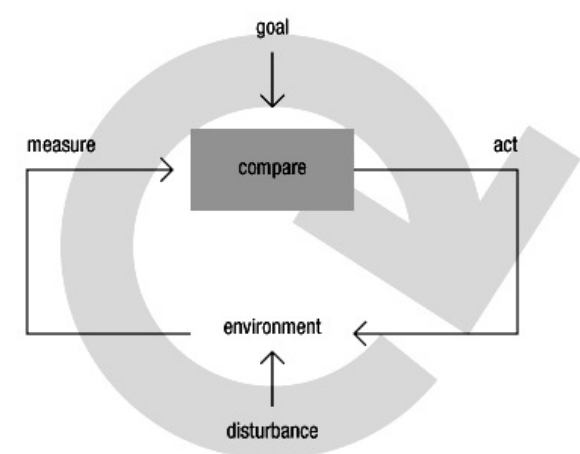

Figura 26 - Sistema cibemético de primeira ord em Fonte: DUBBERLY, HAQUE, PANGARO, 2009, p.6.

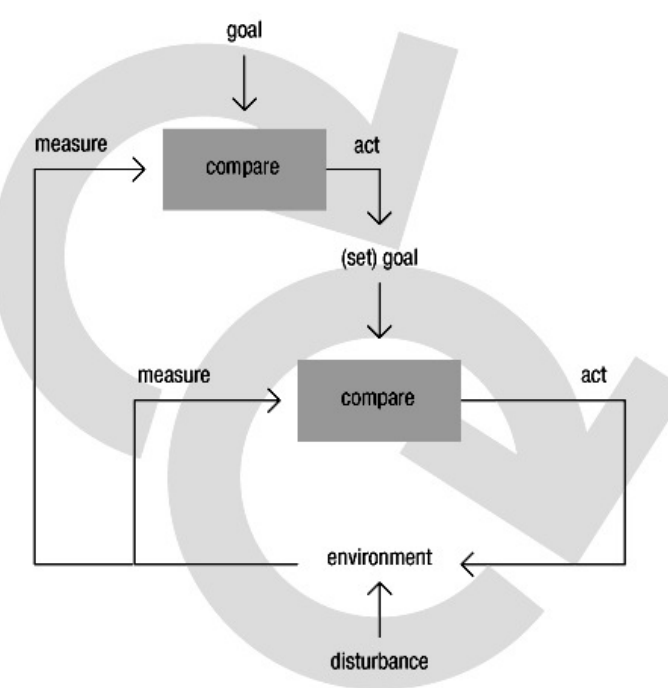

Figura 27 - Sistema cibemético de segunda ordem Fonte: DUBBERLY, HAQUE, PANGARO, 2009, p.6.

\footnotetext{
417 Do original em inglês: "[...] the second order system pursues its goal and tests options, it learns how its actions affect the environment. 'Learning' means knowing which first or der systems can counter which disturbances by remembering those that succeeded in the past."
} 
Este segundo feedback loop também foi denominado de 'volta dupla de aprendizado' por Argyris e Schön $(1978,1996)$ que propuseram sua versão própria ${ }^{418}$ do modelo cibernético de segunda ordem (Figura 28), correlacionando três elementos básicos: 1.Variáveis governantes, as premissas que representam limites aceitáveis e diretrizes para $\mathbf{2}$. Ações, os movimentos e planos estabelecidos para a manutenção dos valores governantes e 3.Consequências, o resultado das ações, que pode corresponder ou não aos valores governantes, podendo levar à revisão destes últimos em caso do reconhecimento de consequências indesejáveis.

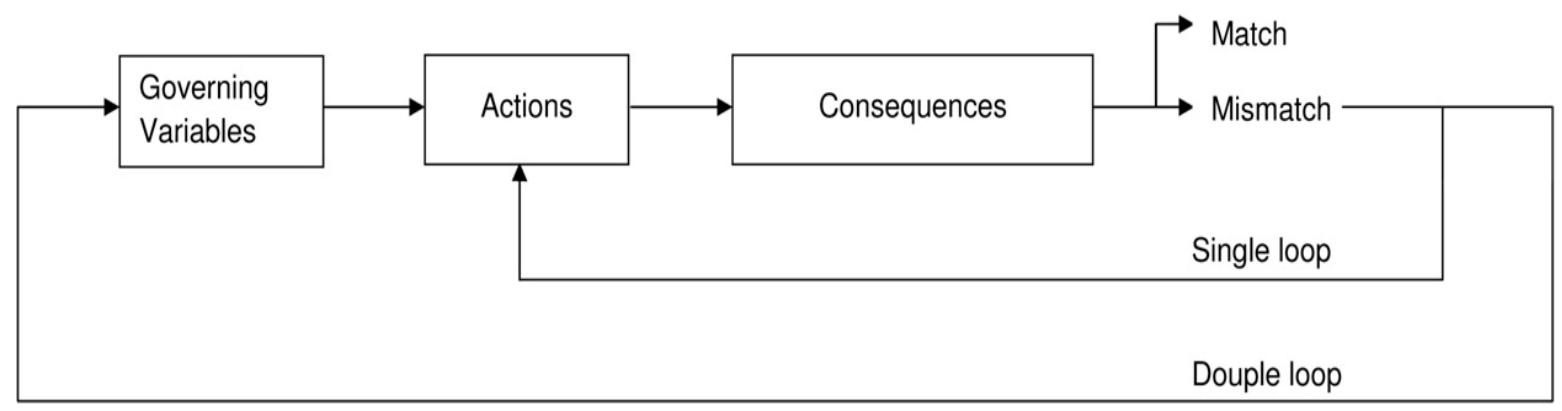

Figura 28 - Modelo da 'volta dupla de aprendizado' segundo Argyris e Schön (1987, 1996). Adaptação a partir da descrição do modelo de Argyris e Schön, 1996, p.21.

Smith (2001) observou que a concepção de aprendizagem de Argyris e Schön (1978) está relacionada à detecção e correção de erro, ou seja, quando se percebe algo errado, uma atitude inicial é a procura de uma outra estratégia de ação que corresponde às variáveis governantes do indiv íduo: objetivos, valores, planos e regras são operacionalizados ao invés de questionados (configurando uma volta simples). Já este questionamento corresponde a um aprendizado de volta dupla, em que as variáveis governantes podem ser alteradas levando a uma mudança no modo em que estratégias e consequências são enquadradas (SMITH, 2001). Podemos afirmar, portanto, que este modelo incorpora tanto fundamentos da estrutura de reflexão-em-ação conforme expressa em Schön (1983) quanto conceitos cibernéticos, justificando o comentário de Glanville (2007a, p.1153) sobre a natureza essencialmente cibernética do trabalho de Schön (1983).

\footnotetext{
418 Argyris e Schön (1996, p.21) afirmam ter emprestado a distinção entre volta simples e dupla de aprendizado a partir de Ross Ashby (1960). Referênci a - ASHBY, R., Design For a Brain. New Yor k. John Wiley and Sons, Inc., 1960.
} 
Evidencia-se com esta leitura que a aprendizagem inerente ao design é uma qualidade essencial tanto na concepção da conversação reflexiva de Schön (1983) quanto na conversação de Pask $(1975,1976)$. Para além da aprendizagem, Dubberly e Pangaro (2007, p.20), observaram (Figura 29) a relevância da conversação do design como uma interação que possibilita a seus participantes: 1. Compartilharem conceitos sobre objetivos e métodos para atingi-los (voltas horizontais), enquanto checam a consistência da conversação (voltas verticais), 2.Cooperação para obtenção de objetivos, em que um participante solicita ajuda, atuando momentaneamente no controle de processos do outro participante (voltas diagonais), mes mo que eles mantenham objetivos distintos; e 3. Colaboração em objetivos comuns, em que os participantes concordam sobre objetivos e métodos para obtê-los. Neste caso, os participantes abrem mão de sua individualidade originando um único sistema de objetivos e ações.

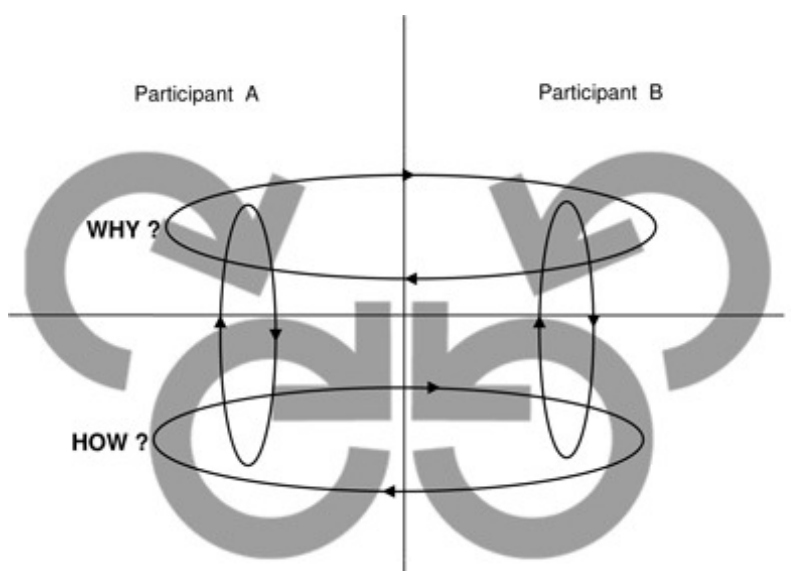

3. CONVERSATION ABOUT GOALS AND METHODS
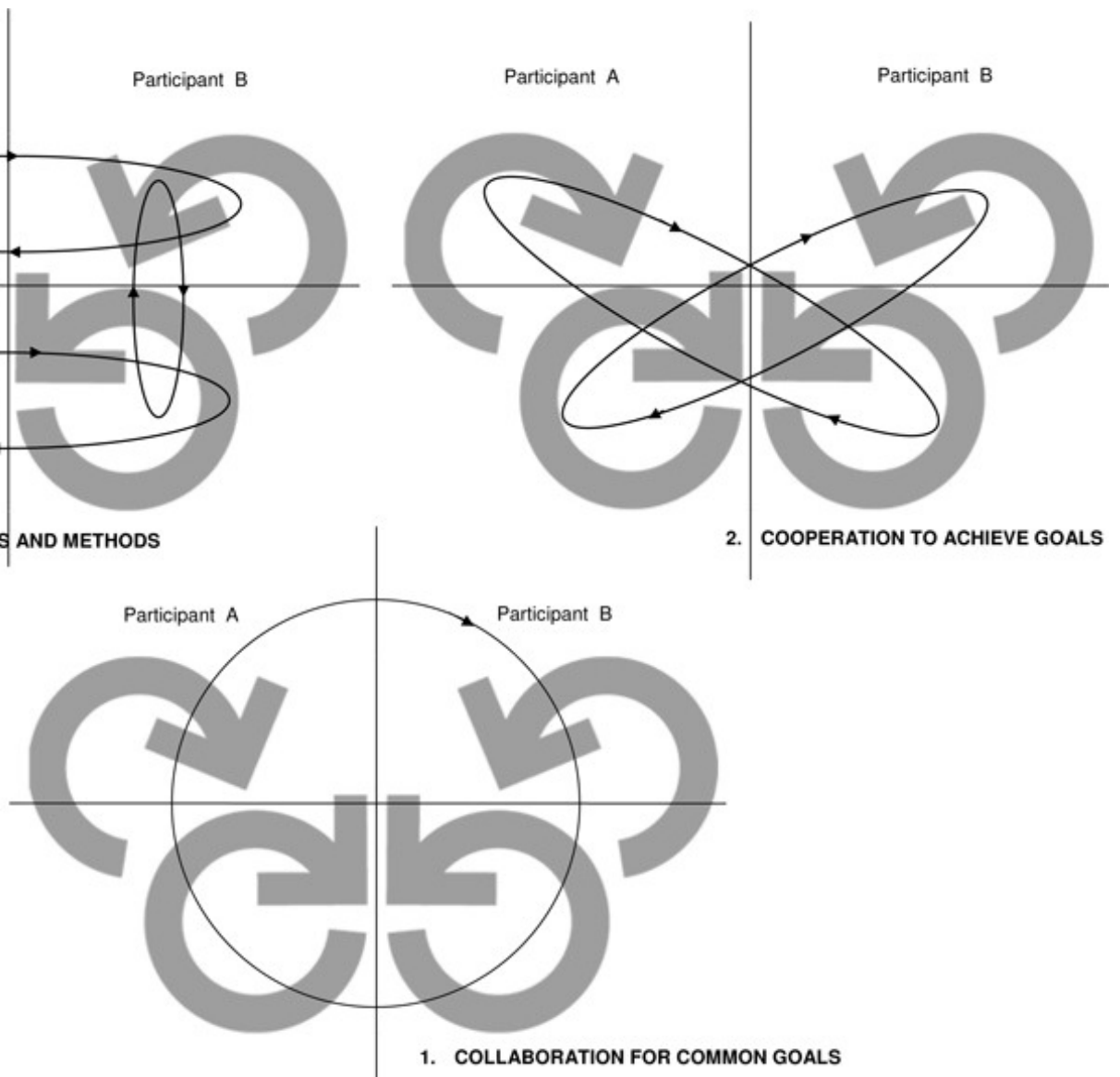

Figura 29 - Três Modelos de Conversação: 1. Conversação sobre objetivos e métodos; 2. Conversação para cooperação em objetivos; 3. Conversação para colaboração em objetivos comuns. Adaptação de (DUBBERLY; PANGARO, 2007, p.20) e (DUBBERLY, HAQUE, PANGARO, 2009, p.11) 
Como observamos anteriormente, a construção de sentidos e compreensões entre objetivos e ações é própria do indivíduo, como um sistema que interpreta perturbações externas a si como informativas, logo, à medida que estas perturbações são desencadeadas através da interação entre sistemas, pode-se afirmar que este processo de compreensão mútua e percepção de sentidos está atrelado intimamente às diferentes configurações assumidas pela conversação que apresentamos, o que representa, por sua vez, uma ênfase na dimensão social, política e compartilhada destes processos em detrimento da concepção epistemológica tradicional racionalista, conforme expressaram Winograd e Flores:

A chave para muito do que nós temos dito [...] está em reconheœr a importância fundamental da mudança a partir de uma concepção de compreensão centrada no indivíduo para uma socialmente baseada. Conhecimento e compreensão (em ambos os sentidos cognitivo e linguístico) não resultam de operações formais em representações mentais de um mundo que existe objetivamente. Ao contrário, eles surgem pela participação empenhada do indivíduo em padrões de comportamento mutuamente orientados de comportamento que são incomorados em um fundo comum socialmente compartilhado de conœrnimento, ações e crenças. ${ }^{419}$ (WINOGRAD; FLORES, 1990, p.78, tradução nossa)

A conversação é assim um tipo especial de interação que possibilita a construção de sentidos, a convergência em acordos (mesmo quando isto significa o acordo sobre o desacordo, funcionando como um mecanis mo de reconhecimento de conflitos e distinções), o aprendizado, a coordenação e colaboração entre sistemas, e finalmente a coevolução sistêmica, em um sentido similar ao observado por Gadamer (1976R002, p.247) sobre seu sentido transformador. Neste sentido, Dubberly e Pangaro conclu íram que "[...] participante A ou B (ou ambos) são diferentes após a interação. Um ou outro, ou ambos defendem novas crenças, tomam decisões, ou desenvolvem novos relacionamentos com outros, com circunstâncias ou objetos, ou consigo mesmos."420 (DUBBERLY; PANGARO 2009, p.3). Segundo Bernard Scott todo o 'domínio consensual' sistêmico coevolui, compreendido como o

\footnotetext{
419 Do original em inglês: "The key to much of what we have been saying [...] lies in recognizing the fundamental importance of the shift from an individual-centered conception of understanding to one that is socially based. Knowledge and understanding (in both the cognitive and linguistic senses) no not result from formal operations on mental representations of an objectively existing world. Rather, they arise from the individual's committed participation in mutually oriented patterns of behavior that are embedded in a socially shared background of concerns, actions, and beliefs."

420 Do original em inglês: "Participant $A$ or $B$ (or both) are different after the interaction. Either or both hold new beliefs, make decisions, or devel op new rel ationships, with others, with circumstances or objects, or with thems elves."
} 
'acoplamento estrutural' da visão de Maturana (Figura 30) constituído entre sistema e ambiente, a trajetória de vida de membros de espécies que compartilham nichos ecológicos e domínios de interação e comunicação consensuais com objetos, eventos e classes destes (MATURANA; VARELA, 1980 apud. SCOTT, 2004 p.345).

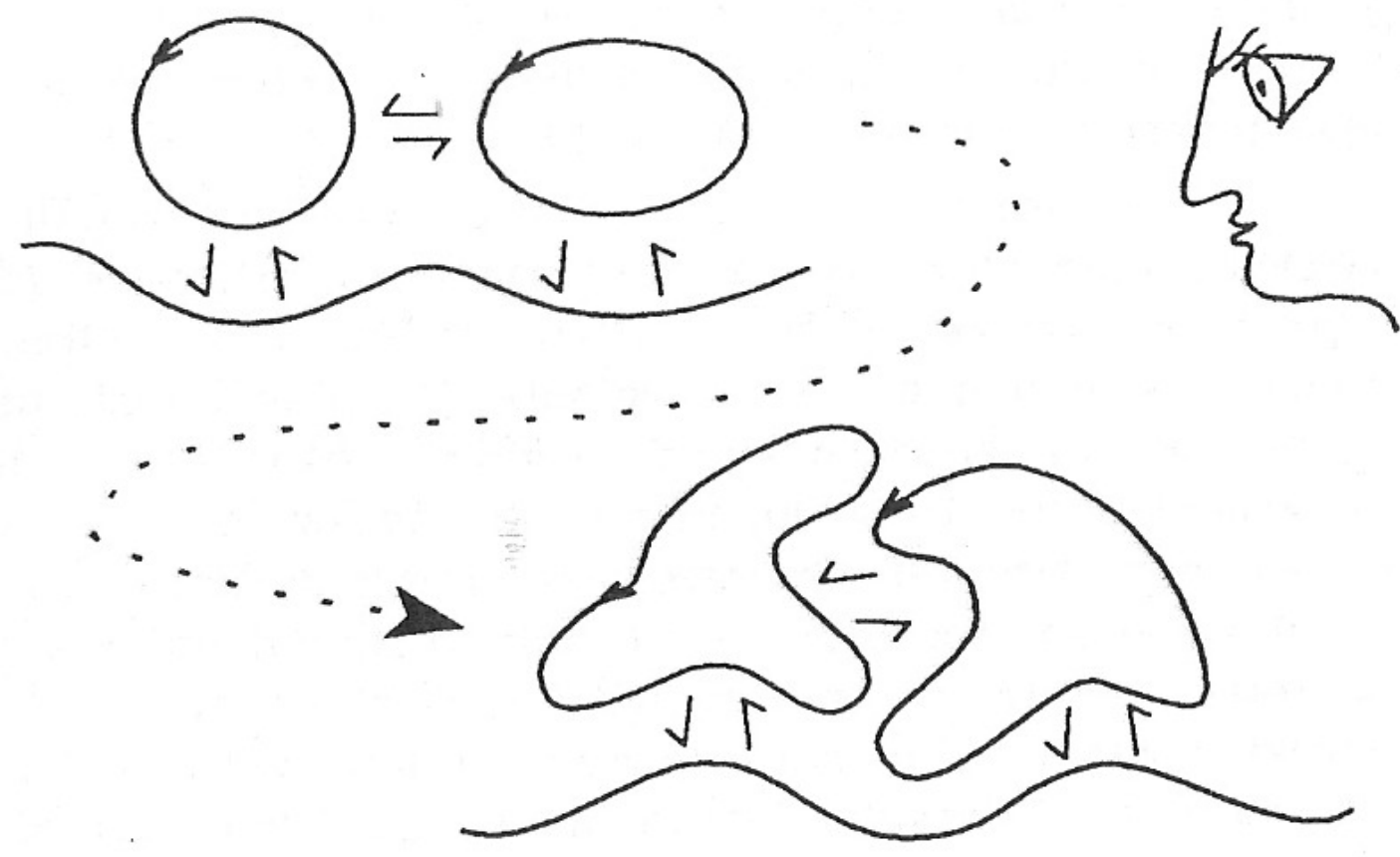

Figura 30 -Acoplamento estrutural de dois org anismos em um flux o de interações que o o bservador por descrever como coo rdenações consensuais de coordenações consensuais de comportamento. Fonte: MATURANA, 1990/2001, p.220.

Podemos assim nos referir à prática projetual como a coordenação de coordenações de comportamentos, o conjunto das interações entre sistemas em suas diversas instâncias, como a configuração e obtenção de objetivos e propósitos pela condução de ações transformadoras e a reacomodação da compreensão pela percepção de consequências imprevistas destas ações. Esta concepção de design como conversação reposiciona uma série de questões sobre sua prática, por exemplo, com relação ao papel do designer como agente central do processo e as implicações de seu fazer com relação às conversações estabelecidas entre os outros agentes do projeto, e entre o projeto concretizado em obra e as pessoas que interagem com ele (seus 'habitantes'). No contexto da arquitetura, percebemos que a efetivação das transformações correspondentes ao projeto arquitetônico pode (e deve) ser compreendida como interdependente de uma rede de conversações para muito além dos diálogos entre o arquiteto e o projeto conduzido na prancheta de desenho ou computador. 


\subsubsection{O Projetar como cons trução de sentidos e acordos sociais}

[Primeiro:] Projetar é uma atividade social que ocorre entre pessoas que negociam, fazem propostas, estabeleœm regras para sua conduta e para o trabalho a ser feito, e seguem tais regras. Em suma, em grande medida, projetar envolve fazer acordos e regras. ${ }^{421}$ (HABRAKEN, GROSS, 1987, p.2, tradução nossa)

Em suas investigações etnográficas sobre a prática arquitetônica, Cuff (1991) anunciou como sua observação mais abrangente, a de que o projetar é essencialmente um processo social e uma das tarefas mais fundamentais do fazer arquitetônico, que consiste em reunir participantes deste processo, internos e externos ao ambiente do escritório de arquitetura, e desenvolver uma maneira de trabalhar e interagir com os mesmos a fim de chegar à soluções de projeto. A autora procurou assim posicionar uma abordagem de design distinta da visão tradicional como um processo relegado à prancheta de desenho ou computador, a favor de um sentido muito mais amplo, que inclui as relações humanas deter minantes para o estabelecimento da forma final do projeto: "[...] do pessoal do escritório para as relações com clientes, de chamadas telefônicas para a negociação de um contrato - todas as atividades relevantes tornam-se parte do projeto." ${ }^{422}$ (CUFF, 1991, p.248, tradução nossa). Entretanto, apesar da aparente simplicidade deste reconhecimento, afirma-se que arquitetos tendem a conhecer bem a parte crucial do instrumental técnico de desenho enquanto há uma ignorância generalizada sobre a 'arte social do projetar' (CUFF, 1991, p.248). Neste sentido, Cuff observou que a profissão de arquitetura tende a lidar explicitamente apenas como uma parte do processo projetual, e que um modelo deste processo na prática pode ser representado através de uma série de dialéticas como a segu inte colocação: "[...] acredita-se que o projeto germina a partir de uma série de decisões tomadas de forma independente, em vez de um sentido emergente feito de uma situação dinâmica." ${ }^{423}$ (CUFF, 1991, p250, tradução nossa). Esta afirmação vai de encontro à concepção de design proposta por John Forester (1985) do

\footnotetext{
421 Do original em inglês: "Designing is a social activity that takes place among people who negotiate, make proposals, set rules for their conduct and for the work to be done, and follow such rules. In short, to a large extent, designing involves an agreement- making and rule- making."

422 Do original em inglês: "[...] from office staffing to client relations, from telephone calls to negotiating a contract - all relevant activities become part of design."

423 Do original em inglês: "[...] design is believed to sprout from a series of independently made decisions rather than from the emergent sense made of a dynamic situation."
} 
projetar como o estabelecimento de sentidos de forma conjunta, pelos seus participantes, em conversações práticas. Cuff (1991, p.254) afirmou que pela perspectiva de seus estudos, a atividade de 'conformação de sentidos' consiste em uma descrição mais precisa da habilidade dos designers sobre a prática projetual do que a ação de 'tomada de decisões', relacionada à concepção tradicional de resolução de problemas. Para a autora, "[...] a noção de fazer sentido ${ }^{424}$ implica um contexto coletivo em que precisamos sentir uma situação, inerentemente social, interpretá-la, e estabelecer sentidos com outros através de conversação e ação em ordem de chegar a acordos." ${ }^{425}$ (CUFF, 1991, p.254, tradução nossa). Forester (1985, p.15-18) evidenciou ordens de concernimento desveladas pela tematização do projetar como construção de sentidos pelas conversações, então obscurecidas pela concepção de design como um processo de busca em um espaço de soluções, dirigido por procedimentos específicos e instrumentais:

Em vez de fornecer um método de livro de reœitas culinárias, então, o compromisso de considerar a atividade de design œmo um processo social de fazer sentido conjuntamente em conversações práticas é duplo. Primeiro, a análise pode alertar designers para as dimensões sociais dos proœssos de design que eles irão influenciar e que irão influenciá-los, por sua vez. Em segundo lugar, chama a atenção não só para o trabalho prático e interpretativo do projetar, mas também para a necessidade de avaliar o contexto organizacional, institucional e político-econômico do trabalho do designer, as restrị̄oes dos rigores institucionais que os designers neœssariamente, se também infelizmente às vezes, enfrentamem práticas cotidianas. ${ }^{426}$ (FORESTER, 1985, p.14, tradução nossa)

Forester (1985, p.14-15) chamou atenção para a relação entre o embate das intenções

\footnotetext{
424 Klaus Krippendorf ( 1989, 2006) é outro autor c ujo trabalho aponta para a relevância da consideração do design pel os seus aspec tos semânticos. Na introdução da obra 'The semantic Turn' de Krippendorf (2006), Bruce Archer obser vou que o axioma primário de Krippendorf compr eende que "humanos não respondem às propriedades físicas das coisas - a sua forma, es trutura e função, mas a seus sentidos individuais e cultur ais." (ARCHER, in: KRIPPENDORF, 2006, xix, tradução nossa) 425 situation, inherently social, interpret it, and make sense with others through conversation and action in order to reach agreements."

426

o original em inglês: "Rather than to provide a cook-book method, then, the promise of considering design activity as a social process of making sense together in practical conversations is two-fold. First, the analysis can alert designers to the social dimensions of design processes that they will influence and that will influence them in turn. Second, it calls attention not only to the practical interpretive work of designing, but also to the need to assess the organizational, institutional, and politicaleconomic context of designer's work, the institutional 'stringencies' that designers necessarily, if also unhappily at times, face in everyday practices."
} 
projetuais conduzidas pelos designers e as restrições institucionalizadas em seu contexto, pontuando a necessidade do enfrentamento de ambiguidades e contradições presentes nos posicionamentos dos diversos interatores deste processo. A este respeito corresponde a descrição de Dorst (2006, p.17) do projetar como a resolução de paradoxos entre discursos em uma situação de design, entendendo um paradoxo como uma oposição real entre visões, pontos de vista ou requisitos incorporados no discurso dos atores envolvidos no processo projetual. Bucciarelli (1994) é outro autor que suportou esta visão, observando que os interesses e perspectivas individuais estão atrelados à especialização e responsabilidade dos participantes do projeto, de modo que "Projetar é um processo de trazer coerência a estas perspectivas e interesses, fixando-os no artefato. Os participantes trabalham para trazer os seus esforços em harmonia através da negociação." ${ }^{\text {227 }}$ (BUCCIARELLI, 1994, p.187, tradução nossa). Assim como Cuff (1991), Louis Bucciarelli (1994), é outro exemplo de pesquisador que conduziu estudos etnográficos sobre a prática projetual. Reconhecemos que o autor chegou à conclusões similares a Cuff (1991) ao afirmar que no processo projetual "[...] o projeto não está contido no conjunto da documentação formal, nem é de posse de qualquer pessoa a descrevê-lo ou defini-lo completamente, embora cada participante irá dizer-lhe a sua história, se solicitado. Este é o forte sentido de 'design é um processo social'."428 (BUCCIARELLI, 1994, p.187, tradução nossa). Bucciarelli (1994) também corroborou com Cuff (1991) e Forester (1985) sobre o sentido de negociação e acordo:

\footnotetext{
Projetar não é simplesmente uma questão de trade-offs, de ponderação instrumental ou racional de interesses uns contra os outros, um processo de medição de alternativas e opções contra algumas condiọões dadas de desempenho. Nada é sagrado, nem as especificações de desempenho, até mesmo estas também, são negociadas, alteradas ou até mesmo jogadas fora, enquanto aquelas que importam são embelezadas e enrijecidas como tempo como produto de design. Elas próprias são os artefatos de design. Assim, também, com outras restrições, até mesmo aos códigos tem que ser dada uma leitura e uma interpretação. Eles estão todos lá para serem negociados se essas leituras seguem em conflito. ${ }^{429}$ (BUCCIARELLI, 1994, p.187, tradução nossa)
}

\footnotetext{
${ }^{427}$ Do original em inglês: "Designing is a process of bringing coherence to these perspective and interests, fixing them in the artifact. Participants work to bring their efforts into har mony through negotiation."

428 Do original em inglês: "[...] the design is not contained in the totality of for mal documentation, nor is it in the possession of any individual to describe or completely define, although every participant will tell you his or her story if asked. This is the strong sense of 'design is a social process'."

429 Do original em inglês: "Designing is not simply a matter of trade-offs, of ins trumental, rational weighing of inter ests against
} 
Todas estas colocações, vinculadas à aspectos essenciais da conversação, conforme caracterizamos anteriormente, vão de encontro ao pensamento de Rittel (1967/1971, 1972a/2010, 1972b/2010, 1987) sobre a prática projetual. Rittel (1967/1971) foi enfático ao afirmar que neste processo de construção de um acordo pela negociação cabe ao designer o cumprimento de seu papel como tal, ou seja, colocar-se junto aos outros participantes do processo como um facilitador das conversações, que seja capaz também de defender e explicitar seu ponto de vista e valores de julgamento:

Há quem diga que o designer é um 'cumpridor de neœssidades', um jarro para reạ̃oes químicas em que pessoas derramam em suas necessidades. Ou que o designer é apenas um catalisador para a cristalização da solução. Essas pessoas esqueœm que o designer se compromete em seu trabalho. Conscientemente ou inadvertidamente, ele usa seu julgamento o tempo todo, assim como qualquer outra pessoa. Cada restrição é uma questão de decisão. Se ele tent manter-se neutro e não envolvido é provável que ele faça o trabalho de alguns oportunistas de classe média ou mesmo o de um reacionário: 'De quemeu como 0 pão, seu projeto eu faço.'430 (RITTEL, 1967/1971, p.23, tradução nossa)

Forester (1985, p.18) observou que ao participar das conversações projetuais, o designer assim como os outros participantes, assume um papel social em que se reafirmam e se recriam identidades sociais o tempo todo. Este sentido corrobora ao mesmo tempo com Rittel (1967/1971) e com os preceitos da cibernética de segunda ordem, assumindo a reprodução e recriação de identidade como uma das qualidades essenciais dos sistemas observadores pela sua comunicação interativa como ambiente e demais sistemas de seu domínio consensual, como vimos anteriormente. É desta forma, portanto, que nas conversações do fazer arquitetônico: "[...] o trabalho do designer não cria apenas um objeto projetado, mas também o seu próprio ser em evolução. [...] A atividade do design então,

each other, a process of meas uring alternatives and options against some given perfor mance conditions. Nothing is sacred, not even performance specifications, for these, too, are negotiated, changed, or even thrown out together, while those that matter are embellished and made rigid with time as design proceeds. They themselves are artifacts of design. So, too, with other constraints; even codes have to be given a reading and an interpretation. They are all there to be negotiated if those readings run in conflict"

430 Do original em inglês: "There are those who say that the designer is a 'need fulfiller', a reaction-jar into which people pour their needs. The designer is just a catalyst for crystallization of the sol ution. These people forget that the designer commits himself in his work. Knowingly or inadvertently, he us es his judgment all the time, as does anybody else. Every constraint is a matter of decision. If he tries to remain neutral and uninvolved he is likely to do the job of some middle-class opportunist or even that of a reactionary: 'whose bread I eat, his design I do'." 
produz designers assim como objetos projetados."431 (FORESTER, 1985, p.18, tradução nossa). Reconhecemos assim, uma leitura sensível em Rittel (1967/1971, p.26) sobre a formação dos arquitetos segundo esta qualidade peculiar da conversação:

[...] 0 bom designer sabe que ele nunca encontrará a melhor solução, mas mesmo assim irá continuar a procurar por melhores. Para ele, é tão importante estar familiarizado œm problemas não resolvidos de hoje quanto $\infty m$ as práticas aprovadas de ontem. Ele terá aprendido a viver com o fato de que tudo o que ele está fazendo é devido à sua própria decisão livre, que quase não há necessidades, que quase tudo - incluindo valores, hábitos e crenças - são sujeitos a potenciais alterações, e que, conseguinte: acidentalmente, ou por instrução, tropeçam nas dificuldades de projetar, e eles descobrem que eles não sabem o suficiente para superá-las. Eles olham para o conhecimento confiável e procedimentos adequados. O resultado é muitas vezes resignação ou cinismo: eles perdema coragem para desenhar uma linha base emuma folha em branœ. Alguns desistem da ideia de se tomarem designers e mudam para uma ciência (preferencialmente psicologia), ou entram para os negócios. Uns poucos sobrevivem este perído de frustração sem desistir, renunciar ou recorrer ao oportunismo. Eles aprendem a projetar, apesar das dificuldades, paradoxos e dilemas. Eles também deduzem que balanœar massas contra o vazio, sequenciar espaços, considerar edifícios como 'declarações' de preferências estéticas, jogos de caixas de vidro com 'megaestruturas', são apenas um grupo de fabres no contex b muito mais rico de projeto de edificaçoes, planejamento urbano e construção. Talvez um sistema educacional para o projeb seja 'melhor', na medida emque aumenta o número de alunos que alcançam esta visão de arquitetura. ${ }^{432}$ (RITTEL, 1967/1971, p.26, tradução nossa)

\footnotetext{
431 Do original em inglês: "[...] the work of the designer creates not only a designed object, then, but the designer's own evolving self. [...] Design activity then, produces designers just as it produces designed objects."

432 Do original em inglês: "[...] The good designer will know that he shall never find the best sol ution, but nevertheless he will continue to search for better ones. For him it is at least as important to be familiar with today's unsolved problems as with yesterday's approved practices. He will have learned to live with the fact that everything he is doing is due to his own free decisions, that there are al most no nec essities, that al most everything - including values, habits and beliefs - are subjected to potential change, and that, second phase: accidentally, or by instruction, they stumble into the difficulties of designing, and they find out that they do not know enough to overcome them. They look for reliable knowledge and appropriate procedures. The result is of ten resignation or cynis m: they lose courage to draw a base line on a blank sheet. Some give up the idea of becoming designers and switch to a science (preferably psychology), or go into business. A few survive this period of frustration without quitting, resigning or resorting to opportunis m. They learn to design in spite of difficulties, paradoxes, and dilemmas. They also deduce that balancing masses against void, sequencing spaces, considering buildings as 'statements' of esthetic preferences, glass-bed games with 'mega-structures,' are only one group of factors in the much richer context of building design, urban planning and construction. Perhaps an educational system for design is 'better' to the extend that it increases the number of students who attain this view of architecture."
} 
É deste modo que nos convencemos da relevância da compreensão do projetar pela chave da conversação, como um horizonte promissor para a pesquisa sobre o processo projetual que permite-nos a 'objetificação', no sentido de Rittel (1972aR010) de uma série de aspectos centrais à prática projetual que são usualmente negligenciados, de acordo com o apontamento de Cuff (1991), do qual corroboramos, pela ênfase predominante do instrumental de desenho e suas diversas variações centradas na concepção da forma arquitetônica. Observamos que mesmo restrito a este escopo, o projetar pode ser compreendido pelo horizonte da conversação, habilitando sua leitura por diversos aspectos e variantes conceituais sobre o tema: seja como fenômeno cognitivo baseado na reflexãoem-ação, como evento hermenêutico da interpretação e compreensão, como interação comunicativa cibernética, ou como jogo na linguagem, em busca da construção de sentidos a partir de nossas narrativas individuais ou experiências compartilhadas, entre outros. Como afirmou Gadamer (1975/1997), a conversação é uma estrutura dialética, que implica encontrar o outro, e também pelo questionamento, suscitar a dúvida, e entrar no contrário: do mesmo modo em que descrevemos o processo projetual e seus agentes como sistemas direcionados à obtenção de objetivos e propósitos, estabelecemos na sequência final deste capítulo uma breve apreensão do sentido de 'vaguear'433 no processo projetual, da indeterminação subjacente a todo o período de coevolução entre problema e solução, em que reconhecemos tanto o produto do projeto quanto seu percurso apenas quando alcançamos um outro ponto de vista que nos permite a construção de uma perspectiva sobre os mesmos. Nestes termos, reafirmamos a relevância desta investigação pelo reconhecimento de que nossas próprias ações, percurso e de nós mesmos em última instância, como sistemas observadores de segunda ordem, refletindo sobre o processo projetual que constitui este trabalho de pesquisa em si, corroboram com as diversas colocações sobre o projetar de que nos ate mos até então.

\footnotetext{
433 Utilizamos aqui o temo 'vaguear' em concor dância com o sentido expresso por Glanville (2007b) e Snodgrass e Coyne (2006) em tradução do termo original em inglês 'wandering'. Outros sentidos associados a este termo incluem: errar, vagar, perambular, bem como os substantivos: errante e nômade.
} 


\subsubsection{O Projetar como livre vaguear}

Leaves are falling all around

It's time I was on my way Thanks to you, I'm much obliged

For such a pleasant stay

But now it's time for me to go

The autumn moon lights my way

'Ramble on' - Led Zeppelin, 1967

Se é possível tratar do design como um processo dinâmico de redirecionamento de objetivos e propósitos, baseado na intenção de transformação de uma situação em outra preferida, também podemos assumir um sentido oposto, ao observarmos a continuidade do movimento do projetar mesmo quando não temos um objetivo claro configurado, nem uma imagem bem definida sobre o que nossos propósitos ou problemas se constituem, ou deveriam se constituir. Mes mo sem a fixação de um destino ou do mapa de um terreno, podemos percorrer uma paisagem como viajantes errantes, fazendo descobertas e encontrando o desconhecido: ainda assim interagimos e interpretamos, construímos sentidos e compreensões. Nosso próprio processo de pesquisa, ao buscar aproximações e interlocuções com concepções distintas, enxergando nelas afinidades e possibilidades para a construção de um horizonte de compreensão comum, acaba assumindo-se como um 'vaguear', pois o percurso acaba por ser desenhado em movimento, e em determinado ponto, olhamos para trás e podemos vê-lo marcado na paisagem a qual percorremos. Sabemos então que chegamos a um destino: e deste ponto podemos refletir sobre a experiência adquirida justamente para problematizar nossa busca, em vista de (re)estabelecer outros rumos. Snodgrass e Coyne (2006) afirmaram que este vaguear pode ser compreendido como caminhar por prazer, com ou sem um destino pré-definido: [...] vaguear e perambular não são planejados, eles são casuais, simplesmente acontecem, são acontecimentos, uma palavra não usada aqui por acaso." ${ }^{\prime 34}$ (SNODGRASS; COYNE, 2006, p.246, tradução nossa). Este mes mo sentido foi observado por Glanville ao afirmar "[...] design e

\footnotetext{
434 Do original em inglês: "[...] wandering and rambling are unplanned; they are haphazard; they simply happen; they are happenings, a word not used here by happenstance."
} 
conversação são ambos como vaguear." ${ }^{435}$ (GLANVILLE, 2007b, p.1193, tradução nossa). O autor expressa que "[...] o vaguear pode ser explicado como proposital de uma maneira que faz sentido da viagem a este lugar, devido ao reconhecimento de chegada: a chegada define e dá sentido à viagem como, tantas vezes em design, a 'solução' define o 'problema'." 436 (GLANVILLE, 2007b, p.1196, tradução nossa). A este respeito sobressai a dimensão positiva do 'permitir-se levar', e nisso estabelecer outros sentidos para além do cumprimento de objetivos pré-estabelecidos:

O ponto do vaguear - seu poder - e o prazer nela, é seguir seu faro, se perder, não planejar, evitar a dominância da 'eficiência' (contrariamente, o resultado obtido desta atividade de (projeto) vaguear transcende o que poderíamos ter imaginado ser ela, de uma maneira que leva a melhoria na 'eficiência' enquanto também promove qualidades como 0 deleite). ${ }^{437}$ (GLANVILLE, 2007b, p.1195, tradução nossa).

De forma similar a Glanville (2007b) para Snodgrass e Coyne (2006), o vaguear significa estar aberto para o que acontece ao acaso, perceber as manifestações das coisas que se desvelam no caminho, de forma que "[...] o trabalho do caminhante é manter-se em movimento, manter os olhos (e a mente) aberta, estar alerta e receptivo." ${ }^{438}$ (SNODGRASS; COYNE, 2006, p.247, tradução nossa). A palavra trabalho aqui possui uma relação subjacente ao vaguear expressa no uso do termo 'jornada' para referindo-se literalmente a um período de dedicação a algo: segundo os autores, todo ofício ou profissão é uma maneira de encontrar um caminho, uma forma de descoberta do próprio percurso, meios ou modos comum a quem se dedica a trabalhar em algo (SNODGRASS; COYNE, 2006, p.246-247). No caso específico da arquitetura como profissão, que lida especialmente com o ato de projetar, Snodgrass e Coyne (2006, p250) compartilharam da convicção de Schön (1984) de que o estúdio de projeto

\footnotetext{
435 Do original em inglês: "[...] the word we use for this sort of walking is wandering: designing and convers ation are both like wandering."

436 Do original em inglês: "[...] the wandering can be explained as if purpos eful in a manner that makes sense of journey to this place, because of the recognition of arrival: the arrival defines and gives purpose to the journey just as so often in design, the 'solution' defines the 'problems'."

437 Do original em inglês: "[...] the same holds with the wandering metaphor. The point of wandering -its power - and the pleas ure in it, is to follow your nose, to get lost, not to plan, to avoid the dominance of 'efficiency' (contrarily, the outcome of this wandering (designing) activity often transcends what we could have imagined without wandering, in a manner that leads to improvements in 'efficiency' while also promoting qualities such as delight)."

438 Do original em Inglês: "[...] The job of the rambler is to keep moving, keep the eyes (and the mind) open, be aware and receptive."
} 
oferece um modelo para outras disciplinas profissionais, principalmente por deter um sentido transgressor, em relação à concepção tradicional de que o profissionalismo requer uma clara justificativa para o destino de cada curso de ação, ou seja, que suas práticas devam ter uma razão ou propósito bem estipulados para sua existência, e que cada procedimento profissional deva ser governado por regras ou princípios que garantem os resultados projetados (SNODGRASS e COYNE, 2006, p.248). Segundo os autores, o projetar permite uma abertura para a exploração de possibilidades potenciais que se apresentam apenas no próprio processo de vaguear, e neste contexto, a instituição de 'princ ípios' pode constituir-se a antítese do movimento necessário à continuidade do percurso, se os mesmos forem entendidos como regras que solidificam-se como verdades absolutas, invariáveis a seu tempo e contexto: diante desta colocação Snodgrass e Coyne (2006) concluíram que os designers não deveriam ser de fato 'pessoas de princípios', ou seja, comprometidos com valores fixos ou resignações inquestionáveis, mas sim com a abertura e atenção aos sentidos e compreensões emergentes na experiência de seus próprios percursos (SNODGRASS; COYNE, 2006, p.149-250). Glanville (2007b) chegou a uma reflexão similar a esta de Snodgrass e Coyne (2006) ao apontar qualidades que julga adequadas aos designers segundo o paralelo entre design e conversação:

Projetar significa para poder ver não as possibilidades que já temos em mente, mas que parecem dadas a nós pelo outro: para fazer isso, precisamos de uma mente aberta (pois a mente fechada nos cega para (o valor de) 0 que o outro diz) e generosidade (de coração) para recebê-lo, pelo menos como algo que vale a pena ouvir, e potencialmente, de mais valor para nós do que o que tínhamos pensado [...] nós admiramos pessoas que são generosas, possuem a mente aberta e aceitam responsabilidade. Portanto, no mundo de hoje próximo do desastre ecológico, são estas qualidades ao invés daquelas egoístas e autocentradas na competição que irão nos salvar, se nos salvarmos. Design nesta conta, é um modo de agir que reflete e requisita estas qualidades admiráveis, em contraste $œ m$ aquela espécie de resolução de problemas que tenta transformar o mundo emuma máquina ainda mais eficiente. ${ }^{439}$ (GLANVILLE, 2007b, p.1198 ,tradução nossa)

\footnotetext{
439 Do original em inglês: "To design means to be able to see the possibilities not that we already have in mind, but that appear given to us by the other: to do this, we need a open mind (for a closed mind blind us to (the value of) what the other says); and generosity (of heart) to welcome it as at least worth listening to, and potentially of more value to us than we had thought of. [...] we do admire people who are generous, open-minded and accept responsability. Indeed, in today's world of approaching ecological disaster it is these qualities rather than those of selfish and self-centered competition that will save us, if we are to save ourselves. Design, in this account, is an way of acting that reflects and requires these more admired qualities; in contrast to that sort of problem solving which attempts to turn the world into an ever more efficient machine."
} 
Evidencia-se, portanto, o valor assumido no processo projetual como um espaço de abertura para a expansão de horizontes ${ }^{440}$ pela troca e compartilhamento, pela possibilidade de vaguear livremente (sem impedimentos impostos por objetivos claros e fixos, princípios ou resignações incapacitantes) por entre opiniões, especulações e questionamentos, de se jogar o jogo da interpretação e compreensão sem o zelo ou compromisso com a certeza ou precisão técnica instrumental habitual das profissões, de ef eito muitas vezes incapacitante e enrijecedor (SNOD GRASS; COYNE, 2006, p.248-250). Nesta concepção está implícito um forte senso de aprendizagem, uma vez que ao se conduzir uma jornada errante, ir até o desconhecido para então regressar a seu ponto de partida, o viajante descreve neste seu percurso um traçado regrado pela forma não linear da experiência:

Na sua mais fecunda interpretação, exaursão e retorno não é sair em linha reta e em seguida refazer os passos, voltando sobre o que é agora um terreno familiar para onde se começou, mas é um movimento em círculo. Nesta compreensão, cada passo do caminho, de volta para o lar onde se começou, é um movimento para dentro e através do estranho e contrário. Tendo retornado, enriquedido, o viajante intrépido começa novamente, traçando um círculo mais amplo, mais abrangente, assim inscrevendo círculos dentro de círculos, como na metáfora do círculo hermenêutico.441 (SNOD GRASS; C OYNE, 2006, p.245, tradução nossa)

É de acordo com estas colocações sobre circularidade que reconhecemos a forma de nosso próprio aprendizado, como um processo não-linear de reacomodação de compreensões (re)estabelecidas e (re)posicionadas por todo o tempo em que nos dedicamos à jornada. À luz desta reflexão, tornamo-nos conscientes de que os produtos obtidos neste processo projetual (este texto, a dissertação como um todo, as discussões e interlocuções propiciadas) apresentam-se também como uma apreensão momentânea deste conjunto de compreensões, que se renova à medida que avançamos neste nosso vaguear por novos horizontes. Demarca-se em nossa paisagem de pesquisa um forte sentido de enriquecimento pela transformação:

\footnotetext{
440 Novamente de acordo com o sentido descrito por Gadamer (1975/1997, p.XX)

441 Do original em inglês: "In its most fecund interpretation, excursion and return is not going out in a straight line and then retracing one's steps, coming back over what is now familiar ground to where one started, but is movement in a circle. In this kenning, every step of the way, right back to the home whence one started, is a movement into and through the strange and otherwise. Having returned, enriched, the intrepid traveler starts out again, tracing a wider, more encompassing circle, thus inscribing circles within circles, as in the metaphor of the her meneutical circle."
} 
Quando nós olhamos para o círculo cibemétio, um ponto chave toma-se claro: que o círculo é organizacional, é a forma. A experiência, a passagematravés deste círculo, é uma espiral. Isto significa, a passagemadquire história, e, ao menos para o observador ciente, existe um processo de aprendizado, de mudança. Em cada interação atuamos, coletando a história das interações em uma espiral cada vez mais enriquecida. Nós não experimentamos o mesmo lugar (duas vezes), mesmo que o lugar possa pareœr o mesmo ao menos em termos de sua localização, nós não somos (os mesmos). ${ }^{442}$ (GLANVILLE, 2007b, p.1184, tradução nossa)

Logo, se o design pode ser descrito em função de metas, objetivos, resolução e configuração de problemas, também o pode ser pelo contrário, como especulação, exploração, busca pela superação de expectativas e pelo encontro com o estranho ou o distinto, realizando-se assim plenamente como um processo dialético. Concluímos que neste sentido a compreensão do projetar pela metáfora e interação da conversação possui de fato a qualidade de abrigar tanto a concepção de um processo dirigido por objetivos quanto como um vaguear sem destino fixo, como momentos complementares e integrados. Reconhecemos como o fazer arquitetônico pelo projetar incorpora todas as qualidades e atributos deste horizonte, e que a sensibilidade de seus profissionais aos diversos questionamentos decorrentes da natureza dialógica do projeto é um elemento central apontado por diversos autores como salutar à prática profissional em geral. Outro aspecto importante neste contexto refere-se ao estúdio de projeto, à medida que a tematização da conversação mostra-se imbuída de um forte sentido de aprendizagem e desenvolvimento (co)evolutivo. A este respeito, acreditamos na possibilidade de revisão de práticas de ensino que incorporem elementos deste horizonte da conversação, principalmente na atenção à dinâmicas capazes de desvelar questionamentos de 'Segunda Ordem', contribuindo para o desenvolvimento de uma cultura de projeto arquitetônico mais abrangente e assim mais aberta efetivamente para trocas e diálogos com outros campos do conhecimento para além da apropriação de técnicas, métodos ou práticas instrumentais entre os mes mos.

\footnotetext{
442 Do original em inglês: "When we look at the cybernetic circle, one key point becomes clear: that the circle is organizational, it is the form The experience, the passage around this circle, is a spiral. That is, the passage acquires history, and, at least for the cognizant observer, there is a process of learning, of change. On each iteraction we act, collecting the history of the iterations in an ever enrichening spiral. We do not experience the same spot (twice), for although the spot may appear the same at least in terms of loc ation, we are not."
} 

Considerações Finais 



\title{
CONSIDERAÇÕES FINAIS
}

\begin{abstract}
Analisando todas as possibilidades que pudessem explicar meus fracassos, cheguei à conclusão de que eles não se deviam à causa apontada pelo mestre, ou seja, à minha incapacidade de liberar-me de toda intenção e do meu próprio eu, mas porque os dedos da mão direita prendiam o polegar comfirmeza excessiva. Quanto mais eu esperava o disparo, tanto mais eu os apertava sem querer, espasmodicamente. Eis aqui o ponto onde devo concentrar meus esforços, pensei. Eu havia encontrado uma solução simples e plausível para o problema. [...] Porém, eu não atentava para o reverso da medalha: para obter êxito, eu dirigia toda a minha atenção para a mão direita. Consolava-me a perspectiva de que essa solução técnica chegaria a ser, pouco a pouø, tão familiar que dispensaria toda atenção. [...] Então, sem dizer uma única palavra, o mestre se aproximou, tomou o arco das minhas mãos e, dando-me as costas, sentou-se numa almofada. Compreendi o que isso significava e retireime.
\end{abstract}

Eugen Herrigel. A arte cavalheresca do arqueiro zen (1948)

\section{Conversação sobre o processo projetual arquite tônico}

Quando se está sentado em frente a uma prancheta convencional ou eletrônica de desenho manipulando traços e idéias, todo um universo de preocupações e concernimentos vem à tona ininterruptamente no movimento dinâmico da consciência, questionamentos que se posicionam espontaneamente, de difícil controle, e que acabam por nos convencer algumas vezes, de que somos realmente em nossa essência entidades orientadas à formulação e resolução de problemas. Sentimos naturalmente a emergência de posicionamentos, de aflições ou angústias, de que 'algo está errado' mes mo sem que saibamos definir o quê, e esta mera sensação de incômodo pode ser sucifiente para 'disparar' nossas ações transformadoras. Esta indefinição causal pode ser entendida como 'intuição'? Quando Alexander (1964, p.8-9) reflete sobre a impossibilidade de se continuar a aceitar 'métodos intuitívos' sobre a atividade projetual a própria colocação do autor parece manifestar um 
paradoxo: como é possivel um método intuitivo? Aceitando-se o método como a prescrição de procedimentos informativos (que informam -'dão forma') para a obtenção de deter minado fim, ou seja, 'carregados' de intencionalidade e forma, parece-nos contraditório supor que o fim a que se dirige esta intencionalidade e forma possa ser justamente a espontaneidade e a ausência de forma. Em outras palavras: é possível uma 'intuição de propósito'? À luz de nossas investigações de pesquisa, podemos entender o trabalho de Schön (1983) sobre os mecanis mos da reflexão-em-ação, e a produção de conhecimento pelo contato direto com os materiais da situação de projeto como estudos para um método intuitívo? Ao antecipar esta ordem de questionamentos, Adrian Snodgrass e Richard Coyne (1997/2006 p.45) explicitaram de antemão a inadequação da proposta de uma 'metodologia hermenêutica', pela afirmação de que o funcionamento do circulo hermenêutico está vinculado em um sentido ontológico ao nosso modo de 'Ser', e portanto não é algo que se escolha utilizar, como uma alternativa, algo que se possa rejeitar ou aceitar, 'de propósito'. Diante desta reflexão e dos questionamentos propostos, permanecemos inclinados a aceitar a impossibilidade de vir a conhecer (ou informar) os processos 'intuitívos' que nos orientam à transformação como resposta à percepção de problemas, bem como em evitar a busca por elucidações sejam elas nos domínios filosóficos, políticos, científicos, religiosos, etc. Por outro lado, seguimos acreditando que 'à algo lá', e neste sentido vemos alguma beleza na definição de Christopher Jones (1966) do projetar como "o desempenho de uma ato muito complicado de fé."

Em concordância com estas colocações, refutamos a idéia de que nossos esforços de pesquisa possam ou devam oferecer suporte teórico para uma instrumentalização imediata dos diversos conceitos abordados, especialmente no sentido do estabelecimento de uma possível 'metodologia da conversação', mes mo assumindo uma correspondência ao sentido original defendido por Rittel (1972a) de uma segunda geração de métodos: em nosso entendimento último, a elaboração metodológica implica a consolidação formal um produto (conjunto definido de procedimentos) que atende a um determinado conjunto de premissas deônticas, expectativas, e intencionalidade que não podem ser meramente 'transplantadas' neste mes mo produto ou instrumental metodológico, a medida que dependem dos sentidos ontológicos e epistemológicos construídos pelos arquitetos ou designers em geral em suas experiências próprias de projeto, em conversações. Novamente, retornamos a supracitada 
premissa de Adrian Snodgrass e Richard Coyne (1997R2006 p.45) pela compreensão da natureza elementar da conversação como um processo comunicativo inerente a condição humana, e de acordo também com as concepções próprias da Cibernética de Segunda Ordem de von Foerster, Maturana, Pask, Glanville e outros.

Á contraparte deste raciocínio consideramos que um relevante mérito do horizonte de pesquisa abordado está em justamente em proporcionar uma perspectiva coerente ${ }^{443}$ à observação dos processos de projeto em arquitetura e urbanismo, capaz de originar futuras investigações sobre o tema, conferindo-Ihe direcionamentos e uma generosa abertura interpretativa (no sentido dialético expresso por Gadamer (1975/1997, p.540)). É sob esta concepção que reconhecemos a obtenção do objetivo específico de delimitação de tópicos preliminares de uma 'agenda da conversação' para a pesquisa, prática e ensino de projeto em arquitetura a partir dos assuntos relacionados nos items 3.2.1, 3.2.2, 3.2.3, 3.2.4 e 3.2.5 do Capítulo 3. Apresentamos abaixo na Tabela 09 uma correlação entre alguns conceitos contemplados no corpo da dissertação e estes tópicos:

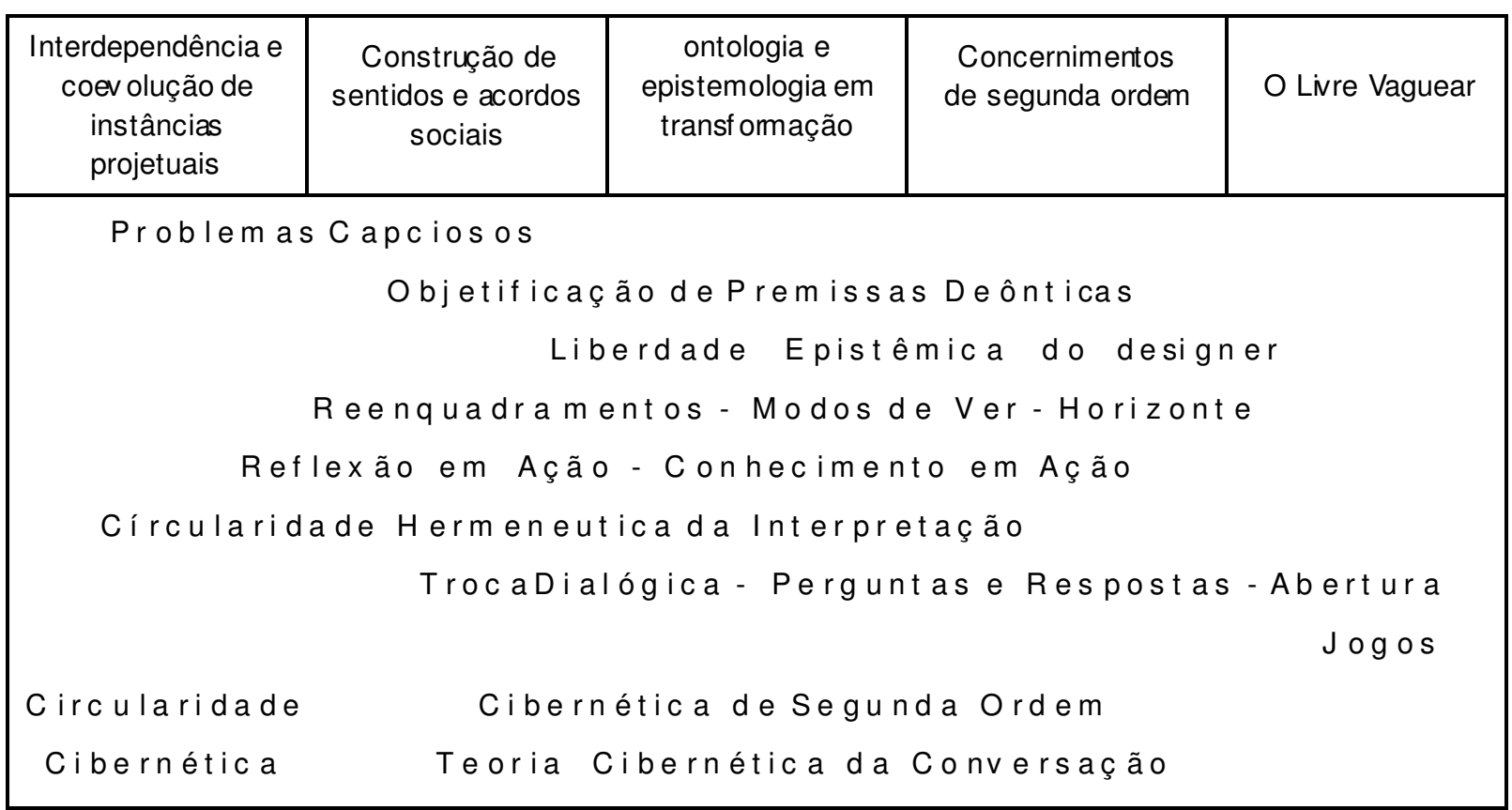

Tabela 09 - Correlação entre conceitos e tópicos de uma possivel 'agenda da conversação' para a pesquisa, prática e ensino de projeto em arquitetura. 0 posicionamento horizontal das palavras indica seu pertencimento aos tópicos delimitados nos campos verticais.

443 De acordo com as correspondências entr e concepções e abordagens das refer ências teóricas que compõem o recorte bibliográfico deste trabalho, conforme evidenciado na segunda parte do Capítulo 3 deste trabalho. 
A seguir retomamos o tema do enunciado inicial desta conversação, voltando nossa atenção sobre uma outra ordem de reflexões que colocam-se quando se está fora do domínio das conversações ocorridas na prancheta de desenho. Neste contexto testemunhamos que o controle sobre a linha, códigos de construção, sensos estéticos e cadeias de justificativas para decisões e opções realizadas sobre os mais diversos assuntos que compõem um projeto arquitetônico, são postos a prova (as vezes à deriva) quando chegam ao plano da comunicação e confirmação exterior 'pelo(s) outro(s)'. Mal entendimentos, ambiguidades, contradições, jogos de interesses e toda a sorte de imprevistos colocam-se no caminho da ef etivação das ações minuciosamente previstas e da forma desenhada, a gênese de todas as familiares lamúrias do contexto profissional arquitetônico hodierno: - "O cliente destruiu meu projeto!” - “O construtor fez o que ele quiz! Nem leu o projeto!", -"Mas a idéia era tão boa..." - "Entenderam tudo errado! Agora tenho de fazer tudo de novo..." e assim por diante. Em seu discurso 'A Solidão das Edificações ${ }^{\not 44}$, o arquiteto Rafael Moneo (1985) destaca a importância da reflexão sobre a 'tirania do desenho', a tendência contemporânea de compreender-se a arquitetura como uma simples materialização ou (re)produção (tri)dimensional das decisões ou do resultado das complexas investigações projetuais conduzidas em processos elaborados de derivação formal. Moneo (1985) põe-nos a pensar sobre a maneira como nos envolvemos na atividade de projeto, pelo qual vinculamos nossa visão e pré-concepção particular frente a produção de algo essencialmente compartilhado, social. Neste sentido, pensar o projetar através da dimensão da conversação nos parece mais uma necessidade primordial que a delimitação de um horizonte temático de pesquisa.

Sabemos que em nossa cultura profissional, o arquiteto ao projetar é convidado a atender uma certa demanda, a estabelecer seu olhar sobre uma situação problemática e "resolvêla". Porém, como Rittel (1972a, 1987) ressaltou a consolidação dos planos ou projetos necessariamente afetam a vida de muitas outras pessoas além de seus agentes, inserindose em um contexto social muito mais amplo que podem-se prever os esforços projetuais, e portanto as decisões (in)formadas de projeto implicam (e ao mes mo tempo 'dependem de')

\footnotetext{
444 "A Solidão das Edificações", ou no original do italiano "La Solitudine Degli Edifici",é uma leitura conduzida pelo arquiteto espanhol José Rafael Moneo Vallés (1937-) em virtude de sua nomeação como chefe do Departamento de Arquitetura da Escola de Design da Uni versidade de Har vard, nos Estados Unidos.
} 
necessariamente uma 'sobre-vida' para além do controle e da fixação imposta pela intencionalidade de seus arquitetos ou designers. Independente da autoria projetual pelo celebrado e reconhecido arquiteto popstar 'fulano', pelo mediano projetista 'siclano' ou a equipe de projeto anônima da prefeitura do município, esta sobrevida parece constituir-se um importante elemento na deter minação do 'sucesso' de um projeto arquitetônico: Moneo (1985) refere-se a esta situação como a 'solidão das edificações', a independência ou autonomia das relações estabelecidas entre usuários, contextos, e a obra arquitetônica em relação às prescrições projetuais originais e motivações por parte de seus autores. Em nossa avaliação esta é uma dimensão da dialógica do projetar que mereceria a concentração de novos esforços de pesquisa, no sentido de somar a uma compreensão projetual mais ampla em arquitetura e urbanis mo o território das reformas, dos 'puxadinhos', das readequações e reapropriações indevidas, a infinidade de intrepretações e ressemantizações possíveis à partir da obra arquitetônica em si e pela qual a presença de um criador original é dissipada. Ver este território como 'o lugar da conversação' parece-nos de acordo com as observações de Pask (1980, p.1006) de que a distinção entre indiv íduos autônomos suporta a própria dinâmica da conversação e vice-versa, de modo que parece coerente a atribuir à materialização de projetos arquitetônicos em espaços construídos uma certa 'capacidade de conversação', como a capacidade de serem apropriados ${ }^{445}$ socialmente na construção de sentidos, coerências, propósitos e objetivos para além dos impostos pelos desígnios preliminares de arquitetos/designers.

Em nossos estudos chegamos à conclusão elementar de que o projetar pode ser compreendido como um processo de transformação tanto da situação projetual quanto do arquiteto/designer, pela interferência mútua entre um e outro. Isto é tão verdade quando se perde noites de sono dedicando-se à concepção de um parque urbano ou uma escola como quando se começa a enxergar as próprias estruturas de pré-conceitos e pré-juízos, diante da contemplação de uma solução projetual inusitada ou da 'apropriação' de que nos referimos agora pouco, por parte dos habitantes de nossos projetos, por exemplo, que insistem em 'agredir' o paisagismo com a vivacidade de suas 'cadeirinhas e mesinhas.' Chegamos mesmo a nos emocionar as vezes com estas 'surpresas' nos termos de Schön

\footnotetext{
445 De acor do com di versos sentidos possíveis para a palava
} 
(1983, p.155), estejam na engenhosidade do encaixe de uma persiana ou na ocupação festiva do novo centro cultural desenhado. Neste sentido destacamos a capacidade do arquiteto/designer em reconhecer em algo mais do que se esperava, pela forma da conversação (SCHÖN, 1988/1992a p.144). Esta forma, no entanto, depende da disposição em sermos bons 'ouvintes' (GLANVILLE, 2007b, p.1198), e de se permitir 'entrar no contrário' (SNODGRASS; COYNE, 2006, p.245). Em termos da dialógica hermenêutica, Gadamer (1975/1997 p.535) enfatizou a qualidade do questionamento pela pergunta em manter a suspensão da resposta, garantindo assim uma abertura para a chance, a causalidade e a troca, o que está para além de nós. Quando nos questionamos abrimo-nos para a possibilidade de 'ver através de outros olhos,' podemos também abrir mão momentaneamente da 'armadura' que suporta nossos valores e crenças e reconstruir a ontologia de nossa própria realidade (SCHÖN 1988/1992ª p.9-11; JONES 1980/1992 p.xxix). Novamente cabe observar que esta reconstrução não é linear mas recíproca, pois necessariamente com ela causamos 'perturbações' na vida do(s) outro(s), na realidade(s) do outro(s), e vice-versa. Ou nos defrontamos com as propriedades das situações de projeto, e através desta reconstrução podemos conhecê-las de outro modo. De fato toda situação de projeto pode ser considerada um 'problema capicioso' a partir desta concepção: suas formulações não são fixas, assim como suas respostas, e eles levam a novos problemas. Deste modo, reconhecemos que o 'permitir-se' à transformação pela abertura ao questionamento e a 'surpresa' e portanto, estar aberto ao diálogo ou conversação é uma postura essencial à prática projetual e portanto deveria ser transportada como um valor explícito no bojo do estúdio de projeto. Em uma passagem sobre a caracterização dos organismos cibernéticos, Scott $(2004$, p.1367) af irma que todos os organismos dotados de vida (no sentido autopoiético) adaptam-se ou evoluem para se 'informarem' das restrições de seus mundos ou perecem. Como observamos anterior mente, para a cibernética os organis mos são sistemas fechados auto-reguladores que respondem a perturbações: talvez este ímpeto transformador do projetar simplesmente corresponda a nossa necessidade inata de adaptar-se ou (co) evoluir junto dos sistemas ambientais e dos outros organismos que nos rodeiam (com os quais literalmente estamos 'dando voltas').

A conversação proporciona ao mesmo tempo a detecção de diferenças e a possibilidade de chegar ao acordo (GADAMER, 1975/1997, p.561), mesmo que um acordo sobre a incapacidade de concordar (PASK, 1987, p.19). A relevância do acordo é sublinhada por Rittel (1987, p.193-194) em 
seu reconhecimento da dimensão política e compartilhada do projetar, à medida que através do acordo é possível que haja de fato compromissos entre as partes, para a coordenação das ações necessárias à condução dos seus planos e projetos. Como afirmou Pangaro (2007, p.177), através da conversação é possível que seus participantes sedam parte de suas individualidades e resignações em favor da obtenção de um fim comum, e portanto esta interação está na essência de toda atividade participativa e colaborativa. A conversação, portanto está relacionada tanto ao estabelecimento do comum pela concordância entre as partes quanto do conflito pela discordância. A mbos os movimentos possuem capacidade grande capacidade transformadora, e estão presentes do projetar, em nossa leitura, através das atividades de configuração e também de resolução de problemas. O modelo do processo projetual pela estrutura da reflexão-em-ação de Schön (1983, p.141) parece-nos explicitar melhor esta dualidade que os modelos baseados na alternância sequencial das etapas de análise, síntese e avaliação. Mesmo aqui guarda-se uma semelhança entre estruturas, se tomarmos a análise e avaliação como processos de apreciação e juízo de acordo com os 'modos de ver' de Schön pela estrutura 'ver-mover-ver' (síntese e movimento também encontrar uma correspondência neste sentido). Porém como vimos anteriormente, a resolução de problemas é apenas parte de um processo maior da transformação mútua entre situações de design e designers, em um sentido conversativo e circular, conforme 0 esquema proposto pela figura $\mathbf{3 1}$, cuja forma deriva de uma releitura dos modelos de 'volta dupla de aprendizado' de Argyris e Schön $(1987,1996)^{446}$ e de um sistema cibernético de segunda ordem ${ }^{447}$ :

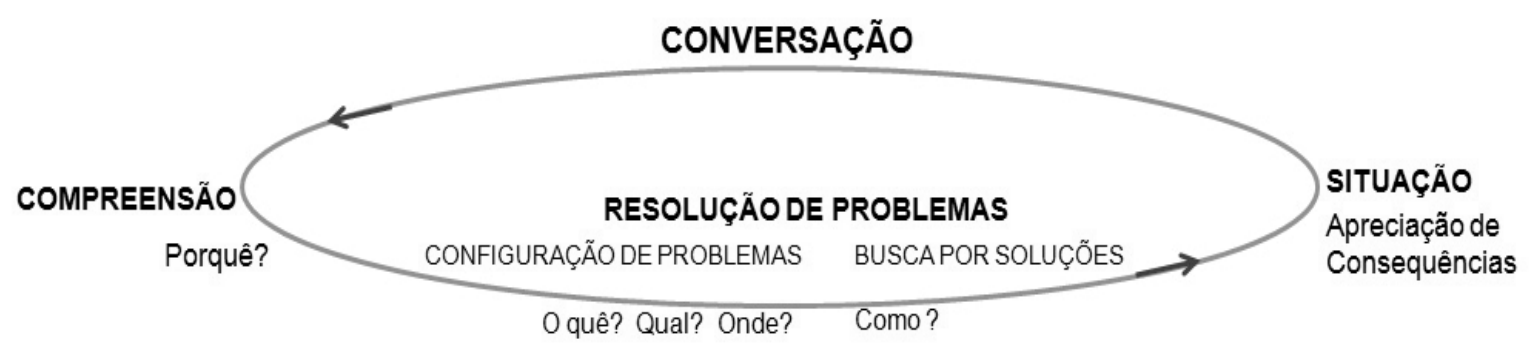

Figura 31 - Ciclo de transformações na conversação do projetar

${ }^{446}$ Ver Figura 28, p. 203
${ }^{447}$ Confor me Figura 27, p.202 
Aqui, compreendemos que não nos cabe contrapor vantagens e demér itos entre modelos ou concepções afim de compor índices de 'eficiência' ou 'eficácia' em seu emprego no projetar, pois como consideramos anteriormente vemos as instrumentalizações (in)formativas com alguma desconfiança. Em outras palavras, acreditamos não ser conveniente a proposição de um modelo 'integrado' da atividade projetual, à partir da síntese ou fusão dos conceitos que conformam as diversas concepções de que investigamos neste trabalho de pesquisa. Neste ponto, concordamos com a posição de Snodgrass e Coyne (1992, p.72) de que podemos buscar por metáforas e estruturas conceituais que permitam uma maior mobilidade frente as dimensões prescritiva e descritiva inerentes à modelagem, que implicam em enrijecimento e fixação. Devemos no entanto conservar a atenção quanto procedência e implicações também de nossos 'enquadramentos', cuidando da percepção das qualidades iluminadas pelo seu enfoque como das obscurecidas pela penumbra que eles também agregam em contrapartida. O compartilhamento destes enquadramentos e a ponderação sobre os mesmos apresenta-se assim um exercício importante para a atividade projetual, em correspondência com as prescrições de Rittel (1972b/2010 p.176) sobre a necessidade de se obter conhecimento 'deôntico' pela 'objetificação' das premissas dos arquitetos/designers. Assim, consideramos que uma abordagem do projetar segundo a metáfora da conversação ou diálogo implica minimamente na troca de conhecimento e compreensões sobre os modos pelos quais transformações podem ser realizadas e os objetivos e propósitos do design podem ser alcançados (o 'como') e sobre as resignações, motivações, valores e crenças subjacentes à configuração destes propósitos, objetivos e ações transformadoras (o (porquê'). Para além destes níveis de concernimentos estão os questionamentos de segunda ordem, ${ }^{448}$ pelos quais podemos revelar ${ }^{449}$ estruturas de pensamento e também modificá-las, eventualmente promovendo alguma aprendizagem pela conversação, como indicam as observações da cibernética (PASK, 1987; SCOTT 2004; GLANVILLE 2007b; PANGARO, 2007).

\footnotetext{
448 o 'porquê' do 'porquê' ou o 'como do 'porquê'.

449 No sentido de chegar a uma 'consci ência' (SCOTT 2001, p.347)
} 
Referências Bibliográficas 



\section{REFERÊNCIAS BIBLIOGRÁFCAS}

ALEXANDER, C. Notes on the synthesis of form. Cambridge, Massachusetts: Harvard University Press, 1964.

. The state of the art in design methodology. DMG Newsletter, n.5 (3), 1971, p.3-7.

. A pattern language. New York: Oxford University Press, 1977.

ARCHER, B. Syste matic Method for Designers. Design Journal, n.172-188, 1963.

ARGYRIS, C.; SCHÖN, D. Organizational Learning: A theory of action perspective. Massachusetts: Reading, Addison Wesley, 1978.

. Organizational Learning II: Theory, Method, and Practice. Massachusetts: Reading, Addison Wesley, 1996.

ASBHY, W. R. An introduction to cybernetics. London: Chapman and Hall, 1956.

ASIMOW, M. Introdução ao projeto de engenharia. São Paulo: Editora Mestre Jou, 1962

ATWOOD, M. E.; MCC AIN, K. W.; WILLIAMS, J.C. How does the design community think about design? In: Proceedings of designing interactive systems. New York: ACM, 2002, p.125-132.

BAYAZIT, N. Investigating design: a review of forty years of design research. Design Issues, Massachusetts, MIT Press, v.20, n.1, p.16-29, 2004.

BAZJANAC, V. Architectural design theory: models of the design proœss. In: SPILLERS, W. R. (ed.) Basic questions of design theory. New York: North Holland, 1974, p.8-16.

BOYD, G. Conversation Theory. In: JONASSEN, D.H. (ed.). Handbook of Research for Educational Communications and Technolog. Local: ed. Lawrenœ Erlbaum, 2004, cap.8, p.179-197.

BROAD BENT, G. Design in architecture: architecture and the human sciences. Letchwoth, Herts: Adlard \& Son Ltd, 1973/1988

. The state of the art in design methodology. DMG Newsletter, n.5 (8-9), 1971, p.2-3.

Design methods in architecture. Architects Journal, n.14, 1966

BUCCIARELLI, L. Designing Engineers . Cambridge, Massachusetts: The MIT Press, 1994

BUCHANAN, R. Rhetoric, Humanism, and Design. In: BUCHANAN, R.; MARGOLIN, V. (Eds.). Discovering design: Explorations in design studies. Chicago: The Univ. of Chicago Press, 1995.

. Wicked Problems in Design Thinking. In: BUCHANAN, R.; MARGOLIN, V. (Eds.). The Idea of Design: A Design Issues reader, MIT Press, Massachusetts, Cambridge, v.8, n.2, 1992, p. 5-21.

COYNE, R. Wicked problems revisited. Design Studies, v.26, n.1, 2005, p.5-17.

COYNE, R.; SNOD GRASS, A. problem setting with prevalent metaphors of design. Design Issues, Massachusetts, MIT Press, v.11, n.2, p.31-61, 1995.

CROSS, N. A history of design methodology. In: DE VRIES, M. J.; CROSS, N.; GRANT, D. P. (eds.) Design methodology and rebationships with science. Netherlands: Kluwer Academic Publishers, 1992, p15-27. 
CROSS, N . Designerly ways of knowing: design discipline versus design scienœ. Design Issues, Massachusetts, MIT Press, v.17, n.3, p. 49-55, 2001.

CUFF, D. Architecture: the story of practice. London, England, Cambridge, Massachusetts: MIT Press, 1993.

DESCARTES, R. Discurso do método. Tradução Guinsburg, J.; Prado Júnior, B. São Paulo: Nova Cultural, 1637/1987

DEWEY, J. Logic, the theory of inquiry. New York: Holt, Rinehart and Winston, 1938

DORST, C., CROSS, N., - Creativity in the Design Proœss: Co-evolution of Problem-solution. Design Studies, Massachusetts, MIT Press, v.22, n.5, p.425-437, 2001

DORST, C . Design Problems and Design Paradoxes. Design Issues, Massachusetts, MIT Press, v.22 n.3, p.04-17, 2006

DORST, K.; DIJKHUIS, J. Co mparing paradigms for describing design activity. In: CROSS, N., CHRISTIANS, H., DORST, (eds.) Analyzing design activity. Chichester, UK: Wiley, p.253-270, 1996.

DOWNTON, P. Design research - Melbourne, Australia: RMIT University Press, 2003.

DUBBERLY, H. How do you design. A compendium of models. Disponivel em: <http://www.dubberly.com/articles/howdo-you-design.html> acesso em: 12/08/2011

On Moldeling - Design in the age of biology: Shifting from a mechanical-object ethos to an organic-system ethos. Interactions Magazine, v.15, n.5, Association for Computer Machinery, New York, EUA, 2008. Disponível em: $<$ http://www.dubberly.com/articles/design-in-the-age-of-biology.html> acesso em: 12/08/2011

DUBBERLY, H.; PANGARO, P. Cybernetics and service-craft: language for behavior-focused design. Kybernetes, v.36, n.9/10, 2007, p.1301-1317. <http://www.dubberly.com/articles/cybemetics-and-serviœ-craft.html> acesso em: 12/08/2011

DUBBERLY, H.; HAQUE, U.; PANGARO, P. What is interaction? Are there different types? Inter actions Magazine, v.XVI.1, Janeiro/Fevereiro, Association for Computer Machinery, New York, EUA, 2009. Disponível em: $<$ http://www.dubberly.com/articles/what-is-interaction html>.

EAST MAN, C. On the analysis of intuitive design processes. In: MOORE, G. (ed.) Emerging methods in envir onmental design and planning. Cambridge, Massachusetts, EUA: MIT Press, 1970, p.21-32.

EBENREUTER, N. The dynamics of design. Kybernetes, Reino Unido, Emerald Group Publishing Limited, v.36, n.9/10, p.1318-1328, 2007. Disponível em: <http://www.emeraldinsight.com> Acesso em 12/08/2011.

FEYERABEND, P. Against Method: An Outline of an Anarchistic Theory of Knowledge. London: Verso, 1975.

FORESTER, J. Designing: Making sense together in practical conversations. Jour nal of Architectural Education , V.38 n.3, p.14-19, 1985

GADAMER, H. G. Verdade e método. Traços fundamentais de uma hermenêutica filosófica. Tradução Flávio Paulo Meurer. Petrópolis, RJ: Ed. Vozes, 1975/1997. $\overline{1976 / 2002}$

Verdade e método II. Complementos e índice. Tradução Ênio Paulo Giachini. Petrópolis, RJ: Ed. Vozes,

GLANVILLE, R. Second order cybernetics. In: Systems Science and Cybernetics, Encyclopedia of Life Support Systems, developed under the auspices of the UNESCO. Oxford,UK: Eolss Publishers, 2004. Disponivelem: <http://www.eolss.net/Sample-Chapters/C02/E6-46-03-03.pdf> Acesso em 12/08/2011.

. Introduction: spedal double issue of kybemetes on cybernetics and design. 2007a. Guest editorial-Kybernetes, Emerald Group Publishing Limited, v.36, n.9/10, p.1153-1157, 2007.

.Try again. Fail again. Fail better: the cybernetics in design and the design in cybemetics. 2007b. Kybernetes, Emerald Group Publishing Limited, v.36, n. 9/10, p.1173-1206, 2007. Disponivel em: <http://www.emeraldinsight.com> Acesso em 12/08/2011. 
GLANVILLE, R. A (Cybernetic Musing): design and cybemetics. In: The Black Boox, Wien: Echoraum, 2009, p.423-435.

HABRAKEN, N. J.; GROSS, M. Concept Design Games Book One: Developing. Report submitted to the National Science Foundation, MIT Cambridge, 1987.

HEIDEGGER, M. O ser e o tempo. Petrópolis, RJ: Ed. Vozes, 1927/1989.

HERRIGEL. E. Aarte cavalheiresca do. arqueiro zen. Prefácio do Prof. D. T. Suzuki. Tradução, prefácio e notas de Ismael, J. C. São Paulo, editora pensamento, 1975.

HEYLIGHEN, F.; JOSLYN,F. Cybernetics and second-order cybernetics. In: MEYERS, R. A. (ed.) Encyclopedia of Physical Science \& Technology (3rd ed.). New York: Academic Press, 2001.

JONES, J.C.; THORNLEY, D. G. Conference on design methods. Oxford University Press, 1963.

JONES, J.C. Design Methods Reviewed. In: GREGORY, S. (ed) The Design Method. London, butterworths, 1966.

Design methods: seeds of human futures. London, New York: John Wiley \& Sons, 1970/1992.

. How my thoughts about design methods have changed during the years." Design Methods and Theories. Vol.11, n.1 pp. $50-62,1977$.

The state of the art in design methodology. DMG Newsletter, n.5 (10), 1971, p.2.

KRIPPENDORFF, K. On the Essential Contexts of Artifacts or on the Proposition That "Design Is Making Sense (Of Things). Design Studies, Massachusetts, MIT Press, v5, n.2, 1989

The semantic turn: A new foundation for design, Boca Raton, FL: CRC Press, 2006.

KUHN, T. The Structure of Scientific Revolutions. Chicago: University of Chicago Press, 1962.

LAWSON, B. What designers know. Oxford: Architectural Press, 2004.

MAGRO, C., GRACIANO, M., VAZ, N. (org.) A Ontologia da Realidade; Humberto Maturana . trad Cristina Magro, Belo Horizonte: UFMG, 1997/2001

MAHER M., L., POON J., BOULANGER S. Formalizing Design Exploration as Co-evolution. A Combined Gene Approach. In: GERO,J., S., SUBWEEKS, F. (eds) Advances in Formal Design Methods for CAD. London: Chapman and Hall, 1996

MATURANA, H. What is to see? In: MAGRO, C., GRACIANO, M., VAZ, N. (org.) A Ontologia da Realidade; Humberto Maturana . trad Cristina Magro, Belo Honizonte: UFMG, 198/2001

Ontolodia del œnversar In: MAGRO, C., GRACIANO, M., VAZ, N. (org.) A Ontologia da Realidade; Humberto Maturana . trad Cristina Magro, Belo Horizonte: UFMG, 1988/2001

Biology of self-consciousness In: MAGRO, C., GRACIANO, M., VAZ, N. (org.) A Ontologia da Realidade; Humberto Maturana . trad Cristina Magro, Belo Horizonte: UFMG, 1990/2001

MATURANA, M.; VARELA, F. Autopoiesis and $\infty g n i t i o n:$ The realization of the living. Boston:Reidel, 1980.

The tree of knowledge: The biological roots of human understanding. Boston, Massachusetts, USA: Shambala Publications, 1987.

MEAD, M. Cybernetics of Cybernetics. In: VON FOERSTER et al. (eds.). Purposive Systems. Spartan Books, 1968

MILNE, M. Whatever became of design methodology? In: NEGROPONTE, N. (ed.) Reflections on computer aids to design and architecture. New York: Petrocelli Charter, 1975.

MITCHELL, W. J. A lógica da arquitetura. Projeto, computação e cognição. Campinas: Ed. Unicamp, 2008. 
MONEO R. The solitude of buildings, lecture, trad. K.Tange . Harvard University Press, 1985

MUNARI, Bruno. Das coisas nascem coisas. Tradução José Manuel de Vasconœlos. São Paulo: Martins Fontes Editora Ltda, 1981.

NEGROPONTE, N. (ed.) Reflections on computer aids to design and architecture. New York: Petrocelli Charter, 1975.

NEWELL, A.; SHAW, C.; SIMON, H. Elements of a theory of problem solving. Psychological Review, v.65(3), p.151-166, 1957.

PANGARO, P. Cybernetics and Conversation. Communication and anti-communication. American Society for Cybemetics, 1996.

. The Architecture of Conver sation Theory. Interpretation of Pask's Conversation Theory framework. In: NEGROPONTE, N. (ed.) Soft Architecture Machines, Cambridge MA, MIT Press, 2002.

. The Past-Future of Cybernetics: Conversation, Von Foerster and the BCL. In: MÜLLER, A.; MÜLLER, K. H. An unfinished Revolution? Wien: Echoraum, 2007, p.144-187.

. Instructions for Design and Designs for Conversation. In: LUPPICINI, Rocci (ed.) Handbook of Conver sation Design for Instructionals Applications, University of Ottawa, Canada, p.35-48, 2008.

PASK, G. The architectural relevance of cybernetics. Architectural Design, v.7, n. 6, p. 494-6, 1969.

Conversation Cognition and Leaming, Elsevier., Amsterdam, 1975

Conversation Theory: Applications in Education and Epistemology. Elsevier, Amsterdam.1976

. Aspects of Machine Intelligence. In: NEGROPONTE, N. (ed.) Soft Architecture Machines, Cambridge MA, MIT Press, 1975b, p.6-31.

. The Limits of Togethemess. In: LAVINGTON, S. (ed.) Proceedings, Invited Keynote address to IFIP, World Congress in Tokyo and Melbourne. Amsterdam, New York, Oxford: North Holland Pub. Co, 1980, p.999-1010.

Conver sation and Support. Inaugural Adress for the University of Amsterdam, Amsterdam, OCC., 1987.

PICKERING, A. The Cybernetic Brain: sketches of another future. University of Chicago Press, 2010.

POLANYI, M. Personal Knowledge.Chicago: University of Chicago Press, 1958

POPPER, K. R. A lógica da pesquisa científica. São Paulo: Cultrix, 1959/1972.

PROTZEN, J.; HARRIS, D. J. (ed.), The universe of design - Horst Rittel's theories of design and planning. London, New York: Ed. Routledge, 2010.

PROTZEN, J. P.; HARRIS, D.; CAVALLIN, H. Limited computation, unli mited design. In: GERO, J. S. (ed.) Artificial intelligence in design'00. Dordrecht, Netherlands: Kluwer Academic Publishers, 2000, p.43-52.

RITH, C.; DUBBERLY, H. Why Horst W. J. Rittel matters. Design Issues, Massachusetts, MIT Press, v.22, n.4, p.1-20, 2006.

RITTEL, H. Some principles for the design of an educational system for design. Journal of Architectural Education, Blackwell Publishing and Association of Collegiate Schools of Architecture Inc., v.25, n.1/2, p.16-27, 1967/1971. Disponível em: http://www.jstor.org/stable/1423929 Acesso em 15/12/2011.

On the planning crisis. Systems analysis of the first and second generations. 1972a. In: PROTZEN, J.; HARRIS, D. J. (ed.) The universe of design - Horst Rittel's theories of design and planning. London, New York: Ed. Routledge, 2010.

. Structure and usefulness of planning information systems. 1972b. In: PROTZEN, J.; HARRIS, D. J. (ed.) The universe of design - Horst Rittel's theories of design and planning. London, New York: Ed. Routledge, 2010. 
RITTEL, H. The reasoning of designers. International congress of planning and design theory, Boston, 1987. In: PROTZEN, J.; HARRIS, D. J. (ed.) The universe of design - Horst Rittel's theories of design and planning. London, New York: Ed. Routledge, 2010.

RITTEL, H.; WEBBER, M. Dilemmas in a general theory of planning. Policy Sciences, Elsevier Scientific Publishing Company Inc., v.4, n.2, p.155-169, 1973.

ROWE, P. Design thinking. Cambridge, Massachusetts: MIT Press, 1987.

SANYAL, B. Learning from Don Schön - A tribute. In: Donald Schön - A life of reflection remarks at special session in honor of the memory of Donald Schön. Conferenœ of the Association of Collegiate Schools of Planning, Fort Lauderdale, 1997. Joumal of planning literature, v.13, issue 1, 1998.

SCHMIDT, M. R. You know more than you can say: in memory of Donald Schön (1930-1997). Public Administration Review, v.60, n.3, p. 266-274, 2000.

SCHÖN, D. A. The reflective practitioner: how professionals think in action. New York: Basic Books, 1983.

. The architectural studio as an exemplar of education for reflection-in-action. Journal of Architectural Education, v.38, n.1, p. 2-9, 1984.

Designing as reflective conversation with the materials of a design situation. Knowledge-Based Systems, Butterworth-Heinemann Ltd, v.5, n.1, março, p.3-14, 1992.

SCHÖN, D.; WIGGINS, G. Kinds of seeing and their functions in designing. Design Studies, MIT, Ca mbridge, MA, USA, v.13, n.2, Abril, p.135-156, 1988/1992.

SCOTT, B. Gordon Pask's conversation theory: a domain independent constructivist model of human knowing. In: RIEGLER, A. Foundations of Science, special issue on "The Impact of Radical Constructivism on Science", v.6, n.4, 2001, p.343-360.

SCOTT, B. Second order cybernetics: an historical introduction. Kybernetes, Reino Unido, Bradford MCD University Press, v.33, n.9/10, p.1365-1378, 2004.

SIMON, H. A. The sciences of artificial. Third edition Cambridge, MA: MIT Press, 1969/1996.

SMITH, M. K. Chris Argyris: theories of action, double-loop learning and organizational learning. the encyclopedia of informal education, 2001. Disponível em: <www.infed.org/thinkers/argyrishtm> Acesso em: 12/08/2011.

SNODGRASS, A.; COYNE, R. Models, metaphors and the hermeneutics of designing. Design Issues, Massachusetts, MIT Press, v.9, n.1, p.56-74, 1992. $\overline{1997 / 2006}$

Is design hermeneutical? In: Inter pretation in architecture. Design as a way of thinking. London: Routledge,

. Inter pretation in architecture. Design as a way of thinking. London: Routledge, 2006.

SOKOLOWSKI, R. Introdução à fenomenologia: uma declaração inicial do que é a fenomenologia. Tradução Alfredo de O. Moraes. São Paulo: Ed. Loyola, 2000/2010.

VON FOERSTER, H. Cybernetics of cybernetics. In: Under standing under standings: essays on Cybernetics and Cognition. New York: ed. Springer-Verlag, 1979/2003, cap.13, p.283-286.

Notes on an epistemology for living things. In: Understanding understandings: essays on Cybernetics and Cognition. New York: ed. Springer-Verlag, 1974/2003, cap.10, p247-259.

WAKS, L. J. Donald Schön's philosophy of design and design education. Inter national Journal of Technology and Design Education, n.11, p.37-51, 2001.

WIENER, N. Cibernética: ou controle e comunicação no animal e na máquina. Tradução Gita K. Ghinzberg. São Paulo: Polígono, 1948/1970. 
WINOGRAD, T.; FLORES, F., - Understanding Computers and Cognition; a New Foundation for Design, Ablex, Norwood, NJ. 1990

WITTGENSTEIN, L. Investigações filosóficas. Coleção Os Pensadores. Tradução José C. Bruni. São Paulo: Ed. Nova Cultural, 1953/1989. 
ANEXOS 

AA Architectural Association School of Architecture

ASC American Society of Cybernetics - Sociedade Americana de Cibernética

APIS Argumentative Planning Information System - Sistema de Informações de Planejamento Argumentativo

BCL Biological Computer Laboratory - Laborab́rio de Compulação Biológica

DMG Design Methods Group - Grupo de Métodos em Design

EDRA Environmental Design Research Association - Associação de Pesquisa em Design Ambiental

HfG Hochschule für Gestaltung - Escola Superior da Forma

IBIS Issue Based Information System - Sistema de Informação Baseado em Assuntos

LP linguagem primitiva ou protolinguagem

MIT Massachusetts Institute of Technology - Instituto de Tecnologia de Massachusetts

PO Pesquisa Operacional - Operational Research - OR

RIBA Royal Institute of British Architects - Instituto Real de Arquitetos Britâniøs

UMPLIS Umweltplanungs-informationsystem - Sistema de Informações de Planejamento Ambiental

LISTA DE TABELAS

TABELA 01 - Definição do 'horizonte da conversação' para o desenvolvimento da pesquisa...

TABELA 02 - Propriedades dos problemas capciosos e domesticados contrastados - tradução nossa. Adaptado de Rittel (1972a /2010, p.155-158)...

TABELA 03 - Possibilidades de resultado de ex perimentação prática quanto o cum primento das ex pectativas do investigador e a desejabilidade das consequências - tradução nossa. Adaptado de Schön (1983, p.155-156)......

TABELA 04 - Horizonte da conversação - Recorte proposto

TABELA 05 - Princípios de organização da atividade do design em dife rentes ethoi segundo Dubberly e Pangaro - tradução nossa. Adaptação a partir do original de (DUBBERLY, 2008, p.3)

TABELA 06 - Comparativo entre ge rações de métodos em design - Adaptação de Hugh Dubberly (2008) de esquema original de Chanpory Rith - tradução nossa. Fonte: (DUBBERLY, 2008, p.10).

TABELA 07 - Comparativo entre concepções do projetar.

TABELA 08 - Comparativo entre ordens da cibemética - Adaptação de Hugh Dubberly (2008) de esquema original de Paul Pangaro - tradução nossa. Fonte: (DUBBERLY, 2008, p.10).

TABELA 09 - Correlação entre conceitos e tópicos de uma possível 'agenda da conversação' para a pesquisa, prática e ensino de projeto em arquitetura 
LISTA DE FGURAS

Figura 1 - 0 projetar como receita de arroz verde. Fonte: (MUNARI, 1981, p.66)......

Figura 2 - Dificuldade em fix ar-se objetivos esoluções no processo projetual. Adaptado de Dubberly (2005, p.66)......

Figura 3 - Diferentes personagens, diferentes visões sobre o mesmo acontecimento. Rashomon, filme de Akira Kurosawa, 1950. Imagens coletadas do próprio filme. Da ei Motion Picture Company. Todos os direitos reservados..

Figura 4 - Acima: Tabela para análise de compatibilidade ambiental entre diversos elementos de uma moradia. Abaixo: Tabela simples de interação mostrando conex ões entre ambientes, referindo-se à necessidade de circulação entre os mesmos. Fonte: (BROADBENT, 1973/1988, p.260-262)..

Figura 5 - Diagrama de escolhas variáveis para toma da de decisão do método de Busca Sistemática. A linha espessa indica uma das 2160 possibilidades de design a escdher. Fonte: (JONES, 1970, p.97)......

Figura 6 - Representação diagramática de estruturas de elementos em subgrupos (à esque rda) e decomposição representada em diagrama de Venn (à direita). Fonte: (ALEXANDE R, 1964, p. 82-83).

Figura 7 - Modelo do processo de design por Tom Maver

Figura 8 - Processo de design por Bryan Lawson.

Figura 9 -"modelo icônico" apresentado por Mesarovic similar ao modelo de Asimow. Fonte: (ROWE, 1987, p.48)..............

Figura 10 - Processo de design descrito no manual do RIBA. Fonte: (LAWSON, 2004, p.35)..

Figura 11 - Designer como um computador humano. Fonte: (JONES, 1970/1992, p.50)...

Figura 12 - Modelo simplificado dos estágios do processo de design por Archer. Fonte: (ROWE, 1987, p.14).......

Figura 13 - Estrutura de raciocínio de um designer sob re a consideração do assunto: "Devo incorporar ' $A$ ' como parte do plano?" Fonte: (RITTEL, 1987/2010, p.189).

Figura 14 - Diagrama da estrutura de reflexão em ação na investigação projetual como uma conversação reflexiva.

Figura 15 - Diagrama da estrutura 'ver-mover-ver' como uma conversação reflex iva...

Figura 16 - Diagrama ex pandido da estrutura da conversação reflex iva conduzida na investigação projetual...

Figura 17 - Croquis de estudo da aluna Pe tra mostrando seu desenvolvimento projetual para uma escola, com a confo rmação de salas em 'L' e sua relação com a topografia acidentada. Fonte: (SCHÖN, 1983, p.86-87)........

Figura 18 - Diagrama de um aquecedor controlado por mecanismo de 'feedback loop'. Fonte: (LOHBERG; LUTZ, 1965, $<$ http://www.lauftex t.de/cybemetic-computer/feed-backs.htm> Acesso em: 12/08/2011)...

Figura 19 - Estrutura da conversação: p roposta pa ra um sistema computacional em aux ílio a arquitetos.Fonte:(PASK,1975b,p.29)

Figura 20 - Diagrama básico de controle e feed back entre dois níveis de organização. Fonte: (PANGARO, 2002).........

Figura 21 - O 'esqueleto' da estrutura da conversação. Fonte: (PASK, 1975, p.29)...

Figura 22 - Dança estrutural de dois organismos em interação com sistemas nervosos fechados que se perturbam estruturalmente Fonte: (MATURANA, 1983/2001, p.92).

Figura 23 - Movimento de transformação das instâncias projetuais em conversação...

Figura 24 - Designer como um sistema de Segunda Ordem. Fonte: (JONES, 1970/1992, p.55)...

Figura 25 - Sistema aprendiz simples 'solitário'. Adaptado de (BOYD, 2004, p.182)...

Figura 26 - Sistema cibemético de primeira ordem. Fonte: (DUBBERLY, HAQUE, PANGARO, 2009, p.6)...................................... 202

Figura 27 - Sistema cibemético de segunda ordem. Fonte: (DUBBERLY, HAQUE, PANGARO, 2009, p.6).................................... 20.

Figura 28 - Modelo da 'volta dupla de aprendizado' segundo Argyris e Schön $(1987,1996)$. Adaptação a partir da descrição do modelo de Argyris e Schön, 1996, p.21.....

Figura 29 - Três Modelos de Conversação: 1. Conversação sobre objetivos e métodos; 2. Conversação para coope ração em objetivos; 3. Conversação para colaboração em objetivos comuns. Adaptação de (DUBBERLY; PANGARO, 2007, p.20) e (DUBBERLY, HAQUE, PANGARO, 2009, p. 11)..

Figura 30 - Acoplamento estrutural de dois organismos em um fluxo de interações que o observador por descrever como coordenações consensuais de coordenações consensuais de comportamento. Fonte: (MATURANA, 1990/2001, p.220)..................

Figura 31 - Ciclo de transformações na conversação do projetar.. 
BIOGRAFAS

\title{
ALEXANDER, Christopher (1936-)
}

Christopher Alexander é arquiteto e matemático austríaco, doutor em arquitetura pela Universidade de Harvard, pesquisador e professor emérito da Universidade da Califórnia, Berkeley, Estados Unidos. Dentre suas principais obras podemos citar: Notes on the Synthesis of Form, Cambridge, MA, Hanvard University Press, 1964; A Pattern Language, Oxford University Press, 1977; e os quatro volumes The Nature of Order, Center for Envionmental Structure, Berkeley, Califórnia, 2001, que correspondem à síntese amadurecida do pensamento de Alexander ao longo de sua carreira acadêmica e profissional.

ARCHER, Leonard Bruce (1922-2005)

Leonard Bruce Archer (1922-2005) foi um engenheiro mecânico inglês, influente pesquisadore teórico em design, professor, em Pesquisa de Design pelo Royal College of Art de Londres, Reino Unido e na Hochsüle für Gestalung de Ulm, Alemanha do Sul.

\section{ARGYRIS, Chris (1923-)}

Chris Argyris foi uma das principais figuras do movimento de relações humanas, na década de 1960 e 1970. Ele é considerado o fundador da organização de aprendizagem. Seu trabalho tem feito contribuições substanciais para a compreensão do comportamento organizacional, aprendizagem organizacional e pesquisa-ação e aprofundou significativamente a nossa compreensão da aprendizagem experiencial. Foi professor universitário na Harvard Business School. Antes, lecionou Ciências Administrativas na Yale University. Sua formação abrange conhecimentos de Psico logia, Economia e Comportamento Organizacional. Fontes: Routlegde. Disponível em: <http:/www.routledge.com> e Administradores sem fronteiras. Disponivel em: $<$ http $/ /$ www.admsf.adm.br> Acesso em 26/02/2012.

\begin{abstract}
ASHBY, William Ross (1903-1972)
William Ross Ashby foi um psiquiatra inglês, Doutor em Psiquiatria pela Universidade de Cambridge, diretor de pesquisa do hospital de Barnwood House em Gloucester de 1947 a 1959, e em 1960 tornou-se professor e pesquisador do Departamento de Biofísica e Engenharia Elétrica da Universidade de llinois em Urbana Champaign, Estados Unidos. É considerado um dos pioneiros da cibernética, entre suas principais obras sobre o tema podemos citar Design for a Brain, de 1950 e An Introduction to Cybernetics, de 1956. Ashby também é conhecido pelo desenvolvimento do Homeostato, em 1948.
\end{abstract}

ASIMOW, Morris (1906-1982)

Morris Asimow foi professor de Engenharia de Sistemas durante 30 anos na University of California. Filho de imigrantes da Rússia, nasceu e cresceu nos Estados Unidos. Graduou-se na Polytechnic High School em Los Angeles, estudou na UCLA, transferindo-se para o campus de Berkeley, onde obteve uma credencial de ensino além de atingir seu pH.d. na área de engenharia. Sempre inovador e inventor, ensinou na engenharia e design, desenvolveu pesquisas na área de gerenciamento e processos de produção, tendo publicado um dos textos mais antigos sobre 0 assunto do procedimento de design tradicional direcionado para áreas específicas. Professor Asimow foi um engenheiro que praticou no campo o que ele ensinou em sala de aula e que acredita-se que o maior objetivo da tecnologia era ajudar as pessoas a ajudarem a si próprios. Um homem da criatividade e da capacidade para o crescimento contínuo e de profundo interesse nos assuntos mundiais, ele tinha uma perspectiva global. Fonte: University of Califormia. Disponivel em:

$<$ http $/ /$ content.cdlib.org/view?docld=hb4d5nb20m\&doc.view=frames\&chunk.id=div0000 7 \&toc.depth=1 \&toc.id =.\% 2520Acesso\% 2520em:\% 252005\% 2520nov\% 25202009.> Acesso em 27/02/2012. 


\title{
BATESON, Gregory (1904-1980)
}

Greannry Ratesonn foi hiólnan antronólnon e cientista sncial hritânim estııdnı na I Iniversidade de Camhridne mas lnan dennis mudhul-se nara ns Fstadns IInidhs SeII livrn mais imnortante Naven (19.36) fni um imvador estıidn do simhnlismn cultural e ritıal haseadn mo trahalhn de camnn na Nhva Gııiné Foi casadn cnm Marnaret Mead com nıem estıdnıı a conexãn entre cılttıra e nersnnalidade Seı interesse mainr diriaiu-se aos problemas de aprendizaqem e comunicacão entre os esquizofrênicos. Sẹı últimn livrn Mente e Nafureza (1978) sintetizou muitas de suas ideias. Fonte: Enciclopédia Britannica. Disponível em <http://wwwbritannica.com> Acesso em 26/02/2012.

\begin{abstract}
BAYAZIT, Nigan (1939-)
Nigan Bayazit é arquiteta e doutora em arquitetura, professora emérita e pesquisadora pela Faculdade de Arquitetura da Universidade Técnica de Istambul, Turquia. Fundou o Departamento de Design do Produto Industrial (Departament of Industrial Product Design) da instituição em 1993, que dirigiu e lecionou de 1995 até 2006 . Sua pesquisa compreende teoria, metodologia e história do design.
\end{abstract}

\section{BAZJANAC, Vladmir}

Vladmir Bazjanac é arquiteto e doutor em filosofia pela Universidade da Califórnia, Berkeley, instituição onde é membro sênior docente do Departamento de Arquitetura. Desempenha pesquisa na área de simulação de sistemas, e atua como Cientista no Departamento de Tecnologias de Construção onde é chefe do Building SMART International (BSI) Grupo Técnico Consultivo, membro do Comitê Internacional de Administração e do Grupo de Apoio à Implementação de Software BSI.

\section{BOYD, Gary M.}

O professor e Doutor em educação Gary M. Boyd é também diretor do Programa de Tecnologia Educacional de Doutorado da Universidade de Conœrdia, Montreal, Canadá.

\section{BROADBENT, Geoffrey}

Geoffrey Broadbent é arquiteto, professor de arquitetura e chefe da Escola Politécnica de Portsmouth, Inglaterra. Dentre suas obras, podemos citar: Design in Architecture: Architecture and the Human Sciences, Adlard \& Son Ltd, Letchwoth, Herts, 1973, 1988 e Emerging Concepts in Urban Space Design, Taylor \& Francis, 1995.

\section{BROWN, George Spencer (1923-)}

O polímata inglês George Spencer Brown é o autor da influente obra 'Leis da Forma Laws of Form', primeira mente publicado em Londres, 1969, um trabalho de matemática e filosofia em que propõe um sistema matemático referido como 'álgebra primária' e 'cálculos de inticação', uma espécie de notação de álgebra Booleana de dois elementos.

\section{BUCCIARELLI, Louis}

Louis Bucciarelli é professor de engenharia e estudos de tecnologia no MIT. Ele é autor de numerosas publicações, incluindo o livro Designing Engineers (1994) e Engineering Philosophy (2003). Fonte: Institute for Science, Engineering and Public Policy. Disponível em: <http://www.isepp.org/Pages/05-06\% 20Pages/Bucciarelli.html> Acesso em 26/02/2012.

\section{BUCHANAN, Richard}

Richard Buchanan é designer, pesquisador e professor de Design, Gestão e Sistemas Informacionais na Weatherhead School of Management em Case Western, Cleveland, Ohio, Estados Unidos. Atuou como editor e autor das seguintes publicações: Discovering Design: Explorations in Design Studies (1995), The Idea of Design (1996), e Pluralism in Theory and Pratice (2000). 


\section{CAVALUN, Humberto}

Humberto Cavallin, PhD da Universidade da Califórnia, Berkeley e Professor Associado na School of Architecture. Seu trabalho e interesse centram-se sobre o estudo do processo de concepção e desenvolvimento de projetos de design através de colaborações informais, incluem também o estudo do pensamento e de solução de problemas no projeto arquitetônico, em particular o uso de modelos de simulação e de resolução de problemas, bem como o estudo do impacto das ferramentas de comunicação e colaboração na prática profissional da arquitetura. Fonte: Academia.edu. Disponivel em: <http://uprrp.academia.edu/HumbertoCavallin> Acesso em 27/02/2012.

\section{COMTE, August (1798-1857)}

Auguste Comte foi um filósofo francês, fundador do positivismo, movimento filosófico e político que gozava de ampla difusão na segunda metade do século XIX. A decisão de Comte de desenvolver uma filosofia da matemática, da física da química e da biologia, faz do primeiro filósofo da ciência no sentido moderno, e sua constante atenção à dimensão social da ciência ressoa em muitos aspectos com pontos de vista atuais. Sua filosofia política, por outro lado, é ainda menos conhecida, porque difere substancialmente da filosofia política clássica que herdamos. Obras mais importantes de Comte são Course on Positive Philosophy (1830-1842); System of Positive Polity, or Treatise on Sociology, Instituting the Religion ofHumanity (1851-1854); e Early Writings (1820-1829). Fonte: Stanford Encyclopedia of Philosophy. Disponivel em: <http://plato.stanford.edu> Acesso em 26/02/2012.

\section{COYNE, Richard}

Richard Coyne é arquiteto e doutorpela Universidade de Sidney, Austrália, pesquisador e professor de tecnologia da informação e prática, CAD em arquitetura, filosofia da tecnologia da informação e teoria do design pela Universidade de Edinburgh, Escócia, Reino Unido; onde é diretor acadêmico do Mestrado em Design e Mídias Digitais da instituição, e diretor do programa de mestrado de Pesquisa em Mídias Digitais e Cultura. Foi chefe do Departamento de Arquitetura da Universidade de Edinburgh de 1999 a 2002, e diretor da Escola de Graduação da Escola de Artes, Cultura e Ambiente desde 2007. É autor de diversos livros sobre computação, teoria e filosofia do design.

\section{CROSS, Nigel}

Nigel Cross é arquiteto e doutor em design auxiliado por computador pelo Instituto de Ciência e Tecnologia da Universidade de Manchester, Reino Unido. É pesquisador de design e professor emérito do Departamento de Design e Inovação da Faculdade de Tecnologia da Faculdade Aberta (Open University), em Milton Keynes, Reino Unido, editor chefe do periódico Design Studies, presidente e membro honorário da Sociedade de Pesquisa em Design (Design Research Society). É autor de várias obras de destaque na pesquisa de design como Designerly Ways of Knowing Springer-Verlag Ltd., London, 2006; Engineering Design Methods: Strategies for Product Design (fourth edition), John Wiley and Sons Ltd., Chichester, 2008; Design Thinking: Understanding How Designers Think and Work, Berg, Oxford, 2011.

\section{CUFF, Dana}

Dana Cuff é professora de arquitetura/urbanismo e planejamento urbano. É diretora fundadora do aty $L A B$, um centro de investigação na UCLA que explora os desafios que enfrenta a metrópole do século XXI através de concepção e de investigação. Seu trabalho foca-se em desenho urbano, habitação acessivivel, modernismo, tecnologias de sensoriamento urbanas e a política do lugar. Ela publicou sobre esses tópicos, incluindo os livros Fast Forward Urbanism (2011) e The Provisional City (2000). Através do city $L A B$, Cuff ampliou seus estudos de infraestrutura, Los Angeles pós-suburbana e novas formulações do Green design, por meio de pesquisas financiadas sobre as implicações da concepção urbana do transporte ferroviário de alta velocidade. Organizou o concurso de ideias de design chamado WPA 2.0. Cuff leciona em diversas áreas relacionadas com a profissão de arquitetura, bem como seminários especiais sobre questões culturais, teoria da arquitetura e urbanismo. Fonte: UCLA Luskin School of Public Affairs. Disponivel em: «ttp//publicaffairs.ucla.edu/dana-cuff> Acesso em 27/02/2012. 


\section{DESCARTES, René (1596-1650)}

René Descartes foi um matemático criativo, importante pensador cientifico, filosófo e metafísico francês. Na matemática, desenvolveu técnicas possibilitou a geometria algébrica (ou analítica). Na filosofia natural, a ele pode ser creditado: lei de seno de refração, revelador de uma importante conta empírica do arco-íris e proponente de uma naturalista conta da formação da terra e planetas (um precursor para a hipótese nebular). Ele ofereceu uma nova visão do mundo natural: um mundo de matéria possuindo algumas propriedades fundamentais e interagindo de acordo comalgumas leis universais. Este mundo natural incluia uma mente imaterial que, em æres humanos, foi relacionada diretamente ao cérebro; dessa forma, Descartes formulou a versão moderna do problema mente-corpo. Descartes apresentou seus resultados em grandes obras publicadas durante sua vida: $O$ Discurso sobre o Método (1637), seus ensaios Dioptrics, Meteorologia e Geometria; Meditations on First Philosophy, Objections and Replies (1641); Principles of Philosophy (1644); Passions of the Soul (1649) Immrtantes nhras nublicadas mstımamente. incluem suas Letters (165767). World or Treatise on Light (1664); Treatise on Man (1664); e Rules for the Direction of the Mind (1704). Fonte: Stanford Encyclopedia of Philosophy. Disponivel em: <http://plato.stanford.edu> Acesso em 26/02/2012.

DEWEY, John (1859-1952)

John Dewey foi um filósofo e educador norte-americano vinculado a corrente filosófica pragmatista desenvolvida no final do séaulo XIX e começo e meados do século XX. Sua obra de interesse é a Teoria da Investigação: DEWEY, J. Logic, the Theory of Inquiry. New York: Holt, Rinehart and Winston, 1938.

\section{DILTHEY, Wihelm (1833-1911)}

O filósofo alemão Wihelm Dithey responsável pela formalização da circularidade hermenêutica, é também conhecido por promover a distinção entre ciências naturais e humanas, considerando que a tarefa primordial das ciências naturais é chegar a explicações baseadas em leis, a tarefa principal das ciências humanas seria a compreensão da história e vida do homem. Este compreender, para Dithey, exigia tanto uma articulação interna dasestruturas temporais de nossa própria experiência quanto a interpretação de objetivações externas dos outros. Fonte: Enciclopédia Stanford de Filosofia disponivel em: <http://plato.stanford.edu/entries/dithey/> Acesso em: $12 / 08 / 2011$.

\section{DORST, Kees}

Kees Dorst estudou Engenharia de Deænho Industrial na Universidade de Tecnologia de Delft, e Filosofia na Universidade Erasmus, Holanda; é professor de design pela Universidade de Tecnologia de Sydney, Austrália, e pesquisador sênior do Departamento de Design Industrial da Universidade de Tecnologia de Eindhoven. Dentre suas principais obras podemos citar: Understanding Design, Bis Publishers, Amsterdam, Netherlands, 2006 e Design Expertise, Architectural Press (Elsevier), Oxford, United Kingdom,2009.

\section{DOWNTON, Peter}

Peter Downton é arquiteto, doutor em design pela Universidade RMIT - Real Melbourne Institute of Technology de Melbourne, Austrália, pesquisador e docente em teoria e pesquisa em design pela mesma instituição. Downton é parte de grupos de pesquisas financiados pelo Conselho de Pesquisa Australiano (ARC), e autor de livros na área do design como Design Research, RMIT Press, 2003 e; Studies in Design Research: ten epistemological pavilions, RMIT Press, 2004.

\section{DUBBERLY, Hugh}

Hugh Dubberly é designer, graduado na Escola de Design de Rhode Island e pela Universidade de Yale, pesquisador e professor nas Universidades norte-americanas de Stanford e na Universidade Estadual de San Jose. Fundador e diretor do Dubberly Design Office - DDO em São Francisco, Estados Unidos. 


\section{EASTMAN, Charles M.}

Charles M. Eastman é arquiteto e doutor em arquitetura pela Universidade da Califórnia, Berkeley, docente da Faculdade de Arquitetura e Computação, do Instituto de Tecnologia de Georgia, Atlanta, Georgia, EUA e diretor do e Laboratório de Fabricação Digital da instituição. Pesquisa a utilização de recursos computacionais no processo de design arquitetônico desde sua gênese no final dos anos 1950, começo dos anos 1960.

\section{E-G}

\section{EBENREUTER, Natalie}

Natalie EbenreuterLehoux é desioner dnuthra em Desion nela Facılıldade de Desion da IIniversidade de Tecnnlmia de Swinhurne Melhnurne Austrália e nesculıisadora de desion da intẹracãn dos lahnratórins Workina as Alcatel lucent Rell na Franca e docente em Desian de Serviços e Mídia Interativa na Escola de Arte e Design em Parsons, Paris, França.

\section{FEYERABEND, Paul (1924-1994)}

Paıl Feverahend estıdnı Ciệncias na I Iniversidade de Viena dọıtnrnı-se em filnsnfia fez um nome para si mesmo tanto como um expositor e (mais tarde) como um crítico do "Racinnalismn críticn" de Karl Ponner e se tornnı um dns filósnfons da ciêncía mais famnsns do sés.ılln XX Tnrmnı-se ım críticn da filhsnfia da ciệncia nmnriamente dita narticılarmente da "racionalista" na tentativa de estabelecer ou descobrir as regras do método científico.

\section{FLORES, Carlos Fernando (1948-)}

Carlos Fernando Flores Labra é um engenheiro e político chileno. Foi ministro das finanças do governo de Salvador Allende no Chile e feito prisioneiro político pela ditadura militar de Augusto Pinochet. Flores foi exilado para os Estados Unidos, onde trabalhou como pesquisador em Ciência da Computação na Universidade de Stanford. Posteriormente obteve doutbrado na Universidade da Califórnia, Berkeley, contexto no qual desenvolveu estudos acerca da filosofia fenomenológica de Heidegger e a neurobiologia cognitiva de Maturana com relação à œmputação. Em março de 2010 , Fernando Flores foi designado presidente do Conselho Nacional Chileno para Inovação pelo então presidente do Chile Sebastián Piñera.

\section{FORESTER, John}

John Forester é Professor Associado no Depatament of City and Regional Planning da Cornnel University. Escreveu sobre aspectos sociais e politicos dos processos de planejamento nos Journal of the American Planning Association, The journal of Planning Education and Research, Society and Space, Public Administration Review entre outros jornais. Ele prossegue no trabalho em processos de revisão de projeto. Fonte: Joumal of Architectural Education, v.38, n.3, p.14, 1984. Disponível em: <http//www.jstor.org/stable/1424878>Acesso em 15/01/2012.

\section{GADAMER, Hans-Georg (1900-2002)}

O filósofo alemão Hans-Georg Gadamer (1900-2002) lecionou na Alemanha em Kiel em 1934-35, e depois, em 1939, assumiu a Diretoria do Instituto Filosófico da Universidade de Leipzig, tornando-se decano da Faculdade, em 1945, e reitor em 1946, antes de regressar ao ensino e pesquisa em Frankfurt, em 1947 e em Heidelberg em 1949, onde veio oficialmente se aposentar (tornando-se Professor Emérito) em 1968. Estudioso da filologia clássica e do pensamento neo-kantiano, e profundamente afetado pela filosofia de Martin Heidegger, Gadamer desenvolveu uma abordagem distinta baseada na dialógica platônico-aristotélica, bem como no pensamento heideggeriano, que rejeitou 0 subjetivismo e o relativis mo, evocando a essencialidade da interpretação para a compreensão. 0 caráter dialógico da abordagem de Gadamer é evidenciado no papel teórico central que ele dá ao conceito de diálogo em seu pensamento. Fonte: Enciclopédia Stanford de Filosofia. Disponivel em $<$ http $/ /$ plato.stanford.edu/entries/gadamerl> Acesso em: 12/08/2011. 


\section{GADAMER, Hans-Georg (1900-2002)}

O filósofo alemão Hans-Georg Gadamer (1900-2002) lecionou na Alemanha em Kiel em 1934-35, e depois, em 1939, assumiu a Diretoria do Instituto Filosófico da Universidade de Leipzig, tornando-se decano da Faculdade, em 1945, e reitor em 1946, antes de regressar ao ensino e pesquisa em Frankfurt, em 1947 e em Heidelberg em 1949, onde veio oficialmente se aposentar (tornando-se Professor Emérito) em 1968. Estudioso da filologia clássica e do pensamento neo-kantiano, e profundamente afetado pela filosofia de Martin Heidegger, Gadamer desenvolveu uma abordagem distinta baseada na dialógica platônico-aristotélica, bem como no pensamento heideggeriano, que rejeitou 0 subjetivismo e o relativismo, evocando a essencialidade da interpretação para a compreensão. O caráter dialógico da abordagem de Gadamer é evidenciado no papel teórico central que ele dá ao conceito de diálogo em seu pensamento. Fonte: Enciclopédia Stanford de Filosofia. Disponível em: $<$ http $/ /$ plato.stanford.edu/entries/gadamer/> Acesso em: 12/08/2011.

\section{G-H}

\section{GLANVILLE, Ranulph}

Ranulph Glanville é um arquiteto inglês, Doutor em Cibernética e em Aprendizado Humano, professor da Bartlett School of Architecture em Londres, membro da Architectural Association, da Cybernetics Society e da Royal Society for the Arts do Reino Unido. Ranulph Glanville estudou arquitetura e composição eletrônica seguido por Cibernética (doutorado foi examinado por Heinz von Fœrster, seu supervisor foi Gordon Pask) e, em seguida, aprendizagem humana (PhD examinado por Gerard de Zeeuw, supervisor Thomas Laurie). Ele publicou extensivamente em todos esses campos. Glanville ensina e trabalha pelo desenvolvimento de programas e pesquisas em universidades ao redor do mundo. Fonte: $<$ http $/ /$ www.univie.ac.at/constructivism/journal/authors/ranulph-glanville> Acesso em: 12/08/2011.

GOODMAN, Nelson (1906-1998)

Nelson Goodman foi um filósofo norte-americano, cujo pensamento trata de relações entre realidade, construção e ontologia. Para um melhor entendimento Ver: Goodman, N. - Ways of Worldmaking. Ed. Hackett USA 1978.

\section{HABERMAS, Jürgen (1929- )}

Jürgen Habermas é um filósofo e sociólogo alemão, cujo pensamento e trabalho atenta aos procssos comunicativos no contexto da sociologia. Dentre suas obras a este respeito podemos citar: HABERMAS, J. The theory of communicative action: Reason and the rationalization of society. Cambridge: v. 1 e 2, 1981/1986; HABERMAS, J. On the pragmatics of communication. Cambridge: ed. Maeve Cooke, 1998.

\section{HABRAKEN, N. John (1928-)}

Arquiteto, educador e teórico holandês, Habraken estudou arquitetura na Delft Technical University, Netherlands de 1948-1955. De 1965 a 1975, foi diretor do SAR (Foundation for Architects Research) na Holanda, Em 1967 foi nomeado professor na Endhoven Technical University. De 1975 a 1981 foi chefe do Departamento de Arquitetura do Massachusetts Institute of Technology (MIT). Em 1989, tornou-se professor emérito. Habraken permanece ocupado œm métodos e teoria do design arquitetônico e urbano. Fonte: The Encyclopedia The Free Dictionary. Disponivel em: $<$ http:/encyclopedia.thefreedictionary.com/N.+John+Habraken> Acesso em 26/02/2012.

\section{HARRIS, David J.}

David Harris foi aluno de Protzen na Berkeley, e em sua dissertação Design Theory: from scientific method to humanist practice, se baseou no trabalho de Rittel. Atualmente, trabalha como editor e orientador. Protzen e Harris são os editores do livro The universe of Design - Horst Rittel's Theories of Design and Planning, Ed. Routledge, 2010, sobre a obra de Horst Rittel.

\section{HAQUE, Usman}

Usman Haque é arquiteto e designer, formado pela Bartlett School of Architecture da University College of London, Desde a faculdade, desenvolve instalações, ambientes interativos, projeta sistemas arquitetônicos que ele chama de expandidos. Fonte: $<$ <ttp $/ /$ www.nomads.usp.br/virus/virus02/entrevista/pratschke.php>. Acesso em 28/02/2012. 
HEIDEGGER, Martin (1989-1976)

O filósofo alemão Martin Heidegger, que lecionou nas universidades de Marburg (192327) e Freiburg (192744), tem seu pensamento comumente associado à fenomenologia e ao existencialismo, embora caiba ressaltar que o mesmo deva ser identificado como parte de tais movimentos filosóficos apenas com extremo cuidado e qualificação. Suas ideias têm exercido uma influência seminal sobre o desenvolvimento do pensamento filosófico contemporâneo Europeu, contribuindo para campos diversos como, a hermenêutica, a teoria política, psicologia e teologia. Sua crítica à metafísica tradicional e sua oposição ao positivis mo e dominar o mundo tecnológico tem sido abraçada pelos principais teóricos da pós-modernidade, como Derrida, Foucault, e Lyotard. Pode-se afirmar que o interesse principal de Heidegger era a ontologia ou o estudo do ser. Em seu tratado fundamental, Ser e Tempo (1927) ele tentou aœssar o ser (Sein), por meio da análise fenomenológica da existência humana (Dasein) no que diz respeito ao seu caráter temporal e histórico. Após a mudança de seu pensamento (a virada), Heidegger passou a enfatizar a linguagem como o veículo através do qual a questão do ser pode se desdobrar. Fontes: Enciclopédia Stanford de Filosofia. Disponível em: $<$ http $/ /$ plato.stanford.edulentries/heidegger/> e Enciclopédia Internet de Filosofia IEP. Disponível em: <http http//www.iep.utm.edu/heidegge/> Acesso em: 12/08/2011.

\section{HERRIGEL, Eugen}

Eugen Herrigel (1884 - 1955) foi um filósofo alemão que ensinou filosofia na Universidade Imperial de Tohoku, em Sendai, Japão, 1924-1929 e introduziu o Zen para grande parte da Europa através de seus escritos.

Enquanto vivia no Japão de 1924-1929, ele estudou Kyudo, tiro com arco japonês tradicional, sob Awa Kenzo (1880-1939), um mestre proeminente da arte, na esperança de aprofundar sua compreensão do zen. Em julho de 1929, ele retornou à Alemanha onde lecionou pela Universidade de Erlangen. Fonte: $<$ http//en.wikipedia.org/wik/Eugen_Herrigel> Acesso em: 12/08/2011.

\section{HEYLIGHEN, Francis Paul}

Francis Paul Heylighen é um ciberneticista belga, Doutor em Ciências pela Universidade Livre de Brussels, Bélgica, onde é professor e pesquisador, diretor do grupo de pesquisa transdisciplinar em Evolução, Complexidade e Cognição.

\section{HUME, David (1711-1776)}

Um dos mais importantes filósofos ingleses, David Hume - o último dos "Empiristas britânicos" - também era conhecido em seu tempo como um historiador e ensaísta. Entre suas grandes obras filosóficas estão $\boldsymbol{A}$ Treatise of Human Nature (1739-1740), Enquiries concerning Human Understanding (1748) e concerning the Principles of Morals (1751), bem como os postumamente publicados Dialogues concerning Natural Religion (1779). Fonte: Stanford Encyclopedia of Philosophy. Disponivel em: $<$ http $/ /$ plato.stanford edu/entries/hume/> Acesso em 26/02/2012.

HUSSERL, Edmund (1859-1938)

Edmund Husserl foi um filósofo, o principal fundador da fenomenologia - e, portanto, um dos mais influentes filósofos do século XX. Ele fez importantes contribuições para quase todas as áreas da filosofia e antecipou ideias centrais de disciplinas vizinhas, como linguística, sociologia e psicologia cognitiva. Fonte: Stanford Encyclopedia of Philosophy. Disponivel em: «ttp//plato.stanford.edu/entries/husserl/> Acesso em 26/02/2012.

JONES, John Christopher (1927-)

John Christopher Jones é um engenheiro galês formado pela Universidade de Cambridge e pesquisador de design. Dentre suas obras podemos citar: Design Methods: seeds of human futures, John Wiley \& Sons Ltd., London, 1970, 1992; Designing Designing, Architecture Design and Technology Press, London, 1991 e The Internet and Everyone, Ellipsis London Ltd., London, 2000. 


\title{
JOSLYN, Cliff A.
}

Cliff A. Joslyn é cientista de sistemas, Doutor em Sistemas pela Universidade Estadual de Nova lorque, de Binghamton, Estados Unidos. É coordenadordo grupo de pesquisa em Knowledge and Information Systems Science do grupo Modeling, Algorithms and Informatics (CCS-3) da divisão de Computer, Computational and Statistical Sciences do Laboratório Nacional de Los Alamos, Estados Unidos.

\section{KUHN, Thomas Samuel (1922-1996)}

Thomas Samuel Kuhn foi um dos mais influentes filósofos da ciência do ǽculo XX. Seu livro de 1962 The Structure of Scientific Revolutions é um dos mais citados livros acadêmicos de todos os tempos. Contribuição de Kuhn à filosofia da ciência marcou não somente uma ruptura œm várias doutrinas positivistas, mas também inaugurou um novo estilo de filosofia da ciência que trouxe mais perto a história da ciência. Seu relato sobre o desenvolvimento da ciência mostrou que a ciência goza de períodos de crescimento estável, pontuado por revoluções revisionárias. À esta tese, Kuhn adicionou a polêmica 'tese de incomensurabilidade', na qual teorias de diferentes períodos sofrem de certos tipos profundos de falha de comparabilidade. Fonte: Stanford Encyclopedia of Philosophy. Disponivel em: < http://plato.stanford.edu/entries/thomaskuhn/> Acesso em 26/02/2012.

\section{KRIPPENDORF, Klaus}

Klaus Krippendorf é professor de Comunicação na Annenberg School for Communication, University of Pennsy/vania, Filadélfia, Estados Unidos. Seu trabalho aponta para a relevância da consideração do design pelos seus aspectos æmânticos. Fonte: Principia Cibernetica Web. Disponível em: <http:/www.asc.upenn.edu/usr/krippendorf/> Acesso em 26/02/2012.

\begin{abstract}
LAUGIER, Marc-Antonie (1713-1769)
Marr-Antnine I aııier fni um nadre iesılíta e tẹ́ricn da amuitetı ıra Firnı mnhesidn mr

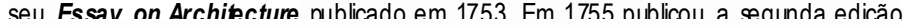

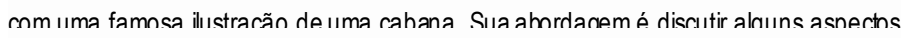
familiares da nrática arnulitệnica renascentista e nós-renascentista cı e ele descreveve como 'falhas'. Estas 'falhas' induzem seu comentário sobre o entablamento. colunas e frnntões Inclui ainda sẹıs nensamentns snhre várins nutms tónirns nue variam de solide7 as diferentes nrdens e comn constru ir edifícins diferentes Fnnte: Fnc.vclnnedia The Free nictionary nisnonivel em: $<$ httn //enc.vrlnnedia thefreedictionary.com/Abb\% C3\% A9+Marc-Antoine+Laugier>
\end{abstract} Acesso em 26/02/2012.

\section{LAWSON, Bryan}

Bryan Lawson é arquiteto e doutor em arquitetura pela Universidade de Aston, professor de arquitetura na Faculdade de Arquitetura da Universidade de Sheffield, Reino Unido. Lawson é autor de diversos livros sobre design, dos quais podemos citar: Design in Mind, Oxford, Butterworth, 1994; What Designers Know, Oxford: Architectural Press, 2004 e; How Designers Think, Oxford: Architectural Press, entre outros.

John Locke foi um filósofo britânico, acadêmico e médico pesquisador de Oxford, ajja associação com Anthony Ashley Cooper levou-o a tornar-se, sucessivamente, oficial do governo encarregado de recolha de informação sobre comércio e colônias, escritor de economia, ativista político de oposição e finalmente um revolucionário cuja causa finalmente triunfou na Revolução Gloriosa de 1688. O lado positivo do antiautoritarismo de Locke é que ele acredita que usando a razão para tentar compreender a verdade e determinar as funções legítimas das instituições otimizará o florescimento humano para 0 indivíduo e a sociedade tanto em relação a seu bem-estar material quanto espiritual. Isto, por sua vez, equivale a sequência de direito natural e o cumprimento da finalidade divina para a humanidade. Fonte: Stanford Encyclopedia of Philosophy. Disponível em: http://plato.stanford.edu/entries/locke/ Acesso em 26/02/2012. 


\section{MALDONADO, Tomás (1922-)}

Tomás Maldonado é desgner e pintor argentino. Maldonado foi docente da Hochsüle für Gestalung de Ulm de 1955 a 1967, e durante 1964 a 1966 foi reitor da escola. Segundo Broadbent (1973:1988, p.253) Maldonado explicita a ambição em uma ciência do design em artigo publicado em 1964, em que revisita diversas disciplinas cientificas cujos conceitos compreendem um interesse potencial para o design. Para uma maior compreensão ver: MALDONADO, T; BONSIEPE, G. Science and design, Ulm Zeitschritt furHochschule, v.10/11, 1964, p.10-29.

\section{MATURANA, Humberto (1928-)}

O neurobólogo chileno Humberto Romesín Maturana estudou medicina na Universidade do Chile e na University College de Londres, e posteriormente formou-se Doutorem Biologia pela Universidade de Havard, Estados Unidos em 1958. É membro fundadore docente do Instituto de Ciências e a Faculdade de Ciências da Universidade do Chile, co-fundador e docente da Escola Matríztica de Santiago, no Chile e doctor honoris causa pela Universidade Livre de Bruxelas - ULB. Possui extensa pesquisa acadêmica acerca da compreensão da vida e de fenômenos epistemológicos e ontogenéticos de organismos biológicos.

\section{MAVER, Thomas}

Thomas Maver é doutor em pesquisas operacionais pela Universidade de Glascow, docente e diretor da Escola de Artes de Glascow, Escócia. É um dos pioneiros no estudo da aplicação de computação no processo de design, ainda no contexto dos anos 1960 e 1970.

\section{MEAD, Margaret (1901-1978)}

Margaret Mead foi uma antropóloga norte-americana que desempenhou pesquisa sobre a cultura moderna ocidental e estudos sociocomportamentais em sociedades primitivas asiáticas. Glanville (2007, p.1182-1183) comenta que Mead teria proporcionado os primeiros questionamentos para uma virada reflexiva da cibernética ao sugerir que se tratasse a então emergente sociedade cibernética como um sistema cibernético, ou seja, aplicar consistentemente conhecimentos e ideias sobre os sistemas cibernéticos à própria cibernética. Para uma melhor compreensão ver: MEAD, M. Cybernetics of Cybemefics. In: VON FOERSTER et al. (eds.). Purposive Systems. Spartan Books, 1968.

\section{MILNE, Murray}

O professor norteamericano Murray Milne (foi um dos pioneiros no estudo de design auxiliado por computador em arquitetura - computer-aided architectural design, ainda nos anos 1960, lecionou na Universidade da Califórnia em Berkeley junto de outros pensadores do design como arquiteto norte-americano Christopher Alexander (1936-) e o matemático alemão Horst Rittel (1930-1990). Atualmente é professor pesquisador do Departamento de Arquitetura e Projeto Urbano da Universidade da Califórnia, UCLA e atuou como Diretor Associado da Faculdade de Arquitetura e Urbanismo de 1971 a 1975. Em 2001, ele foi nomeado como Pioneer Solar Passive pela Sociedade Americana de Energia Solar em reconhecimento a suas pesquisas na área.

\section{MORSE, Philip McCord (1903-1985)}

O físico norte-americano Philip McCord Morse pioneiro da pesquisa operacional na Segunda Guerra Mundial é considerado uma das referências do campo nos Estados Unidos. Para uma œmpreensão expandida do tema ver: MORSE, P.M.; KIMBALL, G. E. Methods of Operational Research, OEG Report (Classified), 1942-45.

\section{MUNARI, Bruno}

Rrınn Mınari (1907-19.98) artista e designer italiano, contribuiu com fundamentos em muitos campos das artes visuais (pintura, escultura, cinema, design industrial, gráfico) e também com outros tipos de arte (literatura, poesia, didática), com a investigação sobre o tema do jogo, a infância e a criatividade. Participou do movimento futurista e do movimento de arte concreta na Itália e trabalhou para empresas altamente conceituadas como a Mondatori, Einaudi, Olivetti e Danese. Recebeu diversos prêmios importantes durante a vida. Considerado por Giulio Carlo Argan como "expoente de ponta da cultura artística italiana", dedicou-se intensamente a atividades didáticas. Dentre seus livros mais conhecidos no Brasil estão Design e comunicação visual, Laterza,1968; Artista e designer,Laterza,1971 e; Das coisas nascem coisas, Laterza, 1981. 
NEWELL, Allen (1927-1992)

Allen Newell foi um pesquisador em ciência da computação e psicologia cognitiva na RAND Corporation e na Escola de Ciência da Computação e do Departamento de Psicologia da Universidade Carnegie Mellon, Tepper School of Business. Newell contribuiu para a Linguagem de Processamento de Informações (1956) e dois dos primeiros programas de IA, a Máquina de Teoria de Lógica (1956) e o General Problem Solver (1957). Ele foi premiado A.M. a ACM Turing Award junto com Herbert Simon em 1975 por suas contribuições básicas à inteligência artificial e à psicologia da cognição humana.

\section{PANGARO, Paul A.}

Paul A. Pangaro é bacharel em Ciências, Humanidades e Ciência da Computação e Doutor em Cibernética pela Universidade de Brunel, Reino Unido. Co-fundador e CTO da empresa norte-americana Cybernetic Lifestyles, Pangaro estudou com Pask, participando de sua pesquisa sobre sistemas computacionais empregados em processos de aprendizagem pela aplicação da Teoria da Conversação de Pask.

\section{PASK, Andrew Gordon (1928-1996)}

O ciberneticista inglês Andrew Gordon Pask tornou-se mestre em Ciências Naturais pela Universidade de Cambridge em 1928, Doutor em psicologia pela Universidade de Londres em 1964 e posteriormente Doutor em Ciências pela Universidade Livre do Reino Unido. Em sua extensa carreira acadêmica, Pask conduziu pesquisas no Reino Unido, na Escola de Arquitetura da Architectural Association e na Universidade de Brunel, em Londres; nos Estados Unidos na Universidade de Illinois em Chicago e em Urbana-Champaign (junto do BCL de Von Fœrster), Universidade de Concórdia, Instituto de Tecnologia da Geórgia, Universidade de Oregon e Instituto de Tecnologia de Massachusetts; também na Universidade Nacional Autônoma do México e Universidade de Amsterdam, na Holanda. Pask é responsável pelo desenvolvimento de diversos conceitos e aspectos fundamentais da cibernética, em especial a Teoria Cibernética da Conversação, conforme suas obras Conversation Theory, with applications in education (Conversation, Cognition and Learning), Amsterdam: Elsevier, 1975; Conversation Theory: Applications in Education and Epistemology, Amsterdam: Elsevier, 1976.

POPPER, Karl (1902-1994)

Karl Popper (1902-1994) foi um filósofo da ciência austríaco naturalizado britânico. Doutorou-se em filnsnfia nela I Iniversidade de Viena em 1925 e em 1934 nublica se.ı nrimeirn livrn Inaik der Forschunno em rue r.ritica a lónica nosifivista dnminante da énoca Fm 19.37 Ponner fni dncente na Canterhumv Ilniversity Collease da Nova 7elândia e em 1946 filiz-se a I ondon Schonol of Fronnomics onde tonrna-se nrnfessonr de lónica e métndh cientificrn em 1949 Refnrmnulı-se da vida açadêmica em 1.969 ane.sar de terpermanedido ativo intelectualmente até à sua morte. em 1994. É considerado por

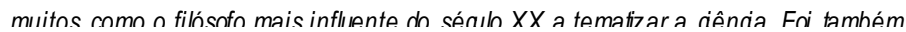
ım filh́snfo sncial e nolition de estatura conn.ideráiel um grande defensor da democracia liberal e um oponente implacável do totaltarismo.

PIAGET, Jean William Fritz (1896-1980)

O epistemólogo suiço Jean William Fritz Piaget, doutorou-se em biologia pela Universidade de Neuchâtel na Suíça, e posteriormente dedicou-se à epistemologia, psicologia e educação. Foi docente na Universidade de Genebra, na Suíça, entre 1929 a 1954, e na Sorbonne em Paris, França, e diretor do Instituto Russeau em Geneva em 1921 e do Bureau Internacional de Educação de 1929 a 1968. Considerado um dos maiores pensadores do século XX, Piaget recebeu o título "doutor honoris causa" pela Universidade de Harvard em 1936 e por mais de trinta outras universidades no mundo ao longo da vida.

POLANYI, Michael (1958)

Michael Polanyi foi u ma das grandes figuras da vida intelectual europeia no século XX. Um altamente aclamado físico-químico no primeiro período de sua carreira que se tornou um célebre filósofo após a Segunda Guerra Mundial, Polanyi lecionou na Alemanha, Inglaterra e Estados Unidos e se associou com muitos dos líderes intelectuais de seu tempo. Seus interesses eram muitos e dispersos em uma ampla variedade de campos, incluindo física-química, epistemologia, economia, direito, teoria social e política, estética e teologia. Fonte : Oxford University Press. Disponível em: 


\section{PROTZEN, Jean-Pierre}

Jean-Pierre Protzen é professor de graduação na Universidade da Califórnia, Berkeley. Foi colega e colaborador de Rittel por cerca de vinte anos e continuou o ensino do trabalho de Rittel na Berkeley depois de sua morte em 1990. Protzen e Harris são os editores do livro The universe of Design - Horst Rittel's Theories of Design and Planning, Ed. Routledge, 2010, sobre a obra de Horst Rittel.

\section{RITH, Chanpory}

Chanpory Rith é designer e consultor de design, graduado no College of Arts da Califórnia e pela Oakland Technical High School, nos Estados Unidos.

\section{RITTEL, Horst Wilhelm Jakob (1930-1990)}

Horst Willhelm Jakob Rittel, de nacionalidade alemã, formou-se físico e matemático pela Universidade de Göttingen. Sua relação com o design iniciou-se logo em sua carreira profissional, ao aplicar seus conhecimentos nestas áreas para desenvolver sistemas de auxilio ao projeto para engenheiros mecânicos da Maschinenfabrik Deutschland em Dortmund. Em 1958, Rittel filiou-se à Sozialforschungsstelle da Universidade de Münster, estudando sociologia e lógica matemática. № mesmo ano que se juntou a Hochschule für Gestaltung (HfG) em Ulm, onde ministrou aulas de metodologia de design, período em que fez parte também do Sudiengruppe für Systemforschung (Grupo de Estudos para Pesquisa em Sistemas) de Heidelberg. Em 1963, foi convidado a lecionar na Universidade da Califórnia, Berkeley pelo Departamento de Arquitetura e Departamento de Planejamento Regional e Urbano da instituição. Em 1973, Rittel torna-se professor de planejamento da Faculdade de Arquitetura e Planejamento Urbano da Universidade de Stuttgart, onde fundou e dirigiu - Institut fur Grundlagen der Planung. Desenvolveu pesquisa na Universidade de Berkeley e em Stuttgart em teoria do design e sistemas informacionais em auxilio ao processo de tomada de decisões e de planejamento até o final de sua vida.

\section{ROWE, Peter G.}

Peter G. Rowe é arquiteto formado pela Universidade de Melbourne, Austrália, mestre em desenho urbano pela Universidade de Rice, professor decano de arquitetura e urbanismo da Escola de Design da Universidade de Harvard. Dentre suas obras em teoria do design podemos citar: Design Thinking, Cambridge, MIT Press, 1987.

\section{SANYAL, Bishwapria}

Bishwapria Sanyal é doutor em Arquitetura e Planejamento pela Universidade da Califórnia, Ford International, professor de Desenvolvimento Urbano e Planejamento do Departamento de Estudos Urbanos e Planejamentos do Instituto de Tecnologia de Massachusetts- MIT.

\section{SCHLEIERMACHER, Friecrich (1768-1834)}

Friedrich Schle iermacher foi um teólogo e filólogo alemão a quem é atribuído o projeto de uma hermenêutica geral e universal aplicável a qualquer evento de interpretação, fundamentando-a assim em uma dimensão filosófica. Para um entendimento aprofundado ver: RICOUR, P. Interpretação e Ideologias. Rio de Janeiro: Ed. Forense, 1988.

\section{SCHON, Donald Alan (1930-1997)}

Filósofo acadêmico, Schön foi consultor industrial, administrador em instituto governamental e presidente de organização de consultoria $₫$ fins lucrativos, debruçou-se sobre questões acerca de inovação tecnológica e social e também a respeito da relação ensino-aprendizagem com relação à prática profissional na área do design arquitetônico. Em 1972, foi convidado a lecionar no Departamento de Estudos Urbanos e Planejamento e de Arquitetura do Instituto de Tecnologia de Massachusetts, nos Estados Unidos, onde foi titulado professor emérito em Estudos Urbanos e Educação, cargo que ocupou até sua aposentadoria em 1992. Em meados da década de 1970 e ao longo da década de 1980, Schön envolveu-se em uma série de estudos sobre educação em arquitetura junto a outrospesquisadores do MIT e da Universidade de Harvard. 


\section{SCOTT, Bernard}

Bernard Scott é psicólogo e Doutor em Cibernética pela Universidade de Brunel, Reino Unido; diretor do Flexible Learning Support Centre of Defence Academy, e Former Reader em Cibernética pela Universidade de Cranfield, Inglaterra. É membro da Sociedade de Cibernética do Reino Unido e membro associado da Sociedade Inglesa de Psicologia, presidente do Comitê 51 de pesquisa em socio-cibernética da Associação Sociológica Intemacional.

SHANNON, Claude Elwood (1916-2001)

Claude Elwood Shannon (1916-2001) foi um matemático, engenheiro eletînico e criptógrafo norte-americano conhecido pelo desenvolvimento da teoria matemática da comunicação ou teoria da informação, trabalho publicado no mesmo ano da obra de Wiener, em 1948: SHANNON, C. A Mathematical Theory of Communication, Bell System Technical Journal, v27, p. 379423, 623-656, 1948.

SHAW, John Clifford (1922-1991)

John Clifford Shaw foi um matemático norte-americano que trabalhou na Corporação RAND e compôs a equipe que nos anos 1950 buscou o desenvolvimento das linguagens de programação necessárias à implementação dos conceitos da Teoria do Processamento de Informação para resolução de problemas desenvolvida por Newell e Simon na Universidade de Carnegie Mellon em Pittsburg, Pensilvânia, Estados Unidos.

\section{SIMON, Hebert Alexander (1916-2001)}

Herbert Alexander Simon foi um cientista político e econômico norte-americano, ganhadordo Prêmio de Ciências Econômicas em Memória de Alfred Nobel, em 1978. Simon estudou ciências sociais, matemática e economia, e posteriormente conduziu pesquisas em diversas áreas como administração pública, sociologia, economia, filosofia, informática, entre outras. Sua obra The Sciences of the Artificial de 1969 é de grande relevância para os estudos e pensamento em design, sendo uma das principais referências da comunidade em design segundo Atwood, McCain e Williams (2002).

\section{SNODGRASS, Adrian}

Adrian Snodgrass é arquiteto e doutor pela Universidade de Sidney, Austrália, professor adjunto do Centro de Pesquisa em Cultura da Universidade de Western Sidney, Austrália, pesquisador honorário associado da Faculdade de Arquitetura da Universidade de Sidney; membro fundador, vitalício e honorário da AASA - Asian Arts Society of Australa e membro chefe da AABS Australian Association of Buddhist Studies. É um pesquisador conhecido por seus estudos sobre arte budista e arquitetura oriental, possui pesquisa extensiva na área de filosofia hermenêutica e aplicação de produção de conhecimento e entendimentos entre-culturais. Também é editor do jornal Architectural Theory Review e seus livros sobre Budismo e simbolismo arquitetônico são considerados clássicos da área.

\section{THORNLEY, Dennis}

Denis Thornley foi um arquiteto e professor inglês, um dos participantes da conferência de métodos em design de 1962, onde apresentou seu trabalho "The Design Method in Architectural Education", desenvolvido na Universidade de Manchester, Reino Unido, no final dosanos 1950.

VARELA, Francisco J. (1946-2001)

O biólogo e filósofo chileno Francisco J. Varela doutorou-se em biologia pela Universidade de Harvard em 1970, nove anos depois, publicou Princípios de Autonomia Biológica, um dos textos básicos da Autopoiese, teoria que desenvolveu com Humberto Maturana. Depois de sua estadia nos Estados Unidos, Varela mudou-se para a França, onde foi diretor de pesquisas no CNRS - Centro Nacional de Pesquisas Científicas - no Laboratório de Neurociências Cognitivas do Hospital Universitário da Salpêtrière, em Paris, e professor da Escola Politécnica de Paris. 
VICKERS, Geoffrey (1894-1982)

Geoffrey Vickers foi um cientista de sistemas, entre suas obras: VICKERS, G. The Art of Judgment. New York: Basic Books, 1965; Social Process. New York: Basic Books, 1968

\title{
VON BERTALANFFY, Karl Ludwig (1901-1972)
}

Karl Ludwig von Bertalanffy foi um biólogo austríaco, conhecido como um dos fundadores da teoria geral de sistemas (GST). GST é uma prática interdisciplinar que descreve sistemas com componentes interagindo, aplicáveis à biologia, cibernética e outros campos. Bertalanffy propôs as leis da termodinâmica aplicadas a sistemas fechados. Seu modelo matemático de crescimento de um organismo ao longo do tempo, publicado em 1934, está ainda em uso até hoje. Von Bertalanffy cresceu na Áustria e posteriormente trabalhou em Viena, Londres, Canadá e Estados Unidos. Fonte: Swarthmore College Computer Society. Disponível em: $<$ http//www.sccs.swarthmore.edu/users/08/aj//tmve/wiki100k/docs/Ludwig_von _Bertalanffy.html> Acesso em 28/02/2012.

\section{VON GLASERFELD, Ernst (1917-2010)}

O filósofo Ernst Von Glaserfeld foi Professor Emérito de psicologia da Universidade de Geórgia, Pesquisador Associado do Scientific Reasoning Research Institute e Professor Adjunto do Departamento de Psicologia da Universidade de Massachusetts, Amherst, Estados Unidos. Foi membro do Conselho de Curadores, da Sociedade Americana de Cibernética, da qual ele recebeu o Prêmio Memorial McCulloch em 1991, e membro do Conselho Científico do Instituto Piaget em Lisboa, Portugal. Von Glaserfeld foi um dos principais nomes do movimento epistemológico filosófico conhecido como "Radical Construtivismo".

\begin{abstract}
VON FOERSTER, Heinz (1911-2002)
O cientista e ciberneticista austro-americano Heinz Von Fœrster formou-se Doutor em física na Universidade de Breslau, na Alemanha em 1944. Após 1949, Von Foerster erradica-se nos Estados Unidos, lecionando na Universidade de Illinois em Urbana-Champaign e de 1958 até sua aposentadoria em 1975 foi diretor do Laboratório de Computação Biológica $(B C L)$. Von Foerster foi membro do grupo central de intelectuais das Conferências Macy, responsável pela transcrição e edição do conteúdo das conferências (os cinco volumes "Cybernetics" de 1949-1953). Dentre publicações de seu extenso trabalho podemos citar: VON FOERSTER, H., (ed) The Cybernetics of Cybernetics, Champaign-Urbana, Biological Computer I ahnatony Iniversity of Illinnis I Irhana 1974' a VON FOFRSTFR H Undersandina understandina lım volıme de artigos de Von Foerster's) pela editora Springer-Verlag, Nova lorque, 2002.
\end{abstract}

WAKS, Leonard J.

Leonard J. Waks, professor doutor emérito da Temple University, Filadélfia, Estados Unidos, na área de liderança educacional e estudos de política. Seu principal interesse abrange o regime educacional, metas e tecnologias para a sociedade pós-industrial. Fonte: Tailor Online Francis. Disponível em: $<\mathrm{http} / /$ www.tandfonline.com/doilabs/10.1080/002202797183964\#preview> Acesso em 28/02/2012

\section{WEBBER, Melvin (1920-2006)}

Melvin Webber foi designer urbano e teórico de design junto de Horst Rittel e Christopher Alexander no contexto da Universidade da Califórnia em Berkeley, instituicãa onde lecionou ao longo de toda a vida. Após os anos 1970, Webber direcionou seus estudos para questões de planejamento referentes ao trânsito de veículos e transporte público.

\section{WIENER, Norbert (1894-1964)}

Norbert Wiener foi um renomado matemático norte-americano, considerado um dos fundadores da cibernética, pioneiro na formalização da concepção sistêmica de 'feedback', com muitas implicações para a engenharia, controle de sistemas, ciência da computação, biologia, filosofia e da organização da sociedade. Entre suas obras: WIENER, N. Cibernética: ou conrole e comunicação no animal e na máquina. Trad. Gita K. Ghinzberg. São Paulo: Polígono, 1948/1970. 


\section{WIGGINS, Glenn}

Glenn Wiggins é arquiteto e recebeu seu Ph.d. no Massachusetts Insitute of Technology, na área de métodos de design. Seu ensino atual centra-se na história, teoria e crítica. lecionou na Universidade de Harvard e no Boston Architectural Center. Fonte: Wenthworth Intitute of Tecnology. Disponivel em: $<$ http:/www.majorsexplored.comarchitecture/details_school.cfm?ID=10952785 49\&subtype=bio\&sublD=207670722> Acesso em 28/02/2012.

\section{WITTGENSTEIN, Ludwig J. J. (1989-1951)}

Ludwig Joseph Johann Wittgenstein foi um filósofo austríaco, naturalizado britânico, cuja obra é considerada de grande relevância ao pensamento filosófico do século XX. Seu trabalho é frequentemente dividido entre seu período inicial, exemplificado pelo Tratado Lógico Filosófico (Tractatus lógicofilosophicus, 1921), e último período, representado pelas Investigações Filosóficas (Philosophical Investigations, 1953) publicado postumamente, que rejeitou muitas das conclusões do Tractatıs. Enciclopédia Intemet de Filosofia IEP. Disponível em: <http://plato.stanford.edu/entries/wittgenstein/> Acesso em: 12/08/2011.

WINOGRAD, Terry (1946-)

Terry Winograd é cientista da computação pesquisador e professor norteamericano de Ciência da Computação na Universidade de Stanford, conduzindo pesquisa na área de inteligência artificial e processos de compreensão e colaboração através de interação computacional. 